\title{
The National Carbon Capture Center at the Power Systems Development Facility
}

Topical Report

Budget Period Four

January 1, 2012 - December 31, 2012

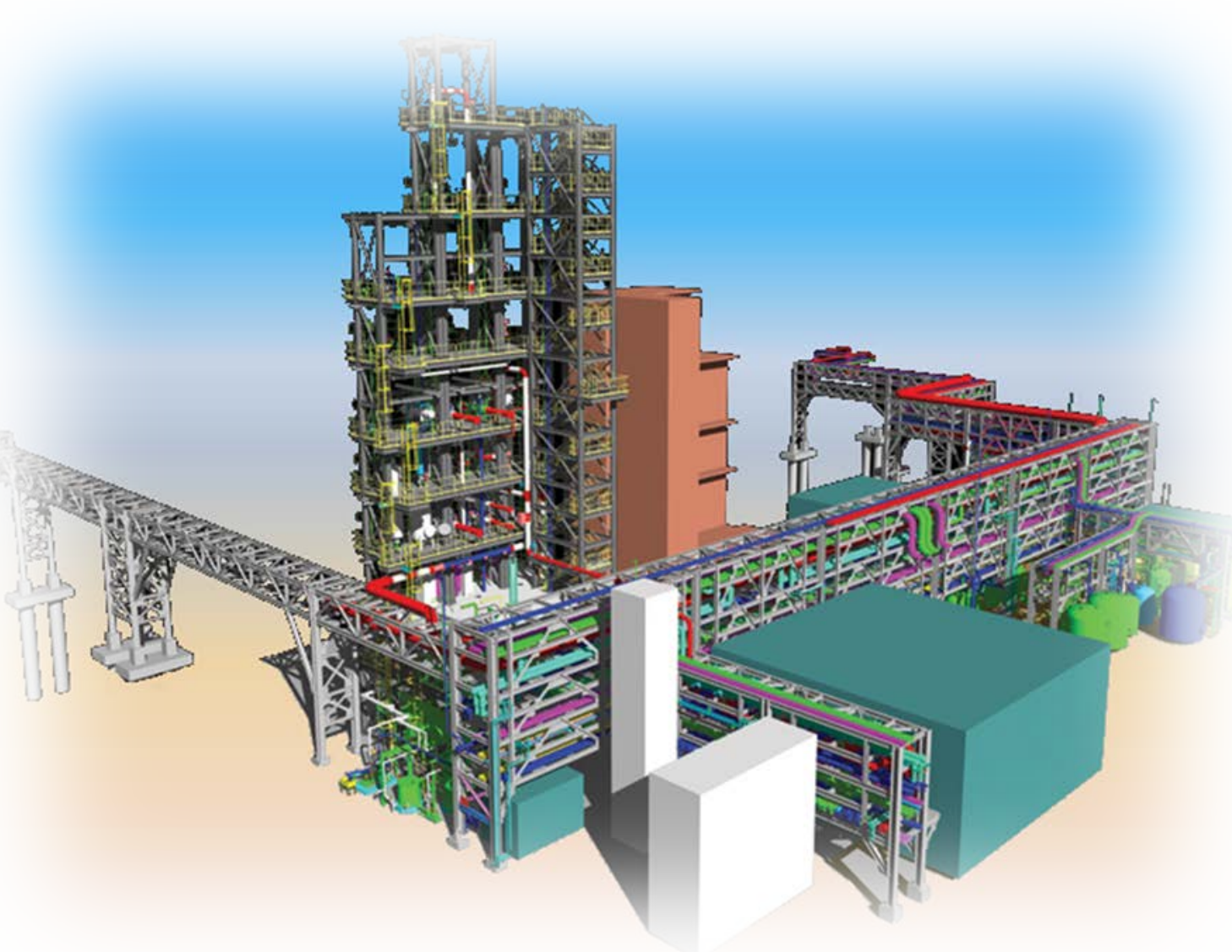

DOE Cooperative Agreement

DE-NT0000749 


\title{
The National Carbon Capture Center at the Power Systems Development Facility
}

\author{
Topical Report \\ Budget Period Four \\ January 1, 2012 - December 31, 2012
}

Prepared by:

Southern Company Services, Inc.

Power Systems Development Facility

P.O. Box 1069, Wilsonville, AL 35186

Phone: 205-670-5840

Fax: 205-670-5843

E-mail: nccc@southernco.com

http://www.NationalCarbonCaptureCenter.com 


\section{Disclaimer}

This report was prepared as an account of work sponsored by an agency of the United States Government. Neither the United States Government nor any agency thereof, nor any of their employees, nor Southern Company Services, Inc., nor any of its employees, nor any of its subcontractors, nor any of its sponsors or co-funders, makes any warranty, expressed or implied, or assumes any legal liability or responsibility for the accuracy, completeness, or usefulness of any information, apparatus, product, or process disclosed, or represents that its use would not infringe privately owned rights. Reference herein to any specific commercial product, process, or service by trade name, trademark, manufacturer or otherwise, does not necessarily constitute or imply its endorsement, recommendation, or favoring by the United States Government or any agency thereof. The views and opinions of authors expressed herein do not necessarily state or reflect those of the United States Government or any agency thereof.

This report is available to the public from the National Technical Information Service, U.S. Department of Commerce, 5285 Port Royal Road, Springfield, VA 22161. Phone orders are accepted at (703) 487-4650. 


\begin{abstract}
The Power Systems Development Facility (PSDF) is a state-of-the-art test center sponsored by the U.S. Department of Energy and dedicated to the advancement of clean coal technology. In addition to the development of high efficiency coal gasification processes, the PSDF features the National Carbon Capture Center (NCCC) to promote new technologies for $\mathrm{CO}_{2}$ capture from coal-derived syngas and flue gas.

The NCCC includes multiple, adaptable test skids that allow technology development of $\mathrm{CO}_{2}$ capture concepts using coal-derived syngas and flue gas in industrial settings. Because of the ability to operate under a wide range of flow rates and process conditions, research at the NCCC can effectively evaluate technologies at various levels of maturity and accelerate their development path to commercialization.

During the calendar year 2012 portion of the Budget Period Four reporting period, efforts at the NCCC focused on testing of pre- and post-combustion $\mathrm{CO}_{2}$ capture processes and gasification support technologies. Preparations for future testing were on-going as well, and involved facility upgrades and collaboration with numerous technology developers.

In the area of pre-combustion, testing was conducted on a new water-gas shift catalyst, a $\mathrm{CO}_{2}$ solvent, and gas separation membranes from four different technology developers, including two membrane systems incorporating major scale-ups. Post-combustion tests involved advanced solvents from three major developers, a gas separation membrane, and two different enzyme technologies. An advanced sensor for gasification operation was evaluated, operation with biomass co-feeding with coal under oxygen-blown conditions was achieved, and progress continued on refining several gasification support technologies.
\end{abstract}




\section{Acknowledgement}

The authors wish to acknowledge the contributions and support provided by DOE project manager Morgan "Mike" Mosser. We would also like to thank our co-funding partners: the Electric Power Research Institute, American Electric Power, Luminant, NRG Energy, Arch Coal, Peabody Energy, and Rio Tinto. The material in this report is based upon work supported by the DOE under award DE-NT0000749. However, any opinions, findings, conclusions, or recommendations expressed herein are those of the authors and do not necessarily reflect the views of the DOE. 


\section{Table of Contents}

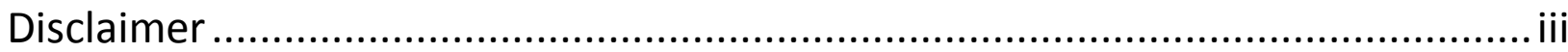

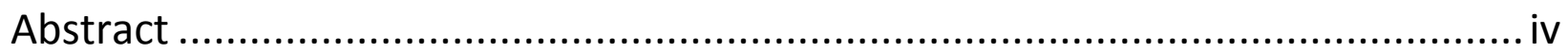

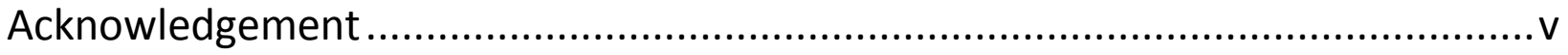

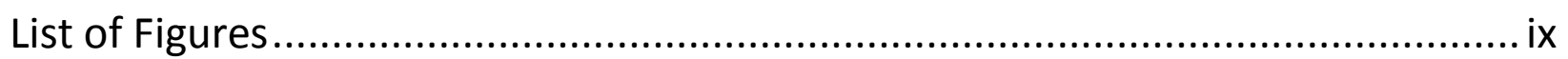

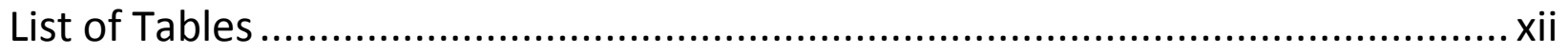

List of Abbreviations and Acronyms .................................................... xiii

1.0 EXECUTIVE SUMMARY .......................................................... 1

1.1 Pre-Combustion $\mathrm{CO}_{2}$ Capture Testing .......................................... 2

1.2 Post-Combustion $\mathrm{CO}_{2}$ Capture Testing ...................................... 3

1.3 Gasification Technology Testing ........................................... 4

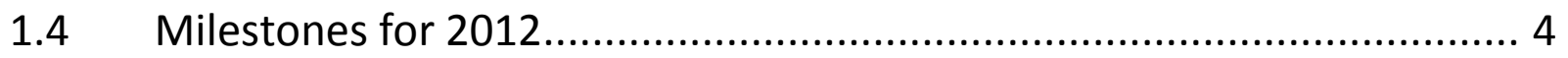

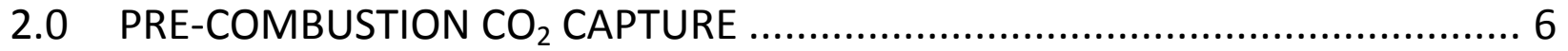

2.1 Syngas Conditioning Unit Modifications ...................................... 6

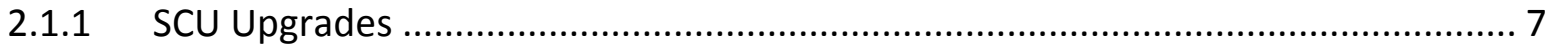

2.1.2 SCU Expansion and Syngas Cleaning System ................................................ 7

2.2 Water-Gas Shift Catalyst .................................................. 8

2.3 Worcester Polytechnic Institute Membranes ................................ 10

2.4 Membrane Technology \& Research Membranes........................... 13

2.4.1 MTR 500-lb/hr CO 2 Membrane System ...................................................... 14

2.4.2 MTR $50 \mathrm{lb} / \mathrm{hr} \mathrm{CO} 2$ Membrane and Hydrogen Stamp Membrane......................... 15

2.5 Media \& Process Technology Membrane ...................................... 16

Eltron Membrane ............................................................. 19

2.7 Membrane Material Coupon Testing ...................................... 21

2.8 TDA Research Sorbent .................................................... 23

University of Alabama Solvent ........................................... 23

2.10 Ohio State University Syngas Chemical Looping ............................ 25

3.0 POST-COMBUSTION CO $\mathrm{C}_{2}$ CAPTURE ......................................... 26

3.1 PC4 Modifications............................................................. 26 


\section{Table of Contents (Cont'd)}

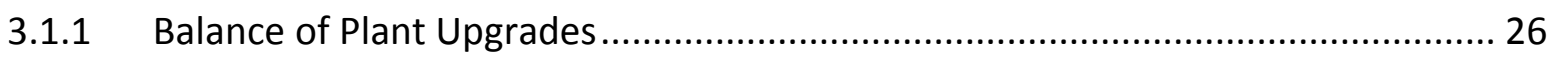

3.1.2 Slipstream Solvent Test Unit.................................................................... 27

3.2 MEA Baseline Test Campaign.................................................... 28

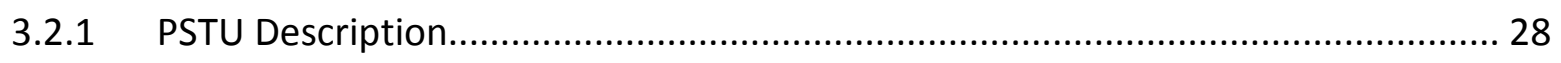

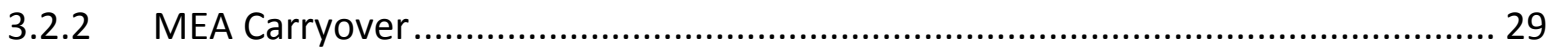

3.2.3 Amine and Degradation Product Carryover ................................................... 32

3.2.4 Breakdown Products Detected in Solvent ........................................................ 34

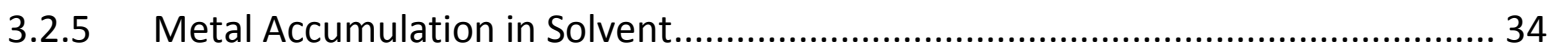

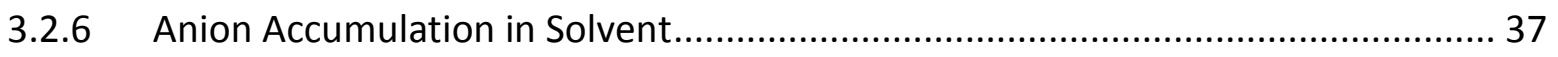

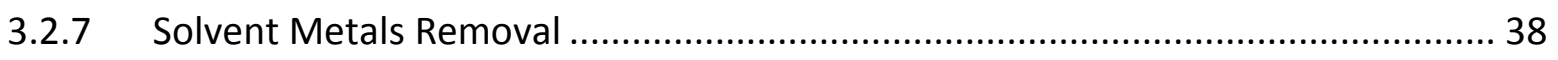

3.2.8 Oxygen Content of $\mathrm{CO}_{2}$ from Regenerator .................................................... 41

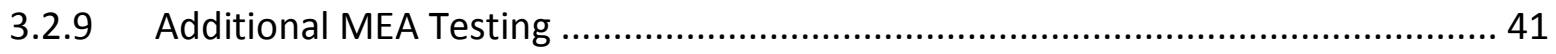

H.3 Hitachi Solvent.............................................................. 41

3.4 BASF / Linde Solvent and Process ............................................ 45

Cansolv Technologies Solvent ............................................ 46

3.5.1 Optimization of Energy vs. L/G Ratio............................................................. 48

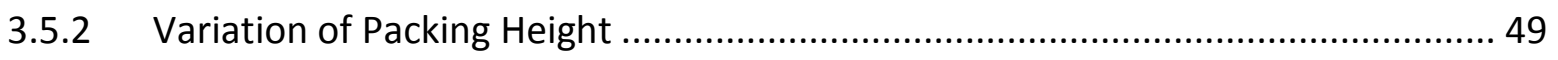

3.5.3 Amine Concentration Experiments............................................................ 50

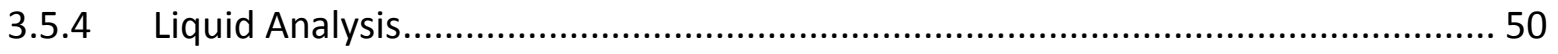

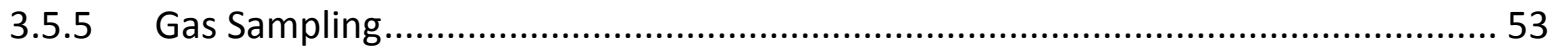

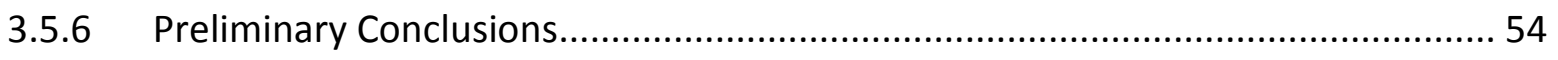

3.5.7 Future Testing with Natural Gas-Simulated Flue Gas........................................ 54

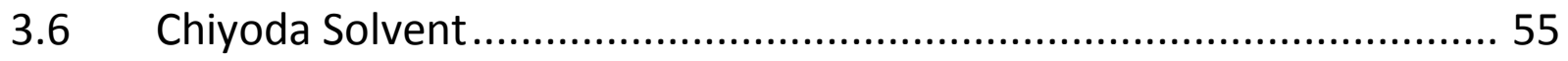

3.7 MTR 1-ton/day $\mathrm{CO}_{2}$ Capture Membrane Skid ............................... 56

3.8 MTR 20-ton/day $\mathrm{CO}_{2}$ Capture Membrane Skid ............................... 61

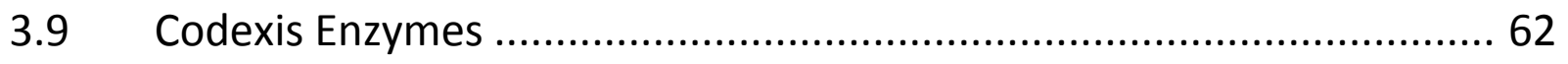

3.10 Akermin Enzymes ...................................................... 63

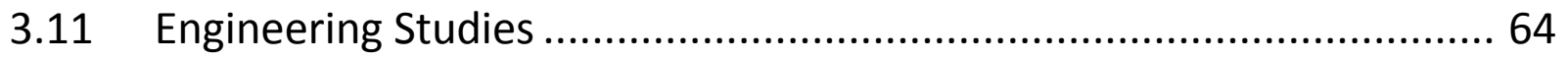

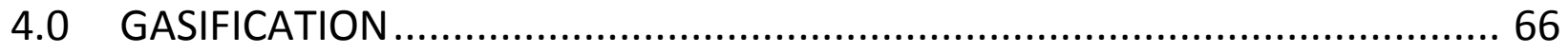




\section{Table of Contents (Cont'd)}

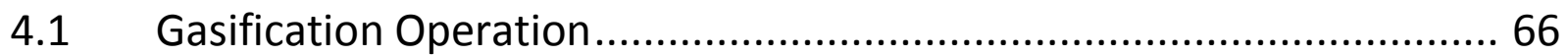

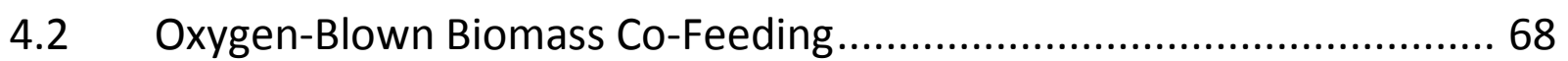

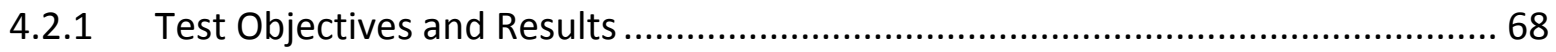

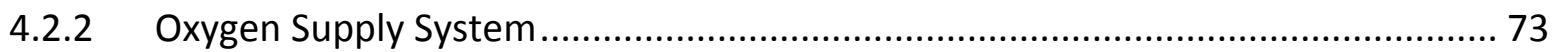

4.3 Hot Gas Filtration ..................................................................... 74

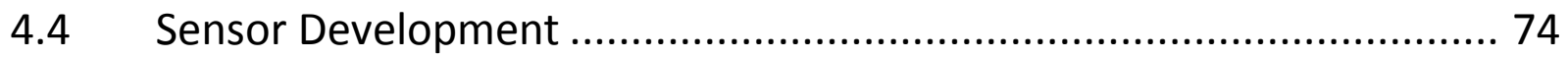

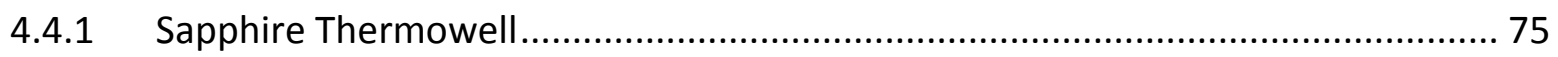

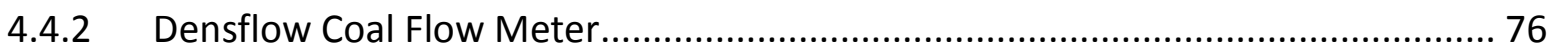

4.4.3 Coal Feeder Level Probes................................................................................. 77

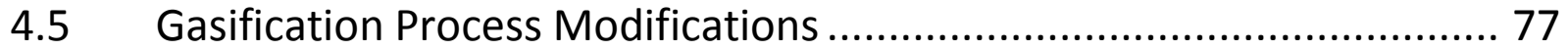

4.5.1 Gasifier Standpipe Replacement ...................................................................... 77

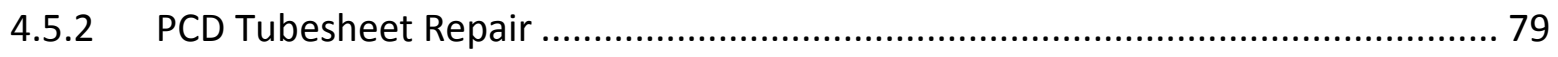

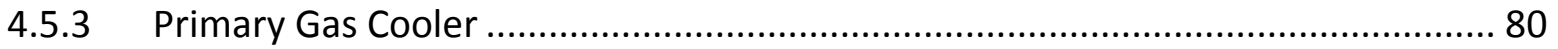

4.5.4 Pressure Letdown Device Design Modifications .................................................. 80

4.6 Stanford University Tunable Diode Laser ......................................... 80

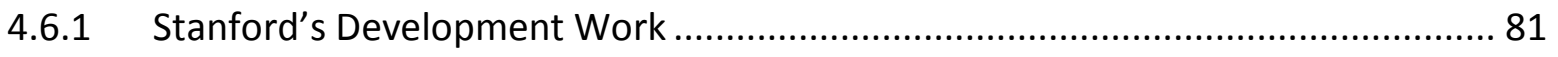

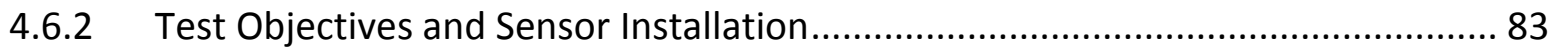

4.6.3 TDL Sensor Design for $\mathrm{H}_{2} \mathrm{O}$ and Temperature Measurements ............................. 84

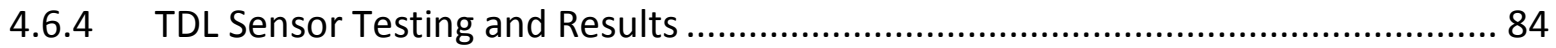

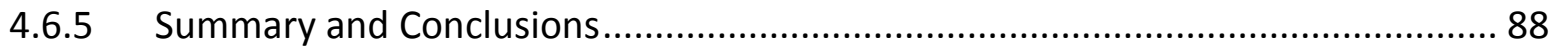

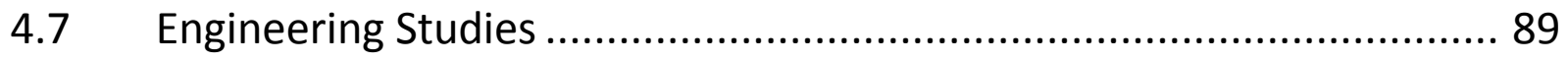

5.0 CONCLUSIONS AND LESSONS LEARNED ............................................ 90

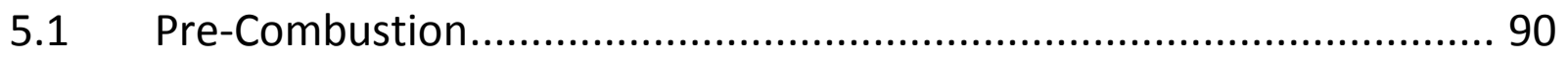

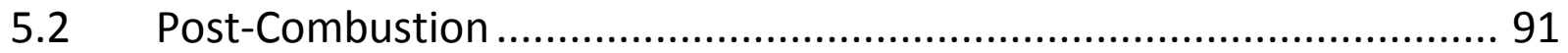

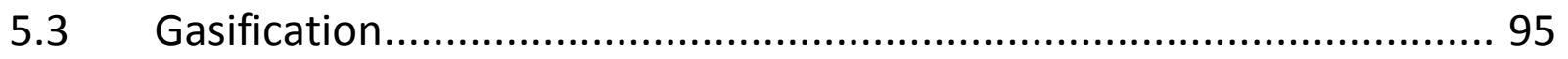




\section{List of Figures}

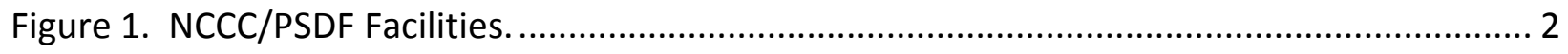

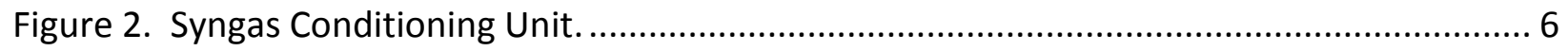

Figure 3. SCU Expansion Area Housing Syngas Cleaning System........................................... 8

Figure 4. SCU Reactor Vessels Used for WGS Catalyst Evaluation. ........................................ 9

Figure 5. Water-Gas Shift Catalyst Test Results for Runs R07 through R09........................... 10

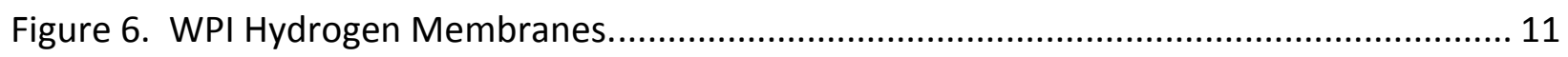

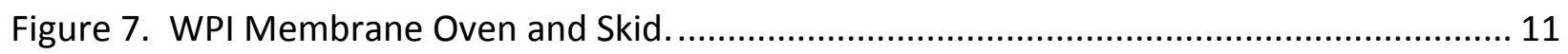

Figure 8. WPI Membrane Permeance for Run R09......................................................... 12

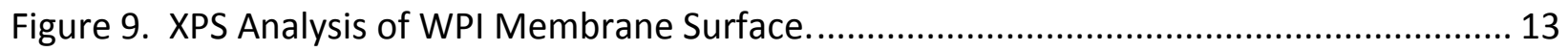

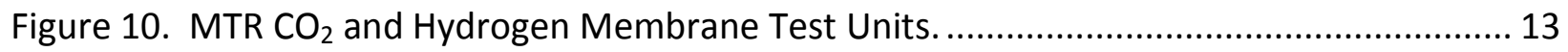

Figure 11. MTR $500 \mathrm{lb} / \mathrm{hr}$ Membrane System Skids in Fabrication. ....................................... 14

Figure 12. Installed MTR $500 \mathrm{lb} / \mathrm{hr} \mathrm{CO}_{2}$ Membrane System................................................. 14

Figure 13. Test Results of MTR $50 \mathrm{lb} / \mathrm{hr} \mathrm{CO} \mathrm{CO}_{2}$ Membrane and Hydrogen Stamp Membrane in

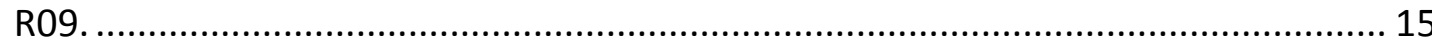

Figure 14. Hydrogen Content of Permeate and Reject Streams for MPT Membrane during

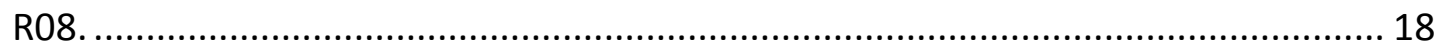

Figure 15. Conceptual Multi-Tube CMS Bundle with Surface Area Greater Than $110 \mathrm{ft}^{2} \ldots \ldots \ldots . . .19$

Figure 16. Schematic of Eltron Hydrogen Membrane Tube................................................... 20

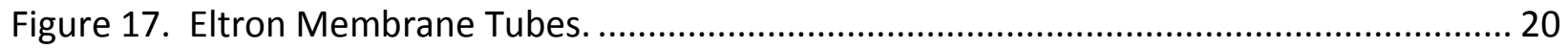

Figure 18. Eltron Membrane Hydrogen Flux during R09 Testing. .......................................... 21

Figure 19. SEM Image of the Surface of an FCC-Structured Palladium-Based Coupon Exposed

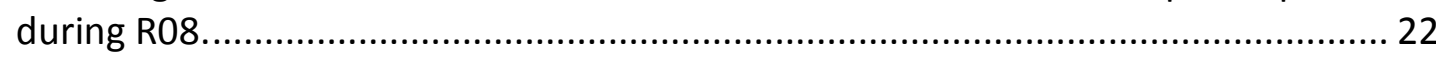

Figure 20. SEM Image of the Surface of a Baseline Coupon of a Super-Permeable Material

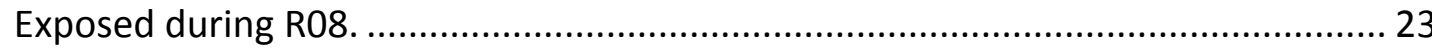

Figure 21. $\mathrm{CO}_{2}$ Capacity as a Function of $\mathrm{CO}_{2}$ Partial Pressure for University of Alabama

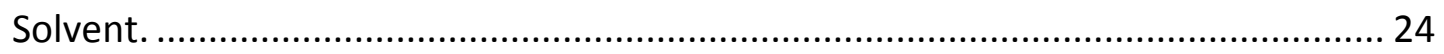

Figure 22. $\mathrm{H}_{2} \mathrm{~S}$ Absorption for University of Alabama Solvent........................................... 24

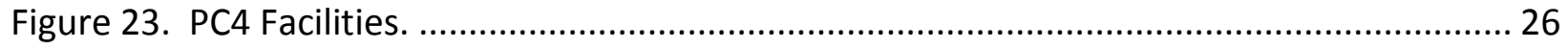

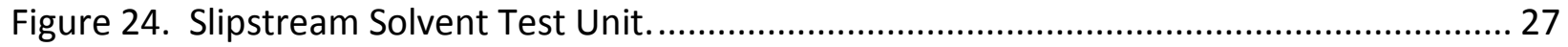

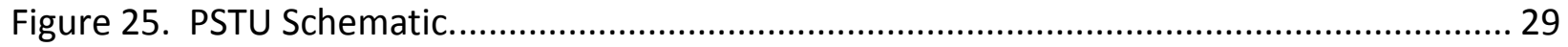

Figure 26. Color Change of Solvent During 2012 MEA Baseline Test Campaign....................... 34

Figure 27. $\mathrm{CO}_{2}$ Capture Efficiency over the Duration of Hitachi Solvent Testing..................... 43 


\section{List of Figures (Cont'd)}

Figure 28. Variation of $\mathrm{CO}_{2}$ Capture Efficiency with Hitachi Solvent Flow Rate....................... 43

Figure 29. Variation of Regeneration Energy with Hitachi Solvent Flow Rate. ......................... 44

Figure 30. Variation of $\mathrm{CO}_{2}$ Capture Efficiency of Hitachi Solvent with Reboiler Steam Flow Rate. 44

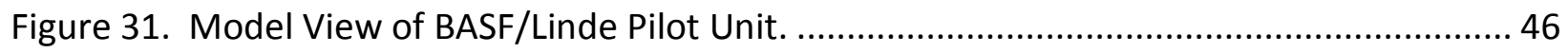

Figure 32. Solvent, Flue Gas, and Steam Flow Rates during Cansolv Solvent Testing............... 48

Figure 33. Optimization of Cansolv DC-201 Solvent at Various Absorber Packing Heights. ....... 48

Figure 34. Variation of Steam Flow and Lean and Rich loadings with Absorber Packing Sections. 49

Figure 35. Variation of $\mathrm{CO}_{2}$ Capture Rate, Amine Concentration, and Stripping Factor............ 50

Figure 36. Increase of Anionic Species in Lean Solvent over Time......................................... 51

Figure 37. Chromatograph of Lean Cansolv Solvent Samples Taken at $\mathrm{t}=0$ and $\mathrm{t}=900$ Hours.... 52

Figure 38. Change in Cations and Metals Concentrations in Lean Cansolv Solvent over Time... 53

Figure 39. Modifications to PSTU Requested by Chiyoda..................................................... 55

Figure 40. MTR 1-ton/day $\mathrm{CO}_{2}$ Membrane Components. ........................................................ 56

Figure 41. Schematic of MTR Flue Gas Membrane Skid.................................................... 57

Figure 42. Schematic Showing MTR Membrane Skid Gas Flows......................................... 57

Figure 43. Deposits in Compressor Outlet and the Filtrand from the Solution made by Deposits. 59

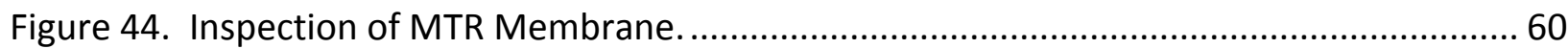

Figure 45. Inspection of Membrane Sheets and Feed Spacer of MTR Module........................ 61

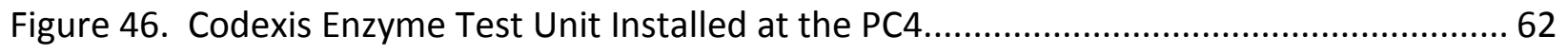

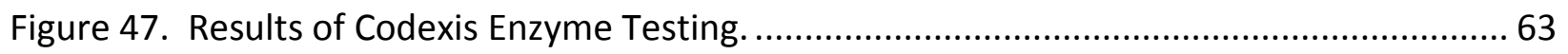

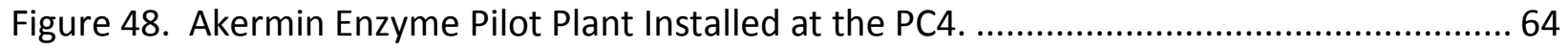

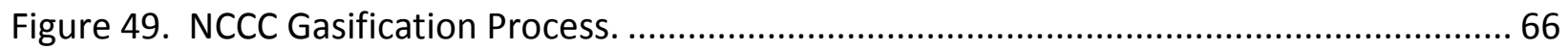

Figure 50. Gasifier Temperature Control during Non-Steady-State Operation. ...................... 67

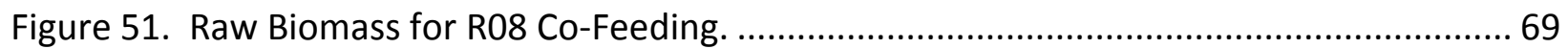

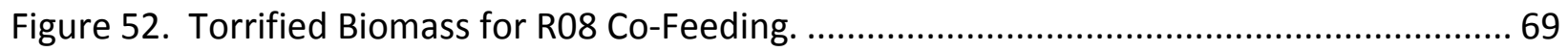

Figure 53. Particle Size Distribution Curves for R08 Gasifier Feedstocks. ............................... 70

Figure 54. Biomass Feed Rate as a Function of Feeder Speed of Original Rotary Coal Feeder... 71

Figure 55. Carbon Conversion during PRB Coal and Biomass Co-Feed Operation..................... 72 


\section{List of Figures (Cont'd)}

Figure 56. Mass and Energy Balances for R08 Biomass Co-Feed Operation............................ 72

Figure 57. Fine and Coarse Ash Particle Size Distribution Curves for R08 Operation. ................ 73

Figure 58. Temperature Readings for Sapphire and HR-160 Thermowells............................ 75

Figure 59. Comparison of Coal Feed Rates Indicated by Weigh Cells and Densflow Meter. ...... 76

Figure 60. Gasifier Standpipe Refractory before and after Standpipe Replacement................ 78

Figure 61. Standpipe Demolition in Progress. .................................................................... 79

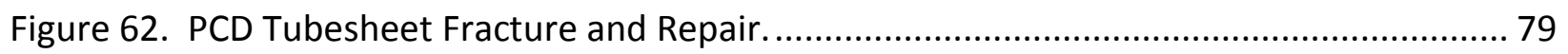

Figure 63. Conceptual Use of TDL Sensor for Control of an IGCC Plant. ................................ 81

Figure 64. Location of TDL Sensor in NCCC Transport Gasification Process............................. 83

Figure 65. TDL Sensor Assembly Installed in Gasification Process. ........................................ 84

Figure 66. In-Situ Measurements of Flue Gas Moisture during Gasifier Start-Up.................... 85

Figure 67. Thermocouple Measurements Compared with TDL Temperature and Syngas $\mathrm{H}_{2} \mathrm{O}$

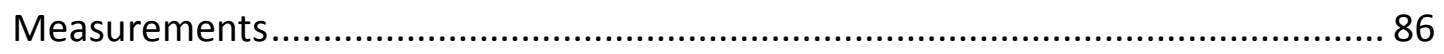

Figure 68. Continuous TDL $\mathrm{H}_{2} \mathrm{O}$ Measurements Compared with $\mathrm{H}_{2} \mathrm{O}$ Sampling Data............... 86

Figure 69. Fluctuations in TDL $\mathrm{H}_{2} \mathrm{O}$ Measurements and Gasifier Thermocouple

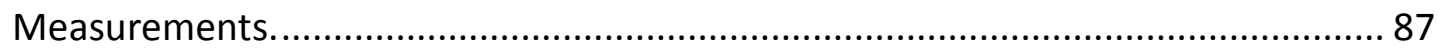

Figure 70. Fluctuations in TDL $\mathrm{H}_{2} \mathrm{O}$ Measurements and PDAC Feeder Pressure....................... 87

Figure 71. TDL $\mathrm{H}_{2} \mathrm{O}$ Measurement and $\mathrm{GC} \mathrm{CO}_{2}$ Measurements during Upset Condition. .......... 88 


\section{List of Tables}

Table 1. Major Project Milestones for the 2012 Portion of Budget Period Four. ....................... 5

Table 2. Design Parameters for WGS Catalyst Reactor Vessels.............................................. 9

Table 3. Results from Testing of Baffle Arrangement in MPT Full-Scale Membrane Bundle...... 17

Table 4. Composition Data for Egress Streams from MPT Membrane during R09................... 18

Table 5. Parametric Tests Results for Solvent Carryover from Absorber Wash Tower.............. 31

Table 6. Amine and Degradation Product Carryover during MEA Testing. .............................. 32

Table 7. Effect of Scrubber Liquid in Impingers on Vapor Emissions. ..................................... 33

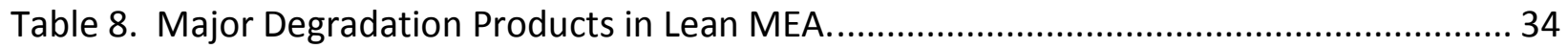

Table 9. RCRA-Listed Metals in Solvent from 2012 MEA Test Campaign................................. 35

Table 10. Non-RCRA-Listed Metals in Solvent from 2012 MEA Test Campaign........................ 37

Table 11. Anions in Solvent from 2012 MEA Test Campaign................................................... 38

Table 12. Selenium Species in MEA Solvent with and without $\mathrm{pH}$ Adjustment......................... 39

Table 13. Efficiency of Metals Removal from MEA Solvent with Texas A\&M ZVI Process.......... 40

Table 14. Operating Parameters for Hitachi Solvent Testing. ................................................. 42

Table 15. L/G Ratio and Heat of Regeneration of 30 wt\% MEA and Hitachi Solvent................. 45

Table 16. $\mathrm{CO}_{2}$ Capture Efficiency of Hitachi Solvent with Varying Number of Absorber Beds in

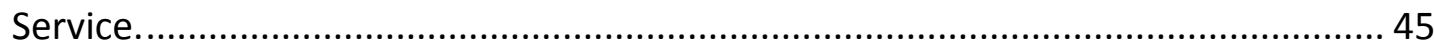

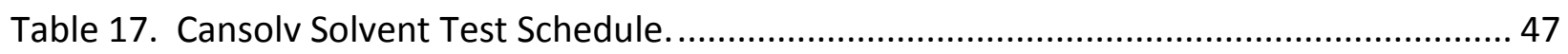

Table 18. Main Contaminants Found in Gas Streams during Three Sampling Surveys.............. 54

Table 19. Steady State Carbon Conversions for R08 and R09............................................... 67

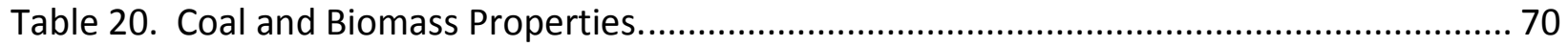

Table 21. Coal and Biomass Co-Feed Operating Parameters.............................................. 71 


\section{List of Abbreviations and Acronyms}

\begin{tabular}{|c|c|}
\hline ARPA-E & Advanced Research Projects Agency-Energy \\
\hline CCAT & Connecticut Center for Advanced Technologies \\
\hline CFAD & Continuous Fine Ash Depressurization \\
\hline CFM & Cross-Flow Membrane \\
\hline CMR & Catalytic Membrane Reactor \\
\hline CMS & Carbon Molecular Sieve \\
\hline CSM & Countercurrent-Swept Membrane \\
\hline DC & Direct Current \\
\hline DCS & Distributed Control System \\
\hline DOE & Department of Energy \\
\hline EERC & Energy and Environmental Research Center \\
\hline EPA & Environmental Protections Agency \\
\hline EPRI & Electric Power Research Institute \\
\hline FCC & Face-Centered Cubic \\
\hline FGD & Flue Gas Desulfurization \\
\hline G & Gas (Flue Gas) \\
\hline GC & Gas Chromatograph \\
\hline $\mathrm{H}_{2} \mathrm{~S}$ & Hydrogen Sulfide \\
\hline HTM & Hydrogen Transport Membrane \\
\hline ICP-MS & Inductively Coupled Plasma Mass Spectrometry \\
\hline IGCC & Integrated Gasification Combined Cycle \\
\hline $\mathrm{L}$ & Liquid (Solvent) \\
\hline L/G & Liquid (Solvent) to Gas (Flue Gas) Ratio \\
\hline LDL & Lower Detection Limit \\
\hline MCC & Motor Control Center \\
\hline MDEA & Methyldiethanolamine \\
\hline MEA & Monoethanolamine \\
\hline MM5 & Modified Method 5 \\
\hline MPT & Media \& Process Technology \\
\hline MTR & Membrane Technology \& Research \\
\hline NCCC & National Carbon Capture Center \\
\hline NDIR & Non-Dispersive Infrared \\
\hline NETL & National Energy Technology Laboratory \\
\hline OD & Outer Diameter \\
\hline OSU & Ohio State University \\
\hline PC & Pulverized Coal \\
\hline PC4 & Post-Combustion Carbon Capture Center \\
\hline PCC & Post-Combustion $\mathrm{CO}_{2}$ Capture \\
\hline PCD & Particulate Control Device \\
\hline PDAC & Pressure Decoupled Advanced Coal \\
\hline PLC & Programmable Logic Controller \\
\hline PRB & Powder River Basin \\
\hline PSDF & Power Systems Development Facility \\
\hline PSTU & Pilot Solvent Test Unit \\
\hline
\end{tabular}




\section{List of Abbreviations and Acronyms (Cont'd)}

$\begin{array}{ll}\begin{array}{ll}\text { RCRA } \\ \text { RP-UHPLC-ICP- }\end{array} & \begin{array}{l}\text { Resource Conservation and Recovery Act } \\ \text { TQMS }\end{array} \\ \text { S } & \begin{array}{c}\text { Coverse Phase, Ultra-High Pressure Liquid Chromatography, Inductively } \\ \text { S/L }\end{array} \\ \text { SCL } & \text { Steam (Reboiler Steam) } \\ \text { SCR } & \text { Syngas Chemical Looping } \\ \text { SCU } & \text { Selective Catalytic Reduction } \\ \text { SSTU } & \text { Syngas Conditioning Unit } \\ \text { TCLP } & \text { Slipstream Solvent Test Unit } \\ \text { TDL } & \text { Toxicity Characteristic Leaching Procedure } \\ \text { UA } & \text { Tunable Diode Laser } \\ \text { WGS } & \text { University of Alabama } \\ \text { WMS } & \text { Water-Gas Shift } \\ \text { WPI } & \text { Wavelength-Modulation Spectroscopy } \\ \text { XPS } & \text { Worcester Polytechnic Institute } \\ \text { ZVI } & \text { X-Ray Photoelectron Spectroscopy } \\ & \text { Zero Valent Iron }\end{array}$




\subsection{EXECUTIVE SUMMARY}

The Power Systems Development Facility (PSDF) is a key national asset for ensuring continued cost-effective, environmentally acceptable energy production from coal. Sponsored by the U.S. Department of Energy's (DOE's) National Energy Technology Laboratory (NETL), the PSDF is an engineering scale test center located in Wilsonville, Alabama. The PSDF staff has effectively developed advanced power systems to meet the national need for cleaner, more efficient power production from coal. In the 18 years of PSDF operation, numerous technologies have been tested under challenging process conditions without any lost-time accidents.

Building on its previous success, PSDF now houses the National Carbon Capture Center (NCCC), established in 2009. The NCCC provides test facilities and wide-ranging support to researchers developing lower-cost $\mathrm{CO}_{2}$ capture technologies that will enable coal-based power generation to remain a key contributor to the energy mix. The facilities accommodate a range of equipment sizes and operating conditions and provide commercially representative settings that allow results to be scaled confidently to commercial application, a crucial element in shortening development times.

\section{Project Partnership with DOE}

The DOE conceived the PSDF as the premier advanced coal power generation research and development facility of the world, to "serve as the proving ground for many new advanced power systems." Since operations began in 1996, the PSDF has been a center for national efforts to develop clean, high efficiency coal-based power generation technologies. Two significant achievements-in addition to many secondary goals that were met-were the development of hot gas filtration to improve energy efficiency and the development of a gasifier suitable for use with low-rank coals, which comprise over half of the total coal reserves in the U.S. and the world. These two technologies have progressed to commercialization with an integrated gasification combined cycle (IGCC) power plant under construction in Kemper County, Mississippi.

\section{Project Mission and Approach}

Offering a world-class neutral test facility and a highly specialized staff, the National Carbon Capture Center accelerates the commercialization of advanced technologies to enable coal-based power plants to achieve near-zero emissions. Work at the NCCC supports the next stages of coal-fired power technologies and the continued operation of conventional coal-fired power plants under $\mathrm{CO}_{2}$ emission constraints.

In undertaking its mission, the NCCC is involved in a range of activities in the areas of pre- and post- combustion $\mathrm{CO}_{2}$ capture and gasification to develop the most promising technologies for future commercial deployment. The test facilities, shown in Figure 1, include the original PSDF site, which houses the gasification and pre-combustion $\mathrm{CO}_{2}$ capture processes, and the PostCombustion Carbon Capture Center (PC4), located at the adjacent Alabama Power E.C. Gaston power plant. 


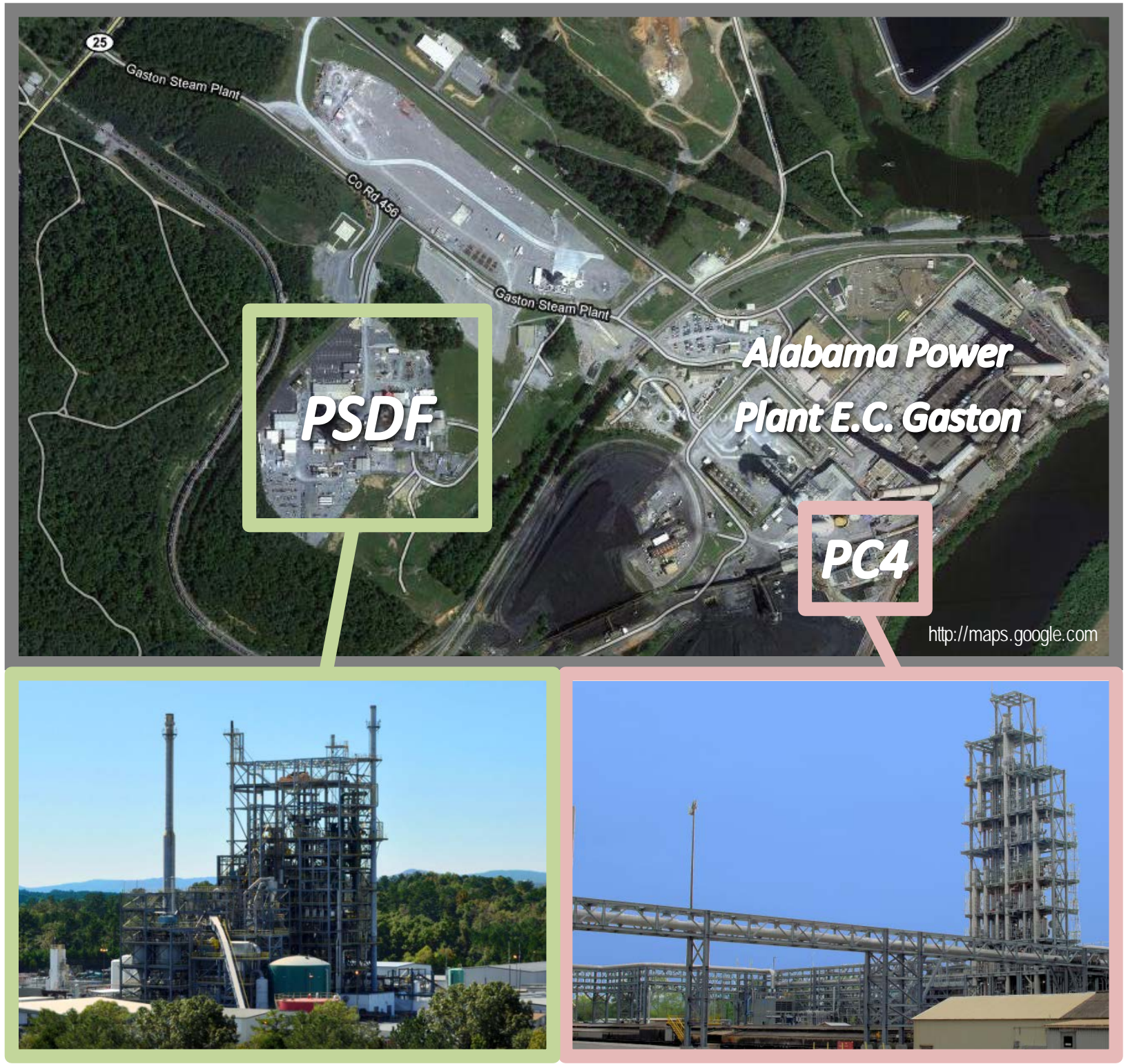

Figure 1. NCCC/PSDF Facilities.

\subsection{Pre-Combustion $\mathrm{CO}_{2}$ Capture Testing}

For the area of pre-combustion $\mathrm{CO}_{2}$ capture, highlights of testing in 2012 are listed below.

- Testing of water-gas shift (WGS) was conducted with a technology developer's catalyst during the two gasification runs of 2012 for parametric studies and long-term evaluation. Result showed up to 70 percent CO conversion with no steam addition.

- Worcester Polytechnic Institute (WPI) completed testing of palladium-based hydrogen membranes, demonstrating product purity as high as 99.9 percent. The group continued to optimize the composition and thicknesses of the membrane and membrane coating. 
WPI secured funding for a five-fold scale up of the technology based on the data collected at the NCCC.

- Membrane Technology \& Research (MTR) continued testing of polymeric $\mathrm{CO}_{2}$ and hydrogen membranes, and successfully commissioned a 10:1 scale up of its $\mathrm{CO}_{2}$ membrane. The scaled-up membrane system operated as designed and demonstrated liquid $\mathrm{CO}_{2}$ production.

- Media \& Process Technology (MPT) completed further testing of its Carbon Molecular Sieve (CMS) hydrogen membrane, which was increased to a full-scale size. Testing verified the effectiveness of a baffle design incorporated to improve gas distribution throughout the tube bundle, and it produced hydrogen purity up to 95 percent.

- Eltron Research \& Development achieved stable operation with its dense-metal, hightemperature hydrogen separation membrane during its first testing at the NCCC in late 2012. Hydrogen purity in the permeate stream was greater than 99.87 percent during the entire testing period, which indicated excellent membrane integrity without leakage.

- Syngas exposure testing of sample coupons from NETL has proved instrumental in guiding the selection of suitable membrane compositions by identifying different corrosion tendencies.

- Operation with a $\mathrm{CO}_{2}$ capture solvent from the University of Alabama was conducted to advance the university's development of its physical solvent. Test results showed that the $\mathrm{CO}_{2}$ absorption of the solvent was within the range of those of previously tested solvents.

\subsection{Post-Combustion $\mathrm{CO}_{2}$ Capture Testing}

Technology development at the PC4 included:

- The Pilot Solvent Test Unit (PSTU) at the PC4 was operated with monoethanolamine (MEA), for a second solvent baseline test campaign. Researchers confirmed the higherthan-expected solvent carryover and are pursuing ways to reduce it. The testing included quantification of the solvent metal contaminants and evaluation of methods for their removal.

- Testing of advanced amine solvents in the PSTU was completed with solvents from Hitachi and Cansolv Technologies, and testing began with Chiyoda's solvent. The data collected are being used to support development of their commercial processes.

- MTR continued long-term testing of an advanced $\mathrm{CO}_{2}$ gas separation membrane, which has demonstrated efficient operation and is being scaled up from a 1-ton $\mathrm{CO}_{2} /$ day unit to a 20-ton $\mathrm{CO}_{2}$ /day unit. Operation of the 1-ton unit has consistently demonstrated greater than 90 percent $\mathrm{CO}_{2}$ capture. Based on operational experience, MTR incorporated a new design for its compressor.

- Codexis exposed its $\mathrm{CO}_{2}$ capture-enhancing enzymes and solvent to flue gas, achieving a $\mathrm{CO}_{2}$ capture rate increase of more than 25-fold compared to solvent alone. This is the largest scale that enzyme-based carbon capture technology has been demonstrated to date. 
- Akermin commenced with commissioning of its pilot plant incorporating immobilized, carbonic anhydrase enzyme in an absorber, with testing to proceed through mid-2013.

\subsection{Gasification Technology Testing}

Accomplishments in the area of gasification testing are listed below.

- The gasification process was operated in two different test runs with stable operation, supporting the development of technologies including automatic gasifier controls, coal feeders, advanced sensors and instrumentation, and high efficiency particulate filtration components.

- Co-feeding of biomass with coal was conducted for over 200 hours in oxygen-blown gasification mode on behalf of the Connecticut Center for Advanced Technologies (CCAT). The biomass was fed at rates ranging from 10 to $30 \mathrm{wt} \%$ of the total feed rate, with average steady-state carbon conversions greater than 98 percent.

- The testing of Stanford University's Tunable Diode Laser (TDL) marked a major milestone in the scale-up of this sensor. The TDL is considered to be a potential breakthrough technology for control of advanced gasification systems.

\section{$1.4 \quad$ Milestones for 2012}

The Budget Period Four performance period for the NCCC entails a total period of twenty-one months, from January 2012 through September 2013. This report describes the results of work at the NCCC for the calendar year 2012 portion of Budget Period Four. In partnership with the DOE, the NCCC established and met the milestones listed in Table 1 during 2012. 
Table 1. Major Project Milestones for the 2012 Portion of Budget Period Four.

\begin{tabular}{|c|c|c|c|}
\hline Research Area & Milestone & $\begin{array}{l}\text { Completion } \\
\text { Date }\end{array}$ & $\begin{array}{l}\text { Report } \\
\text { Reference } \\
\text { Section }\end{array}$ \\
\hline Gasification & Begin field replacement of refractory-lined piping & Jan 2012 & 4.5.1 \\
\hline Post-Combustion & Conduct follow-up testing on baseline MEA solvent & Mar 2012 & 3.2 \\
\hline Post-Combustion & Resume long-term testing of MTR membrane & Mar 2012 & 3.7 \\
\hline Gasification & Complete field replacement of refractory-lined piping & May 2012 & 4.5.1 \\
\hline Post-Combustion & Complete testing of Codexis enzyme-based process & May 2012 & 3.9 \\
\hline Pre-Combustion & Upgrade SCU electrical system to support projected loads & Jun 2012 & 2.1.1 \\
\hline Pre-Combustion & Add new control room and DCS operator workstation for SCU & Jun 2012 & 2.1.1 \\
\hline Post-Combustion & Complete testing of Hitachi solvent in PSTU $(1,000$ hours $)$ & Jun 2012 & 3.3 \\
\hline Pre-Combustion & $\begin{array}{l}\text { In R08, test WGS catalyst and membranes from MTR, MPT, } \\
\text { and WPI }\end{array}$ & Jul 2012 & 2.0 \\
\hline Gasification & $\begin{array}{l}\text { Conduct gasification test run R08 for } 750 \text { hours air-blown } \\
\text { operation using PRB coal }\end{array}$ & Jul 2012 & 4.1 \\
\hline Post-Combustion & Extend testing of Hitachi solvent in PSTU & Jul 2012 & 3.3 \\
\hline Gasification & $\begin{array}{l}\text { Extend test run R08 to conduct oxygen-blown gasification } \\
\text { with biomass/coal co-feed for Connecticut Center for } \\
\text { Advanced Technologies }\end{array}$ & Sep 2012 & 4.2 \\
\hline Post-Combustion & Continue testing MTR membrane & Sep 2012 & 3.7 \\
\hline Post-Combustion & Complete testing of Cansolv solvent in PSTU & Oct 2012 & 3.5 \\
\hline Pre-Combustion & $\begin{array}{l}\text { Install a new syngas cooling and cleaning system to support a } \\
\text { low temperature scale-up polymeric } \mathrm{CO}_{2} \text { membrane field } \\
\text { demonstration; install vendor-supplied module and } \\
\text { interconnections }\end{array}$ & Nov 2012 & 2.1 .2 \\
\hline Gasification & $\begin{array}{l}\text { Conduct gasification run R09 for } 1,000 \text { hours of on-coal } \\
\text { operation with PRB with testing of Stanford's TDL }\end{array}$ & Dec 2012 & $4.1,4.6$ \\
\hline Pre-Combustion & $\begin{array}{l}\text { In R09, test } \mathrm{CO}_{2} \text { solvent from University of Alabama; } \\
\text { membranes from MTR, MPT, WPI, Eltron; WGS catalyst; and } \\
\text { large-scale MTR membrane }\end{array}$ & Dec 2012 & 2.0 \\
\hline Post-Combustion & Initiate installation of SSTU & Dec 2012 & 3.1 .2 \\
\hline Post-Combustion & Continue testing MTR membrane in bench-scale area & Dec 2012 & 3.7 \\
\hline Post-Combustion & $\begin{array}{l}\text { Install and begin commissioning Akermin enzyme process in } \\
\text { bench-scale area }\end{array}$ & Dec 2012 & 3.10 \\
\hline Post-Combustion & Begin testing Chiyoda solvent in PSTU & Dec 2012 & 3.6 \\
\hline
\end{tabular}




\subsection{PRE-COMBUSTION $\mathrm{CO}_{2}$ CAPTURE}

The infrastructure for pre-combustion $\mathrm{CO}_{2}$ capture testing provides for a wide range of test conditions, and includes the Syngas Conditioning Unit (SCU). Figure 2 is a flow diagram of the SCU, which consists of small reactor vessels, arranged to allow operation in series or in parallel, and accommodates a range of flow rates, temperatures, and pressures. During 2012, several upgrades to the SCU were incorporated, and various tests with gas separation membranes, a $\mathrm{CO}_{2}$ capture solvent, and a WGS catalyst commenced. Several technology developers also tested metallic hydrogen membrane coupons of advanced materials for syngas exposure in the SCU vessels. Preparations were also underway to support future testing, including Ohio State University’s (OSU's) Syngas Chemical Looping (SCL) project.

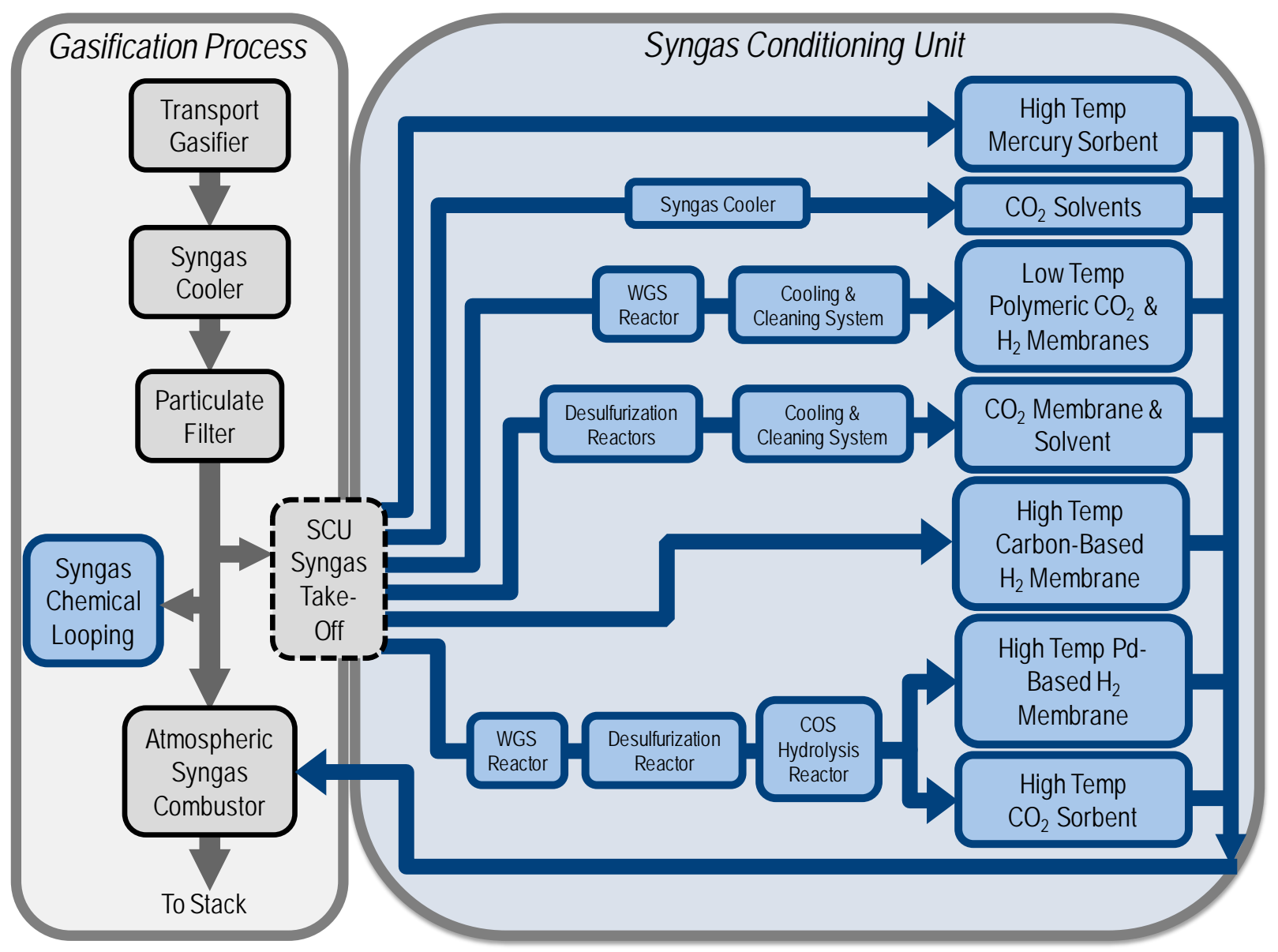

Figure 2. Syngas Conditioning Unit.

\subsection{Syngas Conditioning Unit Modifications}

The increasing number and size of pre-combustion test skids required upgrades to the SCU infrastructure. The NCCC installed new, larger buildings for a Motor Control Center (MCC) and a control room and constructed an expansion area containing a high-capacity syngas cleaning system. 


\subsubsection{SCU Upgrades}

\section{Electrical Upgrades}

To meet the projected increased testing demand, additional electrical supply was required, much of which was routed through an MCC contained in a new electrical building. The building was vendor-supplied according to NCCC specifications, and NCCC staff designed and poured the foundations and laid the underground conduit carrying the power supply cables. The MCC incoming line sections were installed, checked, and energized in June with available equipment.

The MCC equipment was designed to be delivered in two phases.

- The first phase was to support the SCU expansion with the $1,000 \mathrm{lb} / \mathrm{hr}$ syngas cleaning system and to support testing of MTR's new scaled-up $\mathrm{CO}_{2}$ separation membrane system to process $500 \mathrm{lb} / \mathrm{hr}$ of syngas. This phase was completed by August 2012 with all motor control centers installed and fully functional.

- The second phase of MCC equipment will be ordered once the design load requirements of the $800-\mathrm{lb} / \mathrm{hr}$ OSU SCL project are established.

\section{Control Room Upgrades}

The original SCU control room did not provide adequate space for NCCC plant operators and technology developer personnel. This control room was located beneath the sheltered area of the SCU, occupying space that could be used for process equipment. Hence, a more commodious room was installed outside of the sheltered area, opening up space for the SCU expansion. Distributed Control System (DCS) workstations were provided to allow SCU operators to control the equipment directly rather than requesting changes through the main control room. Fiber optic cables were supplied, connecting the new SCU control room to the main DCS and the plant historian. The work was completed and ready for operation in June.

\section{Other Upgrades}

At the end of 2012, process and mechanical design work were underway to install a new fixedbed reactor vessel in the SCU to provide additional capacity for testing of sorbents and catalysts. This project is scheduled for completion in early 2013 to be used initially with a hightemperature mercury sorbent from Johnson Matthey. Another project was underway to increase the syngas flow rates available for testing of WGS and carbonyl sulfide hydrolysis catalysts. Process design was near completion by the end of 2012, and detailed design will be finalized in 2013.

\subsubsection{SCU Expansion and Syngas Cleaning System}

In 2012, the NCCC staff designed and installed the SCU expansion area comprising a process structure and the new syngas cleaning system. The system was initially utilized in December for testing of MTR's $500 \mathrm{lb} / \mathrm{hr} \mathrm{CO}$ separation membrane during run R09. Figure 3 provides views of the expansion area and the syngas cleaning system. 


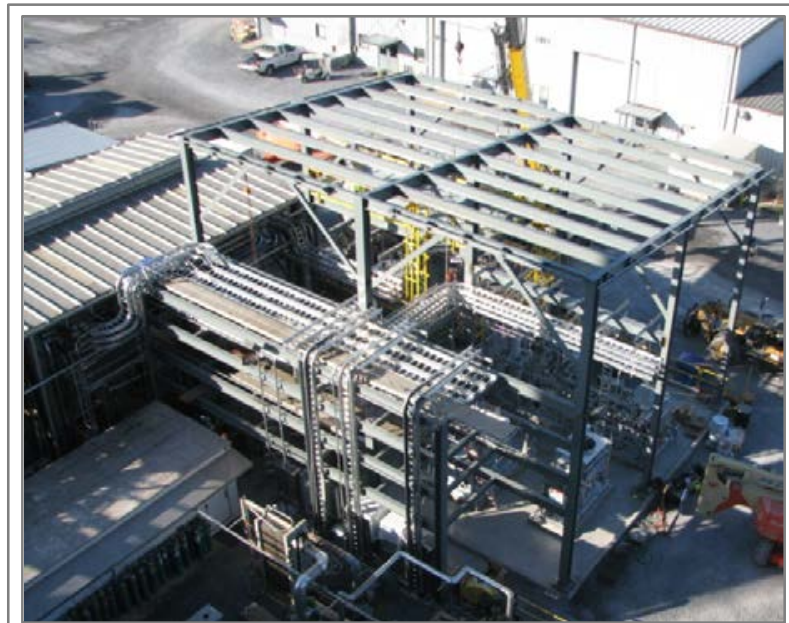

Top View of Expansion Area, with Original SCU Area on Left

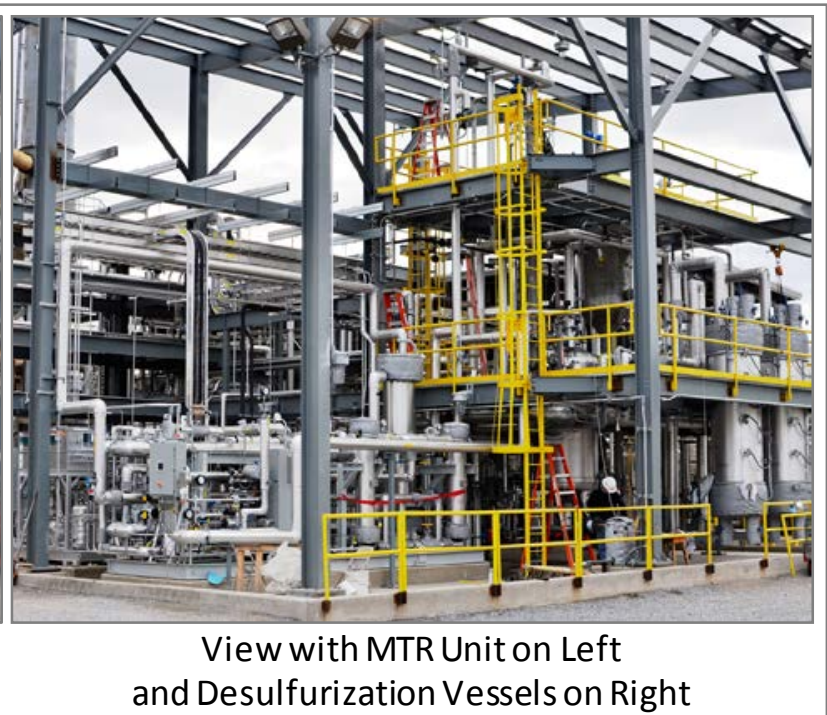

Figure 3. SCU Expansion Area Housing Syngas Cleaning System.

\section{Syngas Cleaning System Process Description}

The syngas passing to the SCU contains hydrogen sulfide $\left(\mathrm{H}_{2} \mathrm{~S}\right)$, which is removed by a hightemperature absorbent. For the MTR membrane, the syngas must be cooled to ambient temperature, which is below the condensation point of most hydrocarbons present. To remove the hydrocarbons and thus prevent fouling of downstream equipment, the hot syngas is bubbled through a stirred quench tank of chilled water at $50^{\circ} \mathrm{F}$, which removes the majority of the hydrocarbons. The syngas leaving the tank passes into a packed column scrubber with a countercurrent flow of chilled water to remove entrained hydrocarbons. The syngas leaving the scrubber is heated from around $50^{\circ} \mathrm{F}$ to $100^{\circ} \mathrm{F}$, which lowers the relative humidity and avoids condensation of water and residual hydrocarbons in the membrane equipment. The ancillary equipment includes heat exchangers utilizing chilled water preceded by a pair of liquid filters to remove the condensed hydrocarbons. When the pressure drop across a filter exceeds the set point, a clean filter is brought into service and the one leaving service is steam cleaned. The steam/ hydrocarbon mixture passes to the atmospheric syngas combustor during the cleaning stage. In addition to removing hydrocarbons, the chilled water also condenses out water vapor, which accumulates in the stirred tank. The level in the quench tank is maintained automatically, and the excess water is drained to a second tank that discharges at a controlled rate to the atmospheric syngas combustor.

\subsection{Water-Gas Shift Catalyst}

Water gas shift catalyst evaluation is completed in one of three pressure vessels shown in Figure 4. The vessels and the lines delivering the syngas are heavily trace heated and insulated to maintain the required operating temperatures. Some of the key design parameters for the vessels are presented in Table 2. 


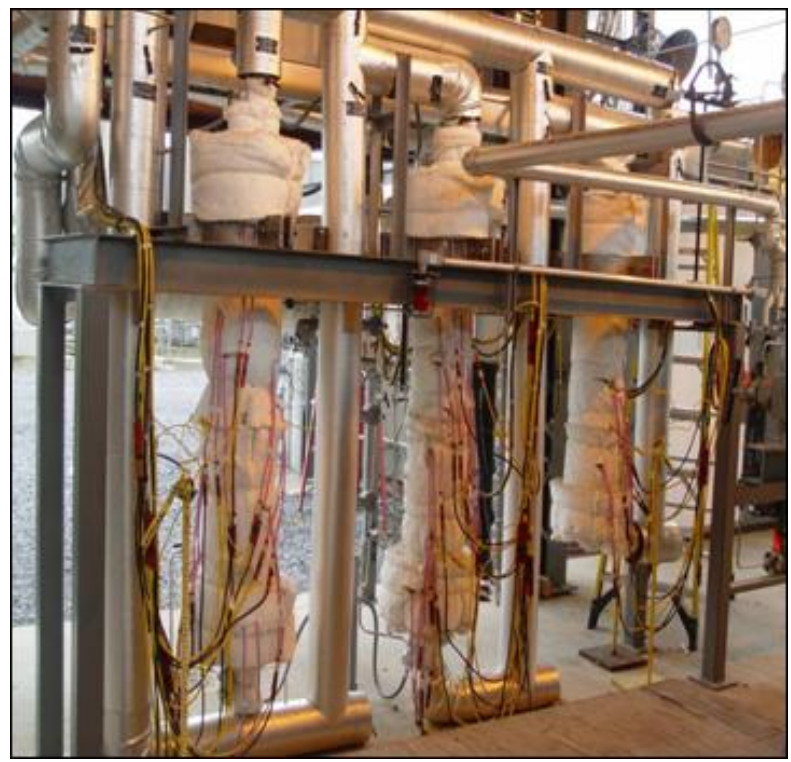

Figure 4. SCU Reactor Vessels Used for WGS Catalyst Evaluation.

Table 2. Design Parameters for WGS Catalyst Reactor Vessels.

\begin{tabular}{|lc|}
\hline \multicolumn{1}{|c|}{ Design Parameter } & Value \\
\hline Vessel Material of Construction & 310 Stainless Steel \\
Design Pressure, psia & 365 \\
Design Temperature, ${ }^{\circ} \mathrm{F}$ & 1,000 \\
Height of Parallel Section, inches & 48 \\
Internal Diameter, inches & 5.2 \\
\hline
\end{tabular}

The syngas at the inlet of the hot gas filtration system (Particulate Control Device, or PCD) of the gasification process is analyzed using two on-line gas chromatographs (GCs) and a NonDispersive Infrared (NDIR) $\mathrm{CO} / \mathrm{CO}_{2}$ meter, and this information is used as the inlet syngas composition to the WGS vessel. The syngas composition leaving the WGS vessel is provided by GC analyzers. Syngas moisture content is determined by condensation measurement, as this has proved to be more accurate than using continuous analyzers. The vessel is equipped with an inlet flow meter and control valve to control flow rate. A similar arrangement is provided for steam should steam addition be needed to promote the shift reaction. The meters are configured so that they can be checked with a known flow of nitrogen prior to start-up and at intervals during the run.

An undisclosed water gas shift catalyst supplier began testing a catalyst under development in 2011 using coal-derived syngas. Parametric testing was completed during R07 at the end of 2011, using $50 \mathrm{lb} / \mathrm{hr}$ of raw syngas at $480^{\circ} \mathrm{F}$ and 200 psia for 850 hours. Steam was added to extend the range of steam-to-CO ratios. 
After completion of testing, the catalyst was removed and returned to the manufacturer for postrun analysis. The analysis was considered favorable, and the supplier requested that the catalyst be tested for a more extended time at constant conditions. For ease of operation, it was agreed that steam would not be added and that the reaction would proceed with the intrinsic syngas moisture content. A fresh batch of catalyst was installed prior to R08. Following 292 hours of operation in R08, the catalyst was blanketed with nitrogen and kept ready for retesting in R09. A further 746 hours of testing was achieved in R09, bringing the exposure time for this batch of catalyst to 1,038 hours.

Test data collected over the three runs are presented in Figure 5. The range of data for R07 is wider because of the steam added during testing. For one pass of syngas, over 80 percent $\mathrm{CO}$ conversion was achieved with a steam-to-CO ratio of 2. For the intrinsic steam-to-CO ratio of around 0.9 , CO conversion was as much as 70 percent. Further testing of this catalyst is planned for 2013.

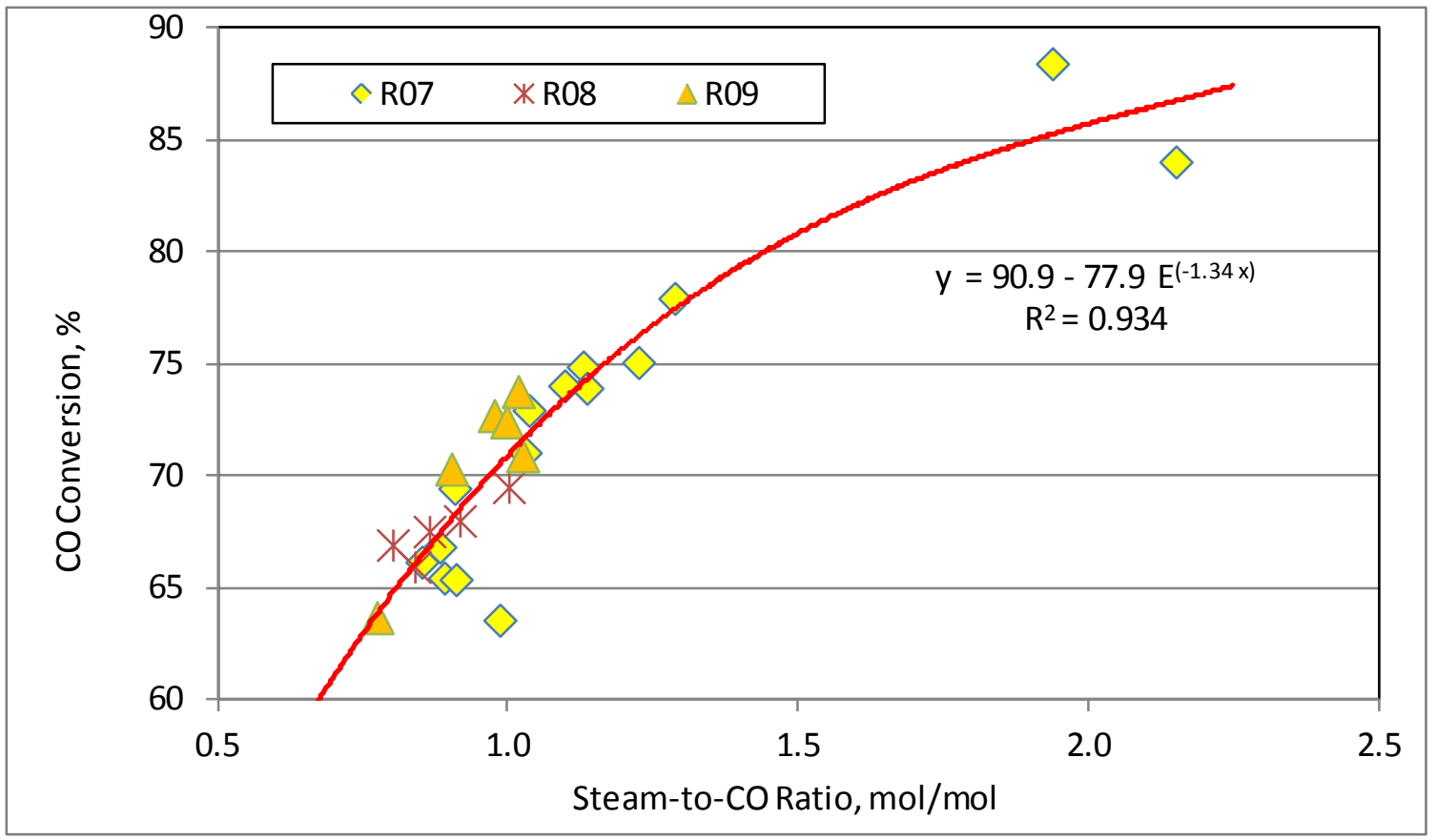

Figure 5. Water-Gas Shift Catalyst Test Results for Runs R07 through R09.

\subsection{Worcester Polytechnic Institute Membranes}

WPI received a DOE award in 2010 to develop high temperature palladium-based membrane technology to separate hydrogen from coal-derived syngas. WPI's composite membrane consists of porous metal substrate (e.g. Inconel or stainless steel) onto which 7 to 12 microns thick dense hydrogen selective palladium (and other alloys) layers are deposited. Figure 6 shows the cross section of membrane layers and completed membrane tubes with various alloys. 


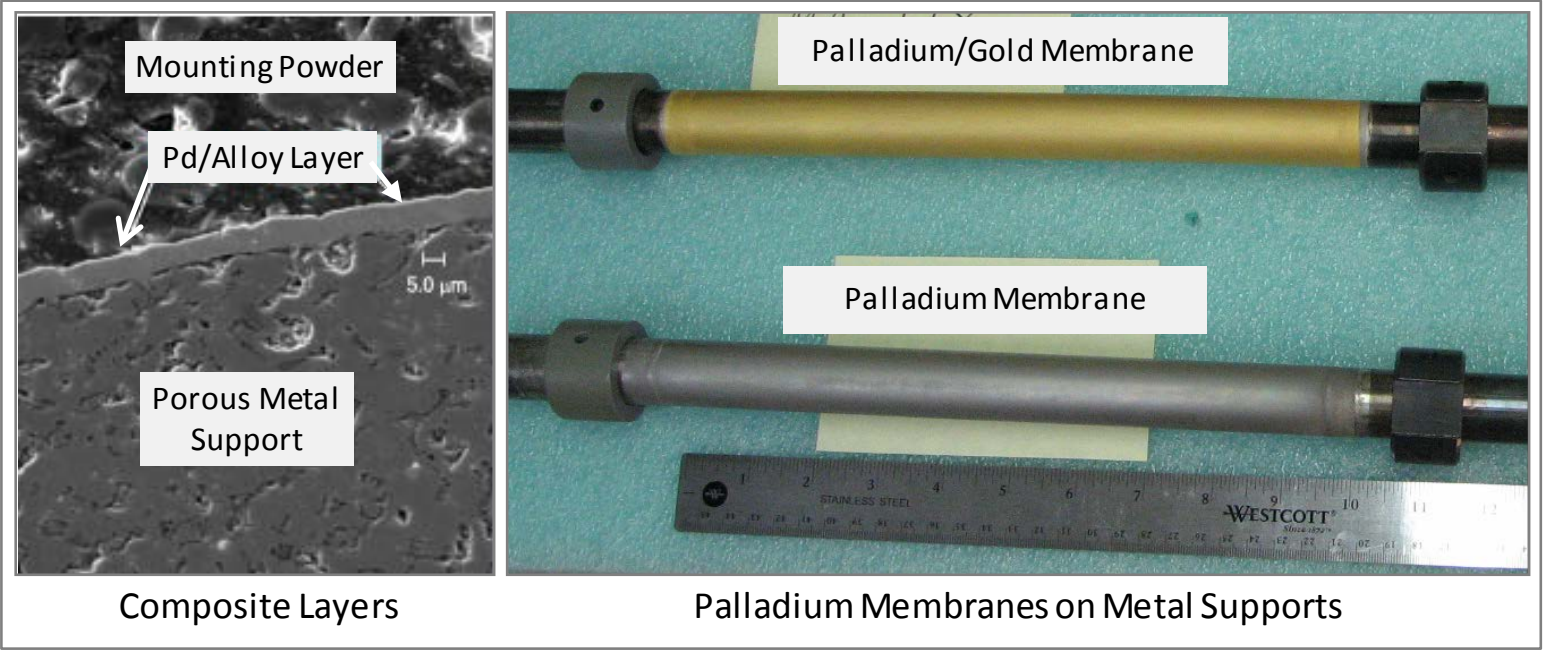

Figure 6. WPI Hydrogen Membranes.

Figure 7 shows the installed membrane test skid, including an oven, membrane module housing the membrane tube, sulfur guard bed, and ballast vessel. The membrane module was designed to process $10 \mathrm{lb} / \mathrm{hr}$ of syngas with hydrogen augmentation from gas cylinders to achieve hydrogen concentrations of 35 to 40 vol\%.

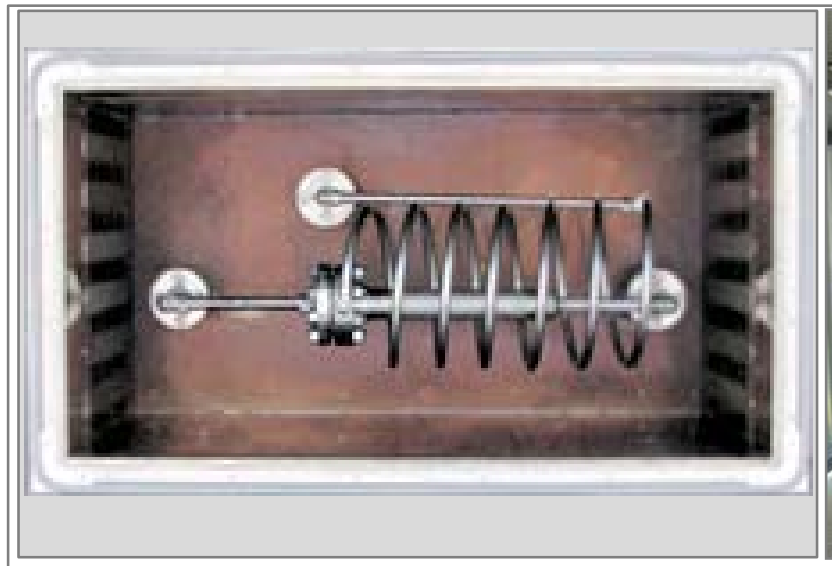

Membrane Installed in Oven

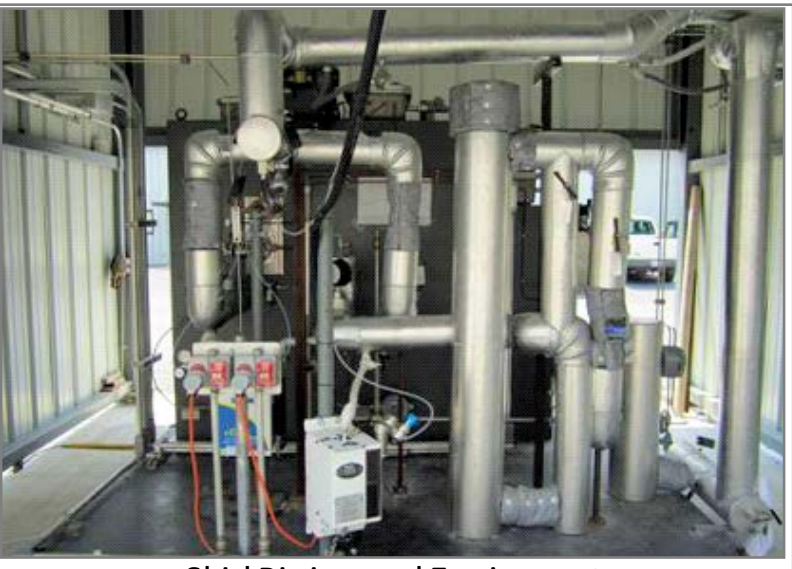

Skid Piping and Equipment

Figure 7. WPI Membrane Oven and Skid.

WPI's testing at the NCCC began in 2011. WPI tested a total of five membranes with various palladium-alloy compositions for a combined 1,337 hours during R06 and R07. Testing continued in 2012 with two new palladium membranes alloyed with two other elements. One of the membranes employed a proprietary coating. A combined 575 hours during the R08 and R09 test runs were completed with these ternary-alloyed membranes. Both tests showed stable performance during the entire testing duration and further demonstrated the robustness of WPI's membranes in a coal-derived syngas environment.

During R08, WPI tested the uncoated ternary alloy membrane, which consistently produced greater than 99.8 percent purity hydrogen with stable performance over a total of 411 hours. A 
parametric test was performed to better understand the hydrogen permeance at hydrogen inlet concentrations varying from 10 to 50 percent. The results showed that hydrogen purity increased with increasing hydrogen concentration in the feed. Hydrogen product purity of 99.9 percent was achieved with 40 percent hydrogen in the feed. After the test, the membrane surface was very clean compared to those tested previously.

For R09, WPI prepared a ternary alloy membrane similar to that tested in R08, but with a slight variation in thickness of the alloy layers. This membrane was also coated with the proprietary material. Though the coating was designed to resist sulfur poisoning, testing during R09 was primarily to determine the hydrogen permeance without any sulfur present for comparison to that from the membrane without the coating. A membrane coupon was also installed inside the membrane module for exposure to the same conditions as the tested membrane. The coupon is currently being analyzed for surface contamination to optimize the material composition and determine appropriate gas pre-treatment requirements.

High product purity and stability of the membrane was demonstrated during the 164 hours of testing. The proprietary coating did not appear to impact hydrogen permeance. Figure 8 plots hydrogen permeance during the R09 test run and shows its stable performance. However, the hydrogen permeance was lower than that measured in the WPI laboratory.

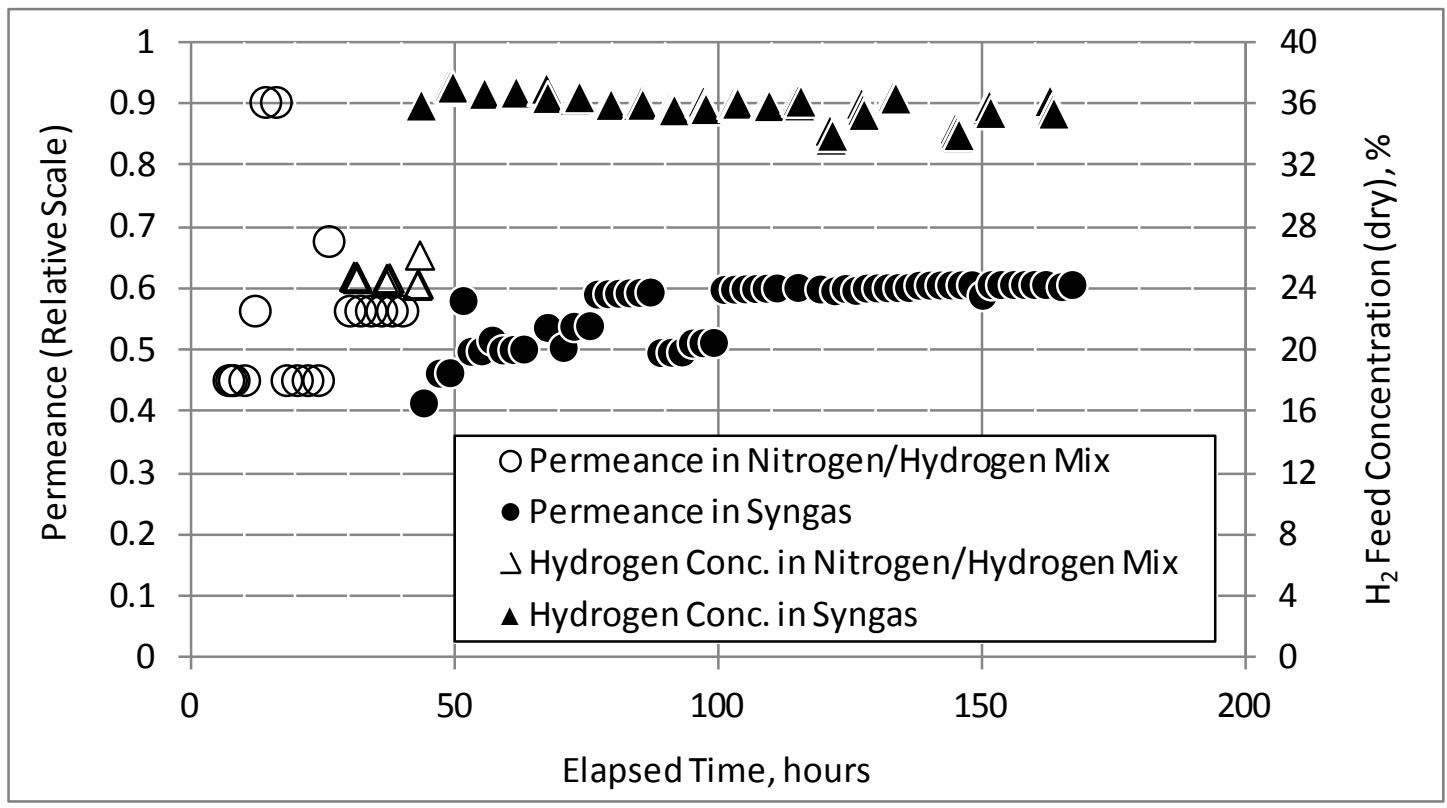

Figure 8. WPI Membrane Permeance for Run R09.

This permeance reduction has also been observed in the previous test runs. Surface contaminant analysis by X-Ray Photoelectron Spectroscopy (XPS) from a previously tested membrane showed high concentrations of carbon on the surface layer as shown in Figure 9. Elemental carbon concentration at the membrane surface was about 46 percent and gradually decreased as the depth increased. However, even at 1,000 $\mathrm{nm}$ depth, the carbon concentration remained at 1 percent. WPI theorized that the presence of unsaturated hydrocarbons in the syngas may have resulted in the carbon deposition on the palladium layer, leading to the loss of active sites for 
hydrogen permeation. Additional testing and analysis is planned to provide insight of the root causes for the permeance reduction.

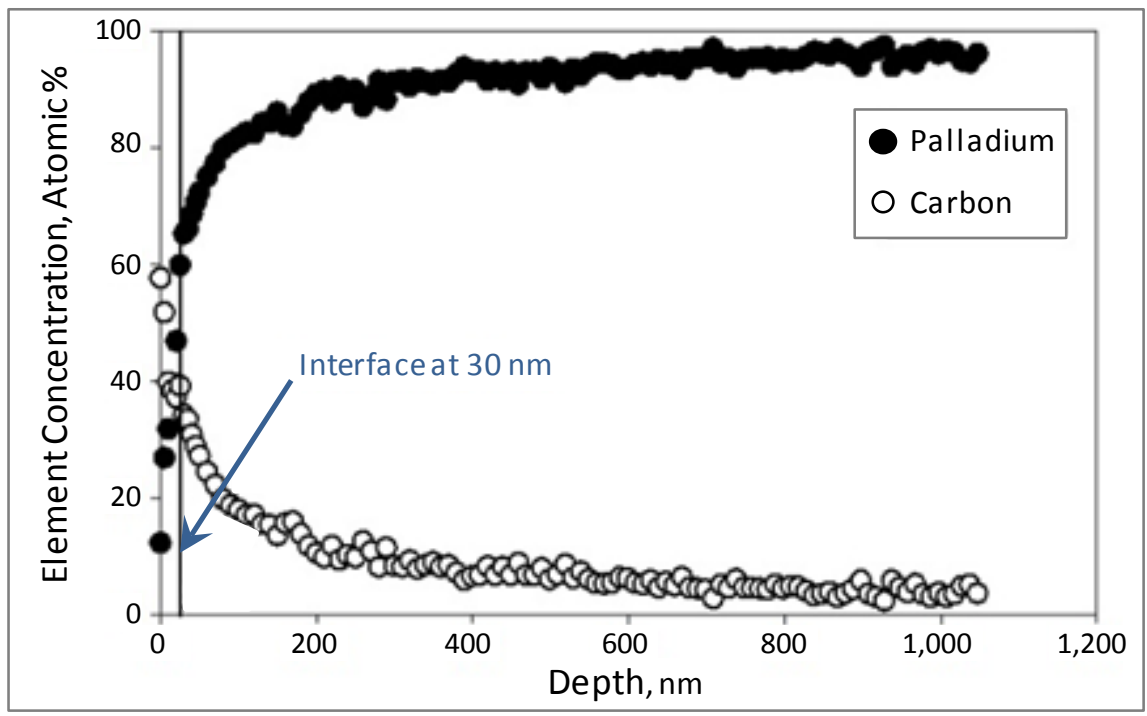

Figure 9. XPS Analysis of WPI Membrane Surface.

\subsection{Membrane Technology \& Research Membranes}

In 2009, MTR, a world leader in the development and production of membrane-based separation systems, began testing two types of polymeric membranes at the NCCC: a $\mathrm{CO}_{2}$-selective Polaris $^{\mathrm{TM}}$ membrane and a hydrogen-selective Proteus ${ }^{\mathrm{TM}}$ membrane. Successful operation has led to scale-ups of both membrane types. In 2011, MTR scaled up the hydrogen membrane from a 1-lb/hr stamp cell to a 10-lb/hr module. In 2012, MTR scaled up the $50-\mathrm{lb} / \mathrm{hr} \mathrm{CO}_{2}$ membrane module to an integrated system designed for $500 \mathrm{lb} / \mathrm{hr}$ syngas. Figure 10 shows the 50-lb/hr $\mathrm{CO}_{2}$ membrane skid and 10-lb/hr hydrogen membrane module.

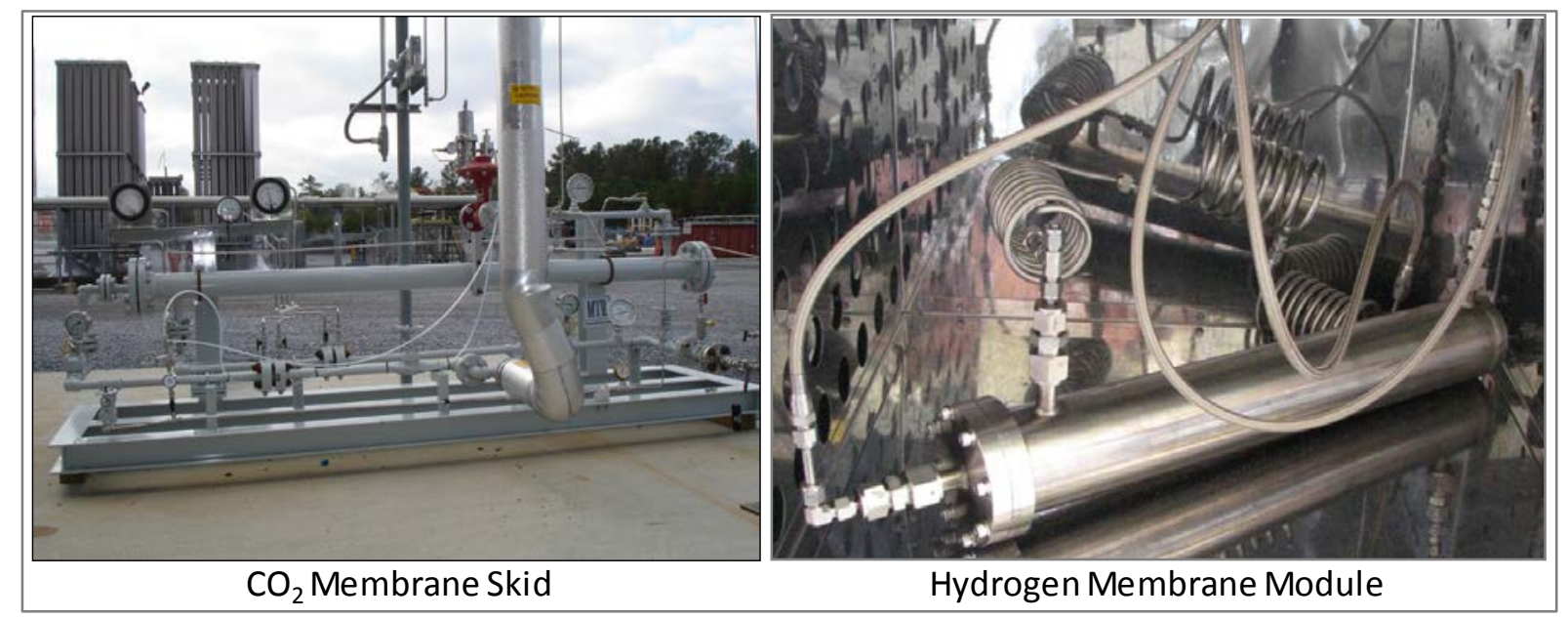

Figure 10. $\mathrm{MTR} \mathrm{CO}_{2}$ and Hydrogen Membrane Test Units. 


\subsubsection{MTR 500-Ib/hr $\mathrm{CO}_{2}$ Membrane System}

The MTR integrated 500-lb/hr $\mathrm{CO}_{2}$ membrane system consists of membrane, compressor, and refrigeration skids, which are shown in Figure 11. Figure 12 shows the membrane system's three skids installed in the newly expanded SCU. The membrane skid includes two stages of membrane modules for $\mathrm{CO}_{2}$ separation. It also houses a sulfur polishing reactor and two desiccant dryers for sulfur and moisture removal upstream of the compressor and refrigeration skids, heaters, and control panels. The first-stage permeate stream from the membrane skid is pressurized to about 420 psig in the compressor skid, and then the compressed gas stream is liquefied in the refrigeration skid which removes the $\mathrm{CO}_{2}$. Uncondensed gas is fed to the second-stage membrane for further $\mathrm{CO}_{2}$ separation. The second-stage membrane permeate stream is combined with the first-stage permeate stream, and the combined stream is treated in the sulfur polishing reactor. Reject streams from both first- and second-stage membrane modules, as well as the liquid $\mathrm{CO}_{2}$ stream, are sent to the atmospheric syngas combustor.

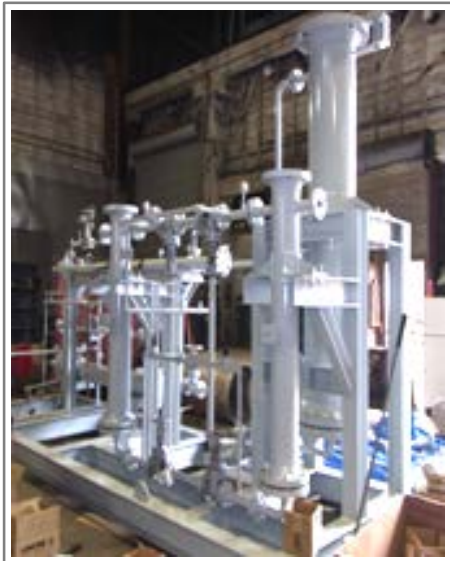

Membrane Skid

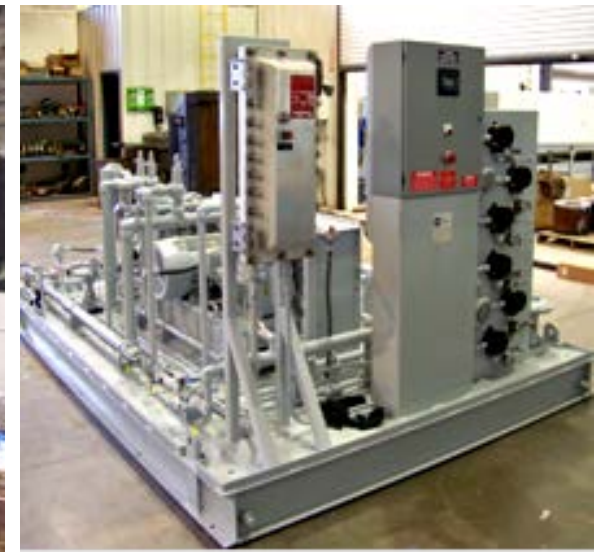

CompressorSkid

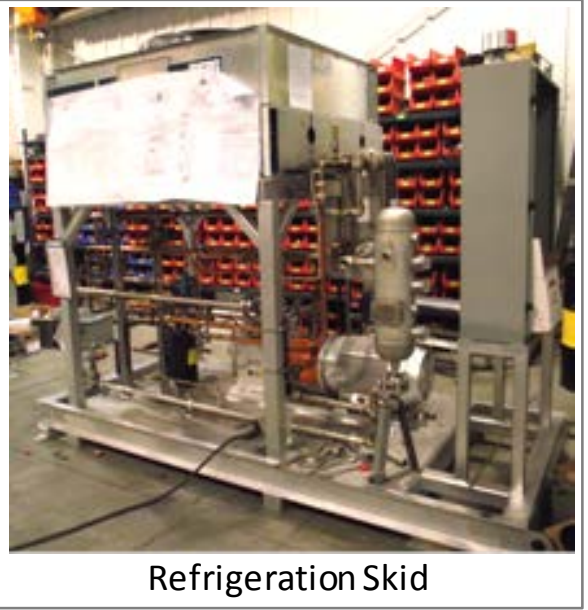

Refrigeration Skid

Figure 11. MTR $500 \mathrm{lb} / \mathrm{hr}$ Membrane System Skids in Fabrication.

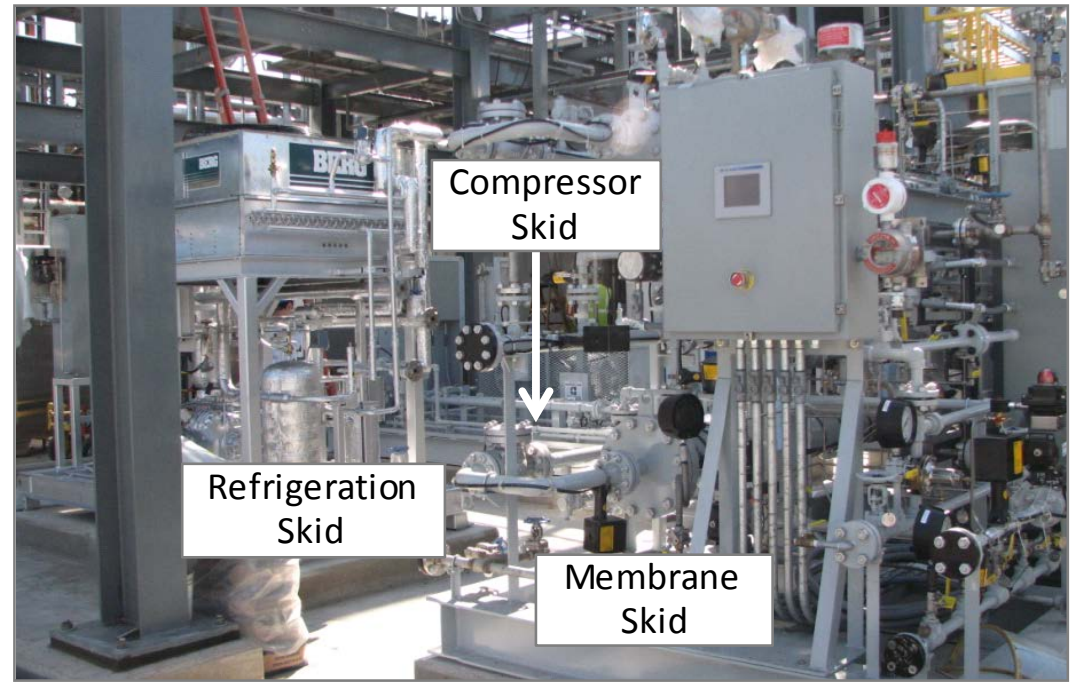

Figure 12. Installed MTR $500 \mathrm{lb} / \mathrm{hr} \mathrm{CO}_{2}$ Membrane System. 
During R09, treated syngas was fed to the MTR system for the first time. The NCCC provided gas composition measurements from four GCs for continuous data from feed, permeate, and reject streams of the two membranes, as well as measurements from an NDIR instrument to measure $\mathrm{CO}_{2}$ concentration in the liquid $\mathrm{CO}_{2}$ stream.

The R09 testing accomplished two major milestones. First, the complete system operated successfully as designed on syngas. Second, the process yielded liquid $\mathrm{CO}_{2}$ with up to 92 percent purity. MTR plans to continue testing of the $500 \mathrm{lb} / \mathrm{hr}$ system in 2013. Prior to further testing, several modifications will be incorporated to improve system performance, including a new membrane design, improved $\mathrm{CO}_{2}$ liquid level control, and reprogramming of the Programmable Logic Controller (PLC).

\subsubsection{MTR $50 \mathrm{lb} / \mathrm{hr} \mathrm{CO}$ Membrane and Hydrogen Stamp Membrane}

MTR also continued testing the smaller $\mathrm{CO}_{2}$ membrane module and the hydrogen membrane stamp cell during R08 and R09 and completed a combined 500 hours of operation. Testing of the scaled-up hydrogen membrane was suspended due to issues with leaks. While these issues were being resolved, MTR continued materials evaluation with the stamp cell. Results are shown in Figure 13 for the most recent testing of the $\mathrm{CO}_{2}$ and hydrogen membranes completed in R09.

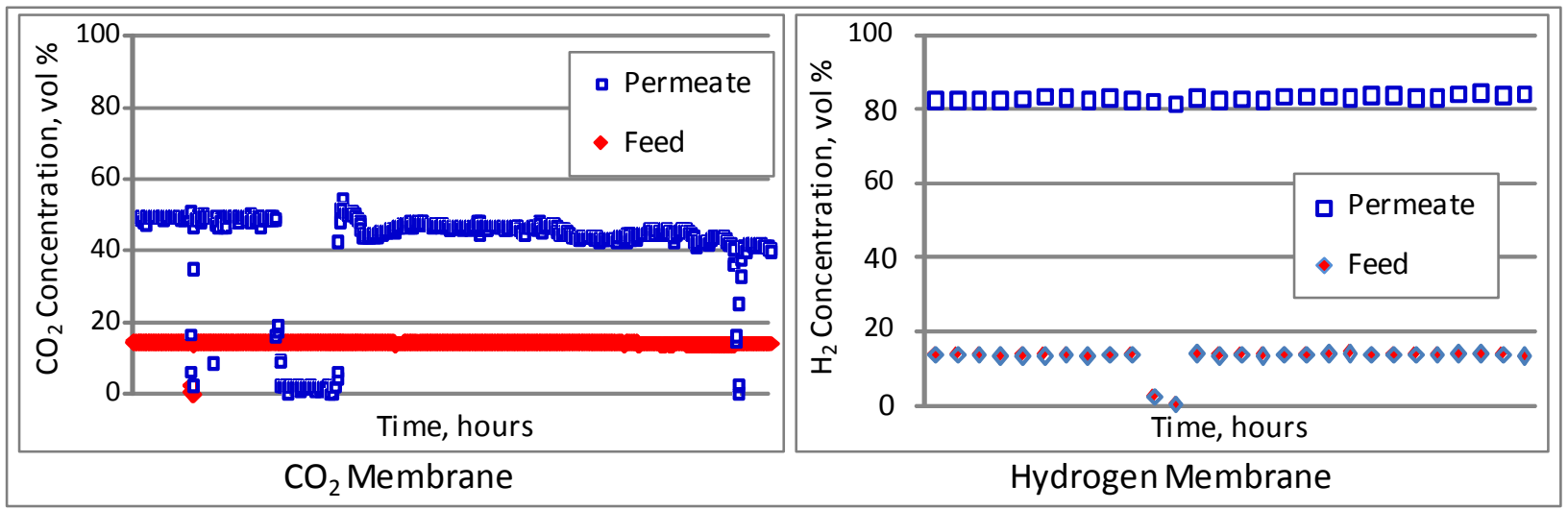

Figure 13. Test Results of MTR $50 \mathrm{lb} / \mathrm{hr} \mathrm{CO}_{2}$ Membrane and Hydrogen Stamp Membrane in R09.

The $\mathrm{CO}_{2}$ membrane was tested in two configurations - as a single membrane module and with two modules connected in series. R09 testing demonstrated $\mathrm{CO}_{2}$ enrichment from about 15 vol\% in the feed to $50 \mathrm{vol} \%$ in the permeate stream. The hydrogen membrane stamp cell enriched the hydrogen from a feed concentration of $14 \mathrm{vol} \%$ to $80 \mathrm{vol} \%$ in the permeate. Both $\mathrm{CO}_{2}$ and hydrogen membranes performed stably, achieving separation performances equal to or slightly above what had been achieved historically. Testing was cut short in R09 due to leaks-first, with a pressure regulator and later with membranes. 


\subsection{Media \& Process Technology Membrane}

Media \& Process Technology, a technology innovator specializing in the development of highperformance, low-cost ceramic membranes, first tested its hydrogen-selective CMS membrane at the site in 2008. MPT began evaluation of the CMS technology with single tubes, progressing to a pilot bundle containing 14 tubes before developing a full-scale 86-tube bundle with a total surface area of $8.2 \mathrm{ft}^{2}$ processing up to $50 \mathrm{lb} / \mathrm{hr}$ of syngas. The bundle consists of 86 alumina tubes contained within a 5-inch diameter pressure vessel and is designed for operating temperatures as high as $570^{\circ} \mathrm{F}$ and transmembrane pressure drops of over 300 psi.

MPT's first test with the full-scale CMS was in 2011 during run R07. Performance with raw syngas at $480^{\circ} \mathrm{F}$ and 215 psia was lower than anticipated based on previous tests with single tubes and the pilot module.

- Hydrogen permeance for the syngas was on average $0.8 \mathrm{~m}^{3} / \mathrm{m}^{2} / \mathrm{hr} / \mathrm{bar}$, about half the value expected for pure hydrogen.

- The hydrogen concentration in the permeate was also lower than expected. With around $7 \mathrm{vol} \%$ hydrogen in the syngas, the permeate contained about 35 vol\% hydrogen compared to $55 \mathrm{vol} \%$ in previous tests. With around $40 \mathrm{vol} \%$ hydrogen in the syngas, the permeate contained 80 vol \% hydrogen compared to 95 vol\% or more in previous tests.

In January 2012 at MPT's Pittsburgh laboratory, MPT investigated performance of the full-scale membrane bundle tested during R07. The lab testing indicated considerable discrepancy between the permeance for pure helium and for gas mixtures of $\mathrm{He} / \mathrm{N}_{2}$ or $\mathrm{He} / \mathrm{Ar}$. As this discrepancy was not observed for the single-tube and the pilot-scale module testing, the reduced performance was attributed to poor radial distribution of the syngas within the bundle. To improve distribution, baffles similar to those used in shell-and-tube heat exchangers were installed longitudinally to force the syngas to flow across the bundle diameter and so access the interior tubes.

MPT tested a number of baffle arrangements using a 60:40 He/Ar mixture and identified one that raised permeance to about $1.4 \mathrm{~m}^{3} / \mathrm{m}^{2} / \mathrm{hr} /$ bar, almost 90 percent of the pure helium value. To extend the range of operating pressure and gas flow rates and confirm the improved performance of the bundle prior to testing with syngas in R08, off-line tests on MPT's test skid at the NCCC were completed. To accommodate the tests, some equipment modifications were required, including additional relief valves and new flow meters for helium and nitrogen supply. All design and installation work was carried out by NCCC personnel who also supported execution of the test program. In addition, several system modifications were completed to facilitate longterm testing. These included the addition of steam lines for on-line cleaning of cooling coils, a larger pre-filter for the reject stream, and a larger vortex cooler for the process cabinet to avoid overheating of instrumentation.

Off-line testing was carried out in April 2012 using a 70:30 He/ $\mathrm{N}_{2}$ mixture and achieved permeance values of 1.45 to $1.51 \mathrm{~m}^{3} / \mathrm{m}^{2} / \mathrm{hr} / \mathrm{bar}, 95$ to 99 percent of the value for pure helium. (The helium simulates the hydrogen in the syngas more safely than using bottled hydrogen and the nitrogen represents the balance of gases in syngas.) Table 3 provides the results from MPT's 
lab testing and off-line testing at the NCCC. These results confirmed that the baffle arrangement identified by MPT improved gas distribution within the membrane bundle, enabling it to achieve results similar to those of single tubes. Hence, this baffle arrangement was included in a new membrane module for testing in R08.

Table 3. Results from Testing of Baffle Arrangement in MPT Full-Scale Membrane Bundle.

\begin{tabular}{|c|c|c|c|c|c|}
\hline $\begin{array}{l}\text { Feed } \\
\text { Rate, } \\
\text { SLPM }\end{array}$ & $\begin{array}{c}\text { Temperature, } \\
{ }^{\circ} \mathrm{F}\end{array}$ & $\begin{array}{c}\text { Reject } \\
\text { Pressure, } \\
\text { psia }\end{array}$ & $\begin{array}{l}\text { Permeate } \\
\text { Pressure, } \\
\text { psia }\end{array}$ & $\begin{array}{c}\text { Helium } \\
\text { Permeance, } \\
\mathrm{m}^{3} / \mathrm{m}^{2} / \mathrm{hr} / \text { bar }\end{array}$ & $\begin{array}{c}\text { Percent of Pure } \\
\text { Helium } \\
\text { Permeance }\end{array}$ \\
\hline \multicolumn{5}{|c|}{ MPT Laboratory Testing with 60:40 He/Ar Binary Gas Mixture } & (1) \\
\hline 76 & 387 & 65 & 15 & 1.41 & 89 \\
\hline 50 & 387 & 63 & 15 & 1.39 & 88 \\
\hline \multicolumn{5}{|c|}{ NCCC Off-Line Testing with 70:30 He/ $\mathrm{N}_{2}$ Binary Gas Mixture } & (2) \\
\hline 69 & 383 & 56 & 18 & 1.48 & 97 \\
\hline 97 & 383 & 56 & 18 & 1.49 & 98 \\
\hline 180 & 383 & 109 & 24 & 1.51 & 99 \\
\hline 226 & 383 & 125 & 20 & 1.45 & 95 \\
\hline 266 & 383 & 155 & 24 & 1.45 & 96 \\
\hline
\end{tabular}

Pure helium permeance is independent of pressure and gas flow rate. Values were determined to be (1) $1.57 \mathrm{~m}^{3} / \mathrm{m}^{2} / \mathrm{hr} /$ bar at $428^{\circ} \mathrm{F}$ and ${ }^{(2)} 1.52 \mathrm{~m}^{3} / \mathrm{m}^{2} / \mathrm{hr} /$ bar at $383^{\circ} \mathrm{F}$.

R08 testing began in June with raw syngas feed containing about 8 vol\% hydrogen and flow rates varying from 150 to 250 standard liters $/ \mathrm{min}$. The operating temperature was maintained at about $480^{\circ} \mathrm{F}$, higher than the $450^{\circ} \mathrm{F}$ used in previous tests, and was selected to avoid the deposition of hydrocarbons previously seen in the membrane. (Post-run inspection showed no evidence of hydrocarbon deposits.) The transmembrane pressure drop was about 200 psi with the permeate-side pressure in the range of 18 to 20 psia. Hydrogen permeance was estimated to be $1.2 \mathrm{~m}^{3} / \mathrm{m}^{2} / \mathrm{hr} / \mathrm{bar}, 85$ to 90 percent of the value for pure hydrogen. Product hydrogen was 50 to 55 percent pure, exceeding the 30-percent purity obtained in R07. This further validated the effectiveness of the baffles in distributing syngas flow through the tube bundle.

The membrane bundle was tested again near the end of R08 for over 100 hours during a period of oxygen-blown gasifier operation when biomass was co-fed with the coal. Figure 14 plots the hydrogen content (dry basis) of the permeate and reject streams during this period. Once the syngas hydrogen composition stabilized at $22 \mathrm{vol} \%$ (after around 20 hours), the permeate stabilized at $80 \mathrm{vol} \%$ hydrogen and the reject stream at $10 \mathrm{vol} \%$ for most of the test period. At the end of the run, the hydrogen in the feed was enriched to $32 \mathrm{vol} \%$, which increased the permeate hydrogen content to about 92 vol\%. 


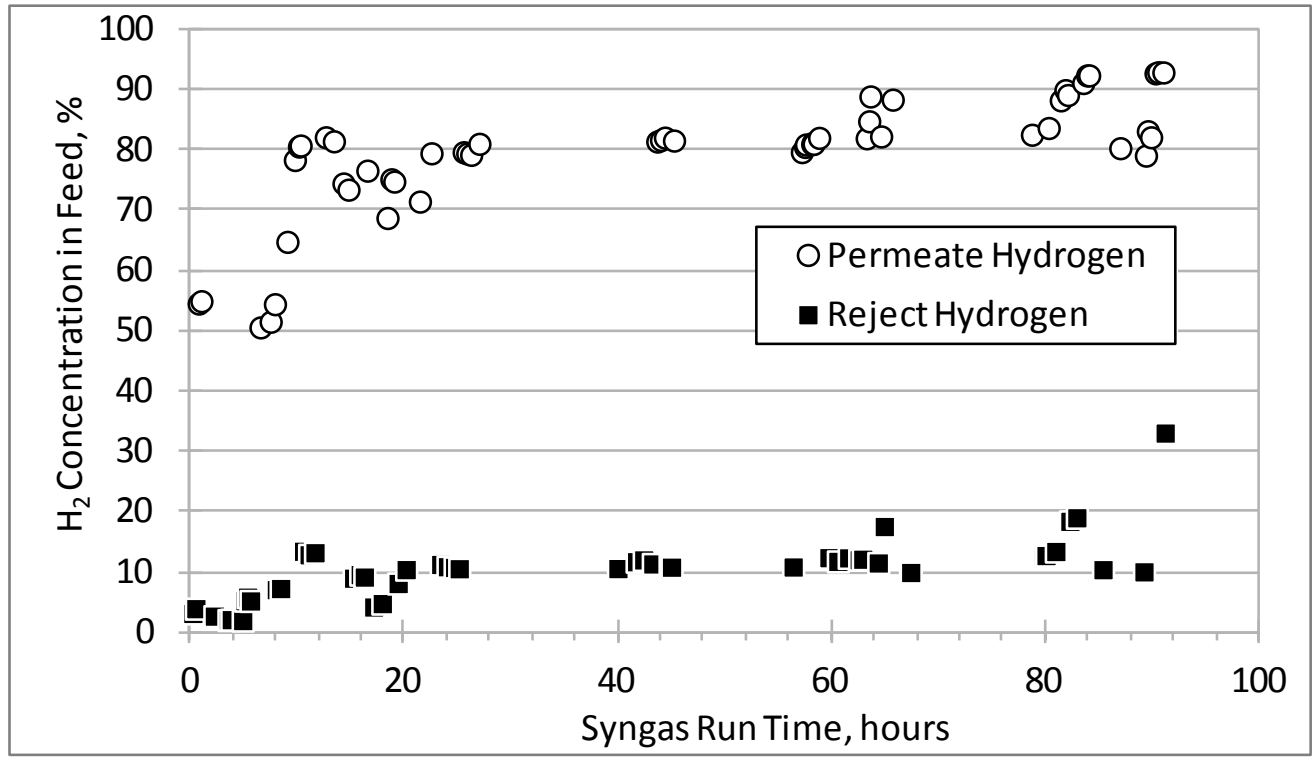

Figure 14. Hydrogen Content of Permeate and Reject Streams for MPT Membrane during R08.

The CMS membrane bundle operated for almost 400 hours during R09, including a 300-hour period of continuous operation under NCCC supervision, processing $50 \mathrm{lb} / \mathrm{hr}$ of raw flue gas at 190 psia and $500^{\circ} \mathrm{F}$. Table 4 provides gas composition data on a dry basis for the two egress streams. For short-duration tests, the syngas hydrogen content was increased to $40 \mathrm{vol} \%$ (simulating the syngas produced by a commercial oxygen-blown gasifier), resulting in hydrogen permeate purity of about 95 percent (dry basis). This degree of product enrichment is greater than that achieved for the single tube and pilot-bundle membranes and indicates the improvements made in the quality of the deposited CMS layer.

Table 4. Composition Data for Egress Streams from MPT Membrane during R09.

\begin{tabular}{|lcc|}
\hline \multicolumn{1}{|c}{ Syngas Constituent } & $\begin{array}{c}\text { Permeate } \\
\text { Concentration }\end{array}$ & $\begin{array}{c}\text { Reject } \\
\text { Concentration }\end{array}$ \\
\hline Hydrogen, vol\% & 95 & 35 \\
$\mathrm{CO}_{2}$, vol\% & 1.3 & 6 \\
$\mathrm{CO}$, vol\% & $<0.3$ & 6 \\
$\mathrm{H}_{2} \mathrm{~S}$, ppmv & Below LDL & 25 \\
Nitrogen (balance), vol\% & 3.4 & 53 \\
\hline
\end{tabular}

High permeate moisture levels limited the accuracy of hydrogen permeance determinations, but helium and nitrogen pure-component permeance measurements were made periodically to give an indication of membrane performance stability. The permeance for helium was about $1.1 \mathrm{~m}^{3} / \mathrm{m}^{2} / \mathrm{hr} /$ bar and that for nitrogen was about $0.01 \mathrm{~m}^{3} / \mathrm{m}^{2} / \mathrm{hr} / \mathrm{bar}$; these values were stable throughout the 300-hour continuous test period and correspond to values obtained from off-line characterization tests for the membrane bundle. 


\section{Future Test Plans}

Based on 2012 performance results, two modifications to MPT's test skid were proposed for 2013. First, improved means to determine the permeate moisture content are to be investigated, which will allow more rigorous data analysis to be performed. Second, measures to reduce false alarms by a hydrogen sensor in MPT's purged membrane cabinet are to be incorporated. As discussed below, MPT is also planning on enhancing the CMS with WGS functionality.

MPT's concept for CMS membrane technology is that it be incorporated with the water gas shift reaction stage producing a catalytic membrane reactor (CMR) that allows the separation of the hydrogen simultaneously with its formation. This increases the driving forces in subsequent WGS/membrane stages, allowing a closer approach to equilibrium. MPT has investigated the CMR concept at the bench scale feeding a synthetic syngas mixture containing $\mathrm{H}_{2} \mathrm{~S}$ to a single CMS membrane tube surrounded by sour WGS catalyst. WGS catalyst will be added to the fullscale membrane bundle to collect CMR performance data at the NCCC during 2013.

To accommodate the high syngas flow rate from a commercial gasifier, the surface area per CMR module must be increased significantly to reduce the number of modules required and the complexity of interconnecting pipe work. MPT has conceived a multiple bundle module shown in Figure 15 that contains 14 of the full-scale CMS bundles (higher numbers are possible) between which the WGS catalyst would be packed. Such an arrangement offers more than $110 \mathrm{ft}^{2}$ of flow area. The total syngas flow would be around $700 \mathrm{lb} / \mathrm{hr}$ and could be tested at the NCCC within the SCU provided that the increased hydrogen demand can be met economically.

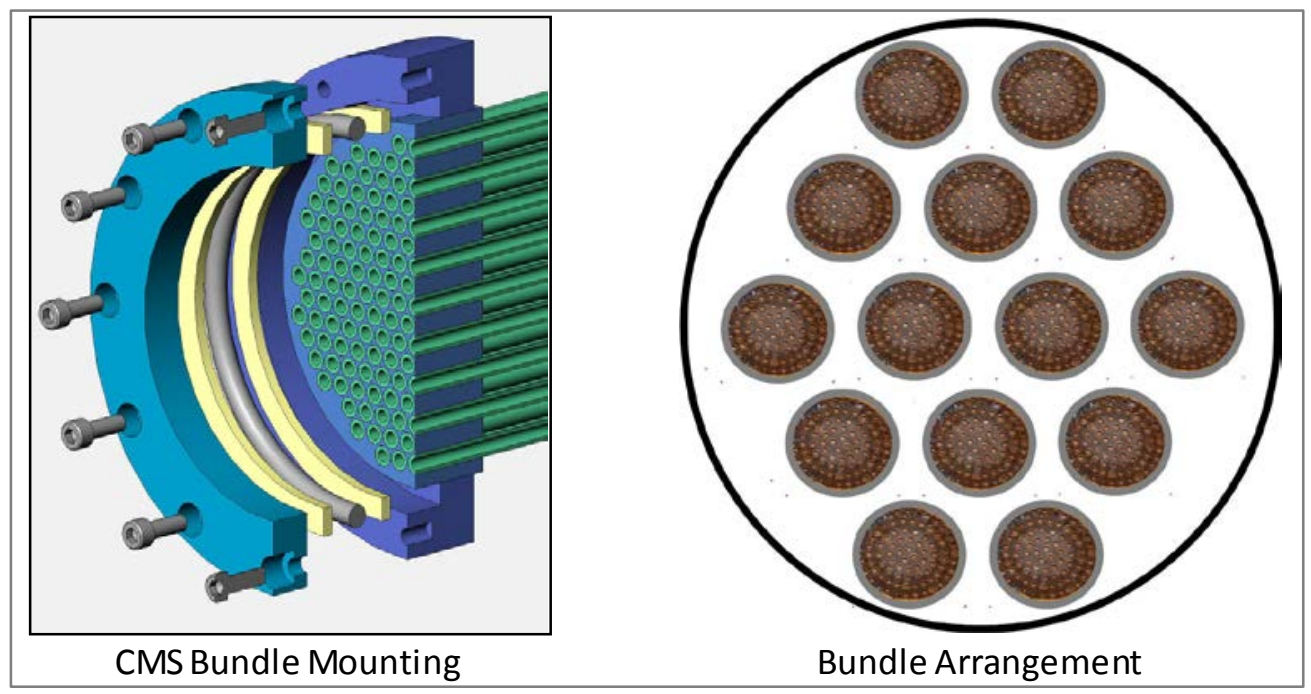

Figure 15. Conceptual Multi-Tube CMS Bundle with Surface Area Greater Than $\mathbf{1 1 0} \mathrm{ft}^{2}$.

\subsection{Eltron Membrane}

Under DOE sponsorship, Eltron Research \& Development, a technology group specializing in chemical and engineering technologies, is developing a high-temperature hydrogen transport membrane (HTM) for pre-combustion capture of $\mathrm{CO}_{2}$. The Eltron HTM technology uses a multi-layer metal alloy tube to separate hydrogen from coal-derived syngas (see Figure 16), providing high purity hydrogen and capture of high pressure $\mathrm{CO}_{2}$ suitable for utilization or 
sequestration. Eltron's membranes can withstand high differential pressures of up to 1,000 psi, allowing for successful integration with advanced, high-pressure coal gasification processes.

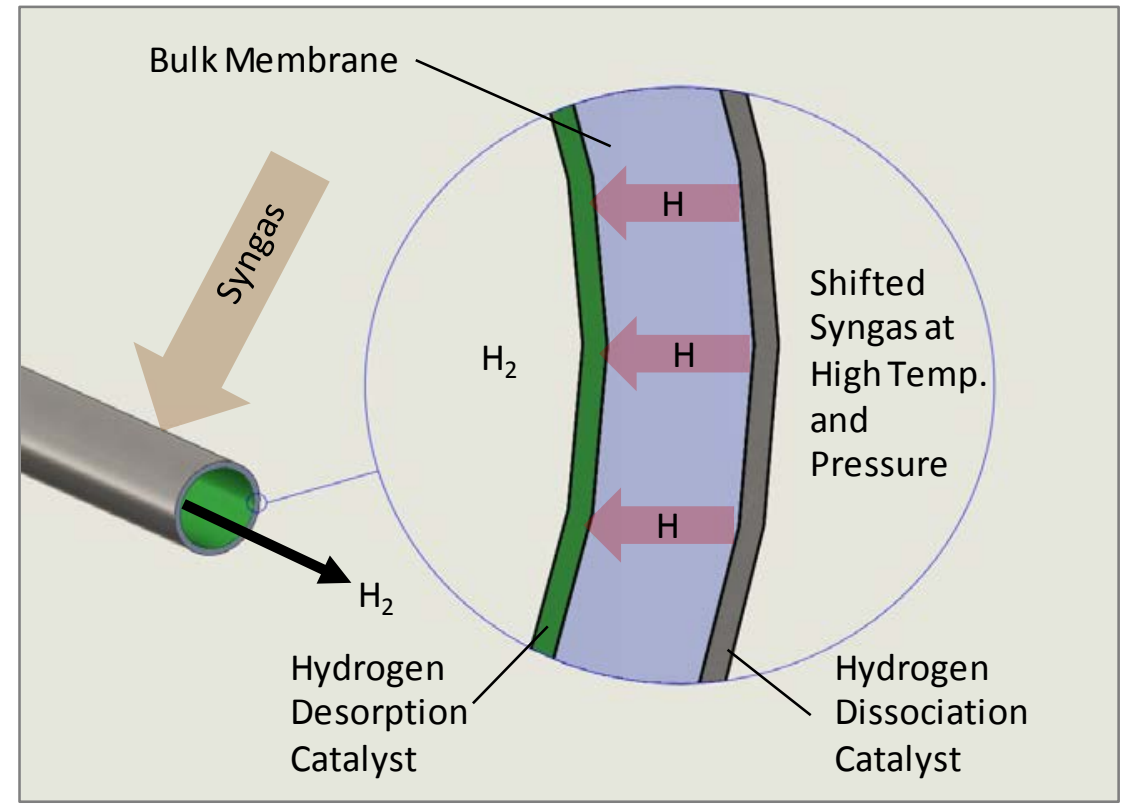

Figure 16. Schematic of Eltron Hydrogen Membrane Tube.

At the direction of DOE, NCCC began discussions with Eltron in early October about testing the HTM at NCCC in run R09. To accommodate the testing within the tight schedule, WPI's existing membrane testing oven was used. A new module and flange connections for the permeate and retentate gas streams were fabricated on-site according to standards of the American Society of Mechanical Engineers. The two membrane tubes tested were of 0.5-inch outer diameter (OD), with one tube 8 inches long and the other, 6 inches long. The 8-inch long tube was installed for permeation testing, and the 6-inch long tube was installed for exposureonly testing. Figure 17 shows these two membrane tubes.

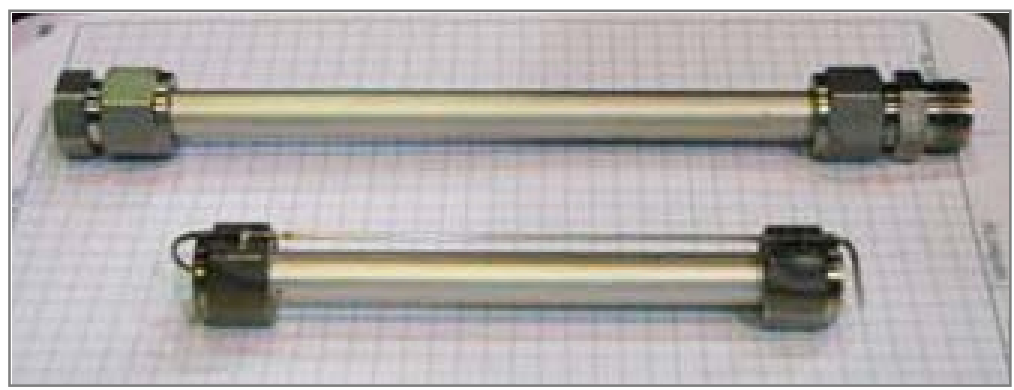

Figure 17. Eltron Membrane Tubes.

The assembled module was installed inside WPI's oven. A new thermocouple was installed to directly measure syngas temperature from the retentate stream in addition to an oven temperature indicator. The oven-heating program was modified to accommodate Eltron's proprietary start-up process, and testing began on December 1. 
The membranes were tested at about $640^{\circ} \mathrm{F}$ for a total of 204 hours, including 183 hours of syngas operation with hydrogen enrichment and 21 hours with bottled hydrogen/nitrogen gases. The system operated with $10 \mathrm{lb} / \mathrm{hr}$ shifted and sweetened syngas (less than $1 \mathrm{ppmv}$ sulfur). With hydrogen enrichment, the hydrogen concentration of the syngas reached about 38 to $40 \mathrm{vol} \%$ (dry basis). During the testing period, the membrane consistently demonstrated a hydrogen flux of about $20 \mathrm{scfh} / \mathrm{ft}^{2}$, as shown in Figure 18. The step increase in flux at around 50 hours was the result of replacing a rotameter with a higher resolution one. Hydrogen purity in the permeate stream was greater than 99.87 percent during the entire testing period, which indicated excellent membrane integrity without leakage.

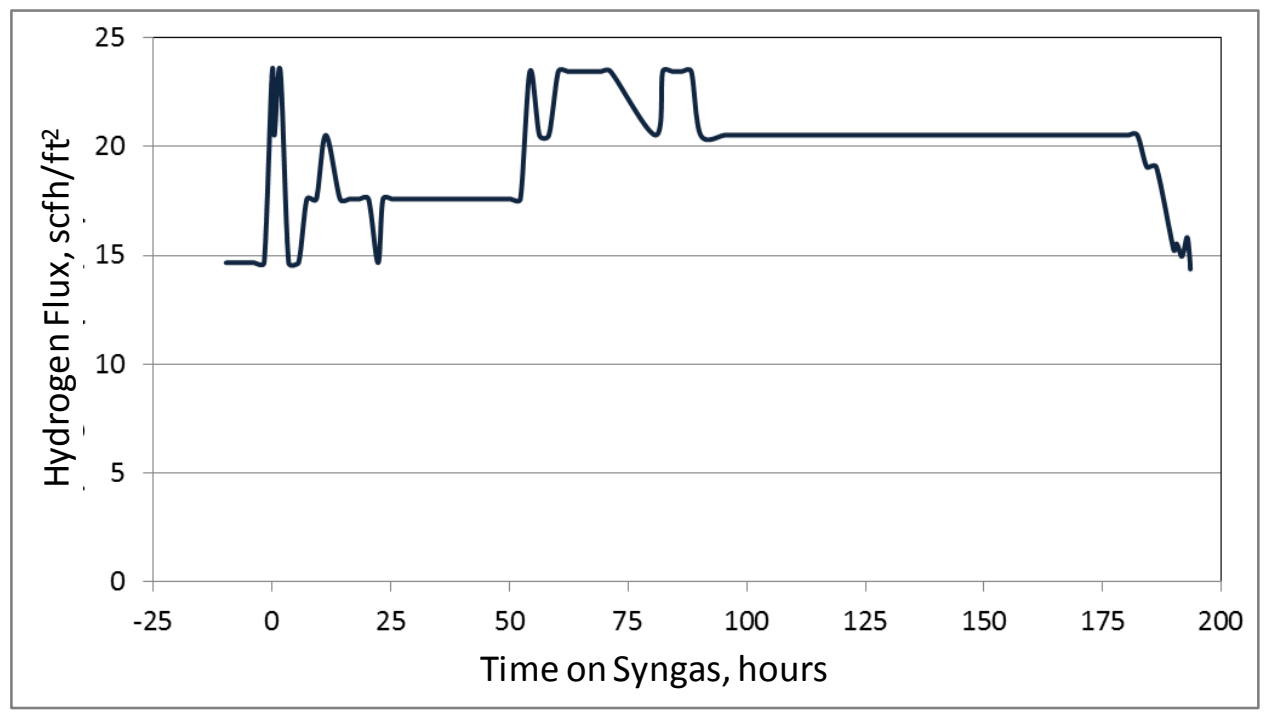

Figure 18. Eltron Membrane Hydrogen Flux during R09 Testing.

Eltron plans to conduct post-operation analysis of the two membranes, including laboratory permeation measurements at conditions similar to those of NCCC testing and surface impurities analysis using various techniques available in-house such as X-ray diffraction, X-ray fluorescence, and scanning electron microscope/microprobe. For higher sensitivity analysis to detect low levels of impurities, samples from each of these tubes will be sent to an independent lab with instrumentation and expertise appropriate for surface analysis such as Auger electron spectroscopy or X-ray photoelectron spectroscopy. Depth profiling will be conducted as well.

\subsection{Membrane Material Coupon Testing}

Because of their high permeability and selectivity, dense metal membranes are a promising technology for the separation of hydrogen from coal-derived syngas. However, syngas impurities can corrode and poison metal-based separation membranes, degrading their performance and causing mechanical failure. Sulfur compounds, particularly hydrogen sulfide, are probably the most detrimental. The effects of other minor contaminants, such as arsenic and selenium compounds, are not investigated in laboratory studies. Testing with syngas containing the full suite of coal-derived contaminants is therefore an essential step the development of metal-based hydrogen separation membranes. 
NETL is currently utilizing a variety of experimental and computational techniques to evaluate and develop potential sulfur-tolerant membrane alloys for application in severe gasification operating environments. Performance of these materials is typically tested under "clean" laboratory conditions using pure hydrogen and hydrogen containing $1,000 \mathrm{ppmv}_{2} \mathrm{~S}$. To evaluate their corrosion resistance, sample coupons of selected materials were installed in the head (dust-free side) of the hot gas filter on the Transport Gasifier train for long-term exposure

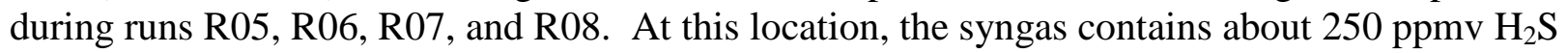
at around $750^{\circ} \mathrm{F}$, and over 25 different coupons, primarily palladium-based, have been tested.

The NCCC results demonstrate that the palladium alloys with B2 crystalline structure tend to be more corrosion resistant than the alloys with face-centered cubic (FCC) crystalline structures, which is in agreement with laboratory studies. In the B2 alloys, corrosion products formed a very thin surface coating with high levels of arsenic and selenium in addition to sulfur. The membrane alloys are effective in scavenging the impurities, especially arsenic and selenium, from the syngas and indicate that minor gas stream impurities are much more important than previously thought. Figure 19 shows a scanning electron microscope (SEM) image of the surface of an FCC-structured palladium ternary alloy coupon exposed in R08. The surface is thickly covered with corrosion products consisting of palladium arsenides and sulfides, showing that this specific composition is not acceptable for use with syngas.

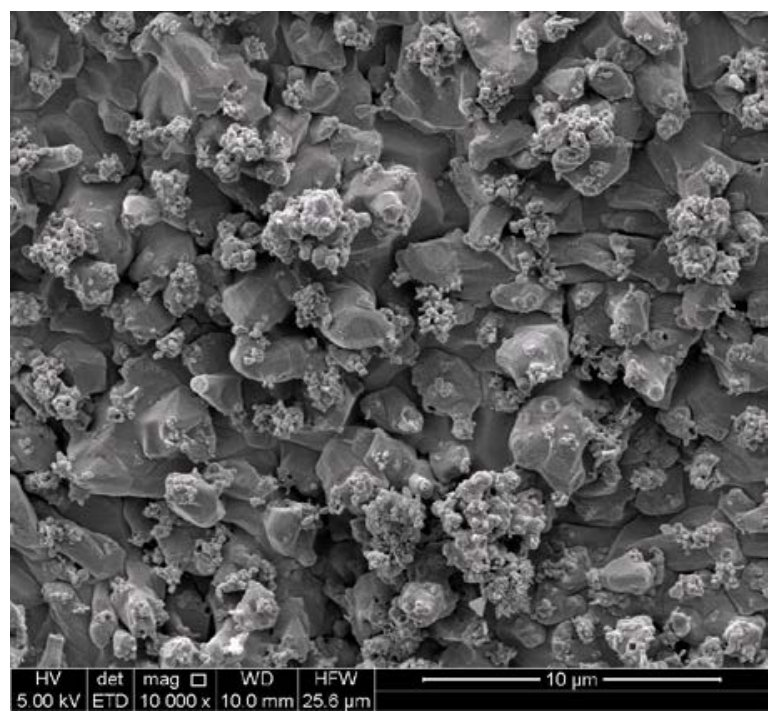

Figure 19. SEM Image of the Surface of an FCC-Structured Palladium-Based Coupon Exposed during R08.

NETL is also investigating protective coatings for hydrogen membrane alloys. The so-called super permeable metals and alloys (tantalum, niobium, vanadium, etc.) are promising for separation applications due to their permeability and lower cost, but they are very susceptible to corrosive degradation. Several uncoated coupons of these materials were also exposed during R08 to provide a performance baseline for coating research. Figure 20 presents an SEM image of the surface of one on these coupons. For this material, the surface was also thickly covered with a layer of corrosion products consisting only of oxides. No sulfur was detected. Results 
such as these can only be achieved using coal-derived syngas and are extremely important in guiding future hydrogen separation alloy development efforts.

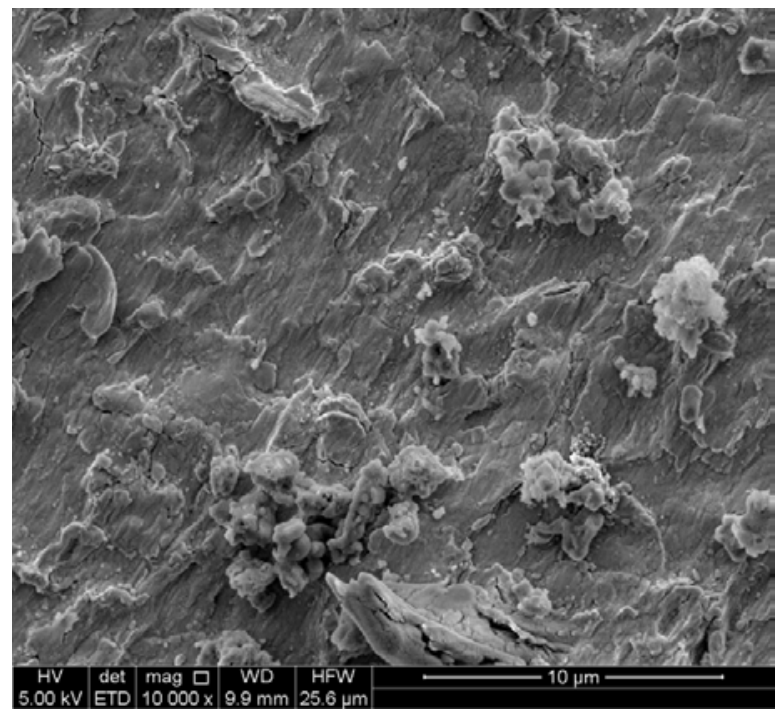

Figure 20. SEM Image of the Surface of a Baseline Coupon of a Super-Permeable Material Exposed during R08.

\section{$2.8 \quad$ TDA Research Sorbent}

Technology developer TDA Research is advancing a new pre-combustion $\mathrm{CO}_{2}$ capture technology that uses a proprietary carbon-based sorbent modified with surface functional groups to physically adsorb $\mathrm{CO}_{2}$ from shifted syngas. TDA Research tested the sorbent during R07 in November 2011, utilizing about $5 \mathrm{lb} / \mathrm{hr}$ sweet, shifted syngas. Preparations were ongoing in 2012 for further testing of TDA's sorbents during R10 in 2013.

For R10 testing TDA will incorporate a WGS reactor in the test skid to control the degree of the shift reaction. The $\mathrm{CO}_{2}$ sorbent materials to be tested will also incorporate a WGS catalyst for simultaneous WGS and $\mathrm{CO}_{2}$ capture. As $\mathrm{CO}_{2}$ is continuously removed from syngas during $\mathrm{CO}_{2}$ adsorption, the WGS reaction within the sorbent reactor will approach equilibrium more closely. The NCCC will deliver a new, heat-traced raw syngas stream to the TDA skid and provide deionized water for steam generation for the WGS reaction. NCCC staff will also assist in gas analysis to supplement TDA's own gas analysis.

\subsection{University of Alabama Solvent}

The Bara Research group of the University of Alabama (UA) has been researching the use of alkylimidazoles, a group of low volatility and low viscosity liquids, as physical solvents for economical $\mathrm{CO}_{2}$ separation from processes like IGCC. UA provided an alkylimidazole solvent for testing in the SCU stirred batch reactor during R09 using bottled gases and syngas. Results indicated that the solvent performed as expected in regard to the solvent's capacity for $\mathrm{CO}_{2}$. All tests were performed at $70^{\circ} \mathrm{F}$. $\mathrm{CO}_{2}$ capture was evaluated using bottled gases with 35 and 40 
vol\% $\mathrm{CO}_{2}$ at 150 and 300 psig. $\mathrm{CO}_{2}$ capacity of the UA solvent as a function of partial pressure is compared with other physical solvents in Figure 21.

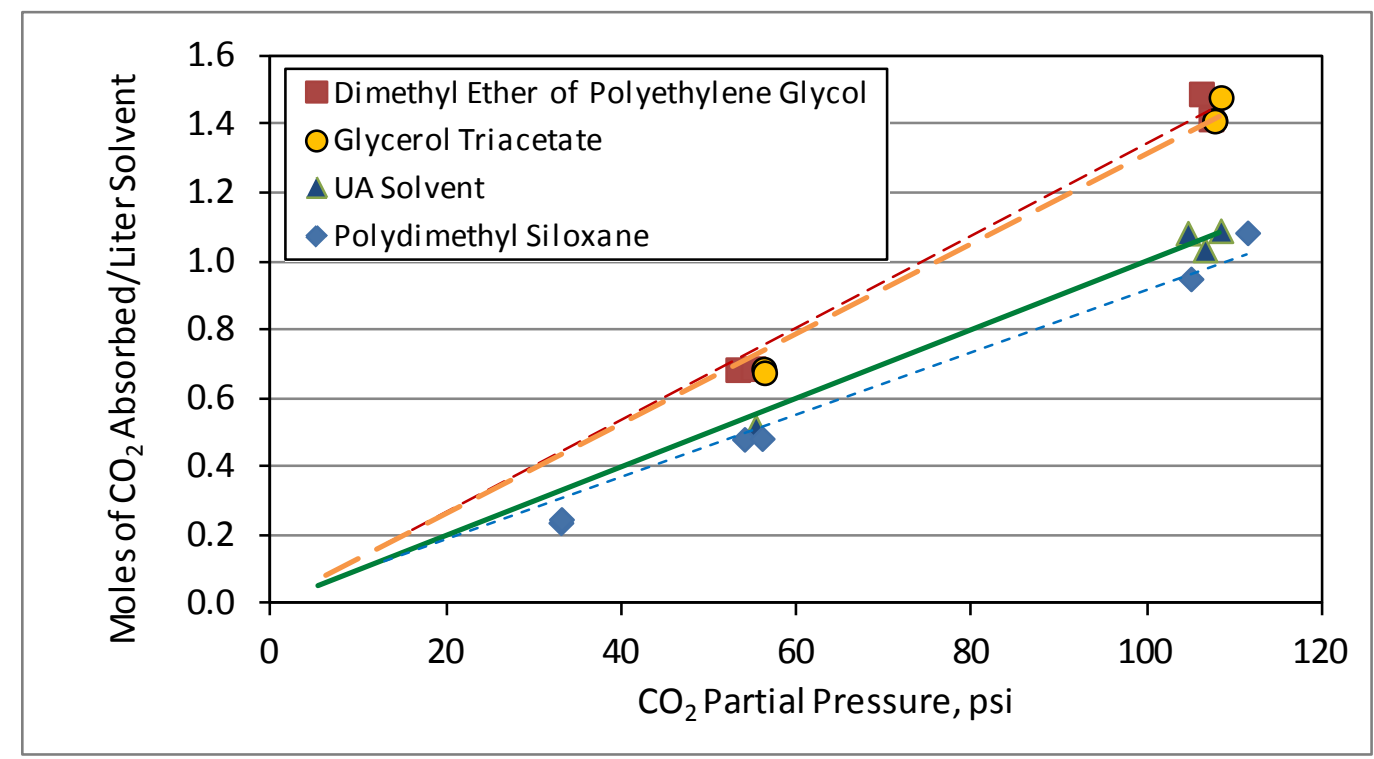

Figure 21. $\mathrm{CO}_{2}$ Capacity as a Function of $\mathrm{CO}_{2}$ Partial Pressure for University of Alabama Solvent.

Absorption of $\mathrm{H}_{2} \mathrm{~S}$ from the syngas is indicated by Figure 22. This graph shows the reactor outlet concentration of $\mathrm{H}_{2} \mathrm{~S}$ in the syngas and indicates that with fresh solvent essentially all of the $\mathrm{H}_{2} \mathrm{~S}$ was collected for over an hour.

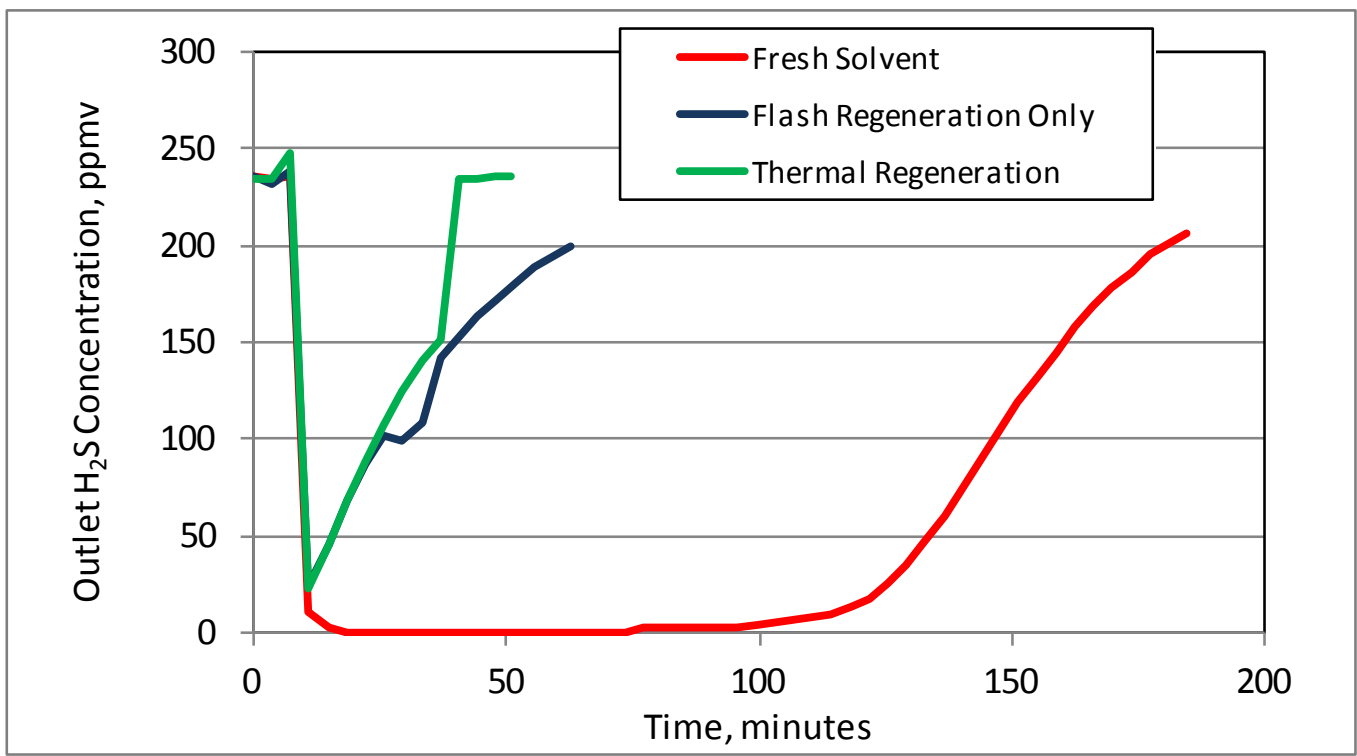

\section{Figure 22. $\mathrm{H}_{2} \mathrm{~S}$ Absorption for University of Alabama Solvent.}

The solvent was saturated with $\mathrm{CO}_{2}$ after about 20 minutes, but this did not affect the $\mathrm{H}_{2} \mathrm{~S}$ capacity. Also shown in Figure 22 are data from subsequent $\mathrm{H}_{2} \mathrm{~S}$ absorption tests after 
regeneration by various techniques. Flash regeneration released all of the $\mathrm{CO}_{2}$ from the sample but was not very effective at removing $\mathrm{H}_{2} \mathrm{~S}$ from the solvent (restoring less than 10 percent of the original capacity). Flash regeneration followed by thermally soaking the solvent at $212^{\circ} \mathrm{F}$ while purging with nitrogen did not appear to remove any additional $\mathrm{H}_{2} \mathrm{~S}$. This behavior seems to indicate that it acts as a physical solvent for $\mathrm{CO}_{2}$ but reacts chemically with $\mathrm{H}_{2} \mathrm{~S}$ irreversibly. This interaction will be studied more closely in future testing. For the next test campaign, planned for 2013, a blend of the base and a new solvent will evaluated for improvements. Also, water may be introduced to the solvent to observe the effect on the $\mathrm{H}_{2} \mathrm{~S}$ interaction.

\subsection{Ohio State University Syngas Chemical Looping}

One of the major upcoming projects at the NCCC is the installation and testing of the SCL process developed at OSU. This process aims to convert syngas into separated hydrogen and $\mathrm{CO}_{2}$ streams using a countercurrent moving-bed reducer/oxidizer reactor system. The project is funded by DOE's Advanced Research Projects Agency-Energy (ARPA-E), which is providing OSU \$5 million for this project. SCL has been successfully demonstrated at bench and sub-pilot scales. OSU is working with a team of engineering and consulting firms to address all the industrial concerns and ready the technology for demonstration.

In this project, a 250-kW pilot scale SCL plant will be constructed adjacent to the NCCC gasification structure and will utilize up to $900 \mathrm{lb} / \mathrm{hr}$ of raw syngas at elevated temperature. In early 2012, demolition of unused equipment was completed to make room for the SCL unit, which is approximately 26 by 28 feet and 70 feet tall. Construction for the project is scheduled to begin in April 2013 with initial start-up planned for late 2013 and testing planned into the spring of 2014.

NCCC supported the OSU team by participating in an initial Design Hazard Review and assisting with developmental engineering work. NCCC developed conceptual designs for connecting the SCL system to the Transport Gasifier process and other balance of plant equipment. OSU and NCCC cooperatively developed plans for construction and operation of the system. OSU received the Phase 3 funding release from ARPA-E in December 2012, which releases the project for detailed engineering, purchasing of long-lead capital equipment, and construction. 


\subsection{POST-COMBUSTION $\mathrm{CO}_{2}$ CAPTURE}

The PC4 was constructed to advance flue gas $\mathrm{CO}_{2}$ capture technologies at a range of operating conditions and technology development stages. A major area of the PC4 is the PSTU, which is designed to test absorption and regeneration of $\mathrm{CO}_{2}$ solvents at flue gas rates up to 5,000 lb/hr (equivalent to $0.5 \mathrm{MWe}$ ). The PC4 also features test bays for larger units (up to $1.0 \mathrm{MWe}$ ) and for bench-scale units (up to 0.1 MWe each). See Figure 23. The site also includes an independent control room, electrical infrastructure, and a balance of plant area containing utilities and chemical storage/handling facilities.

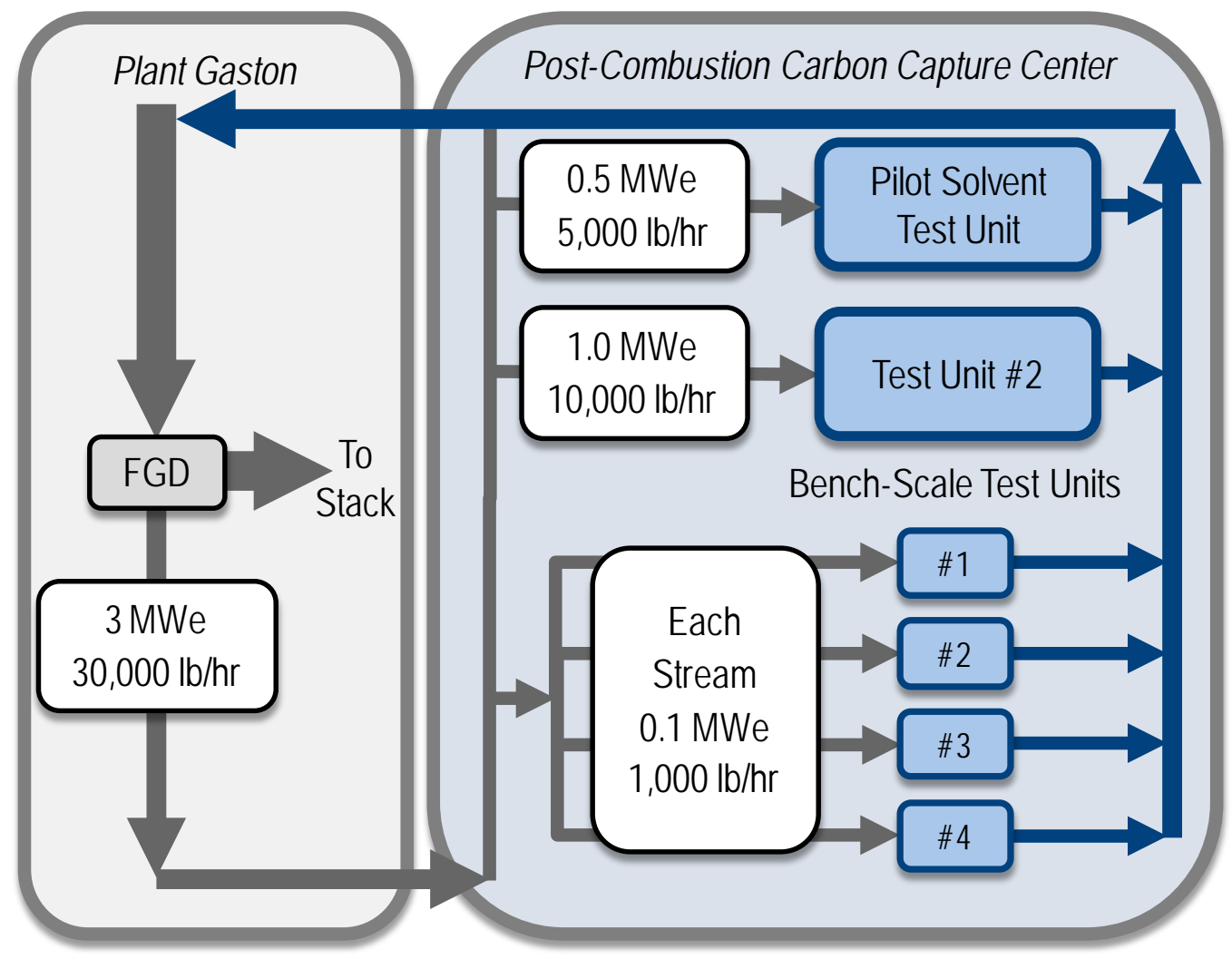

Figure 23. PC4 Facilities.

\subsection{PC4 Modifications}

Work progressed on several modifications at the PC4 to increase the center's flexibility and enhance data collection and operation. A Slipstream Solvent Test Unit (SSTU) is being added to the site to provide bench-scale testing of solvents.

\subsubsection{Balance of Plant Upgrades}

To accommodate testing of the two 1-MW-equivalent projects, MTR's $\mathrm{CO}_{2}$ separation membrane and BASF/Linde's pilot solvent unit, as well as other future projects, several upgrades are being implemented. Design and procurement activities began for these upgrades, which will 
be installed at the NCCC during 2013 for the start of testing of the MTR and BASF/Linde units in early 2014. The modifications include:

- A forced draft fan delivering 20,000 lb/hr with a higher delivery head will replace the current fan with a delivery rate of $12,000 \mathrm{lb} / \mathrm{hr}$. The higher flow will allow simultaneous operation of the two 1-MW skids with excess flue gas for testing in the bench-scale area.

- The random packing in the pre-scrubber will be replaced with structured packing to maintain high $\mathrm{SO}_{2}$ collection efficiency at the higher flue gas flow rate.

- To meet the higher cooling duty requirements, a second cooling tower cell will be added along with larger water circulation pumps.

- Electrical infrastructure additions included the design of a new 2,500 KVA transformer and switchgear. A factory acceptance test for new switchgear took place in early December, after which the unit was shipped to the site.

\subsubsection{Slipstream Solvent Test Unit}

The NCCC purchased and began installation of the SSTU, which is shown in Figure 24, to increase the flexibility of the PC4 by allowing testing of solvents (such as those in early stages of development) available only in amounts smaller than the 4,000 gallons required for the PSTU. The SSTU comprises a pre-scrubber, condenser, absorber, regenerator, and associated equipment along with analytical instrumentation. During the year, the process flow scheme was developed, the foundation for the SSTU was installed adjacent to the PSTU, and design work was underway to determine needed modifications to the unit and to prepare utility tie-ins. Sulzer, a technology development firm with expertise in mass transfer equipment, is being contracted to collaborate with the NCCC on this project.
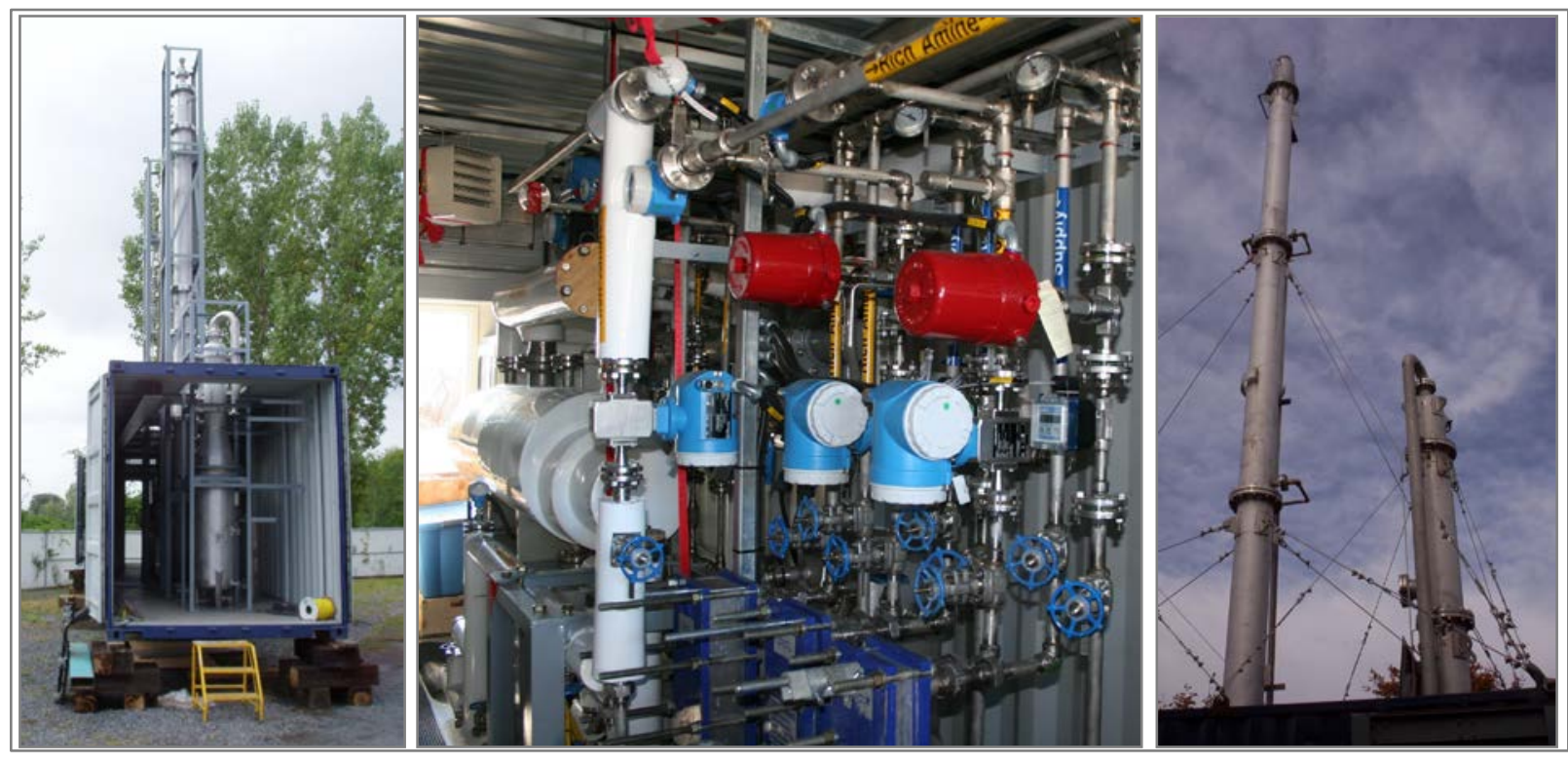

Figure 24. Slipstream Solvent Test Unit. 


\subsection{MEA Baseline Test Campaign}

The 1,140-hour MEA Baseline Test Campaign completed in May 2011 identified some issues that required further investigation.

- MEA carryover from the wash tower was in excess of 100 ppmv, compared to the vapor equilibrium value of 3 ppmv. These high values exceed limits for volatile organic compounds and result in excessive solvent make up rates.

- Degradation products in the regenerated $\mathrm{CO}_{2}$ stream were not sampled.

- The laboratories used to measure degradation in the $\mathrm{CO}_{2}$-depleted flue gas streams declined to measure degradation products in the solvent. They were concerned that the time required for cleaning of the instruments after analysis would result in sample backlogs.

- End-of-run analysis of the used solvent revealed selenium and chromium contents, each in excess of 1 ppmw, which makes the solvent a hazardous waste if sent to disposal.

An MEA follow-up test campaign was completed in 2012 to investigate these observations further. The 30-wt \% MEA solution was loaded on March 7, and flue gas was introduced later that day. Most of the solvent had been used in the 2011 Baseline Test Campaign, but make-up was required to achieve the operating inventory. The first test started on March 8, and the campaign was completed on March 25, achieving just over 400 test hours.

This section provides a description of the PSTU and the sampling and analytical procedures used to measure the MEA carryover and degradation products present in the $\mathrm{CO}_{2}$-depleted flue gas stream leaving the absorber and the $\mathrm{CO}_{2}$ leaving the regenerator. The data collected are discussed along with measures being pursued to resolve the issues identified.

\subsubsection{PSTU Description}

The PSTU was designed to achieve 90 percent $\mathrm{CO}_{2}$ capture using $30 \mathrm{wt} \%$ aqueous MEA. This is the reference solvent to determine baseline performance against which other solvents tested can be compared. These solvents may include hindered amines, amino acid salts, and ionic liquids. To accommodate the range of solvent properties, the PSTU design is very flexible operationally. A schematic of the PSTU is presented in Figure 25. 


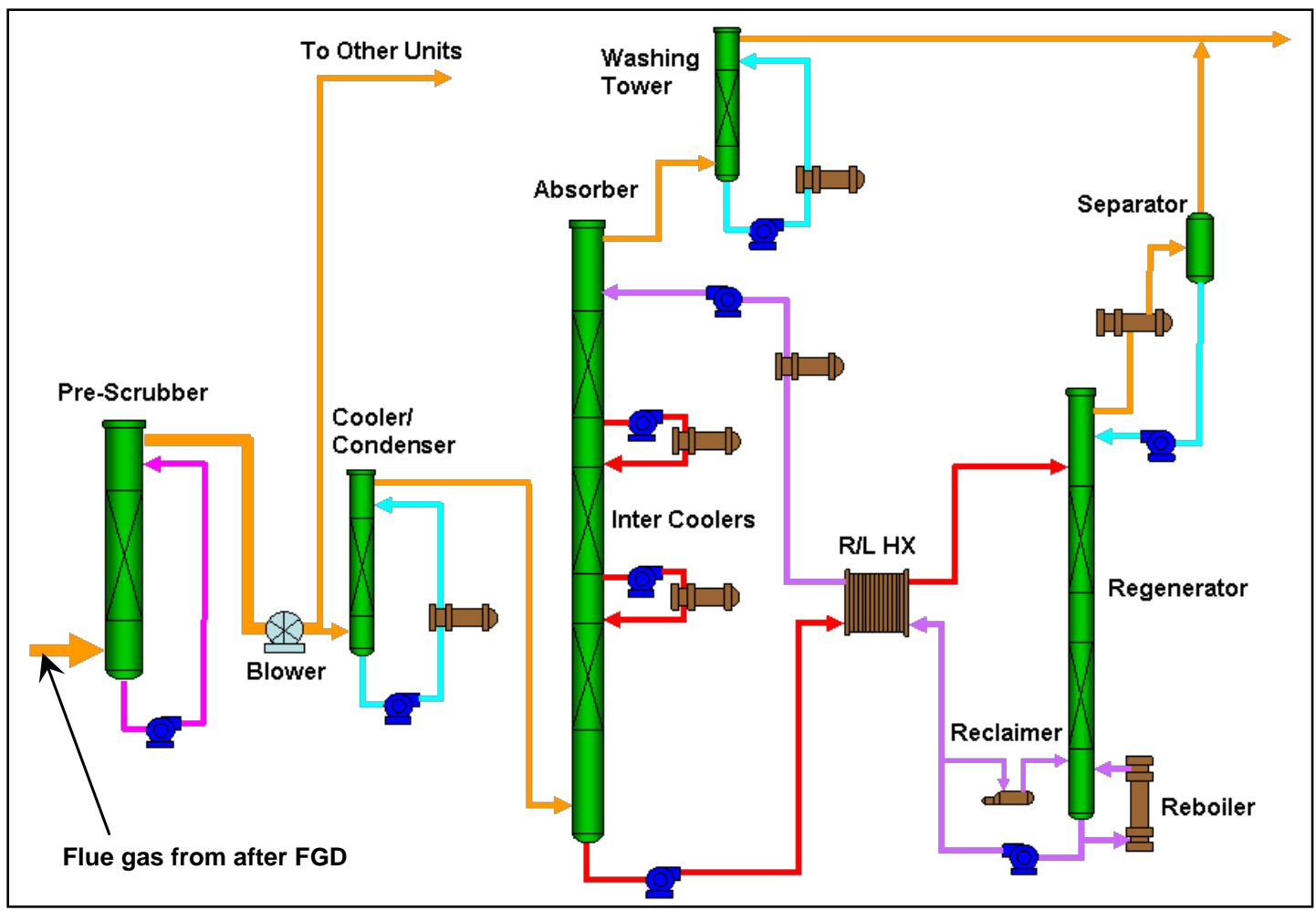

Figure 25. PSTU Schematic.

Up to 35,000 lb/hr of flue gas is extracted from downstream of the Plant E.C. Gaston Unit 5 flue gas desulfurization (FGD) system and is utilized for PC4 testing activities. Of this amount, $5,000 \mathrm{lb} / \mathrm{hr}$ of flue gas flows to the PSTU. There are five major columns, or subsystems, which include:

- The pre-scrubber which removes the small amount of $\mathrm{SO}_{2}$ remaining in the flue gas

- A cooler/condenser unit that cools the flue gas to appropriate reaction temperatures and removes flue gas moisture

- An absorber to promote efficient gas-liquid contacting to remove $\mathrm{CO}_{2}$ from the flue gas

- A washing tower that cools the $\mathrm{CO}_{2}$-depleted flue gas, removing trace amounts of entrained solvent

- A regenerator that provides heat to release the $\mathrm{CO}_{2}$ from the solvent

Further description of the PSTU subsystems has been published previously (see NCCC/PSDF Budget Period Two Topical Report, which can be found at the web address www.NationalCarbonCaptureCenter.com).

\subsubsection{MEA Carryover}

Based on information gleaned from discussions with industry experts, the MEA carryover is thought to occur because of the presence of $\mathrm{SO}_{3}$ aerosol in the flue gas. The aerosol acts as a 
nucleation site for the formation of droplets into which the MEA diffuses. Many of the droplets are too small to be collected efficiently in the wash tower and thus escape with the $\mathrm{CO}_{2}$-depleted flue gas. It was theorized that MEA carryover could be reduced by controlling absorber temperature (higher or lower) to increase droplet size and make them more easily removable. A parametric test program was defined, the major variables of which were:

- Operation with two and three beds, with and without intercooling

- Adjusting of the wash water MEA concentration

Coincidentally, for a portion of the test period, a higher sulfur coal was burned, allowing the effect of higher $\mathrm{SO}_{3}$ to be investigated also.

- Test 1 was a repeat of the major operating conditions in the 2011 MEA testing, using three beds without intercooling. The MEA concentration in the wash water was the intrinsic value determined by the operating conditions.

- Test 2 was similar to Test 1 but with both intercoolers in service to provide the maximum degree of cooling. The MEA concentration in the wash water was adjusted to the same value as for Test 1 to eliminate this as a variable. Solvent carryover increased 3.5 times, presumably as a consequence of lowering the absorber solvent temperature.

- Test 3 employed only two beds with one intercooling stage, and again the MEA concentration in the wash water was adjusted to the value achieved in Test 1 . Solvent carryover was reduced, possibly because the unused upper bed was collecting droplets.

- Test 4 was similar to Test 3 but with the wash water flushed several times to achieve the lowest possible MEA concentration, which is considered responsible for the reduced solvent carryover.

- Test 5 was similar to Test 3 but without intercooling and with the MEA concentration in the wash water achieving its intrinsic value. The solvent carryover was the lowest of all the tests, presumably because the higher solvent temperatures resulted in the formation of larger droplets coupled with the droplet interception capability of the inactive upper bed.

- Test 6 was similar to Test 3 but allowing the wash water to achieve its intrinsic MEA concentration, which accounts for the increased solvent carryover.

- Tests 7, 8, and 9 were similar to Test 5, but conducted with flue gas from a higher sulfur coal, resulting in higher $\mathrm{SO}_{3}$ in the flue gas entering the absorber. On average, this resulted in 80-percent higher solvent carryover, roughly proportional to the increase in $\mathrm{SO}_{3}$ level. The three results indicated a high level of data reproducibility.

The results are presented in Table 5. 
Table 5. Parametric Tests Results for Solvent Carryover from Absorber Wash Tower.

\begin{tabular}{|c|c|c|c|c|c|}
\hline Test & Beds & $\begin{array}{l}\text { Number of } \\
\text { Intercoolers }\end{array}$ & $\begin{array}{c}\text { Maximum } \\
\text { Temperature, }{ }^{\circ} \mathrm{F}\end{array}$ & $\begin{array}{c}\text { MEA in Wash } \\
\text { Water, wt.\% }\end{array}$ & $\begin{array}{c}\text { Total MEA } \\
\text { Carryover, lb/hr }\end{array}$ \\
\hline \multicolumn{6}{|c|}{ Alabama Bituminous Coal (Flue Gas with 1.8 ppmv $\mathrm{SO}_{3}$ ) } \\
\hline 1 & 3 & 0 & 174 & $1.05^{(1)}$ & 2.1 \\
\hline 2 & 3 & 2 & 160 & $0.98^{(2)}$ & 7.3 \\
\hline 3 & 2 & 1 & 162 & $1.06^{(2)}$ & 4.9 \\
\hline 4 & 2 & 1 & 163 & $0.22^{(3)}$ & 3.8 \\
\hline 5 & 2 & 0 & 174 & $0.92^{(1)}$ & 1.1 \\
\hline 6 & 2 & 1 & 163 & $5.58^{(1)}$ & 5.9 \\
\hline \multicolumn{6}{|c|}{ Higher Sulfur Illinois Coal (Flue Gas with $3.2 \mathrm{ppmv} \mathrm{SO}_{3}$ ) } \\
\hline 7 & 2 & 0 & 176 & $1.16^{(1)}$ & 1.8 \\
\hline 8 & 2 & 0 & 174 & $1.02^{(1)}$ & 2.1 \\
\hline \multirow[t]{2}{*}{9} & 2 & 0 & 174 & $1.08^{(1)}$ & 1.7 \\
\hline & \multicolumn{2}{|c|}{ (1) Intrinsic Values } & Adjusted to 1\% & Reduced Using Fres & Nater \\
\hline
\end{tabular}

These data indicate that MEA carryover:

- Increased with $\mathrm{SO}_{3}$ level-In the moist environment of the absorber, the $\mathrm{SO}_{3}$ aerosol forms a nucleus for droplet formation, the liquid composition being determined by local water-MEA concentrations. Stack measurements performed by others indicate that $4 \mathrm{ppm}$ of $\mathrm{H}_{2} \mathrm{~S}$ in flue gas corresponds to about $10^{6}$ particles $/ \mathrm{cm}^{3}$, the majority being 0.1 microns or smaller, so there are abundant sites for droplet formation.

- Decreased with increasing solvent temperature-It is hypothesized that the higher the temperature, the larger the droplets formed and so the easier they are removed in the wash tower.

- Decreased with the upper absorber bed inactive-It is hypothesized that the liquid present on the surface of the structured packing in the upper bed intercepts some of the smaller droplets that would have otherwise passed through the wash tower.

- Decreased with wash water MEA content-The lower the MEA content of the wash water, the lower the equilibrium MEA vapor content of the gas stream.

Based on these results, NCCC staff communicated with suppliers of gas-liquid contactor equipment to determine how wash tower performance might be improved. One designer recommended that the structured packing be replaced with a bubble tray design, recirculating water between tray levels and feeding clean water to the upper tray. The supporting modeling work did not predict the increased solvent carryover, reducing confidence in the success of the proposed modification.

Currently the NCCC is working with Sulzer, the original equipment supplier, to test an innovation that is expected to reduce greatly carryover without increasing water usage. The 
current proposal is to install Sulzer's devices in the head of the absorber and the wash tower and test their effectiveness separately and in combination in reducing solvent carryover.

As reported in the NCCC's Budget Period Three Topical Report, during tests completed at the PC4, Aker Clean Carbon used an anti-mist technology on the wash tower of its Mobile Test Unit that was able to eliminate solvent carryover. This proved effective for Aker's CCAmine solvent as well as for MEA, showing that reduced solvent carryover can be achieved. The basis of the technology is proprietary.

\subsubsection{Amine and Degradation Product Carryover}

To determine the composition of the vapor and liquid leaving the wash tower and the regenerator condenser, the NCCC uses a modified version of the Environmental Protection Agency (EPA) Modified Method 5 (MM5) extractive sampling train. See Budget Period Three Topical Report for further description of the sampling method and the analytical methods used.

The results of the analyses are presented in Table 6. The majority of the species collected were in the liquid phase. For example, the total MEA present is 135 ppmv and only 4 ppmv was present in the vapor (both concentrations are expressed as being present in the gas phase). However, this is the vapor content at $40^{\circ} \mathrm{F}$ (leaving the ice bath of the MM5 sampling apparatus), not the flue gas temperature $\left(125^{\circ} \mathrm{F}\right)$. Passage through the bath results in the condensation of an unknown amount of vapor; hence, by convention, results are expressed as vapor.

Table 6. Amine and Degradation Product Carryover during MEA Testing.

\begin{tabular}{|c|c|c|}
\hline \multirow{2}{*}{ Analyte } & \multicolumn{2}{|c|}{ Outlet Concentration, ppmv ${ }^{(1)}$} \\
\hline & Wash Tower & Regenerator \\
\hline MEA & 135 & 0.061 \\
\hline Formaldehyde & 0.32 & 2.09 \\
\hline Acetaldehyde & 0.69 & 2.04 \\
\hline Ammonia & 140 & 3.5 \\
\hline Ethyl amine & 0.036 & ND \\
\hline Acetone & 0.18 & 0.033 \\
\hline Acetonitrile & 0.039 & 0.023 \\
\hline Acetic acid & 0.021 & 0.020 \\
\hline Propionic acid & 0.23 & 0.26 \\
\hline N-Nitrosodimethylamine ${ }^{(2)}$ & 0.000225 & 0.0000058 \\
\hline N-Nitrosodiethanolamine ${ }^{(2)}$ & 0.00106 & ND \\
\hline \multicolumn{3}{|c|}{ (1) Expressed as ppmv in the gas phase } \\
\hline \multicolumn{3}{|c|}{ (2) Present only in vapor samples } \\
\hline ND $=$ Not Detected & & \\
\hline
\end{tabular}

The conclusions from this area of testing were: 
- Almost all the MEA carryover from the capture plant occurs downstream of the wash tower. As discussed previously, this is because of the $\mathrm{SO}_{3}$ present in the flue gas. There is essentially no $\mathrm{SO}_{3}$ present in the regenerator, and MEA carryover is almost negligible.

- Over 97 percent of the ammonia produced is carried over from the wash tower, possibly indicating that oxidation degradation is more pronounced than thermal degradation. Adding an oxidation inhibitor will reduce solvent degradation and so lower ammonia release.

- As ammonia is a degradation by-product, it is likely that the other degradation products are also promoted by oxidation. The majority of the formaldehyde and acetaldehyde are carried over from the regenerator, most likely due to their lower volatility compared to ammonia.

- Only two nitrosamines were detected. These were nitrosodimethylamine, which was below $1 \mathrm{ppb}$, and nitrosodiethanolamine, at about $1 \mathrm{ppb}$. Neither compound was detected in the liquid samples.

In the 2011 MEA Baseline Test Campaign, an additional impinger was added to the sampling train to allow the $\mathrm{CO}_{2}$-depleted flue gas to bubble through $0.02-\mathrm{N}$ sulfuric acid $\left(\mathrm{H}_{2} \mathrm{SO}_{4}\right)$. It was anticipated that this would react with the MEA and lower the carryover. The MEA was indeed reduced, but so too were other species that do not react readily with sulfuric acid (e.g., acetaldehyde). Hence, it was possible that removal was as a result of bubbling the gas through a liquid not necessarily sulfuric acid.

The tests were repeated in March 2012 using water and sulfuric acid as the reagent. As only one sample train is available, three separate runs had to be completed: a baseline test with the additional impinger dry, followed on subsequent days by runs with sulfuric acid and with water. The results are presented in Table 7. The mode of testing may account for some of the variability, but both liquids appear equally able to remove the species listed. On the basis of these results, passing the $\mathrm{CO}_{2}$-depleted stream through an acid-wash stage would not be effective. Moreover, the solvent would be lost to the process, so if used would increase solvent makeup costs.

Table 7. Effect of Scrubber Liquid in Impingers on Vapor Emissions.

\begin{tabular}{|lcllrr|}
\hline \multirow{2}{*}{ Sampled Compound } & \multicolumn{3}{c}{ Wash Tower Outlet, ppmv } & \multicolumn{2}{c|}{$\begin{array}{c}\text { Scrubbing } \\
\text { Efficiency, \% }\end{array}$} \\
\cline { 2 - 6 } & No Liquid & $\mathbf{H}_{\mathbf{2}} \mathrm{SO}_{\mathbf{4}}$ & Water & $\mathbf{H}_{\mathbf{2}}$ SO $_{\mathbf{4}}$ & Water \\
\cline { 2 - 6 } MEA & 4.40 & 3.02 & 2.13 & 31.44 & 51.52 \\
Formaldehyde & 0.035 & 0.0020 & 0.0031 & 94.34 & 91.19 \\
Acetaldehyde & 0.628 & 0.492 & 0.734 & 21.53 & -16.97 \\
Ammonia & 53.7 & 4.75 & 1.74 & 91.14 & 96.75 \\
Ethyl amine & 0.0356 & 0.0325 & 0.0255 & 8.47 & 28.18 \\
N-Nitrosodimethylamine & 0.000225 & 0.0000371 & 0.0000172 & 83.51 & 92.36 \\
\hline
\end{tabular}




\subsubsection{Breakdown Products Detected in Solvent}

The major degradation products present in the lean solvent are presented in Table 8. The values in the rich solvent were similar. The concentration of five individual constituents generally increased with time. The amount of the compounds would be reduced by use of an oxidation inhibitor. As the constituents originated from breakdown of MEA, the constituents will vary with the solvent used. Activated carbon filters are in place to remove degradation products, and their efficacy will be assessed in subsequent runs.

Table 8. Major Degradation Products in Lean MEA.

\begin{tabular}{|lccc|}
\hline \multirow{2}{*}{ Constituent } & \multicolumn{3}{c|}{ Concentration, ppmw } \\
\cline { 2 - 4 } & $\mathbf{3 / 9 / 2 0 1 2}$ & $\mathbf{3 / 1 5 / 2 0 1 2}$ & $\mathbf{3 / 2 2 / 2 0 1 2}$ \\
\hline Formaldehyde & 1.91 & 4.69 & 6.48 \\
Acetaldehyde & 0.21 & 0.29 & 0.37 \\
Acrolein & 0.15 & 0.30 & 0.39 \\
Total & $\mathbf{2 . 2 7}$ & $\mathbf{5 . 2 8}$ & $\mathbf{7 . 2 4}$ \\
\hline
\end{tabular}

Figure 26 shows how the color of the solvent varied during the run, moving from pale yellow to a rich reddish brown. Similar color changes have been observed with other solvents. The cause of the color change has not been established, but may be degradation products or the accumulation of metals.

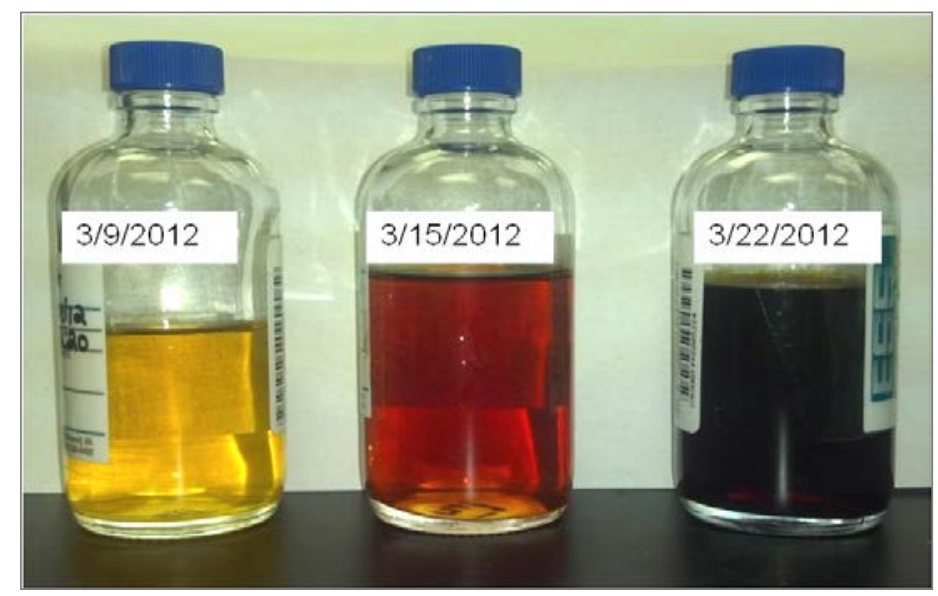

Figure 26. Color Change of Solvent During 2012 MEA Baseline Test Campaign.

\subsubsection{Metal Accumulation in Solvent}

According to the EPA, a waste is considered hazardous if it exhibits at least one of four characteristics: ignitability, corrosivity, reactivity, and toxicity. Solvent disposal was deemed to only be influence by toxicity criteria, so only this characteristic is discussed.

Over time, water percolates through solids in a landfill and dissolves contaminants that may pose health risks if that water enters the food chain. The Toxicity Characteristic Leaching Procedure 
(TCLP) simulates this leaching process and determines which of the contaminants identified by the EPA are present and in what concentration. Forty chemicals are currently listed, including heavy metals, pesticides, solvents, and some other organics. In the case of a liquid with less than 0.5-wt\% solids, the liquid is considered to be the TCLP leachate.

If regulated limits of any one of the 40 chemicals are exceeded, then the waste is considered hazardous under the Resource Conservation and Recovery Act (RCRA) and must be disposed meeting strictly enforced requirements, all at increased cost to the waste producer. If sent to disposal, the landfill must include a barrier to contain groundwater with a facility to treat any run off. Before entering the landfill, some hazardous wastes may require treatment such as stabilization and/or solidification. In some instances, to reduce the volume of waste, incineration with stringent flue gas cleanup may be used.

If more than 2,200 lb of hazardous waste is produced per calendar month, then the producer is determined to be a Large Quantity Generator, and this carries additional onerous requirements, such as reporting and accounting requirements, further adding to the cost of waste disposal. The most economical way to proceed is likely to be identifying how to avoid producing the hazardous waste, if at all possible.

At the end of the 2011 MEA Baseline Test Campaign, consideration was given to disposing of the used solvent. In accordance with RCRA requirements, solvent analysis was completed for the eight metals listed in Table 9 and included the 40 regulated chemicals. These were all determined by inductively coupled plasma mass spectrometry (ICP-MS) except for mercury, which was determined by cold-vapor atomic fluorescence spectroscopy. While the RCRA limits provided in the table are in units of ppbw, the RCRA limit is actually defined in units of mg/L (1,000 ppbw is approximately equal to $1 \mathrm{mg} / \mathrm{L})$.

Table 9. RCRA-Listed Metals in Solvent from 2012 MEA Test Campaign.

\begin{tabular}{|c|c|c|c|c|c|c|}
\hline \multirow[b]{2}{*}{ Metals } & \multirow{2}{*}{$\begin{array}{c}\text { Inlet Gas, } \\
\text { ppbw }\end{array}$} & \multicolumn{3}{|c|}{ Liquid Concentrations, ppbw } & \multirow{2}{*}{$\begin{array}{l}\text { RCRA } \\
\text { Limit, } \\
\text { ppbw }\end{array}$} & \multirow{2}{*}{$\begin{array}{c}\text { Probable } \\
\text { Source of } \\
\text { Buildup }\end{array}$} \\
\hline & & $\begin{array}{c}\text { Fresh } \\
\text { MEA }\end{array}$ & $\begin{array}{c}\text { Makeup } \\
\text { Water }\end{array}$ & $\begin{array}{c}\text { Final MEA } \\
\text { Solution }\end{array}$ & & \\
\hline Arsenic & 1.13 & $<12$ & 0.462 & 219 & 5,000 & Flue Gas \\
\hline Barium & 3.40 & $<12$ & 54.3 & 265 & 100,000 & Flue Gas \\
\hline Cadmium & $<0.14$ & $<12$ & $<0.225$ & $<10$ & 1,000 & \\
\hline Chromium & 0.315 & $<12$ & 0.927 & 45,090 & 5,000 & Corrosion \\
\hline Lead & 0.271 & $<12$ & 2.34 & $<10$ & 5,000 & \\
\hline Mercury & 0.009 & $>0.50$ & $>0.50$ & $>0.50$ & 200 & \\
\hline Selenium & 9.74 & 44.1 & $<0.225$ & 1,950 & 1,000 & Flue Gas \\
\hline Silver & $<7.00$ & $<12$ & $<0.225$ & $<500$ & 5,000 & \\
\hline
\end{tabular}

The initial solvent for the 400-hour 2012 campaign was 50 percent fresh MEA and 50 percent from the 1,140-hour 2011 campaign, so the metals concentration is roughly equivalent to a 1,000 hour run $(1140 / 2+400)$. Even in this short time, two metals exceeded the RCRA limit. 
- Chromium was measured at 45,090 ppbw, well in excess of the 5,000 ppbw limit. The majority of the chromium originates from corrosion of the 316L stainless steel, which is composed of about 18 percent chromium. The 316L was selected for the vessel material due to its corrosion resistance, although these results indicate that a corrosion inhibitor is needed as well. The chromium would be significantly reduced by fabricating the plant from carbon steel, which is standard industrial practice.

- Selenium was measured at 1,950 ppbw, almost twice the 1,000 ppbw limit. The selenium originates mainly from the flue gas. Speciation testing using Reverse Phase, Ultra-High Pressure Liquid Chromatography, Inductively Coupled Plasma, Triple Quadrupole Mass Spectrometry (RP-UHPLC-ICP-TQMS) showed that 50 percent of the selenium was selenide, 25 percent selenite, and 25 percent elemental selenium. Selenate, the most toxic form of selenium, was below the detection limit.

- The presence of amine interfered with the RP-UHPLC-ICP-TQMS procedure when used to determine the chromium species present, but the procedure successfully determined the species of arsenic present. For arsenic, 17 percent was present as arsenite and 83 percent as arsenate. Although both are toxic, the former is the most toxic.

- The other metals present above the lower detection limits (LDLs), arsenic (219 ppbw) and barium (265 ppbw) both originate mainly from the flue gas. The variability seen in LDL values is normal, and varies between chemicals and the medium in which they are present.

- The flue gas content of RCRA metals is very low, but the high level of gas-liquid contact and the chemical environment in the absorber appears effective at removing much of it.

- The fresh MEA contained about 44 ppbw of RCRA metals (mainly selenium) but the used MEA contained 47,250 ppbw (mainly chromium).

- The solvent process includes a reclaimer to thermally separate the solvent from heat stable salts. It is likely that the metals in Table 9 will remain with the residue, and although this will reduce the quantity of waste, the concentration will be approximately 10 times higher.

The ICP-MS analysis revealed the presence of a range of other metals not included in the RCRA limit. Table 10 presents these additional metals that originate either from corrosion of the materials of construction or from the flue gas. Discussion on some of the metals follows. 
Table 10. Non-RCRA-Listed Metals in Solvent from 2012 MEA Test Campaign.

\begin{tabular}{|c|c|c|c|c|c|}
\hline \multirow[b]{2}{*}{ Metal } & \multirow{2}{*}{$\begin{array}{c}\text { Inlet Gas } \\
\text { Concentration, } \\
\text { ppbw }\end{array}$} & \multicolumn{3}{|c|}{ Liquid Concentrations, ppbw } & \multirow{2}{*}{$\begin{array}{c}\text { Probable Source of } \\
\text { Buildup }\end{array}$} \\
\hline & & $\begin{array}{l}\text { Fresh } \\
\text { MEA }\end{array}$ & $\begin{array}{l}\text { Makeup } \\
\text { Water }\end{array}$ & $\begin{array}{l}\text { Rich MEA } \\
\text { Solution }\end{array}$ & \\
\hline Aluminum & 281 & $<120$ & 272 & 4,060 & Flue Gas \\
\hline Calcium & 684 & $<1200$ & 15,720 & 23,100 & Flue Gas/FGD \\
\hline Cobalt ${ }^{(1)}$ & $<0.07$ & $<12$ & 0.431 & 1,020 & Corrosion \\
\hline Iron & 17.6 & 191 & 18,410 & 137,200 & Corrosion \\
\hline Magnesium & 21.4 & $<240$ & 4,660 & 15,340 & Flue Gas/FGD \\
\hline Manganese & 74.3 & $<60$ & 83.2 & 5,620 & Flue Gas/Corrosion \\
\hline Molybdenum ${ }^{(1)}$ & $<0.28$ & $<12$ & 0.886 & 5,270 & Flue Gas \\
\hline Nickel ${ }^{(1)}$ & 0.205 & 24.8 & 2.42 & 28,770 & Corrosion \\
\hline Potassium & 38.8 & $<1200$ & 1,520 & 6,480 & Flue Gas \\
\hline Sodium & 49.7 & $<1200$ & 5,110 & 399,100 & Flue Gas/Pre-scrubber \\
\hline Strontium & 3.20 & $<12$ & 46.2 & 84.7 & Flue Gas \\
\hline Tungsten & $<0.70$ & $<12$ & $<0.225$ & 1,590 & Flue Gas \\
\hline Vanadium & $<0.28$ & $<12$ & 3.14 & 165 & Flue Gas \\
\hline Uranium & $<0.14$ & $<12$ & $<0.225$ & 12.3 & Flue Gas \\
\hline Zinc & 2.95 & $<120$ & 27.4 & 940 & Flue Gas \\
\hline
\end{tabular}

- Cobalt was above 1,000 ppbw and is considered to be a corrosion product. The cobalt present in the solvent may have originated from metal workings from fabrication, as cobalt is used to harden and thus increase wear resistance of metal components.

- Iron (137,200 ppbw), manganese (5,620 ppbw), and nickel (28,770 ppbw) (with chromium) were present in the same proportions as are those metals in 316L stainless steel, the material used in fabricating the PSTU vessels. Iron and manganese are also present in the flue gas.

- Calcium (15,720 ppbw) and magnesium originate from the flue gas, probably material picked up from the FGD as fine particulate.

- Sodium (399,100 ppbw) originates from the flue gas, and is almost certainly material picked up from the pre-scrubber. Ways of reducing this carryover will be investigated.

- The fresh MEA contained about 920 ppbw of other metals (mainly aluminum), but the used MEA contained 628,750 ppbw (mainly sodium and iron).

\subsubsection{Anion Accumulation in Solvent}

The anions in the MEA and presented in Table 11 were measured using ion chromatography. Note that the concentrations were measured in ppmw, not ppbw as for the cations. The major inorganic anion detected was sulfate, the majority of which likely arises from salts of sodium 
(pre-scrubber), calcium and magnesium (wet FGD), and potassium and aluminum (coal ash), all cations being detected in used MEA (see Table 10). Some sulfate may also arise from the transmission of $\mathrm{SO}_{2}$ from the caustic scrubber, but this is thought to be a minor source. The chloride, nitrate, and nitrite originate from the flue gas, and the oxalate and formate are solvent degradation products.

Table 11. Anions in Solvent from 2012 MEA Test Campaign.

\begin{tabular}{|lcc|}
\hline Anion & $\begin{array}{c}\text { Rich MEA } \\
\text { Concentration, } \\
\text { ppmw }\end{array}$ & $\begin{array}{c}\text { Probable Source of } \\
\text { Buildup }\end{array}$ \\
\hline Sulfate & 1,010 & Flue Gas \\
Chloride & 21.2 & Flue Gas \\
Nitrate & 19.3 & Flue Gas \\
Nitrite & 2.3 & Flue Gas \\
Oxalate & 393 & Solvent Degradation \\
Formate & 1,820 & Solvent Degradation \\
\hline
\end{tabular}

\subsubsection{Solvent Metals Removal}

While contaminants in the solvent must be limited to prevent operational issues such as foaming, deposition, and sludge formation, one of the greatest concerns is reducing the selenium level, as it infringes the RCRA limit. Because chromium originates from corrosion, it is assumed that its concentration can be managed by appropriate selection of materials of construction. Hence, the initial studies concentrated on the removal of selenium with the effect on the other materials present.

\section{Metals Removal Using Established Water Treatment Methods}

NCCC staff has consulted with water treatment experts to determine how selenium might be most economically removed. Based on studies of selenium chemistry for water treatment, three different waste water chemical treatment procedures were identified.

- Treatment with copper chloride solution without $\mathrm{pH}$ adjustment

- Treatment with ferric chloride solution with $\mathrm{pH}$ adjustment using sulfuric acid

- Treatment with zero-valent iron (ZVI) powder with and without $\mathrm{pH}$ adjustment

All three treatment techniques have been reported to remove selenium successfully from a variety of wastewater streams, but there is no experience of their use to treat MEA solutions. The tests were carried out using a bench-scale jar tester, consisting of several stirred beakers that allowed a range of conditions to be tested simultaneously and so accelerate progress of parametric testing.

No precipitation of solids was observed with either copper or ferric chloride, even when a flocculant was added, indicating that there was no removal of selenium or any other metals. It is 
assumed that the MEA interfered with the precipitating reaction, possibly by chelating the metal cations. As MEA is a buffer, a large amount of acid was needed to adjust the $\mathrm{pH}$, and consequently much of the MEA was consumed. From this observation, it was concluded that for a removal process to be successful, it should not require acidification.

For the ZVI tests with acidification for $\mathrm{pH}$ adjustment into the range 5 to 6 , approximately 75 percent of the selenium in the MEA solution was removed, lowering the concentration from approximately 900 ppbw to 200 ppbw. No other metals were removed. Speciation tests revealed the following characteristics of the removal process:

- Selenide constituted 54 percent of the selenium and the ZVI removed 95 percent of it, reducing the concentration from 490 ppbw to 20 ppbw.

- Selenite constituted 44 percent of the selenium, and the ZVI removed 75 percent of it, reducing the concentration from 400 ppbw to 100 ppbw.

- The selenate constituted around 1 percent of the selenium, and the ZVI reduced the amount to below the lower detection limit.

- The elemental selenium was not detected initially, but increased to around 80 ppbw, possibly the acid promoting a conversion from one of the other species.

The selenium species in the used solvent were determined twice, first without treatment (at a $\mathrm{pH}$ of 10.3) and then with acidification to reach a $\mathrm{pH}$ of 5 to 6 . The results are presented in Table 12. The biggest change was the increase in selenite and corresponding reduction in elemental selenium occurring as a result of acidification. Variation of species with oxygenreduction potential and $\mathrm{pH}$ has been observed by researchers investigating water treatment processes. These are the first known results for aqueous amine solutions.

Table 12. Selenium Species in MEA Solvent with and without pH Adjustment.

\begin{tabular}{|lcc|}
\hline \multirow{2}{*}{$\begin{array}{c}\text { Selenium } \\
\text { Species }\end{array}$} & \multicolumn{2}{c|}{ Percentage of Selenium Species } \\
\cline { 2 - 3 } Selenide & Without $\mathbf{p H}$ Treatment & With pH Treatment \\
Selenite & 50 & 54 \\
Elemental & 25 & 45 \\
Selenate & 25 & Below LDL \\
\hline
\end{tabular}

\section{Metals Removal Using ZVI Method at Texas A\&M University}

MEA samples were sent to Texas A\&M University to be treated using their proprietary process based on ZVI without acidification. A bench-scale jar tester was used with the $\mathrm{pH}$ of the MEA at its intrinsic value of 10.3. Table 13 lists the removal efficiency after six hours of ZVI treatment for the RCRA metals that were measurable in the solvent as well as several non-listed metals. The difference in separation performance compared to the NCCC test results may arise from not using sulfuric acid for $\mathrm{pH}$ adjustment. Some of the non-listed metals (calcium, iron, and potassium) increased in concentration, presumably because they are present in the ZVI oxide mixture. 
Table 13. Efficiency of Metals Removal from MEA Solvent with Texas A\&M ZVI Process.

\begin{tabular}{|lc|}
\hline \multicolumn{1}{|c|}{ Metal } & Removal Efficiency, \% \\
\hline RCRA Listed Metals & \\
Arsenic & 96 \\
Barium & 98 \\
Selenium & 80 \\
Chromium & 31 \\
Non-Listed Metals & \\
Aluminum & 15 \\
Cobalt & 80 \\
Magnesium & 39 \\
Manganese & 86 \\
Molybdenum & 16 \\
Nickel & 66 \\
Sodium & 5 \\
Strontium & 74 \\
Tungsten & 63 \\
Vanadium & 83 \\
Uranium & 67 \\
Zinc & 64 \\
\hline
\end{tabular}

\section{Metals Removal Using Sorbents}

One supplier recommended three sorbents developed for water treatment, which were evaluated in the bench-scale jar tester without acidification. The sorbents are 650 micron silica matrix materials (marketed as Self Assembled Monolayers on Mesoporous Supports) licensed from Battelle. The three sorbents tested were:

- ESL-63 for removal of lead, zinc, cobalt, iron, and nickel

- FESL-63 for removal of selenium, chromium, and arsenic

- THSL-63 for removal of mercury, cadmium, lead, selenium, cobalt, iron and magnesium None of the sorbents, individually or in combination, removed any of the metals. Again, the MEA is believed to interfere with the separation mechanism, and there are no plans to test other sorbents.

\section{Other Methods of Metal Removal}

Methods used by the petrochemical industry for removing contaminants from MEA include ion exchange and electrodialysis. Samples of used MEA will be tested to determine if these two techniques remove metals as well as degradation products. 


\subsubsection{Oxygen Content of $\mathrm{CO}_{2}$ from Regenerator}

The $\mathrm{CO}_{2}$ specification for pipeline transportation is that it contains less than $100 \mathrm{ppmv}$ of oxygen to inhibit corrosion of carbon steel. The oxygen can be transferred into the regenerator either dissolved in the solvent or as flue gas entrained with the solvent pumped from the absorber sump. It was decided to measure this important parameter. A gas chromatograph was investigated initially but the argon peak of the carrier gas obscured the oxygen peak. Instead, a GE O2X1 fuel-cell oxygen detector probe was selected for the measurement program. Attempts to make continuous measurements were confounded by small leaks resulting in high oxygen contents. Therefore, a batch mode of sampling and analysis was used.

- First, all the air was displaced from the bomb using a nitrogen purge for an extended period. The bomb was then valved off to prevent oxygen re-entering.

- The bomb was attached to a tapping on the regenerator outlet and $\mathrm{CO}_{2}$ at 1.7 bar (25 psia) was purged through for an extended period. The bomb was then valved off, enclosing the $\mathrm{CO}_{2}$ sample at elevated pressure.

- The bomb was attached to the inlet of the GE O2X1 analyzer and the gas passed through for about one minute until the pressure had decayed.

- Six samples were taken, and the average oxygen content was about 10 ppmv.

The conclusion is that the oxygen content of the $\mathrm{CO}_{2}$ is comfortably below the 100 ppmv limit.

\subsubsection{Additional MEA Testing}

A third MEA run would be beneficial in confirming the effectiveness of measures to reduce solvent carryover and to maintain solvent metals content at low levels. The current plan is to use the SSTU to screen proposed measures and then confirm their long-term effectiveness in the PSTU.

\subsection{Hitachi Solvent}

Since the early 1990’s, through extensive research, development, and demonstration, Hitachi has developed and continually improved $\mathrm{CO}_{2}$ capture process designs and technologies for full-scale power plant applications. Hitachi's latest advanced amine solvent, H3-1, reportedly has a high $\mathrm{CO}_{2}$ capture capacity, low regeneration energy, high resistance to degradation, low amine losses, and low corrosivity. Hitachi conducted testing in the PSTU to demonstrate the solvent for use at coal-burning facilities in the U.S.

Testing of Hitachi's H3-1 solvent began in the PSTU in April and concluded in mid July, with a total of over 1,300 hours of testing. The test campaign included parametric testing followed by continuous long-term testing at an optimum condition. The parametric tests were conducted over a range of operating conditions including a varying number of absorber beds in service and with and without intercoolers in service. The operating condition ranges are listed in Table 14. 
Table 14. Operating Parameters for Hitachi Solvent Testing.

\begin{tabular}{|lc|}
\hline \multicolumn{1}{|c|}{ Operating Parameter } & Range \\
\hline Absorber Flue Gas Flow Rate (G), lb/hr & 4,000 to 6,000 \\
Solvent Flow Rate (L), Ib/hr & 7,000 to 17,000 \\
Reboiler Steam Flow Rate (S), Ib/hr & 700 to 1,100 \\
Absorber Inlet Flue Gas Temperature, ${ }^{\circ} \mathrm{F}$ & 96 to 122 \\
Absorber Inlet Solvent Temperature, ${ }^{\circ} \mathrm{F}$ & 96 to 114 \\
Wash Tower Exit Temperature, ${ }^{\circ} \mathrm{F}$ & 107 to 123 \\
Regenerator Pressure, psig & 3 to 22 \\
Inlet Flue Gas $\mathrm{CO}_{2}$ Content, vol\% & 11 to 13 \\
Number of Absorber Beds & 1,2 , and 3 \\
Intercoolers & On and Off \\
\hline
\end{tabular}

The test objectives include the verification of operational performance, establishment of absorber flooding conditions, and determination of the effects of the following:

- $\mathrm{L} / \mathrm{G}$ and $\mathrm{S} / \mathrm{L}$ ratios on $\mathrm{CO}_{2}$ capture performance

- The number of beds and intercooling on $\mathrm{CO}_{2}$ capture performance

- Flue gas and solvent temperature on $\mathrm{CO}_{2}$ capture performance

- Operating pressure on solvent regeneration

- Wash tower exit temperature on solvent carryover

During testing, an automatic titrator determined the $\mathrm{CO}_{2}$ loading and amine content of the solvent entering and leaving the absorber. Periodic checks were completed by manual titration of the samples. Both titration devices were calibrated with an analytical standard provided by Hitachi. During testing, NCCC staff performed mass balance checks to ensure the reliability of data yielded from plant instrumentation. A variety of gas and liquid samples were taken by NCCC staff during the test period. The PC4 gas sampling system was used to determine solvent carryover from the wash tower. Gas sampling methods suggested by Hitachi were used to collect samples from the wash tower and regenerator to determine the carryover of amine and nitrosamines.

Hitachi is working with NCCC staff on data analysis and preparation of the final report. Preliminary information presently available has been released as a series of figures, which are presented and discussed briefly.

Figure 27 plots the variation in capture efficiency over the test campaign. The range of variables covered is given in Table 14 . On average, $\mathrm{CO}_{2}$ capture efficiency of over 90 percent was achieved over the test period. 


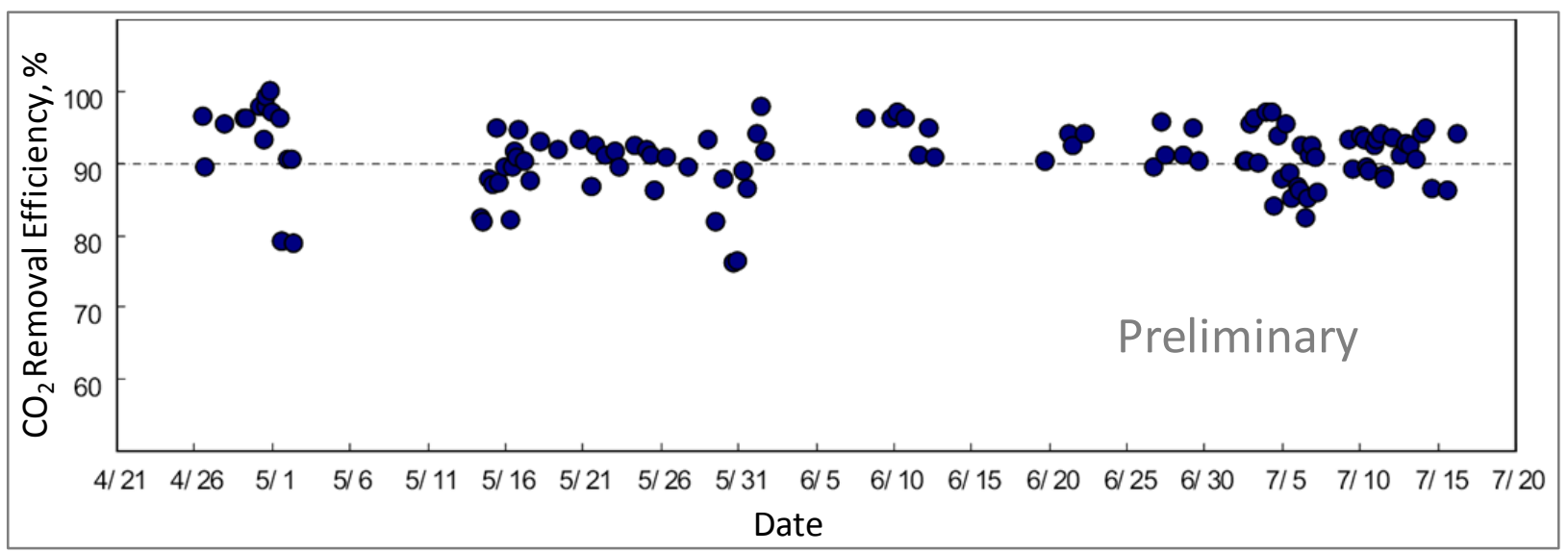

Figure 27. $\mathrm{CO}_{2}$ Capture Efficiency over the Duration of Hitachi Solvent Testing.

The variation of $\mathrm{CO}_{2}$ capture efficiency with solvent flow rate for a constant reboiler steam flow is presented in Figure 28. For these conditions, capture efficiency reaches a maximum at a particular solvent flow rate. At the lower flow rates before the maximum, as less solvent is available, solvent leaving the absorber is richer, and this limits the amount of $\mathrm{CO}_{2}$ that can be captured. At the higher solvent flow rates after the maximum, more of the heat supplied is used to provide sensible heat. As the heat supplied is constant, less is available for regeneration and less $\mathrm{CO}_{2}$ is released, increasing the loading of the lean solvent. This in turn results in the solvent leaving the absorber becoming richer and again limiting the amount of $\mathrm{CO}_{2}$ that can be captured. The operating conditions for these tests are as follows:

- Inlet flue gas $\mathrm{CO}_{2}$ content: 11.5 to 11.9 percent

- Flue gas flow rate: 5,000 lb/hr

- Number of packed beds in service: 3 without intercooling

- Regenerator operating pressure: 14 psig

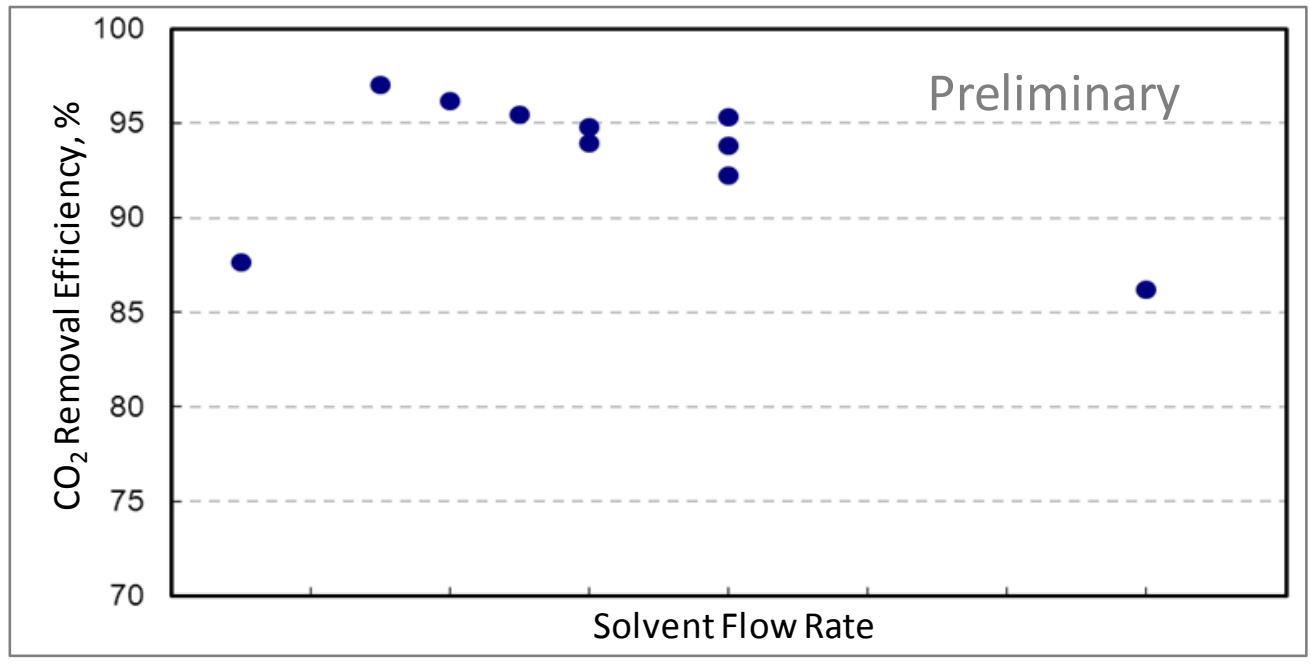

Figure 28. Variation of $\mathrm{CO}_{2}$ Capture Efficiency with Hitachi Solvent Flow Rate. 
The variation of regeneration energy with solvent flow rate for a constant reboiler steam flow is presented in Figure 29. For these conditions, regeneration energy reaches a minimum at the same solvent flow rate producing the maximum in Figure 28. This occurs because regeneration energy is inversely proportional to the amount of $\mathrm{CO}_{2}$ captured. The operating conditions for these tests were the same as those listed above.

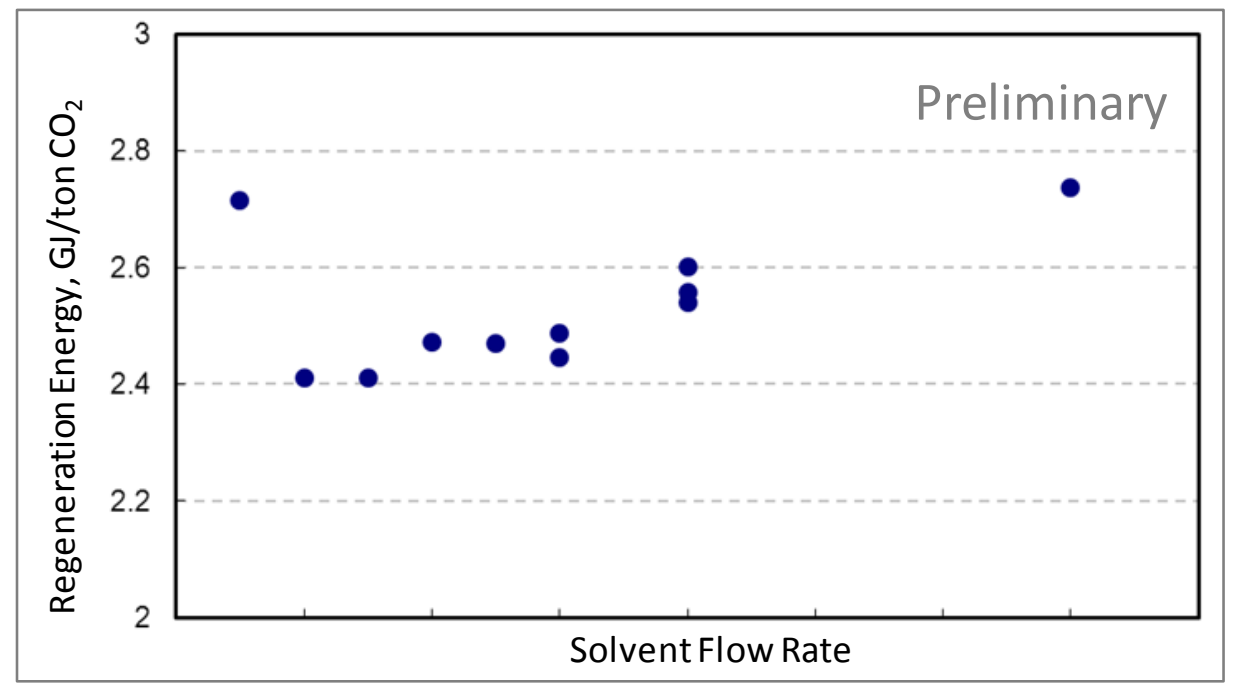

Figure 29. Variation of Regeneration Energy with Hitachi Solvent Flow Rate.

The variation of $\mathrm{CO}_{2}$ capture efficiency with reboiler steam flow and flue gas $\mathrm{CO}_{2}$ content is presented in Figure 30. The operating conditions were the same for both data sets. Data showed that efficiency fell for steam flow rates below the optimum value. At the lower steam flows, the lean solvent returning to the absorber is richer in $\mathrm{CO}_{2}$, and this limits the amount of $\mathrm{CO}_{2}$ that can be captured. Efficiency also fell with increasing flue gas $\mathrm{CO}_{2}$ content. Presumably, the rich solvent leaving the absorber is saturated with $\mathrm{CO}_{2}$ in both cases, and so a lower percentage is removed for the flue gas with the higher $\mathrm{CO}_{2}$ content.

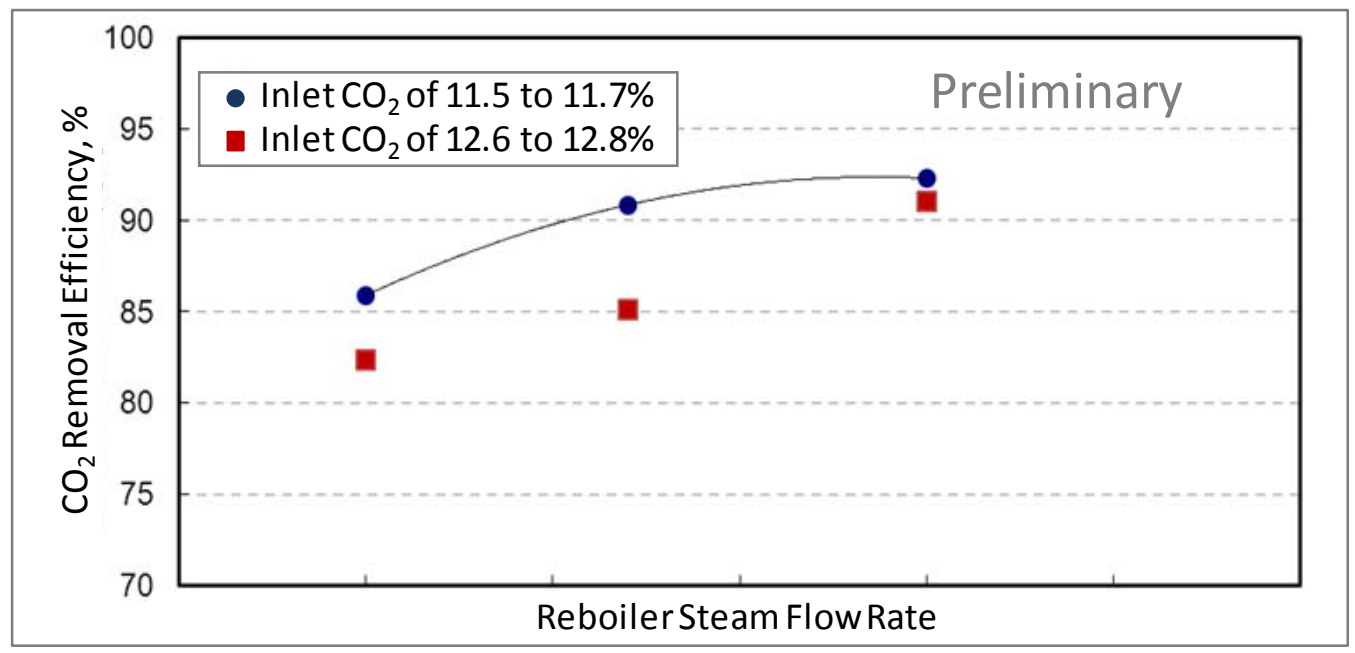

Figure 30. Variation of $\mathrm{CO}_{2}$ Capture Efficiency of Hitachi Solvent with Reboiler Steam Flow Rate. 
The data collected and given in Table 15 showed that compared to 30 wt\% MEA, Hitachi's H3-1 operated with a 37 percent lower $L / G$ ratio, achieving a 33 percent lower heat of regeneration. Operation with the H3-1 solvent requires lower regeneration energy because less liquid has to be heated in the reboiler in combination with a lower heat of reaction with $\mathrm{CO}_{2}$. The operating conditions for these tests were:

- Inlet flue gas $\mathrm{CO}_{2}$ content: 12.5 to 13.0 percent

- $\mathrm{CO}_{2}$ capture efficiency: 92 to 94 percent

- Flue gas flow rate: $5,000 \mathrm{lb} / \mathrm{hr}$

- Number of packed beds in service: 3 without intercooling

Table 15. L/G Ratio and Heat of Regeneration of 30 wt\% MEA and Hitachi Solvent.

\begin{tabular}{|lcc|}
\hline \multicolumn{1}{|c}{ Solvent } & L/G Ratio & Heat of Regeneration, Btu/lb \\
\hline 30 wt\% MEA & 3.2 & 1,550 \\
H3-1 & 2.2 & 1,030 \\
\hline
\end{tabular}

With three beds in service, using the intercoolers was shown to raise the $\mathrm{CO}_{2}$ capture efficiency from 89 to 94 percent. By lowering average solvent temperature in the absorber enabling operation in the optimal range of 100 to $140^{\circ} \mathrm{F}$, the intercoolers enhance $\mathrm{CO}_{2}$ capture efficiency. For these values, the inlet flue gas $\mathrm{CO}_{2}$ content ranged from 11.7 to 12.0 percent, and the flue gas flow rate was $5000 \mathrm{lb} / \mathrm{hr}$.

The $\mathrm{CO}_{2}$ capture efficiency increased with the number of absorber beds in service, as demonstrated by the data provided in Table 16. With more beds, the surface area available for gas-liquid contacting is increased and the gas residence time in the reaction zone is increased. Both factors help raise $\mathrm{CO}_{2}$ capture efficiency. For these values, the inlet flue gas $\mathrm{CO}_{2}$ content ranged from 11.7 to 12.3 percent, and the flue gas flow rate was $5000 \mathrm{lb} / \mathrm{hr}$.

Table 16. $\mathrm{CO}_{2}$ Capture Efficiency of Hitachi Solvent with Varying Number of Absorber Beds in Service.

\begin{tabular}{|cc|}
\hline $\begin{array}{c}\text { Number of Beds } \\
\text { in Service }\end{array}$ & $\begin{array}{c}\mathrm{CO}_{2} \text { Capture } \\
\text { Efficiency, \% }\end{array}$ \\
\hline 1 & 76.5 \\
2 & 87.7 \\
3 & 91.7 \\
\hline
\end{tabular}

\subsection{BASF / Linde Solvent and Process}

BASF and Linde are designing and planning the construction and operation of a pilot-scale test facility to be installed and tested at the PC4. Figure 31 provides a model view of the $1-\mathrm{MW} \mathrm{CO}_{2}$ capture pilot plant. The plant, which will incorporate BASF/Linde's enhanced $\mathrm{CO}_{2}$ capture process and an advanced amine solvent from BASF, is designed to process up to 30 tons/day of 
$\mathrm{CO}_{2}$. The group plans to optimize the process through parametric testing and to accumulate critical data for commercial scale-up through long-term testing.

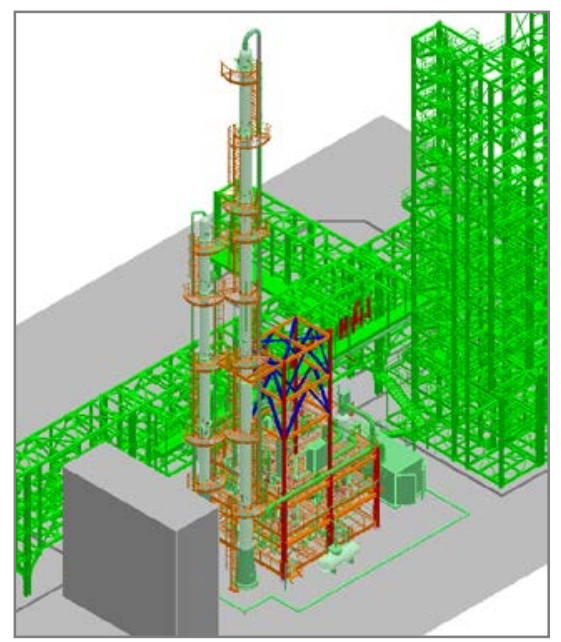

\section{Figure 31. Model View of BASF/Linde Pilot Unit.}

Progress during the year for the BASF/Linde project included:

- Establishing a design basis

- Developing a project schedule

- Preparing engineering drawings and a 3-D model

- Completing a design hazard review

- Initiating procurement of major balance of plant equipment

- $\quad$ Preparing the test site

Installation of the pilot plant is scheduled to begin in the fourth quarter of 2013. Testing is planned to begin in 2014 and to continue into 2015.

\subsection{Cansolv Technologies Solvent}

As part of its research and development of $\mathrm{CO}_{2}$ capture processes, Cansolv Technologies conducted extensive testing of its DC-201 solvent in the PSTU in the third quarter of 2012. Testing involved parametric studies, equipment configurations, and solvent additives.

The piloting campaign duration was three months, from July 24 to October 28, 2012. A total of 1,725 hours of testing was achieved, which represents 80 percent of stable operation over the period. The test plan was interrupted on three occasions due to E.C. Gaston power plant shut-down or maintenance on the selective catalytic reduction (SCR) unit and scrubber: from August 15 to August 19; from September 7 to September 17; and on September 27. 
Typically, two data points were collected per day, comprising of critical pilot unit parameters, such as temperatures, flows, and pressures, as well as liquid and gas sample analyses. Data collection was initiated after conditions had been stable for at least three hours. Liquid samples consisted of pre-scrubber sump, lean amine, rich amine, reflux, and water-wash recirculation fluids. Mass balance closures between the absorber and the stripper were very good (within 2 percent). The test protocol was discussed and refined by Cansolv Technologies and NCCC staff prior to the test. The test was divided into the sub-tests indicated by Table 17.

Table 17. Cansolv Solvent Test Schedule.

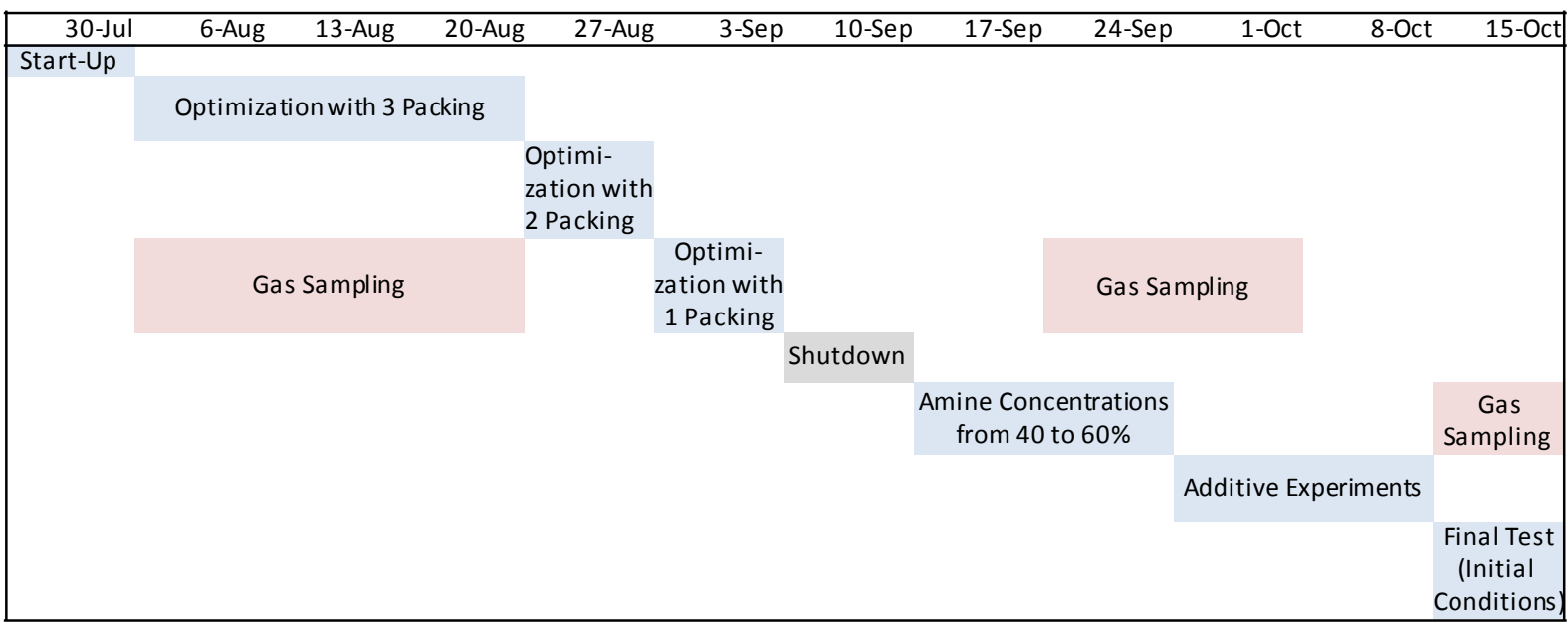

The technical objectives defined for the test included evaluation of the following:

- Approach to equilibrium at various temperatures and L/G ratios (including 1,2 , or 3 absorber beds in service with 0,1 , or 2 intercoolers operating)

- Regeneration energy at various $L / G$ ratios and regeneration temperatures and pressures

- $\mathrm{CO}_{2}$ capture percentage at various solvent concentrations

- Amine or degradation product concentrations upstream and downstream of the water-wash section as well as in the $\mathrm{CO}_{2}$ product

- Solvent stability under the oxidative environment, including the effect of $\mathrm{SO}_{2}$ and $\mathrm{NO}_{2}$ concentration in the gas

- Corrosion rates

- The effect on $\mathrm{CO}_{2}$ capture performance at different concentrations of an additive

Figure 32 plots the solvent, flue gas, and steam flow rates during the test period. The gas flow through the absorber was kept constant at 5,000 lb/hr. The liquid flow rate was varied from 11,000 to $6,800 \mathrm{lb} / \mathrm{hr}$ and the steam flow rate from 750 to $1,000 \mathrm{lb} / \mathrm{hr}$, depending on test conditions. 


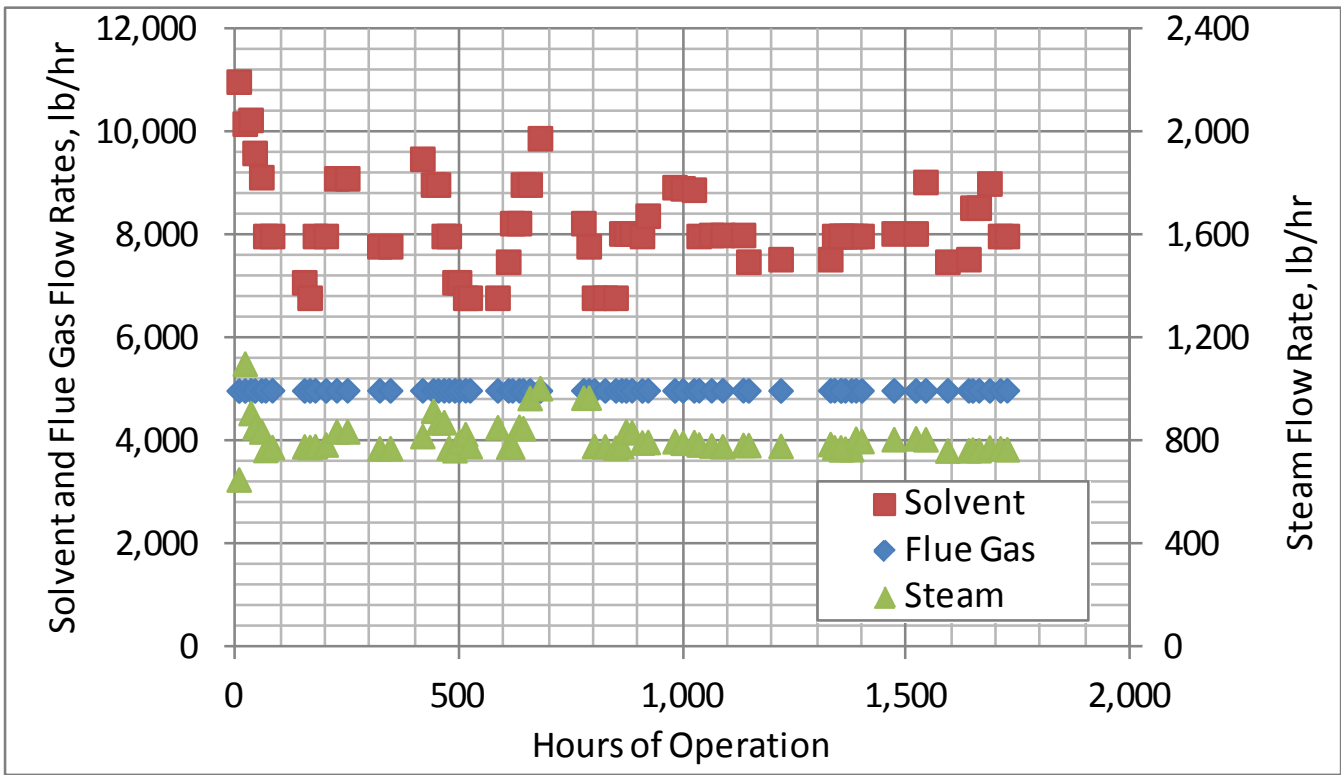

Figure 32. Solvent, Flue Gas, and Steam Flow Rates during Cansolv Solvent Testing.

\subsubsection{Optimization of Energy vs. L/G Ratio}

This part of the test investigated the loading capacity of the solvent in the absorber and its influence on reboiler steam usage. These tests were performed at the same gas flow rate that was used for the evaluation of MEA on the PSTU unit. The amine and steam flows were varied to achieve 90 percent $\mathrm{CO}_{2}$ capture. Figure 33 gives the results of this first set of experiments. The DC-201 solvent required 40 percent less energy than MEA to achieve the same capture rate using three packing sections in the absorber. The solvent also required 50 percent less circulation (L/G being $4 \mathrm{~kg} / \mathrm{Nm}^{3}$ for MEA and $2 \mathrm{~kg} / \mathrm{Nm}^{3}$ for DC-201).

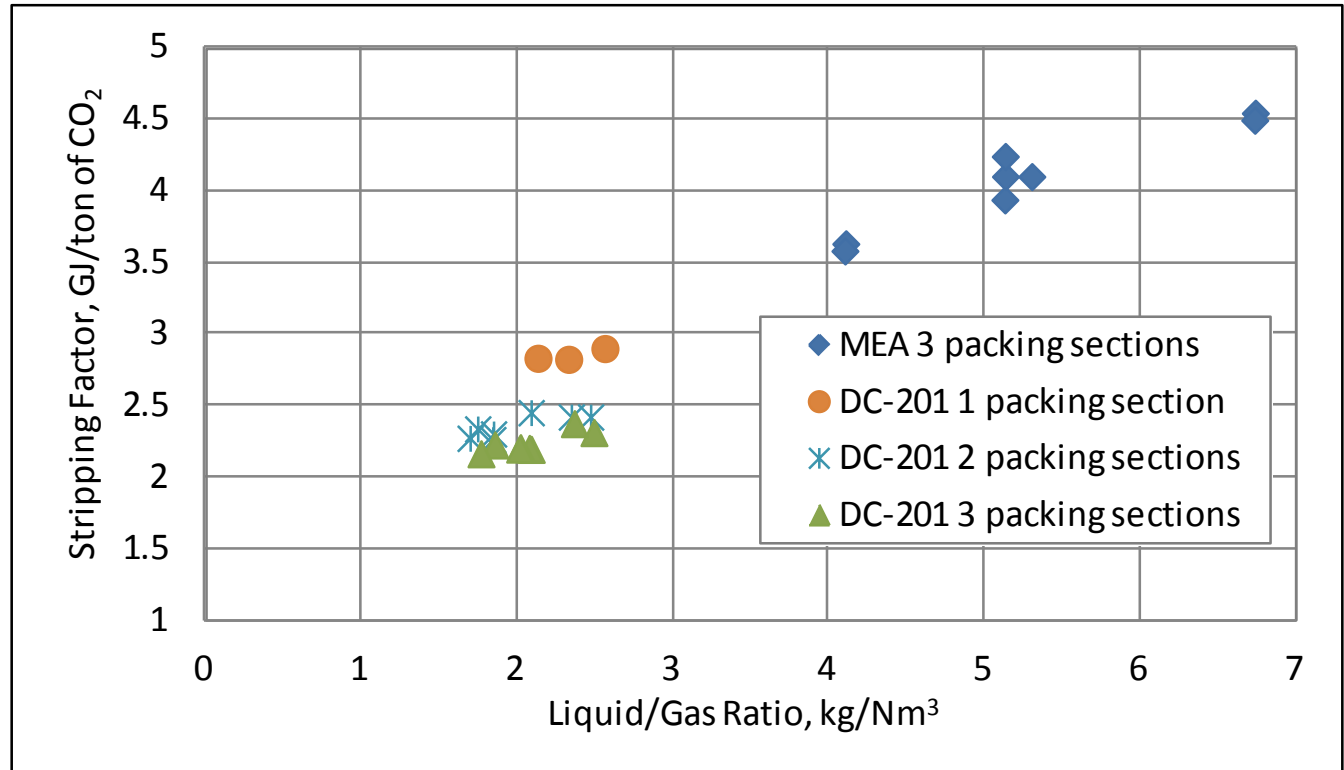

Figure 33. Optimization of Cansolv DC-201 Solvent at Various Absorber Packing Heights. 


\subsubsection{Variation of Packing Height}

This part of the campaign focused on the effect of absorber packing height on the performance of the capture system. The PSTU is equipped with three packing sections in the absorber, each 20 feet tall. An intercooler is located between each packing section. The solvent is withdrawn from the column at the bottom of one packing section, cooled in a heat exchanger, and returned to the column at the top of the packing section below. Lowering the solvent temperature into the optimal range increases the $\mathrm{CO}_{2}$ solvent loading.

Three absorber configurations were tested:

- 3 packing sections, 2 intercoolers

- 2 packing sections, 1 intercooler

- 1 packing section, 0 intercooler

The amine and steam flows were varied to achieve 90 percent $\mathrm{CO}_{2}$ capture. Results of this set of experiments are shown in Figure 34. The operating conditions (liquid to gas ratio and steam usage per ton of $\mathrm{CO}_{2}$ captured) were not significantly affected while switching from three to two packing sections. The $\mathrm{L} / \mathrm{G}$ did not vary, and the stripping factor increased from $2.2 \mathrm{GJ} /$ ton $\mathrm{CO}_{2}$ to $2.3 \mathrm{GJ} /$ ton $\mathrm{CO}_{2}$. Under these conditions, the solvent is not kinetically limiting and can reach adequate rich loading.

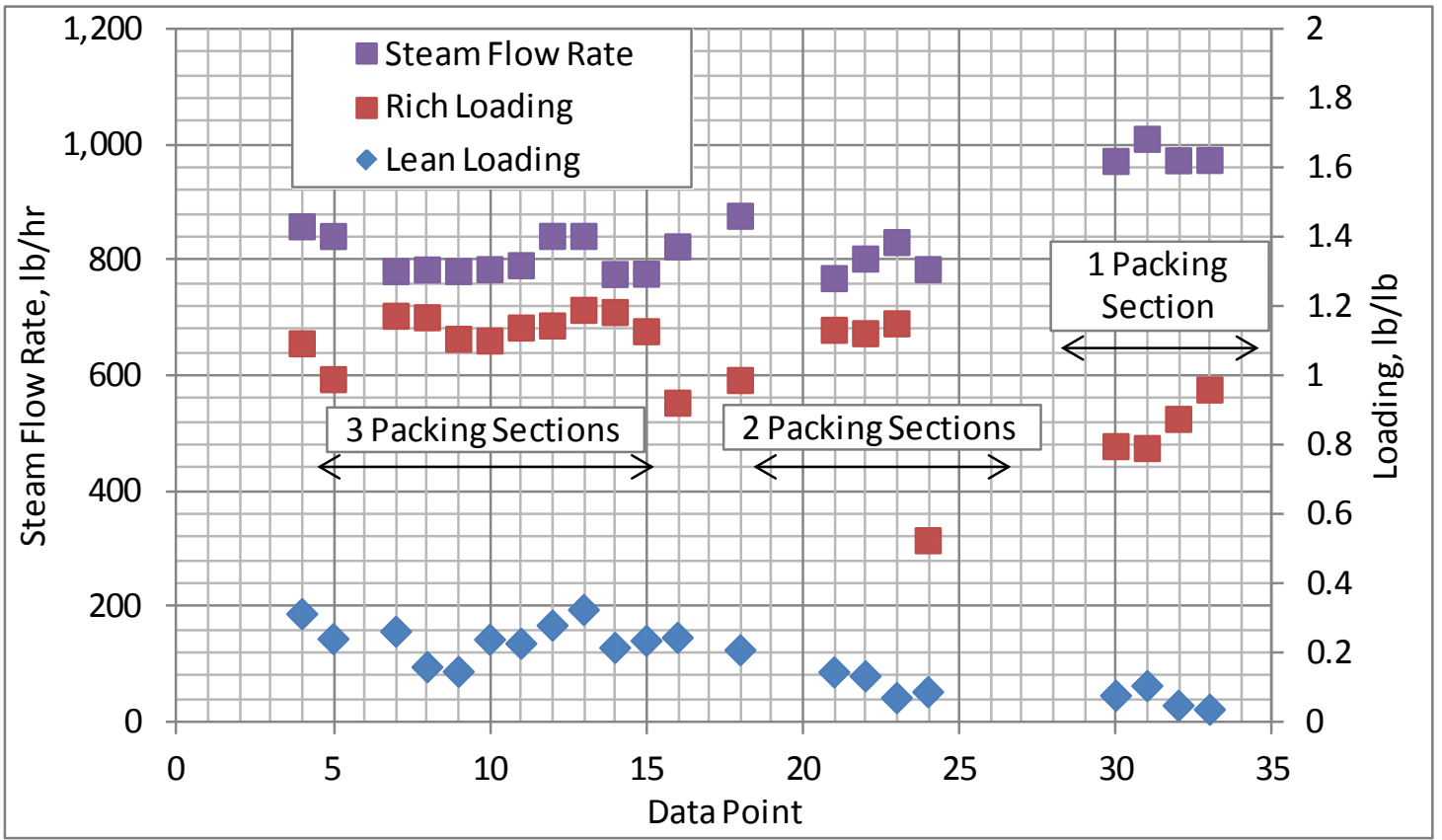

Figure 34. Variation of Steam Flow and Lean and Rich loadings with Absorber Packing Sections.

A clearer response can be seen when switching from two to one packing sections. In this case, to maintain 90 percent $\mathrm{CO}_{2}$ capture, the amine flow had to be increased ( $\mathrm{L} / \mathrm{G}$ going from 2.0 to 
$2.5 \mathrm{~kg} / \mathrm{Nm}^{3}$ ), as well as the steam flow. (Stripping factor increased from $2.3 \mathrm{GJ} /$ ton $\mathrm{CO}_{2}$ to $2.8 \mathrm{GJ} /$ ton $\mathrm{CO}_{2}$.) With only one packing section, the solvent appears to be kinetically limiting, and the lower rich loading achieved results in a lower lean loading and a higher steam flow rate.

\subsubsection{Amine Concentration Experiments}

During these experiments, the amine concentration in the solvent was varied from 40 to $60 \mathrm{wt} \%$ to study the effect on $\mathrm{CO}_{2}$ capture efficiency and on steam usage (or stripping factor, expressed in $\mathrm{GJ} /$ ton $\mathrm{CO}_{2}$ captured). When the amine concentration in the solvent falls below a given value, the $\mathrm{CO}_{2}$ capture efficiency decreases due to loss of active amine sites in the solvent. This is shown in Figure 35 where reducing amine concentration from 53 to $40 \mathrm{wt} \%$, reduced $\mathrm{CO}_{2}$ capture efficiency from about 90 to 84 percent. Similarly, if the amine concentration is increased too much, some limitation in $\mathrm{CO}_{2}$ mass transfer from the gas to the liquid phases may occur due to the increased viscosity of the solvent. A counter-measure to this loss in performance is to increase reboiler steam flow to lower the lean $\mathrm{CO}_{2}$ solvent loading and provide extra $\mathrm{CO}_{2}$ capacity in the absorber. These results are also shown in Figure 35. These tests indicate the following:

- Operational flexibility from 40 to $60 \mathrm{wt} \%$ solvent concentration

- Optimum operation with respect to energy consumption between 45 to $55 \mathrm{wt} \%$ solvent concentration

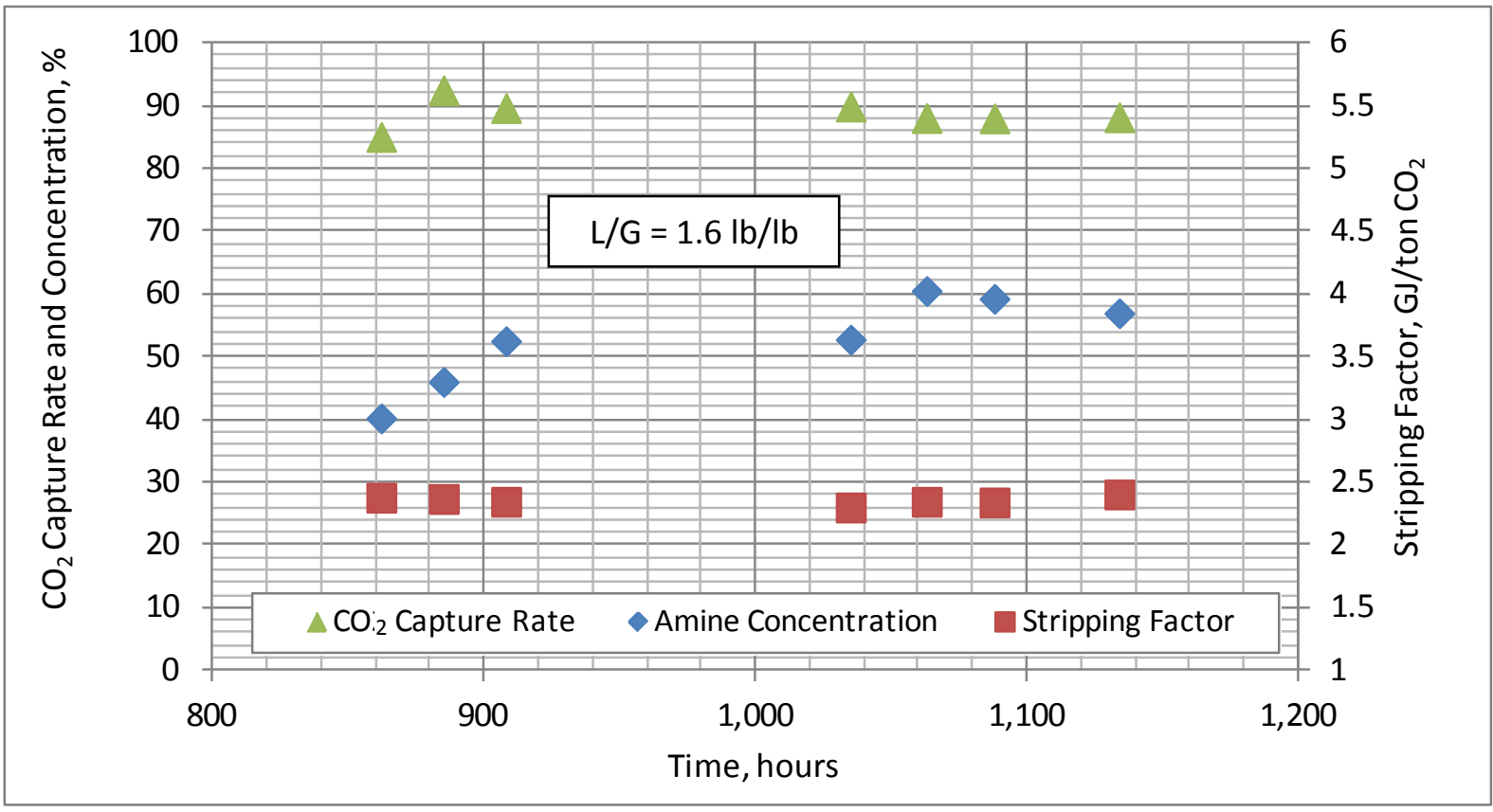

Figure 35. Variation of $\mathrm{CO}_{2}$ Capture Rate, Amine Concentration, and Stripping Factor.

\subsubsection{Liquid Analysis}

Samples from the amine loop, as well as from the pre-scrubber were taken and analyzed for anions, cations, and metals. This activity was handled jointly by NCCC and Cansolv 
Technologies. Figure 36 presents the change of anion concentrations over time in the lean solvent, as analyzed at Cansolv's laboratory in Montreal. Sulfate build-up in the solvent is related to the accumulation of sulfate salts (for example, sodium from the caustic scrubber) although there was also some $\mathrm{SO}_{2}$ slippage from the pre-scrubber. An average of $1.5 \mathrm{ppmv}$ of $\mathrm{SO}_{2}$ has been measured in the gas entering the absorber, although this is close to the lower detection limit of the ultraviolet $\mathrm{SO}_{2}$ analyzer used. In a similar way, the nitrate build-up is related to $\mathrm{NO}_{2}$ entering the absorber (average measured at 2 ppmv in the gas). No drop in performance was noticed as a result of this contamination.

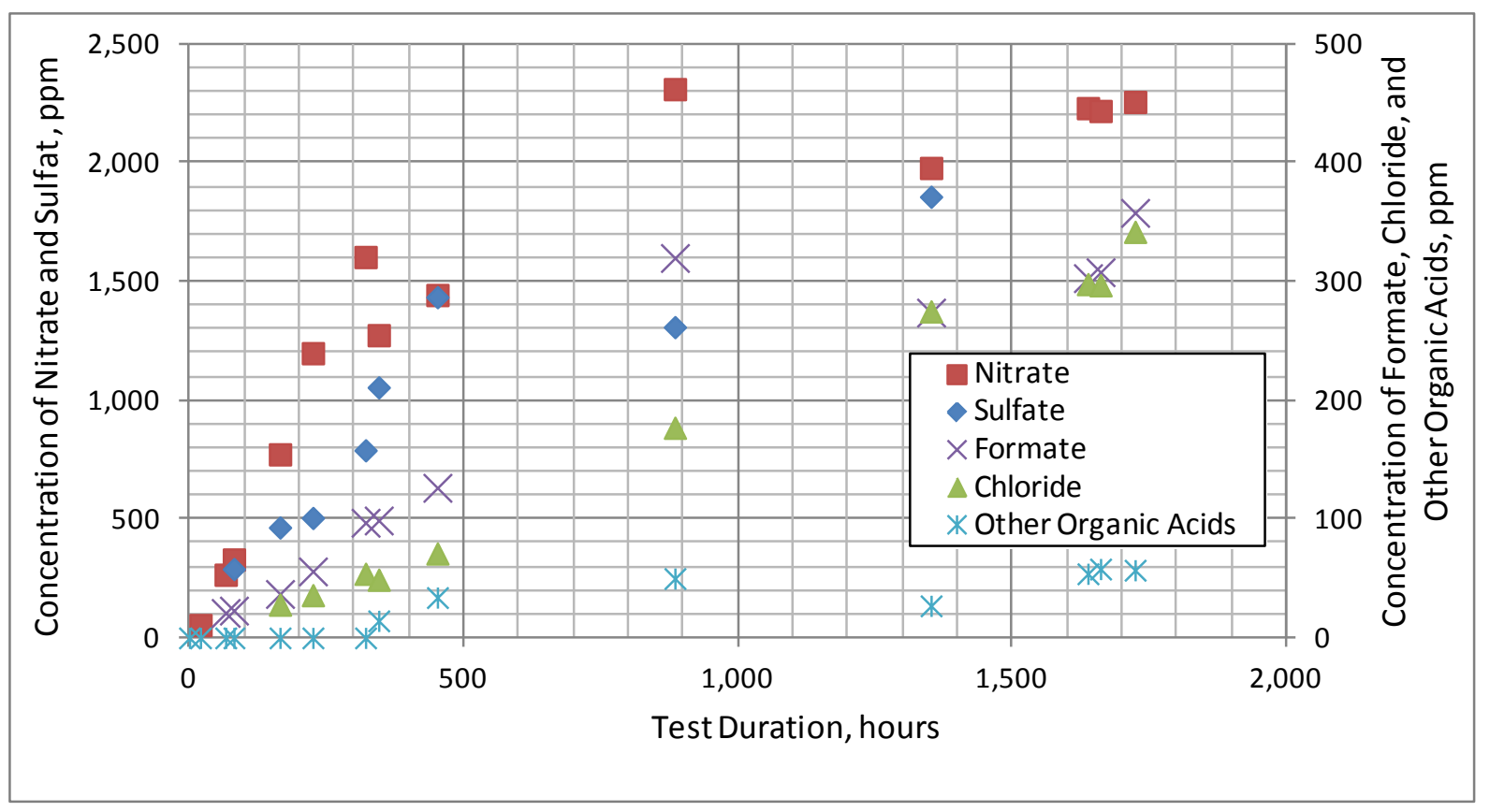

Figure 36. Increase of Anionic Species in Lean Solvent over Time.

Three main types of reaction are involved in the degradation of amine-based solvents:

- Oxidation of amine or hydroxyl functionalities, leading primarily to low molecular weight organic acids and ammonia

- Formation of heavier molecular weight species by coupling of two amine molecules (The product is still an amine and may have suitable $\mathrm{CO}_{2}$ absorption properties.)

- Irreversible reaction with $\mathrm{SO}_{2}$ leading to sulfonated neutral species

- Irreversible reaction with $\mathrm{CO}_{2}$, leading to the formation of non-alkaline compounds such as oxazolidone, imidazolidone, etc.

The increase in concentrations of formate and acetate gives a primary indication of the degradation rate of the solvent. After three months of testing, the total amount of organic acids was 500 ppmw in solution, which indicates a very low degradation rate of the DC-201 solvent under these conditions. It should be noted that some bleed-and-feed occurred during the test, mainly due to mechanical losses through automated sampling lines. 
Analysis of lean amine samples was also carried out by means of liquid chromatography coupled with mass spectroscopy. This technique allows for the detection of high molecular weight non-ionic degradation products. Although analysis of the samples has not yet been finalized, Figure 37 gives a preliminary indication of the degree of stability of the DC-201 solvent.

Comparison between lean amine samples taken at the start of testing and after 900 hours reveals a minor peak at a retention time of 11.5 minutes on the chromatograph. It is considered that this degradation peak represents only a minor portion of the total amine content, but further analysis is required to quantify the degradation products present.

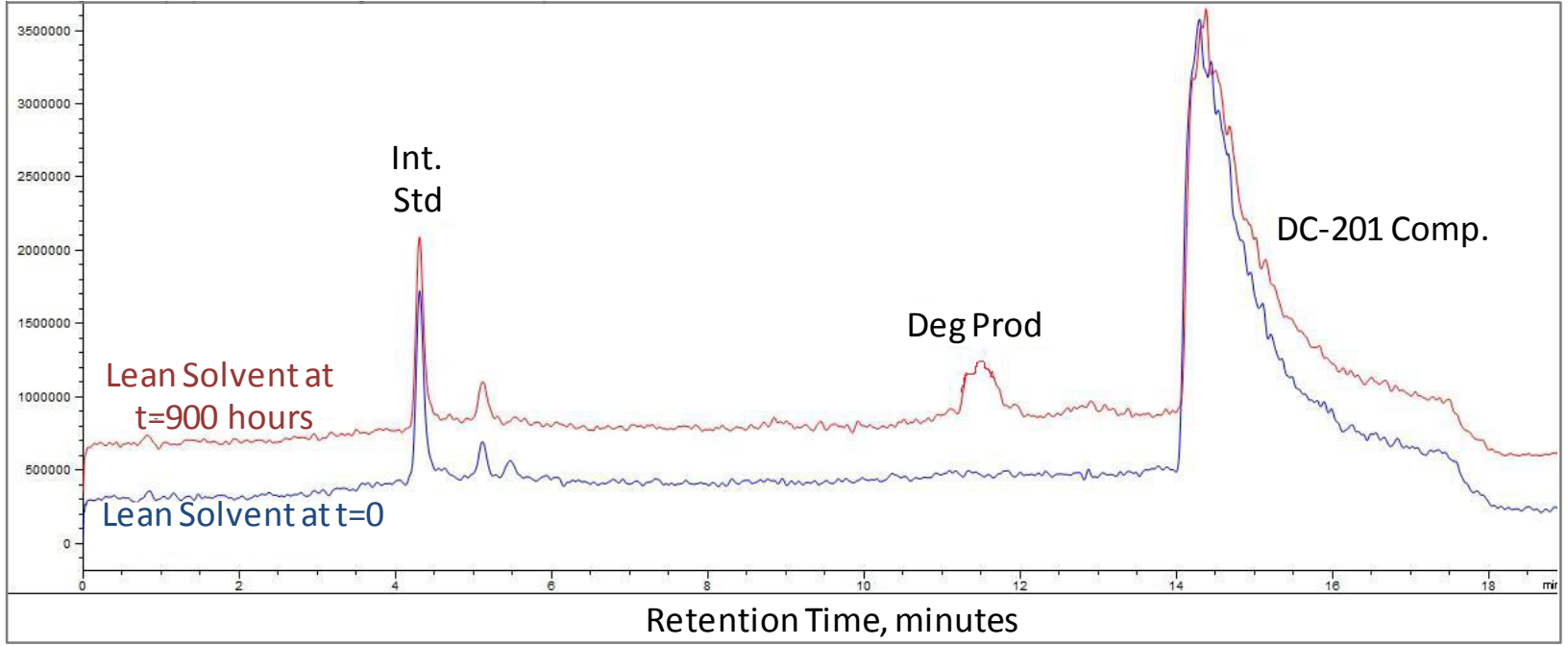

Figure 37. Chromatograph of Lean Cansolv Solvent Samples Taken at $t=0$ and $t=900$ Hours.

Analysis for metals was performed by Southern Research Institute at its Birmingham laboratory. Results are summarized below.

- Metals originating from the flue gas

o Selenium (2 ppmw in pre-scrubber loop after 1 month of testing)

o Arsenic (0.4 ppmw)

o Manganese (2 ppmw)

- Alkyl metals found in the pre-scrubber and the amine loops originating in the caustic and water used in the pre-scrubber

o Sodium (1.9 wt\% in the pre-scrubber and 79 ppmw in the solvent)

o Calcium (9 ppmw in the pre-scrubber and 3.5 ppmw in the solvent)

- Other metals found relating to the metallurgy of the system

o Iron (8 ppmw in the pre-scrubber and $1.1 \mathrm{ppmw}$ in the solvent)

0 Nickel (0.22 ppmw in the pre-scrubber and $0.08 \mathrm{ppmw}$ in the solvent)

0 Chromium (0.57 ppmw in the pre-scrubber and 0.07 ppmw in the solvent) 
These metals concentrations were much lower than for MEA, and were a good indication of the DC-201 solvent's lower corrosivity. For example, iron was measured at 137 ppmw in MEA (see Table 10), an order of magnitude higher than for DC-201.

Figure 38 plots the concentrations over time of other metals and cations detected in the lean solvent. Aside from the sodium and sulfur levels, no metals were found at sufficient levels to have any impact on the solvent $\mathrm{CO}_{2}$ capture performance.

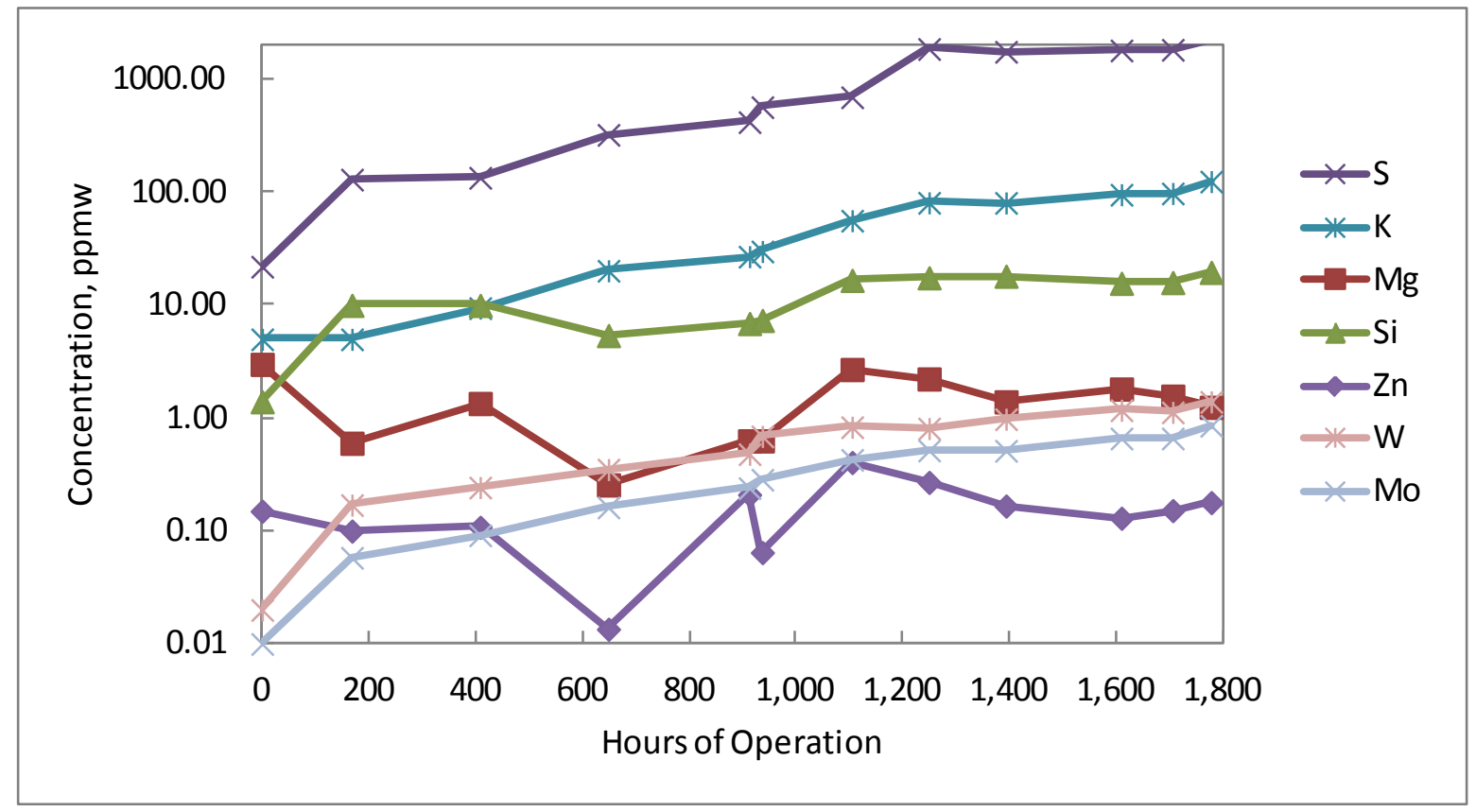

Figure 38. Change in Cations and Metals Concentrations in Lean Cansolv Solvent over Time.

\subsubsection{Gas Sampling}

Three emissions surveys were completed, with NCCC sampling at three locations: the $\mathrm{CO}_{2}$ depleted flue gas streams upstream of the absorber wash tower (outlet of absorber) and downstream of the absorber wash tower, and the $\mathrm{CO}_{2}$ product gas from the regenerator. Results are presented in Table 18. While analyses for nearly 50 different species were performed, only those with concentrations above the lower detection limit are reported.

Acetaldehyde, which typically comes from coal combustion gas, was detected at ppmv levels in the three streams. Formaldehyde, ammonia, and dimethylamine emissions result from the degradation of the solvent. The emissions level leaving the water-wash and in the product $\mathrm{CO}_{2}$ (were found to be low, in the ppmv to the sub-ppmv range. Nitrosamines were also detected, but at the ppbv level. It should be noted that additional analyses related to amine emissions are still pending and will be presented when they become available. 
Table 18. Main Contaminants Found in Gas Streams during Three Sampling Surveys.

\begin{tabular}{|c|c|c|c|c|c|c|c|c|c|}
\hline Outlet Sample Location & Abs & Wash & Regen & Abs & Wash & Regen & Abs & Wash & Regen \\
\hline Run Date & \multicolumn{3}{|c|}{$8 / 16 / 2012$} & \multicolumn{3}{|c|}{$9 / 25 / 2012$} & \multicolumn{3}{|c|}{$10 / 9 / 2012$} \\
\hline \multicolumn{10}{|c|}{ Concentration in flue gas, ppmv } \\
\hline Acetaldehyde & 5.51 & 9.83 & 5.33 & 5.22 & 5.26 & 4.94 & 5.7 & 5.51 & 5.47 \\
\hline Acrolein & 0.12 & 0.0146 & 0.124 & 0.069 & 0.03 & 0.115 & -- & -- & 0.047 \\
\hline Formaldehyde & 0.066 & 0.097 & 0.042 & 0.035 & 0.014 & 0.016 & 0.13 & 0.056 & 0.025 \\
\hline Ammonia & 0.732 & -- & -- & -- & -- & -- & 0.907 & 0.668 & -- \\
\hline THC as Hexane & -- & 0.479 & 0.941 & -- & -- & -- & -- & -- & 0.408 \\
\hline Dimethylamine & 0.738 & 0.951 & -- & 0.283 & 0.432 & 0.119 & 1.395 & 1.024 & -- \\
\hline \multicolumn{10}{|c|}{ Concentration in flue gas, ppbv } \\
\hline N-Nitrosodiethanolamine & -- & 0.078 & 0.206 & 0.041 & 0.014 & -- & -- & -- & -- \\
\hline N-Nitrosodimethylamine & 52.1 & 26.7 & -- & 0.718 & 0.339 & 0.112 & 4.081 & 1.234 & 0.205 \\
\hline
\end{tabular}

\subsubsection{Preliminary Conclusions}

During the 1,725-hour test campaign, the Cansolv DC-201 solvent demonstrated:

- The targeted 90 percent $\mathrm{CO}_{2}$ capture rate

- 50 percent reduction in solvent flow compared to MEA

- 35 percent reduction in energy consumption compared to MEA

- Minimal effect of solvent concentration on performances

- Minimal degradation under oxidative environment, including effect of $\mathrm{SO}_{2}$ and $\mathrm{NO}_{2}$

- Low emissions upstream and downstream of water-wash section

- Low corrosion rates

Additional data processing and sample analysis are pending in order to complete a final report.

\subsubsection{Future Testing with Natural Gas-Simulated Flue Gas}

Cansolv has identified value in testing at lower flue gas $\mathrm{CO}_{2}$ concentrations that are representative of those from natural gas combined cycle plants. This can be achieved by introducing air into the flue gas upstream of the blower. The proposed scheme was reviewed with Cansolv personnel and a cost estimate for the work prepared. The lower $\mathrm{CO}_{2}$ flow requires that the solvent flow also be reduced, and this could result in either flooding or insufficient wetting of the packing. The NCCC contracted the technology firm Sulzer for consultation to assess any effects upon absorber operation and recommend any necessary design or operational changes. The simulated natural gas run is planned to begin in the third quarter of 2013. 


\subsection{Chiyoda Solvent}

Based on its experience as a worldwide engineering, procurement, and construction contractor, the Chiyoda Corporation is focusing on suitable commercial plant designs for low carbon emissions. As part of this effort, Chiyoda has been developing an advanced amine solvent in conjunction with an optimized $\mathrm{CO}_{2}$ capture process. After equipment modifications to the PSTU requested by Chiyoda were completed, testing of the T-3 solvent began in December 2012. Chiyoda plans to continue testing into mid-2013, completing parametric testing and long-term operation. The design modifications to the PSTU requested by Chiyoda, illustrated in Figure 39, were as follows:

- Adding piping to recirculate cold-rich solvent back to different levels in the absorber. As the absorption rate for the T-3 solvent is slower than for MEA, in once-through operation the solvent leaving absorber is not fully loaded. Recycling solvent increases rich solvent $\mathrm{CO}_{2}$ loading, reducing solvent flow to the regenerator for a given capture rate and lowering the heat of regeneration. The recycled flow might also help to flatten the vertical temperature profile in the absorber, which would also improve performance.

- Installing new piping to the regenerator to allow the hot-rich solvent to be introduced at the top of the lower level of packing instead of at the top of the column. This modification was initiated to address the concern about excess solvent carryover from the regenerator. The top bed will be flushed by the condensate return, and this will help suppress solvent carryover.

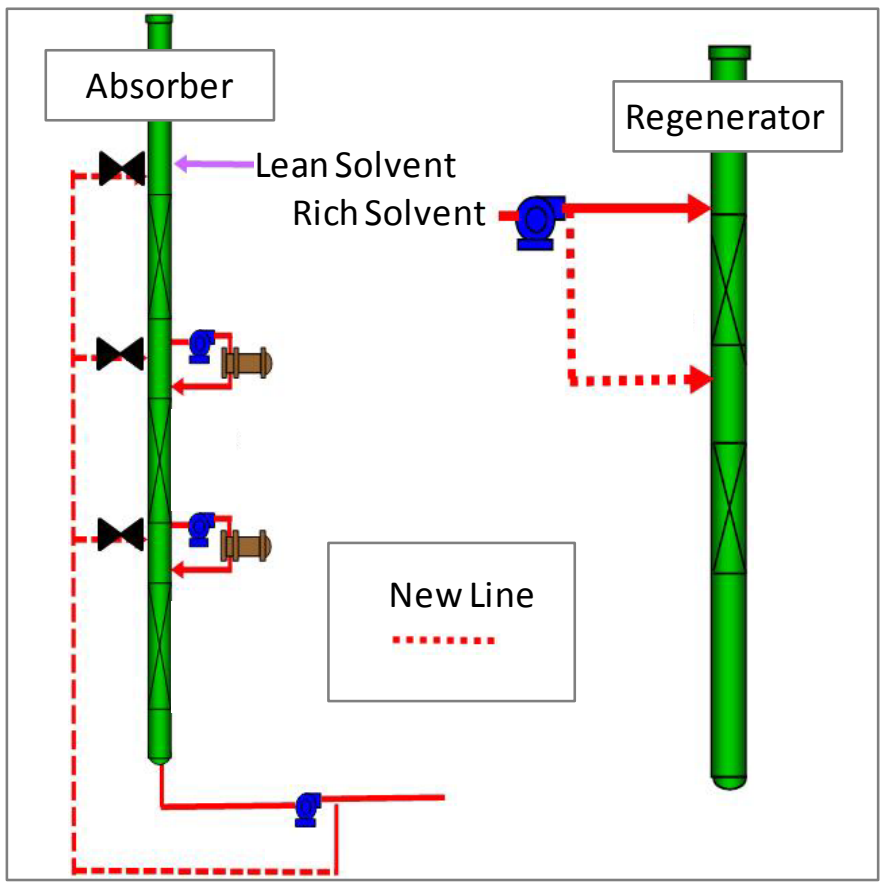

Figure 39. Modifications to PSTU Requested by Chiyoda.

The initial operation in December was truncated due to foaming in the wash tower, which resulted in a high pressure drop across the packing and the loss of solvent with the $\mathrm{CO}_{2}$-depleted 
flue gas. There was no evidence that foaming had occurred in the absorber or regenerator. Testing was planned to resume in January following a Gaston Unit 5 outage. Meanwhile laboratory tests to understand and prevent foaming will be carried out.

\subsection{MTR 1-ton/day $\mathrm{CO}_{2}$ Capture Membrane Skid}

In addition to pre-combustion applications, MTR's polymeric Polaris ${ }^{\mathrm{TM}}$ membrane is being tested for separating $\mathrm{CO}_{2}$ from coal-derived flue gas. In October 2008, in response to a solicitation, the DOE awarded \$3.4 million to MTR to build a 50-kW equivalent postcombustion capture unit and conduct a six-month field test at Arizona Public Service's Cholla coal-fired power plant near Phoenix, Arizona. Testing ran from April to July 2010, and based on the operating experience and the data collected, an improved unit was designed for testing at the NCCC.

The membrane test skid, shown in Figure 40, includes two membrane module designs required for commercial units, cross-flow membrane (CFM) and countercurrent-swept membrane (CSM) modules. The skid processes 250,000 scf/day of flue gas drawn from downstream of the prescrubber, and is designed to capture one ton/day of $\mathrm{CO}_{2}$ with a capture efficiency of 90 percent.

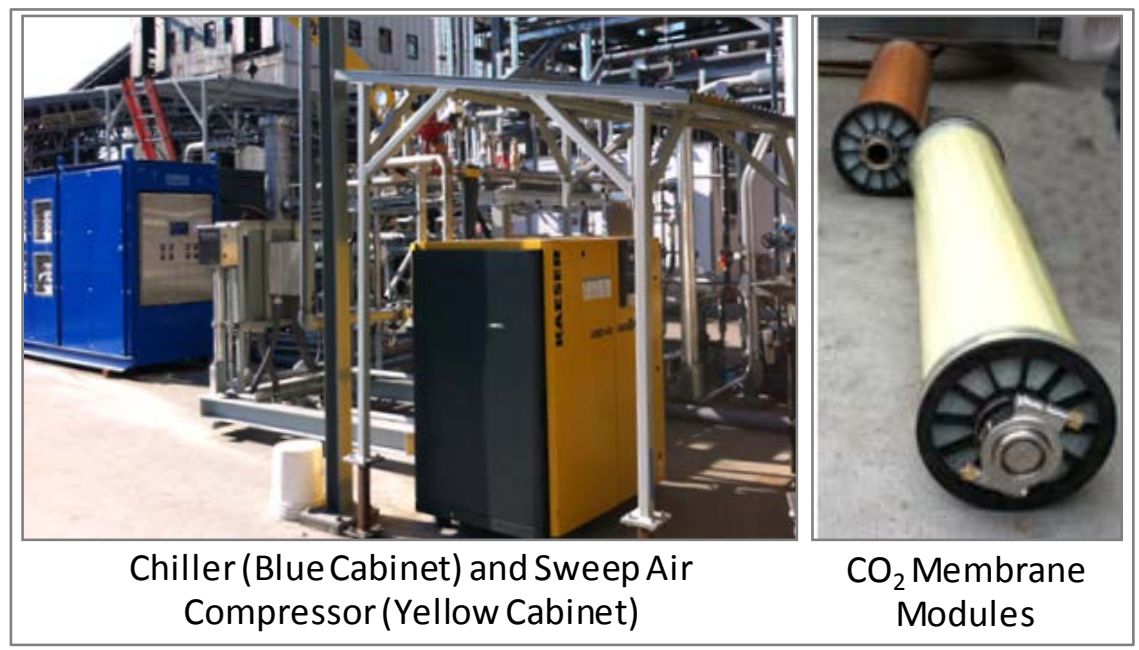

Figure 40. MTR 1-ton/day $\mathrm{CO}_{2}$ Membrane Components.

Figure 41 is a schematic of the skid. The incoming flue gas is cooled by chilled water, and the condensate is removed in the separator upstream of the flue gas compressor (oil-free screw design). The flue gas leaves the compressor at around $300^{\circ} \mathrm{F}$ and 45 psia before being cooled to around $100^{\circ} \mathrm{F}$ by chilled water. The condensate is removed in a separator, which also includes a coalescing filter, before the flue gas passes to the two first-stage membrane vessels. Each vessel contains two CFM membranes connected in series, individual membranes being 8-inches OD by 39-inches long. Two second-stage membrane vessels each contain a single CSM membrane, also 8-inches OD by 39-inches long. The chilling circuits are not expected to be included in commercial designs and are used on the test skid to vary inlet flue gas conditions as part of parametric testing. 


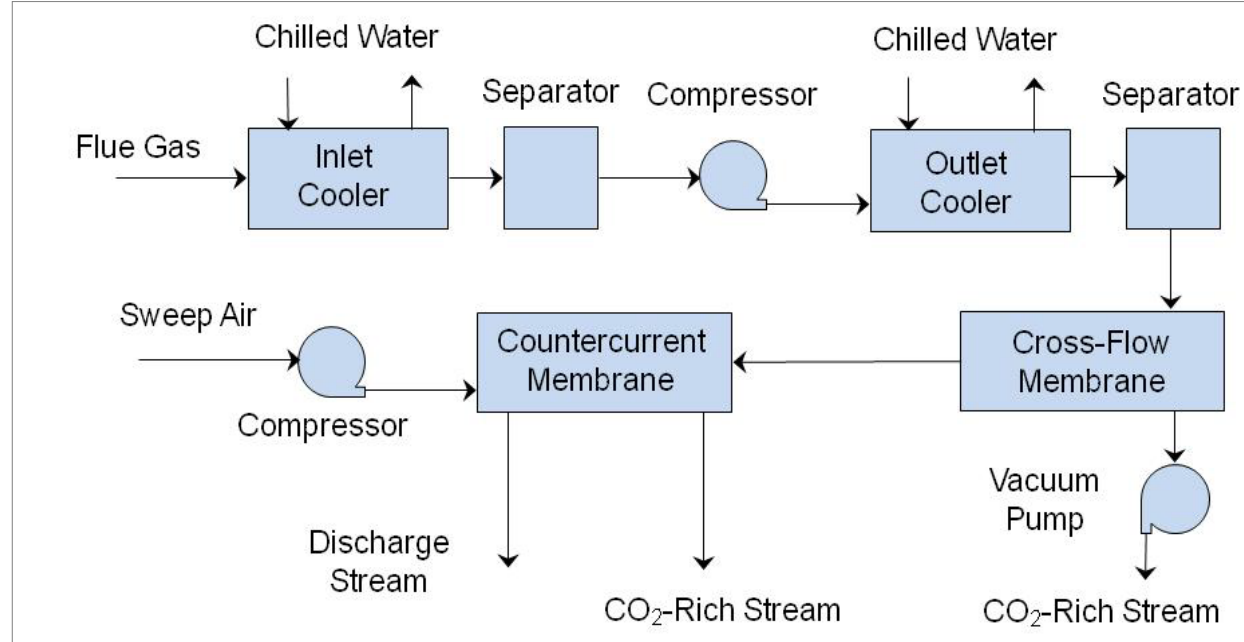

Figure 41. Schematic of MTR Flue Gas Membrane Skid.

A vacuum pump on the permeate side of the first-stage membrane increases the pressure driving force to increase the amount of $\mathrm{CO}_{2}$ removed to as high as 70 percent. The second-stage membrane extracts additional $\mathrm{CO}_{2}$ from the residual flue gas by using sweep air on the permeate side to increase the concentration driving force. The additional removal is sufficient to increase the $\mathrm{CO}_{2}$ capture efficient to 90 percent or higher.

The arrangement of the membranes is shown schematically in Figure 42. The flue gas leaving the separator (A) is split before entering two CFM vessels in parallel. The two $\mathrm{CO}_{2}$-depleted flue gas streams, still at pressure, are recombined (C) then split again before entering two CSM vessels in parallel. Sweep air (D) enters each CSM vessel and the $\mathrm{CO}_{2}$-rich air (E) leaves at the opposite end. The $\mathrm{CO}_{2}$-rich permeate streams (B) leaving the CFM vessels are the product stream and the $\mathrm{CO}_{2}$-lean flue gas streams (F) leaving the CSM vessels are the reject stream. All flows are eventually re-combined and passed to the return header.

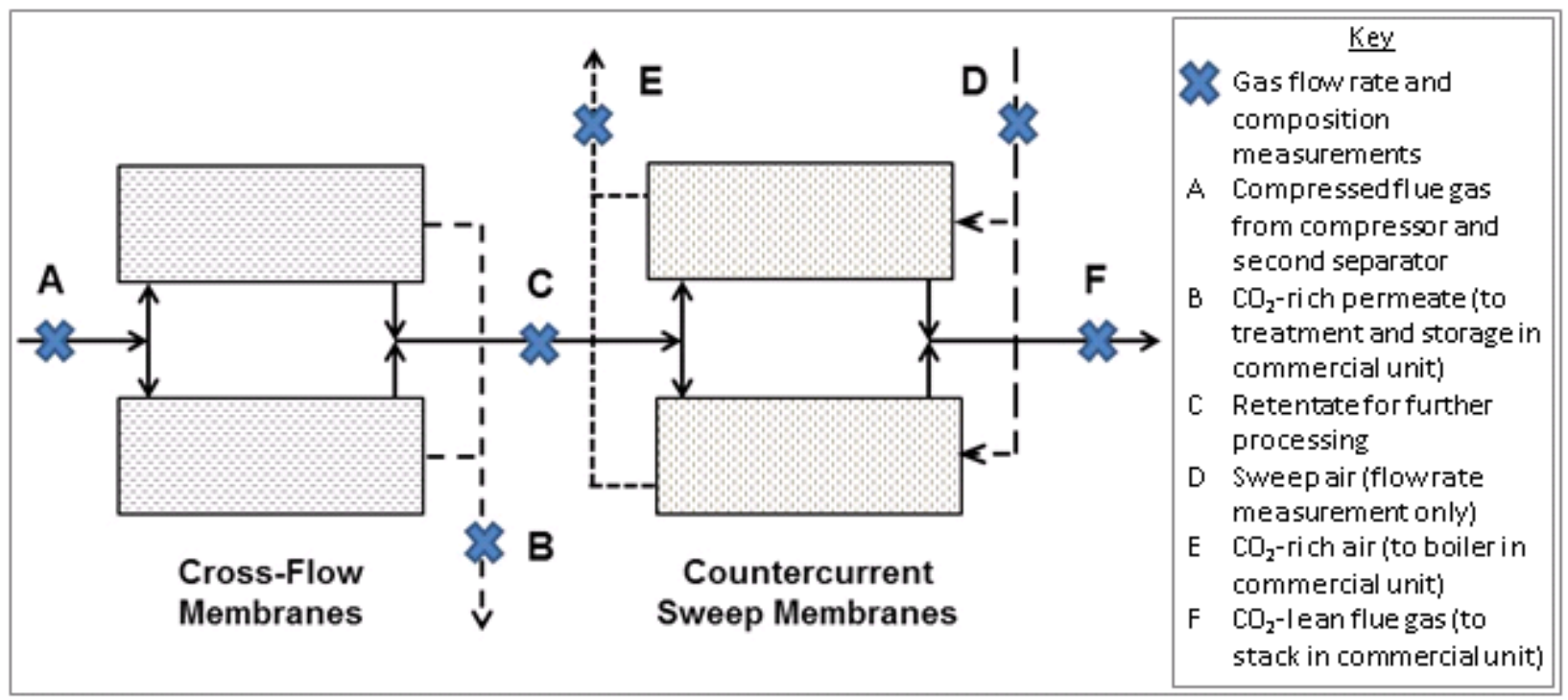

Figure 42. Schematic Showing MTR Membrane Skid Gas Flows. 
Commissioning of the skid was completed in December 2011 prior to shutdown for the holiday period. It operated for two days in mid-January before Unit 5 was placed in marginal reserve until early March. During restart of the membrane, the carbon-steel compressor rotor was unable to turn and was found to have rusted and seized on the casing. The corrosion almost certainly occurred because of the humid conditions within the compressor and could possibly have been avoided if it had been purged with dry gas during the extended outage.

A replacement rotor was ordered and installed. The supplier does not provide a stainless rotor for this size of compressor, so the replacement was carbon steel. A compressor bypass line was added to allow testing to continue in case of future compressor issues. A service technician also came to site and made several repairs and adjustments to improve chiller performance to further reduce flue gas humidity at the compressor inlet.

The system was restarted in April. Although operational, the chiller still had difficulty in achieving the membrane inlet flue gas design temperature of $50^{\circ} \mathrm{F}$. The heat exchanger was sized for the inlet flue gas temperature at Cholla, $90^{\circ} \mathrm{F}$; however, the corresponding temperature at the NCCC is typically between 120 and $150^{\circ} \mathrm{F}$, depending on the PSTU blower load. To reduce cooling duty, the compressor bypass line was used to recirculate half of the $1,000 \mathrm{lb} / \mathrm{hr}$ cooled flue gas back to the compressor inlet so that only $500 \mathrm{lb} / \mathrm{hr}$ of hot flue gas was drawn from the header. Previously, the excess flow was vented.

Flue gas recirculation reduced the inlet temperature to the membrane by about $5^{\circ} \mathrm{F}$. To further reduce temperature, MTR decided to use process cooling water to cool the flue gas downstream of the compressor, allowing all the chilled water to be supplied to the cooler upstream of the compressor. In September, some chiller components failed, and as the chiller is not included in the commercial design, it was removed from service. After this, all cooling was achieved by process cooling water.

In May 2012, the two-stage membrane skid was operating steadily, reducing the $\mathrm{CO}_{2}$ from about 12 vol\% in the flue gas to about 5 vol\% in the $\mathrm{CO}_{2}$-depleted discharge stream. This corresponds to around 60 percent $\mathrm{CO}_{2}$ capture. In early June, two new CSM modules were installed with higher $\mathrm{CO}_{2}$ permeance membrane material and configured for improved flue gas flow distribution. These improvements lowered the $\mathrm{CO}_{2}$ content in the $\mathrm{CO}_{2}$-depleted stream to around 3 vol\%, corresponding to $\mathrm{CO}_{2}$ capture of approximately 87 percent.

The system was shut down at the end of July to perform routine maintenances on all rotating equipment (i.e., vacuum pump, sweep air compressor, and flue gas compressor). The flue gas compressor would not turn upon attempted restart, and as in March, the rotor had rusted and seized on the casing. After evaluating various options, instead of replacing the rotor, MTR decided to install a liquid-ring compressor, which is designed to handle harsh gas conditions and is available in stainless steel.

Further inspection of the compressor showed that, in addition to corrosion, significant dark/yellowish materials were deposited in the compressor discharge line and to a much lesser degree in the inlet. The deposits were mainly water soluble, and the insoluble material was filtered from the solution. Figure 43 provides photographs of these deposit materials. 


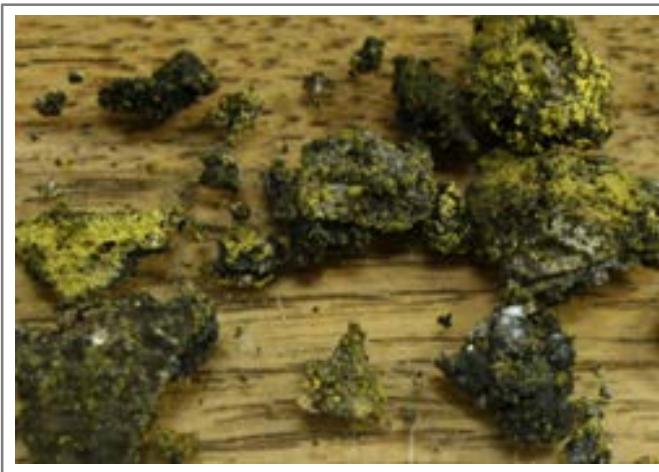

Deposits from Compressor Outlet

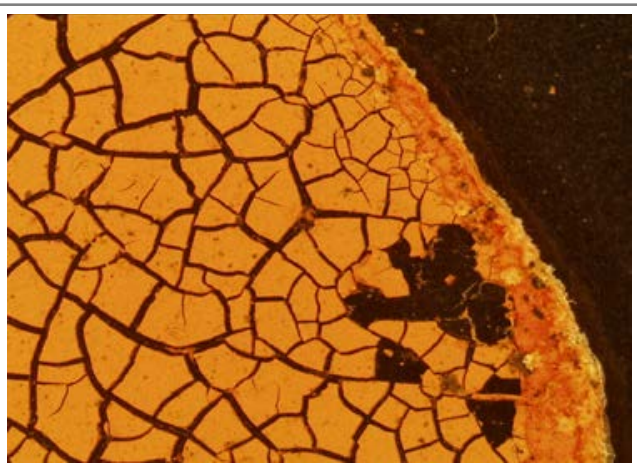

Particulate Filtered from Solution

Figure 43. Deposits in Compressor Outlet and the Filtrand from the Solution made by Deposits.

The three materials (deposit, solution, and filtrand) were each analyzed, and findings are given below.

- Energy-dispersive X-ray spectroscopic (EDX) analysis showed the deposits to consist primarily of oxygen, carbon, and sulfur with lesser amounts of iron, silicon, sodium, magnesium, and aluminum.

- EDX analysis showed the filtrand to consist primarily of oxygen, iron, and sulfur with lesser amounts of carbon, silicon, sodium, magnesium, calcium, phosphorous, and aluminum. As it is insoluble, the iron is assumed to be present as a ferric compound.

- Analysis of the solution by ion chromatography showed that ammonium and sulfate ions were present. Inductively coupled plasma mass spectrometry analysis showed the predominant metal to be iron. As it is soluble, the iron is assumed to be present as a ferrous compound.

Based on these analyses, the deposit was determined to consist of:

- Around $18 \mathrm{wt} \%$ ammonium sulfate and/or bisulfate-This determination was made assuming double sulfates of ammonium with iron (alums) are not formed.

- Around $53 \mathrm{wt} \%$ iron sulfate, an approximate 50:50 mix of ferrous and ferritic salts-The iron salts are considered to be formed as a corrosion product from the reaction of the ammonium salts (which are acidic) with the iron present in the compressor exit pipe work.

- Of the remaining $29 \mathrm{wt} \%$, approximately half is carbon and the other half consists of elements found in fly ash (e.g., silicon, sodium, and magnesium).

The deposits are similar to those formed in the baskets of air heaters, but the question arises as to how the ammonia penetrated Unit 5's wet FGD and the PSTU's caustic pre-scrubber. It is hypothesized that some of the $\mathrm{SO}_{3}$ aerosol formed in the boiler and across the SCR unit (where ammonia is injected to promote NOx reduction) is present as an ammonium compound, not as a 
free radical. Measurements by others suggest the aerosol is below 0.1 microns and extremely difficult to remove from the gas stream.

A second question is why the aerosol dropped out after the compressor. Up to this point, the gas has been saturated and all surfaces wetted. Compression raises the gas temperature and lowers the saturation level. The higher temperature also increases the stickiness of ammonium sulfate/bisulfate, which then sticks to the dry surface present after the compressor.

Whether the deposits formed over a period of time, or as a consequence of an upset in the power plant is not known. Inspections of the compressor outlet in March did not reveal anything obvious, but this was after only a limited number of operating hours.

Particulate material was also found in the coalescing filter downstream of the compressor. EDX analysis indicated the presence of sulfur, iron, silicon, magnesium, phosphorous, selenium, and chlorine. This material may have been carried over from the deposits in the compressor outlet and if not removed would have passed to the membranes. If correct, this material would be eliminated if the compressor outlet deposit did not form. In the liquid ring compressor, cooling water comes into direct contact with the flue gas, which will prevent dry surfaces being created onto which the deposit can form. Moreover, any deposit that might form would rapidly dissolve in the water.

During the August outage, two CFM modules (one from each vessel) were removed for inspection by MTR. These that had been in operation since the beginning of testing in December 2011 and had been exposed to flue gas for almost 1,500 hours with some additional hours on air when flue gas was not available. No particulate was found on either end of the membranes (see Figure 44) or within the membrane envelopes (see Figure 45). Membrane performance did not degrade with time or with pressure drops increase, suggesting that the pretreatment system worked effectively and prevented fouling of the membranes by flue gas contaminants.

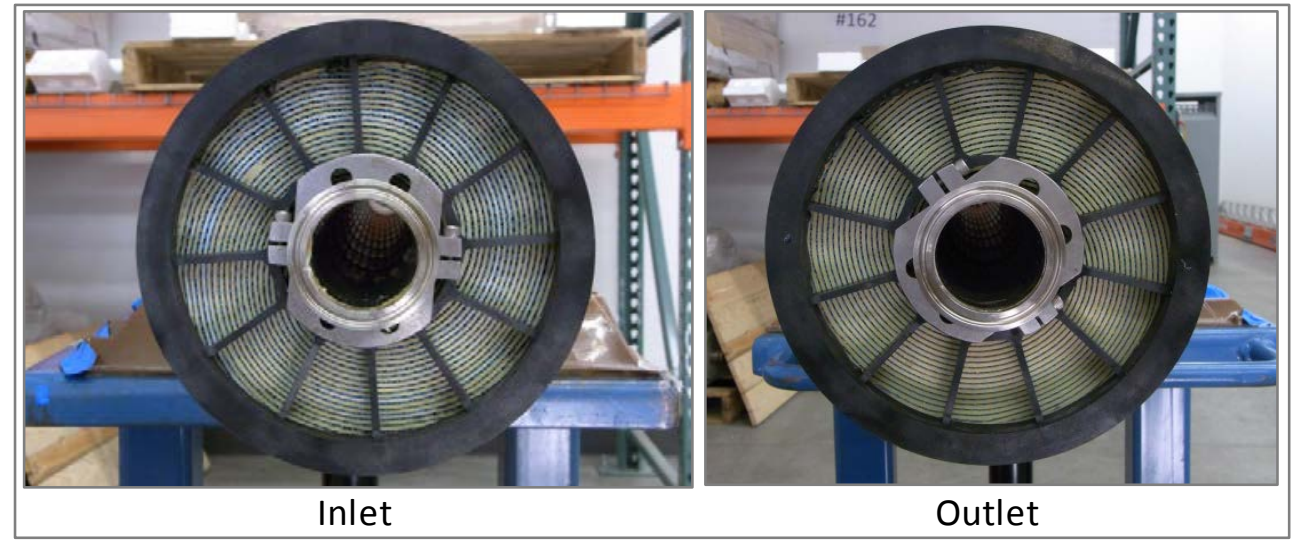

Figure 44. Inspection of MTR Membrane. 


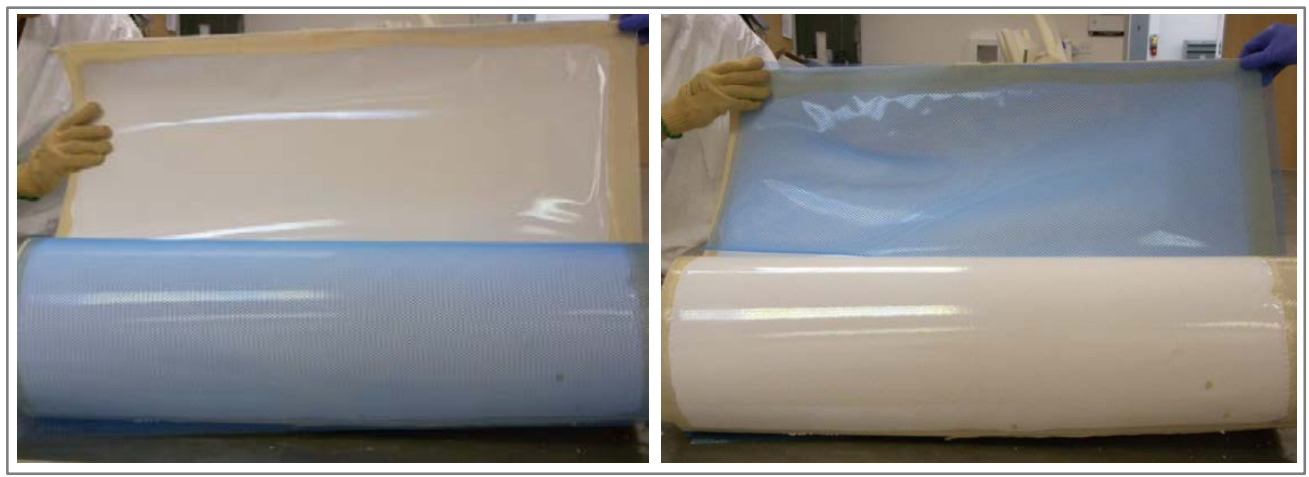

Figure 45. Inspection of Membrane Sheets and Feed Spacer of MTR Module.

The membrane was put back in operation in September with just two first-stage CFM membranes and with the flue gas compressor bypassed. The driving force for $\mathrm{CO}_{2}$ permeation was from the PSTU blower on the feed side (sufficient to overcome the pressure drop across the entire membrane system) and the vacuum pump on the permeate side of the CFM module. This mode of operation provided useful operational experience, as a flue gas blower may be used on commercial systems. Near the end of September, the chiller failed, and the switch to process cooling water was made.

The liquid-ring compressor was delivered on October 29, set in the location occupied by the previous compressor, and the flue gas piping modified accordingly. Two cooling water lines were also installed to the new compressor, and a new cooling water line was installed to provide cooling duty previously provided by the chiller. A full set of six new membrane modules were also installed, two modules in series in each CFM vessel, and a single membrane module in each CSM vessel. Local flow gauges on the permeate and reject streams were replaced with transmitters to facilitate continuous collection of flow rate data, and program logic was written to start, stop, and operate the new compressor.

The system was successfully restarted on December 14 and ran for about 100 hours before being shut down on December 18 due to an outage on Unit 5. The $\mathrm{CO}_{2}$ content of the flue gas feed was reduced from about 12 percent to around 1 percent in the residual stream leaving the skid, corresponding to $\mathrm{CO}_{2}$ capture greater than 90 percent. This is an improvement over the previous capture efficiency of 87 percent and indicates the continuing improvements being made in membrane performance.

\subsection{MTR 20-ton/day $\mathrm{CO}_{2}$ Capture Membrane Skid}

MTR is currently working to install a 20-ton/day $\mathrm{CO}_{2}$ membrane test skid based on the 1-ton/day $\mathrm{CO}_{2}$ system test results. During 2012, NCCC engineers participated in several design reviews at NETL, reviewed the system process, design, and layout, and began design on the preliminary routing of the new flue gas line.

Lessons learned from the operation of 1-ton/day unit provided valuable inputs to the 20-ton/day system design changes. Some of the critical skid modifications included equipment rearrangement to fit the skid to the footprint available at PC4, addition of a Venturi scrubber 
upstream of the compressor, replacement of a screw compressor with a liquid ring compressor, and provision of additional instrumentation for better monitoring and control. The skid delivery is currently scheduled for the first quarter of 2014.

\subsection{Codexis Enzymes}

In May 2010, Codexis received \$4.7 million from ARPA-E to investigate the use of carbonic anhydrase enzymes to accelerate the rate of $\mathrm{CO}_{2}$ capture for solvents that have desirably low heats of reaction such as methyldiethanolamine (MDEA), ammonia, and potassium carbonate. The enzyme is mixed with the solvent and so must be resistant to decomposition at regeneration temperatures. Thus, a major objective of this ARPA-E funded research was to demonstrate the stability of the enzyme under operating conditions.

Previous testing on the enzyme technology was conducted with synthetic flue gas in bench-scale stirred cell reactors and a wetted wall column and in a pilot-scale with the Codexis Test Unit (shown in Figure 46). The tests at the PC4 were the first using coal-derived flue gas to determine the stability of the enzyme in the presence of trace contaminants.

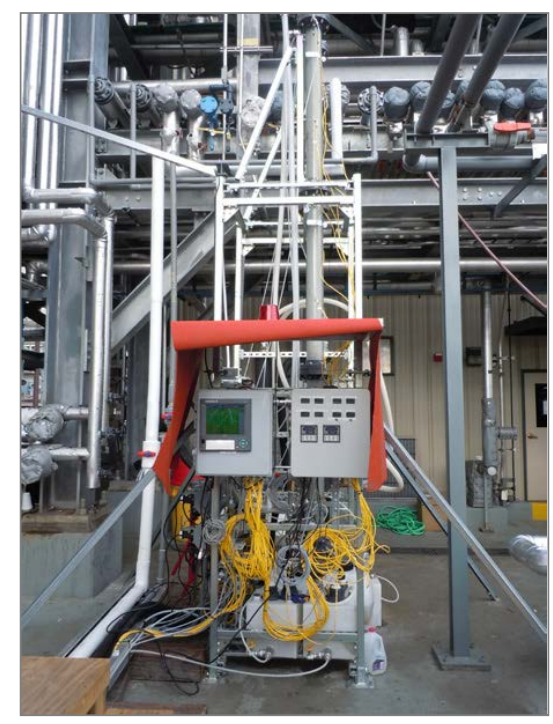

Figure 46. Codexis Enzyme Test Unit Installed at the PC4.

The Codexis Test Unit consists of absorber columns and a desorber tank. Both absorber columns are over 20 feet tall with a 4-inch internal diameter. The absorber contains loose packing while the desorber is an open vessel without packing. The flue gas flow is 850 standard $\mathrm{ft}^{3} / \mathrm{hr}$, the solvent flow rate is $260 \mathrm{lb} / \mathrm{hr}$, and the $\mathrm{CO}_{2}$ removal rate is $14 \mathrm{lb} / \mathrm{hr}$.

NCCC staff completed the design and construction necessary to accommodate the Codexis Test Unit for initial exposure of the solvent and enzymes to flue gas. Commissioning and testing were completed in a two-week period at the end of May using MDEA. Figure 47 provides trends of the operation over a six-day period with $\mathrm{CO}_{2}$ capture averaging around 65 percent at a rate of capture over 25 times greater than for MDEA alone with $0.2 \mathrm{~g} / \mathrm{L}$ of enzyme loading. No 
apparent effect of trace metals or elevated process temperatures on enzyme performance was seen.

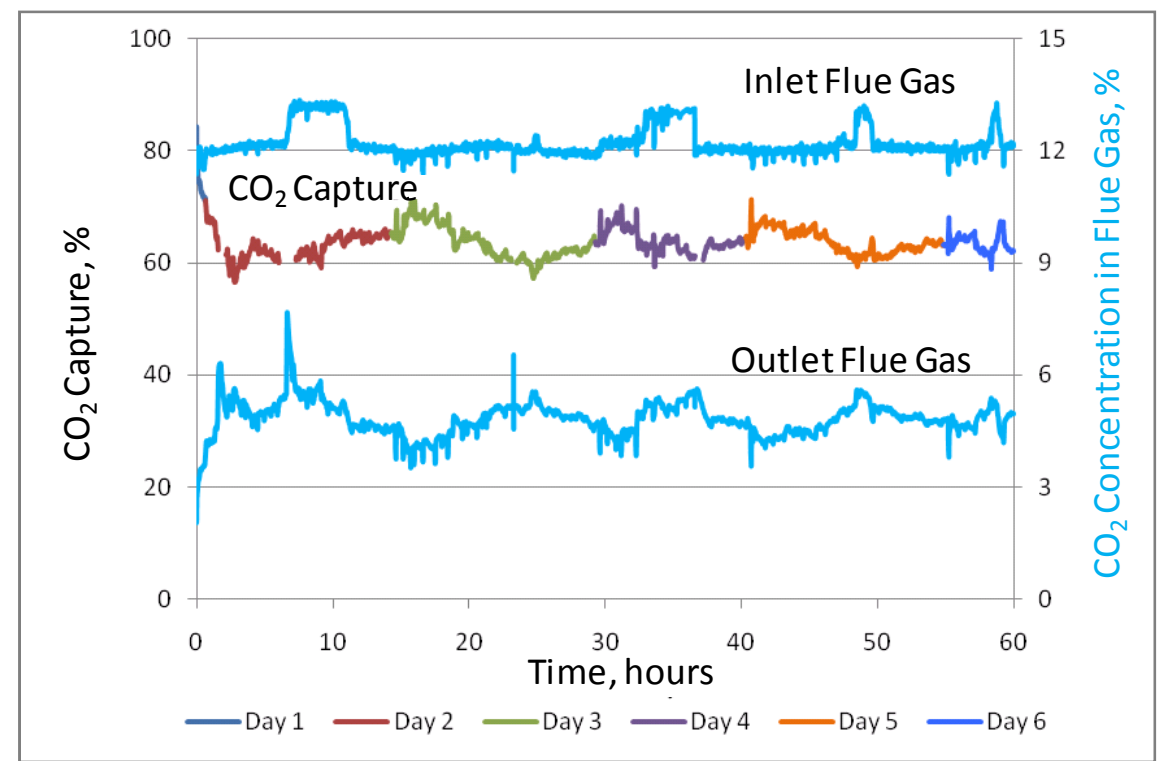

Figure 47. Results of Codexis Enzyme Testing.

Although Codexis has plans to test their carbon capture technology in a larger system (e.g., the PSTU) using the enzyme-accelerated MDEA solution, they have yet to receive the funding to do any additional work.

\subsection{Akermin Enzymes}

Akermin is developing a carbonic anhydrase enzyme to accelerate the capture of $\mathrm{CO}_{2}$ by potassium carbonate, a widely available low-cost commodity chemical. Unlike most amine solvents, potassium carbonate is non-volatile, does not degrade in the presence of oxygen, $\mathrm{SO}_{2}$ and other impurities, and has low corrosivity. These properties lower the cost of wash towers and solvent clean up equipment, and eliminate the need for corrosion inhibitors. Although the heat of reaction is half that of MEA, the potassium carbonate reaction with $\mathrm{CO}_{2}$ (below) is much slower, hence the need for the enzyme to improve the kinetics.

$$
\mathrm{CO}_{2}+\mathrm{H}_{2} \mathrm{O}+\mathrm{K}_{2} \mathrm{CO}_{3} \leftrightarrow 2 \mathrm{KHCO}_{3}
$$

The enzyme is embedded in a thin polymer film on the surface of the absorber packing and is referred to as being immobilized. This avoids transferring the enzyme into the high-temperature stripper column where it can potentially thermally decompose.

Akermin completed laboratory testing at its St. Louis site and constructed a pilot plant to process $88 \mathrm{lb} / \mathrm{hr}$ of flue gas. The NCCC performed design and installation of flue gas supply/return and utilities. In addition, heat tracing modifications were made within the Akermin skid, and Ethernet connections to operator stations in the control room were installed. Figure 48 provides a photograph of the pilot plant installed at the PC4. Checkout and commissioning of the pilot plant was completed in December 2012. Testing is planned to proceed to mid-2013. 


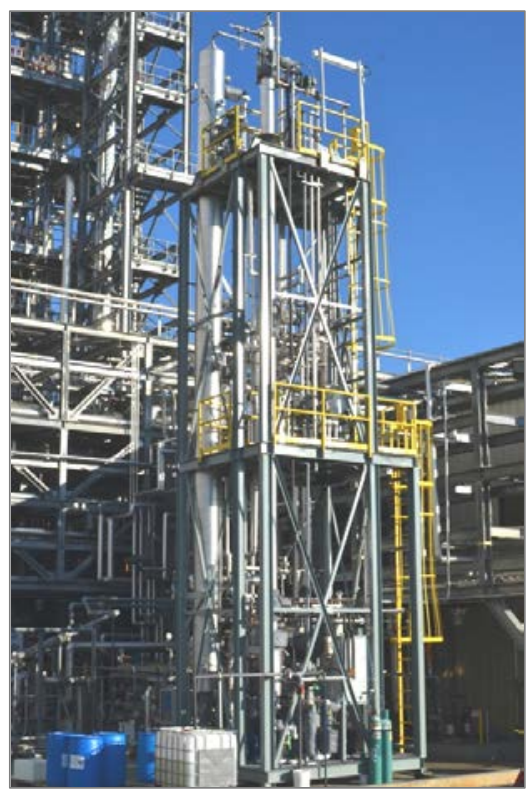

Figure 48. Akermin Enzyme Pilot Plant Installed at the PC4.

\subsection{Engineering Studies}

The NCCC's Engineering and Economic Evaluations group began work on a post-combustion $\mathrm{CO}_{2}$ capture (PCC) baseline study. In collaboration with NETL and the Electric Power Research Institute (EPRI), a study basis and scope was developed and finalized. NETL provided a process simulation model of a pulverized coal (PC) unit using AspenPlus software, and this model served as the starting point for the modeling work completed by the study. The model was expanded to include post-combustion flue gas cleanup processes and $\mathrm{CO}_{2}$ compression. Validation of the model against data from MEA solvent tests at the PC4 and against Southern Company steam cycle data resulted in significant expansion and modification of the model.

As an example of optimization efforts during this study, fourteen heat and material balances were computed to determine the optimum lean solvent loading and regenerator pressure for MEA. Heat integration was optimized starting with methods suggested by EPRI in a 2011 study on a pulverized coal unit with post-combustion cleanup. The condensation of sulfuric acid on the heat exchanger surfaces was investigated to determine the appropriate heat exchanger material of construction. An investigation was conducted on the impact of MEA concentration, operating temperature, and $\mathrm{CO}_{2}$ loading on corrosion, oxidation degradation, and polymerization. The engineering firm WorleyParsons was contracted to provide a capital cost estimate for the amine system of plant. The PCC study was nearly completed in 2012, and four cases will be reported in early 2013.

An economic evaluation was completed comparing PRB coal and an Illinois bituminous coal in a PC+PCC plant based on different flue gas cleanup technology to provide equivalent amine slip. It was determined that bituminous coal gives a lower cost of electricity. An investigation was also conducted of the thermodynamic feasibility of pressurized coal drying for very high moisture coals. 
Over the course of 2012, the NCCC migrated its process simulation software from AspenTech to ChemCAD software from ChemStations. Work was begun to establish a design basis for a NCCC system study of using membranes for post-combustion $\mathrm{CO}_{2}$ capture and to establish a relationship between DOE and ChemStations that will allow DOE's membrane unit operations model to be integrated into CHEMCAD software. 


\subsection{GASIFICATION}

The NCCC gasification process, represented in Figure 49, features several key components of an IGCC plant. These include high pressure solids feed systems; a Transport Gasifier; syngas coolers; a hot gas filter vessel, the PCD; and continuous ash depressurization systems for ash cooling and removal. During the year, the gasification process operated over two test runs, R08 and R09, for a total of more than 1,250 hours. Progress continued on the development of the pressure decoupled advanced coal (PDAC) feeder, gasifier control automation, sensors, and instrumentation. Run R08 included a 219-hour test period of co-feeding biomass with coal in oxygen-blown gasification conducted on behalf of CCAT, and R09 featured testing of Stanford University's TDL sensor. At the conclusion of R09, the gasification process had operated for over 18,000 total hours with over 2,000 hours in oxygen blown operation.

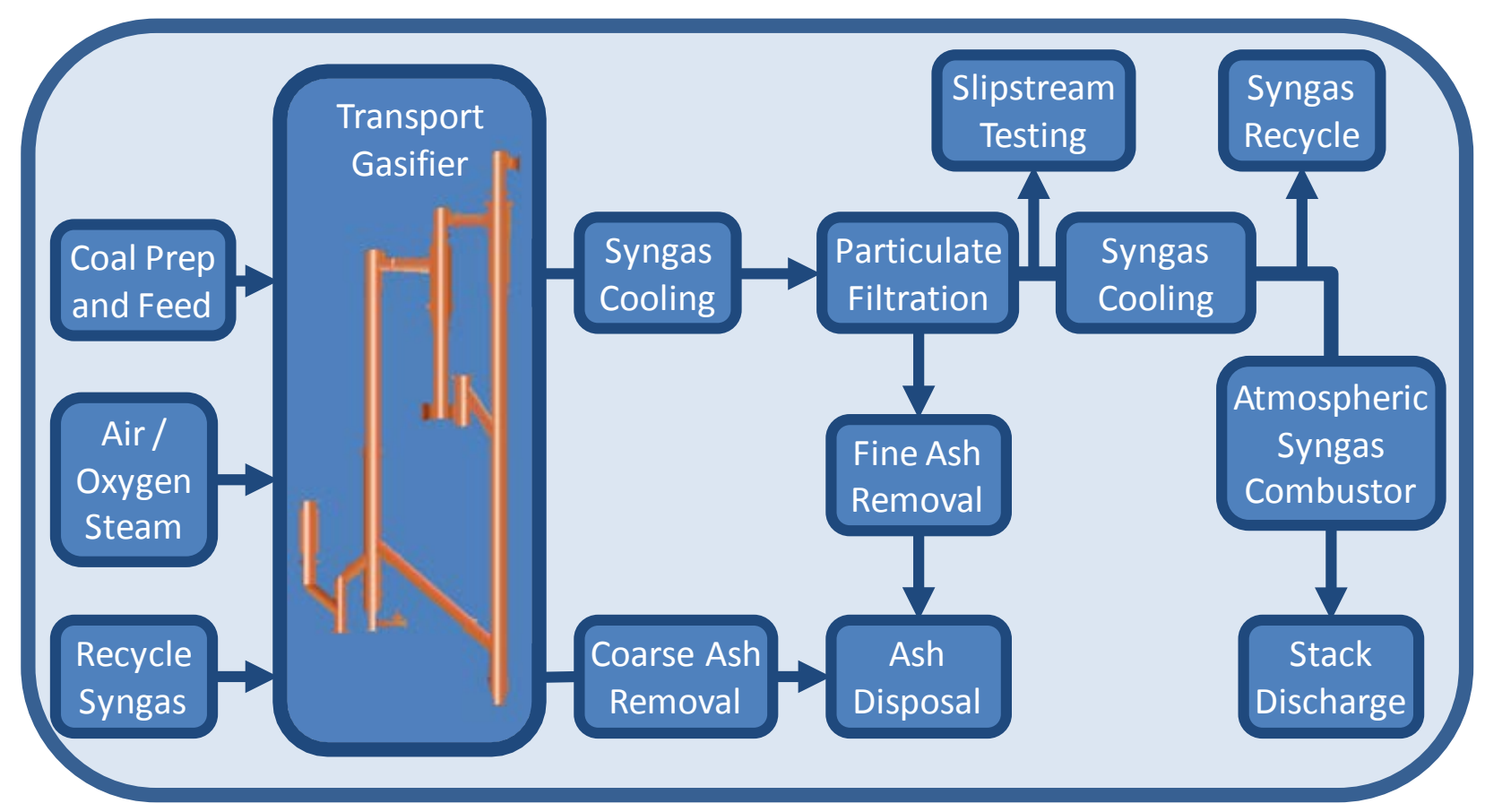

Figure 49. NCCC Gasification Process.

\subsection{Gasification Operation}

Gasifier operation was stable during runs R08 and R09, with steady-state carbon conversions comparable to previous test runs, as demonstrated by Table 19. The historical PRB coal carbon conversion represents average values from PRB test runs since the 2006 gasifier modifications were completed. 
Table 19. Steady State Carbon Conversions for R08 and R09.

\begin{tabular}{|lccc|}
\hline & Maximum & Minimum & Average \\
\hline Historical PRB Coal Carbon Conversion, \% & 99.6 & 95.3 & 98.4 \\
R08 PRB Coal Carbon Conversion, \% & 98.9 & 97.9 & 98.4 \\
R09 PRB Coal Carbon Conversion, \% & 98.7 & 97.8 & 98.1 \\
\hline
\end{tabular}

Gasifier temperature control enhancements utilizing upper and lower mixing zone air flow adjustments were ongoing during R08 and R09. Beginning in R06, a more aggressive algorithm was created that accounted for sudden increases and decreases in gasifier temperature resulting from non-steady-state operation, such as changing coal feed rate. Using a rate-of-change analysis for gasifier temperature, the controller can scale its response by varying the total air flow rate set point more aggressively. After steady-state operation has been reached again, the slower tuned controllers take control again. Figure 50 illustrates the improvement in gasifier exit temperature control achieved by these efforts. Gasifier temperature variation has been decreased from $5^{\circ} \mathrm{F}$ achieved during initial control implementation to less than $2^{\circ} \mathrm{F}$ during R08 and R09.

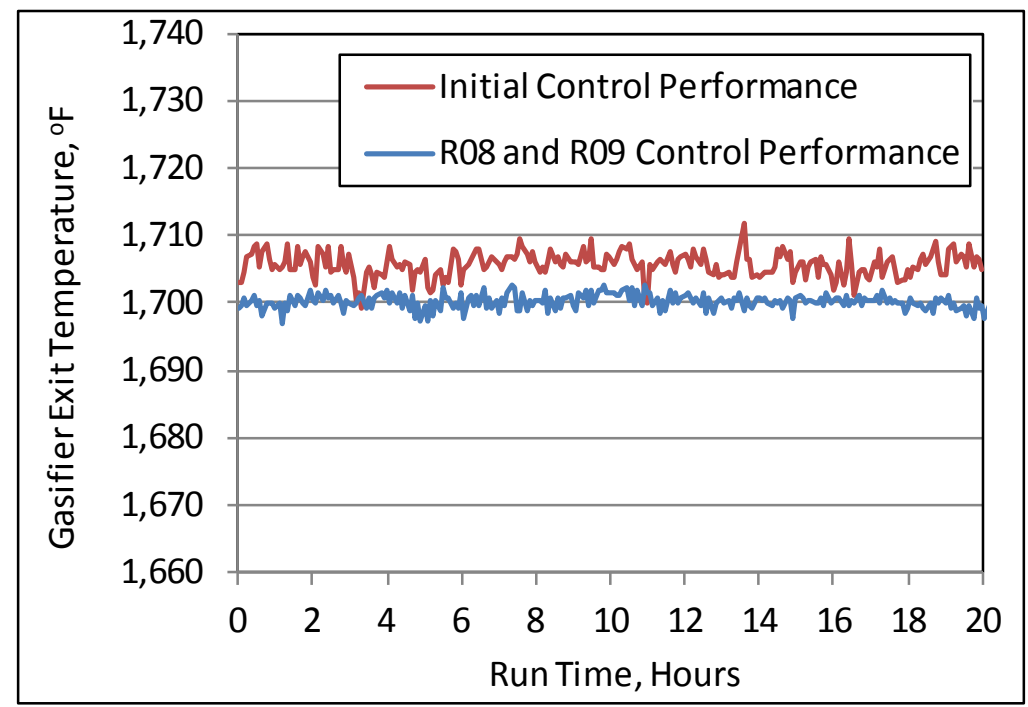

Figure 50. Gasifier Temperature Control during Non-Steady-State Operation.

During the R08 gasifier start-up, finer sand than that typically used as bed material was employed to assess any improvement the finer material might yield in overall temperature distribution through the gasifier. Initial results showed a decrease in temperature differential, although the data may have been skewed slightly due to the extended heat-up ramp rate required to cure refractory in the newly installed standpipe. The test may be repeated in the future during a more typical gasifier start-up to gain additional insight.

Testing of previous PDAC feeder control logic improvements also continued during R08 and R09. The coal feed rate trim controller successfully maintained a consistent coal feed rate as evidenced by the SWR Engineering flow meter and conveying line differential pressure. This controller was especially important during R08 since the feeder functioned as the sole coal feeder 
during the biomass co-feed testing. This run also marked the first time the PDAC feeder had been utilized during oxygen-blown gasifier operation. The gasifier pressure feedback controller installed previously permitted automatic adjustments to feeder pressure and nitrogen flow as gasifier pressure was reduced for oxygen-blown operation. The adjustments made by the controller permitted the pressure differential between the feeder and the gasifier to be maintained at a constant level, helping keep the coal feed rate steady.

The annual stack testing for environmental permit compliance was also completed during R08 operation. The official report confirmed that the facility is well under the permitted limits for all measured species.

\subsection{Oxygen-Blown Biomass Co-Feeding}

During the final portion of the R08 run, 219 hours of oxygen-blown gasification testing were conducted with biomass co-feed on behalf of CCAT. CCAT received funding through the Department of Defense as part of its initiative to develop alternative liquid fuels for U.S. military applications through the utilization of gasification techniques and sustainable fuel sources such as biomass. Previous gasification testing had been conducted by CCAT at the Energy and Environmental Research Center (EERC) at the University of North Dakota utilizing biomass cofeed with coal in the EERC Transport Gasifier. Testing at the NCCC provided an opportunity to validate data collected from testing at the EERC at a larger scale.

The NCCC test plan included co-feeding of two forms of biomass, raw pellets and torrified pellets, with PRB sub-bituminous coal during oxygen-blown gasifier operation. This biomass co-feed testing extended the operational experience the NCCC obtained previously during the R03 and R04 gasification runs when raw pellets were co-fed with PRB and lignite coal respectively during air-blown gasifier operation.

\subsubsection{Test Objectives and Results}

The NCCC test plan included co-feed testing of both raw and torrified southern pine biomass pellets with PRB sub-bituminous coal at concentrations ranging from 10 to $30 \mathrm{wt} \%$ of the total feed to the gasifier. Each biomass co-feed test condition was maintained for approximately 24 hours to allow for all required sampling and analysis to be conducted. The objectives for testing were developed jointly by CCAT and NCCC as follows:

- Collect test results and compare with those obtained from the EERC test to determine if operating at a larger scale results in better conversion, higher efficiency, and a syngas quality more suitable for producing liquid fuels

- Achieve the desired coal-biomass mixtures with separate feeding of coal and biomass

- Demonstrate gasification of the coal-biomass mixtures under the test conditions

- Determine carbon conversion and the amount of carbon in the gasifier solids for each test condition

- Demonstrate successful gasifier circulation without forming deposition or agglomeration 
- Determine the extent of tars production with the coal/biomass mixtures in the gasifier

- Evaluate hot gas filtration performance at each test condition

- Monitor gasifier operating parameters including solids circulation rate, syngas recirculation rate, and coal/biomass blend

One of the NCCC mill systems was dedicated during the run to processing biomass. The raw biomass pellets, shown in Figure 51, had been previously used as feedstock during the R03 and R04 runs. This was the first gasification operation with torrified biomass pellets, which are shown in Figure 52. The torrified pellets had mill operational characteristics similar to PRB coal due to the breakdown of the wood fiber structure by the torrification process.

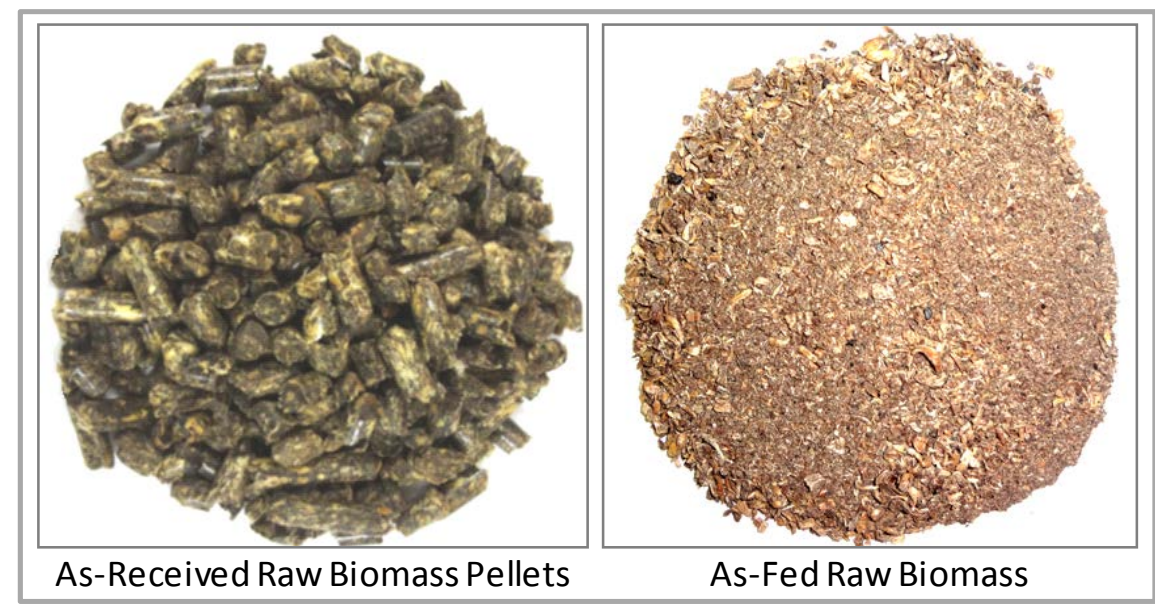

Figure 51. Raw Biomass for R08 Co-Feeding.

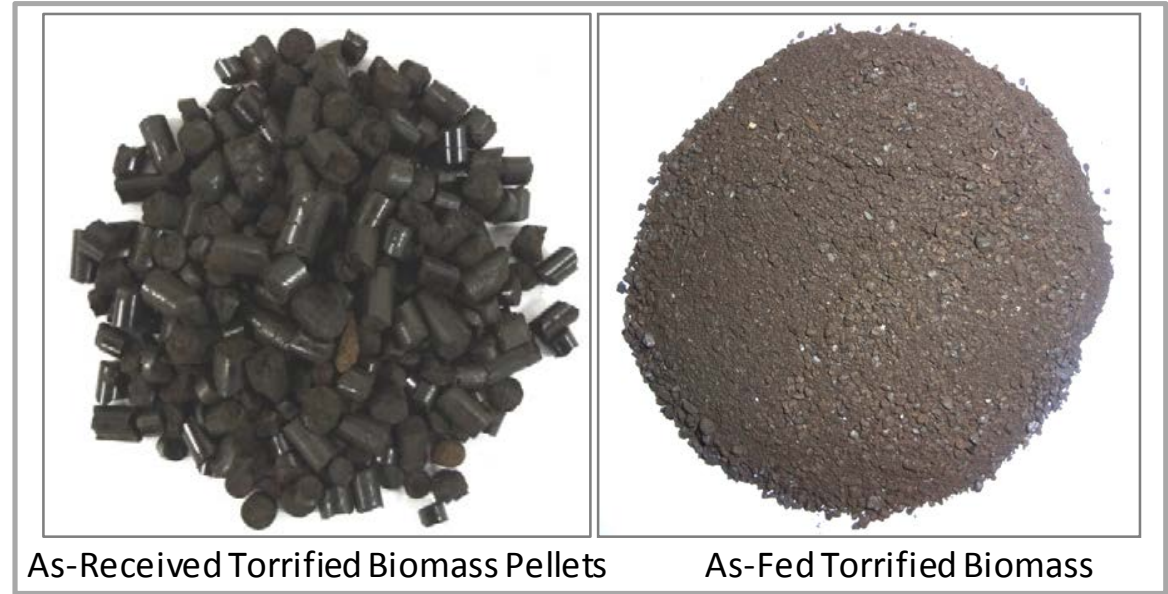

Figure 52. Torrified Biomass for R08 Co-Feeding.

The average particle size distributions for the three feedstocks are shown in Figure 53, with the torrified biomass more closely following the normal distribution for PRB coal. For the run, a total of 1,600 tons of PRB coal and 41 tons each of torrified and raw biomass were processed. Table 20 lists the as-received and as-fed properties of the coal and biomass. 


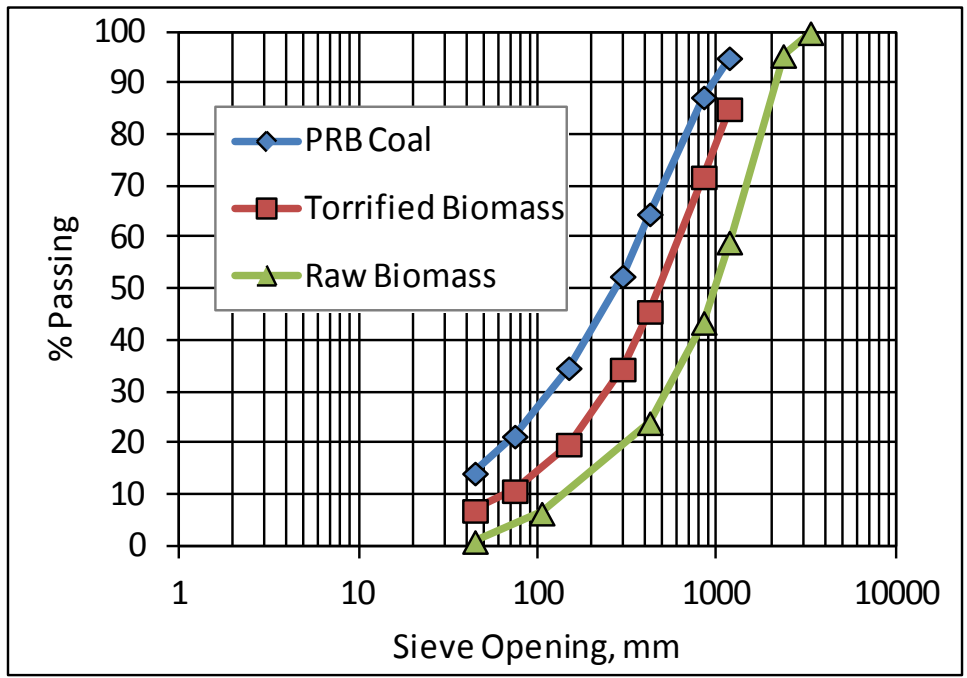

Figure 53. Particle Size Distribution Curves for R08 Gasifier Feedstocks.

Table 20. Coal and Biomass Properties.

\begin{tabular}{|c|c|c|c|}
\hline Property & PRB Coal & $\begin{array}{l}\text { Torrified } \\
\text { Biomass }\end{array}$ & $\begin{array}{c}\text { Raw } \\
\text { Biomass }\end{array}$ \\
\hline As-Received Carbon, wt \% & 52.1 & 57.5 & 48.5 \\
\hline As-Received Hydrogen, wt \% & 3.5 & 5.3 & 5.7 \\
\hline As-Received Nitrogen, wt \% & 0.9 & 0.3 & 0.02 \\
\hline As-Received Sulfur, wt \% & 0.2 & 0.01 & 0.06 \\
\hline As-Received Ash, wt \% & 6.6 & 1.8 & 1.2 \\
\hline As-Received Oxygen, wt \% (by difference) & 12.1 & 30.9 & 38.4 \\
\hline As-Received Volatiles, wt \% & 42.3 & 65.3 & 72.2 \\
\hline As-Received Fixed Carbon, wt \% & 26.4 & 28.8 & 20.3 \\
\hline As-Received Heating Value, Btu/lb & 8,960 & 9,670 & 8,070 \\
\hline As-Received Moisture Concentration, wt\% & 25 & 4.2 & 6.3 \\
\hline As-Fed Moisture Concentration, wt\% & 18 & 7.8 & 8.0 \\
\hline As-Fed Mass Median Diameter, micron & 280 & 536 & 990 \\
\hline As-Fed Oversize (>1,180 micron) Content, wt $\%$ & 5 & 14.9 & 40.8 \\
\hline As-Fed Fine (<45 micron) Content, wt\% & 14 & 7.1 & 1.0 \\
\hline
\end{tabular}

The increase in moisture concentration of both forms of biomass after milling operations was unexpected. Two potential causes were longer than planned exposure to ambient moisture before material processing began and lower mill system exhaust gas flow (i.e. higher recycle gas flow) leading to higher relative moisture levels inside the mill system.

After establishing steady gasification operation with PRB feed utilizing the PDAC feeder, torrified biomass was fed followed by the raw biomass. The actual co-feed percentages for the torrified biomass were 17, 20, and $29 \mathrm{wt} \%$. Due to the turndown limits of the rotary feeder and 
the bulk density of the torrified material, the lowest percentage co-feed was higher than the planned $10 \mathrm{wt} \%$. The actual co-feed percentages for the raw biomass were 12, 20, and $28 \mathrm{wt} \%$. The lower bulk density (larger volume) of the raw biomass allowed for a closer approach to the planned lower co-feed test condition. Biomass feed rate as a function of feeder speed is given in Figure 54. Feeder performance was stable during testing.

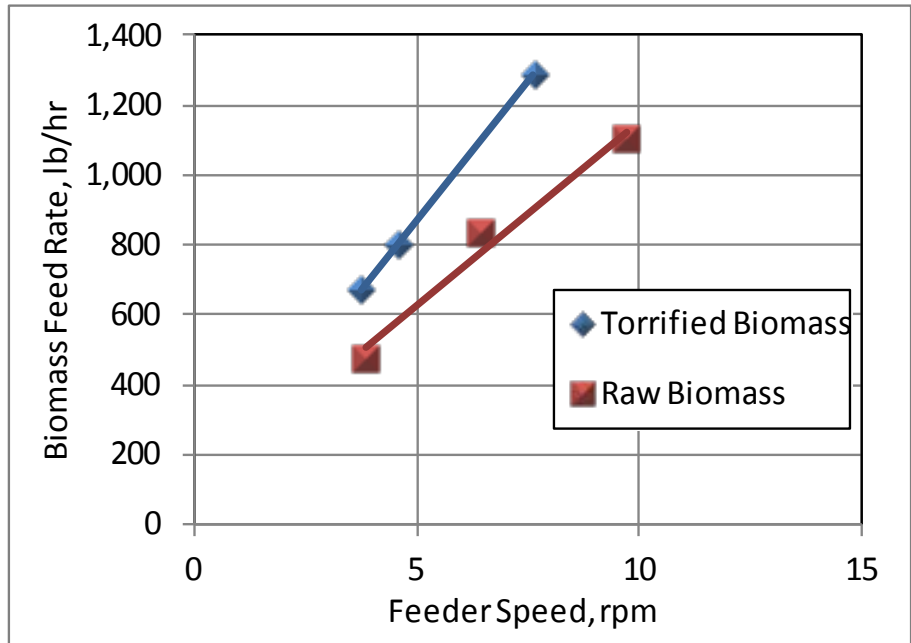

Figure 54. Biomass Feed Rate as a Function of Feeder Speed of Original Rotary Coal Feeder.

Gasifier operating conditions remained stable during all tests and yielded high carbon conversions during both coal-only and biomass co-feed operation as shown in Table 21. Syngas lower heating values (LHVs), also given in Table 21, remained stable during the biomass co-feed periods, and there was no appreciable tar generation during the testing.

Table 21. Coal and Biomass Co-Feed Operating Parameters.

\begin{tabular}{|c|c|c|c|c|c|c|c|}
\hline & \multirow{2}{*}{$\begin{array}{l}\text { PRB } \\
\text { Coal } \\
\text { Only }\end{array}$} & \multicolumn{3}{|c|}{ Torrified Biomass Co-Feed } & \multicolumn{3}{|c|}{ Raw Biomass Co-Feed } \\
\hline & & $17 w t \%$ & $20 w t \%$ & $29 w t \%$ & $12 w t \%$ & $20 w t \%$ & $28 w t \%$ \\
\hline Gasifier Exit Temp., ${ }^{\circ} \mathrm{F}$ & 1,707 & 1,699 & 1,698 & 1,699 & 1,701 & 1,708 & 1,692 \\
\hline Coal Feed Rate, lb/hr & 3,607 & 3,302 & 3,259 & 3,201 & 3,552 & 3,386 & 2,784 \\
\hline Biomass Feed Rate, lb/hr & 0 & 652 & 795 & 1,288 & 472 & 835 & 1,100 \\
\hline Total Feed Rate, lb/hr & 3,607 & 3,954 & 4,054 & 4,489 & 4,024 & 4,221 & 3,884 \\
\hline Oxygen/Fuel Ratio, lb/lb & 0.80 & 0.78 & 0.76 & 0.72 & 0.75 & 0.71 & 0.74 \\
\hline Steam/Fuel Ratio, lb/lb & 1.20 & 1.15 & 1.11 & 1.02 & 1.12 & 1.06 & 1.18 \\
\hline Carbon Conversion & 98.3 & 98.2 & 98.4 & 98.2 & 98.5 & 98.0 & 98.2 \\
\hline Syngas LHV, Btu/scf & 97.7 & 86.7 & 97.6 & 110.8 & 96.7 & 98.0 & 95.2 \\
\hline
\end{tabular}


The carbon conversions achieved during co-feed operation also compared well with previous biomass co-feed operation with PRB coal as shown in Figure 55.

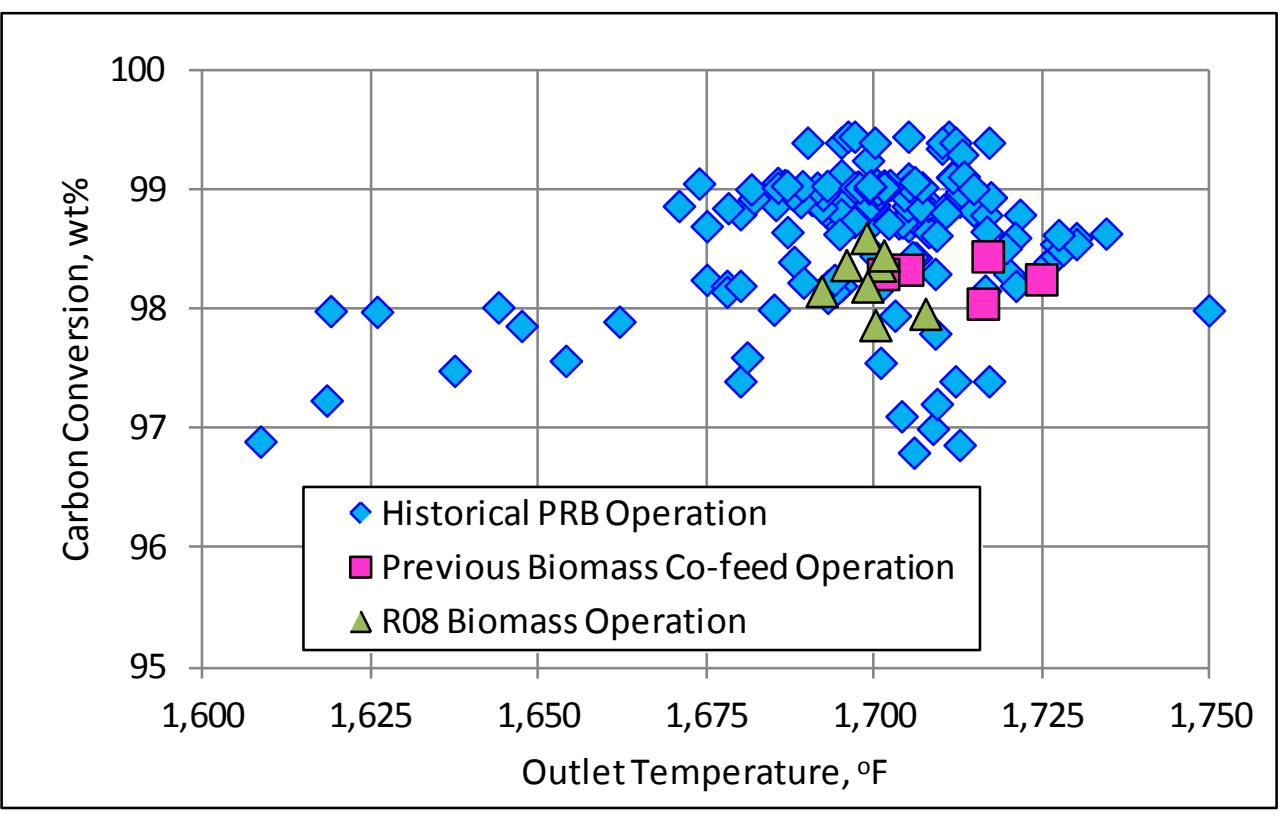

Figure 55. Carbon Conversion during PRB Coal and Biomass Co-Feed Operation.

Comprehensive mass and energy balances were conducted for each test condition with acceptable closures achieved in both cases, as illustrated in Figure 56.

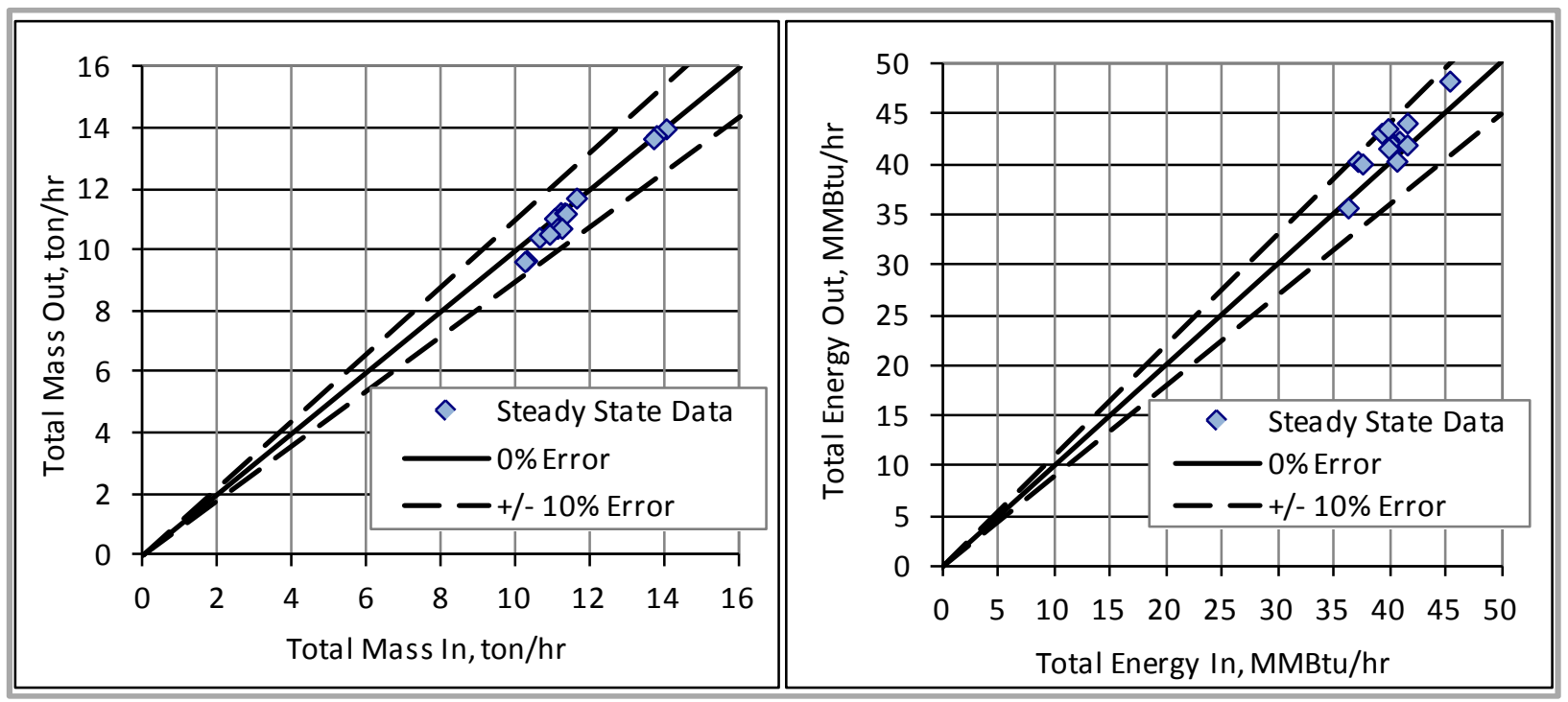

Figure 56. Mass and Energy Balances for R08 Biomass Co-Feed Operation.

No evidence of agglomeration was observed in the circulating solids, and the continuous coarse ash discharge system functioned well during all test conditions. PCD performance remained stable with a consistent pressure drop and low particulate loading in the outlet gas (less than 0.1 ppmw). The continuous fine ash discharge system also performed well during all test conditions. 
The observed range of ash particle size distributions for both ash discharge systems during testing is shown in Figure 57.

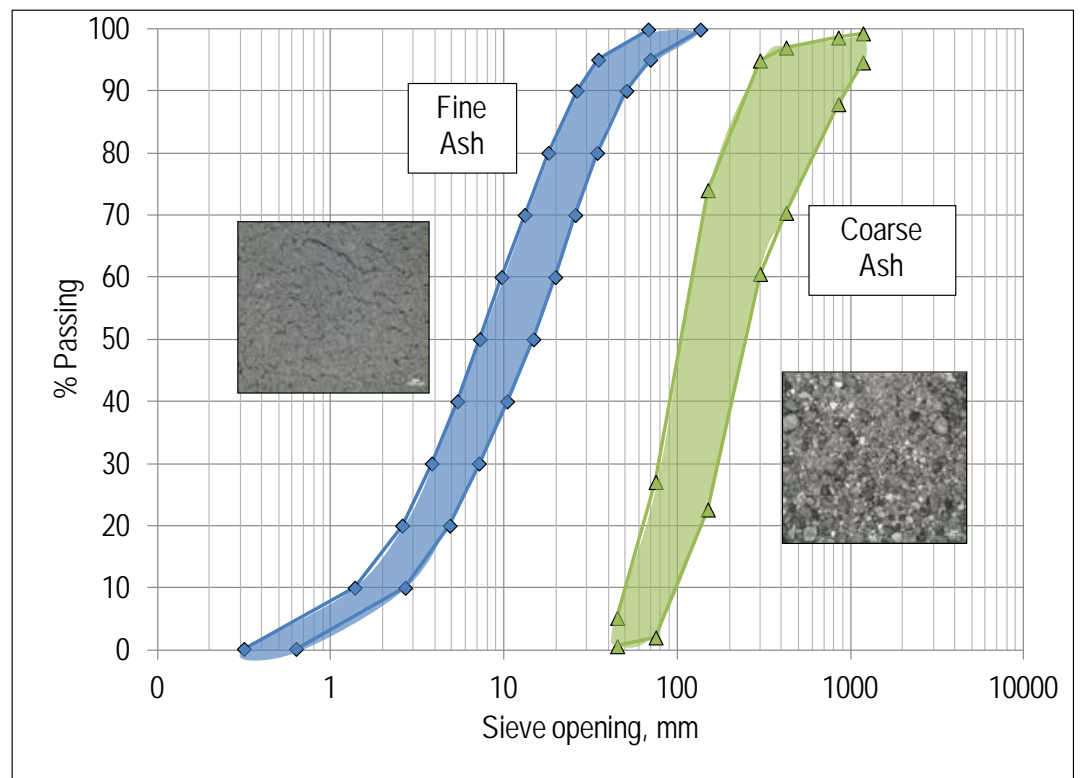

Figure 57. Fine and Coarse Ash Particle Size Distribution Curves for R08 Operation.

In summary, performance of the gasification system during the oxygen-blown biomass co-feed testing was stable with no operational problems. All data analysis, system operating parameters, and sample data has been shared with the CCAT team. Collaboration with CCAT personnel will continue to generate a final test report during 2013.

\subsubsection{Oxygen Supply System}

In support of biomass co-feed with oxygen feed for CCAT in R08, significant design effort was spent on the re-commissioning and modification of the oxygen supply system. The work included installation of a new oxygen flow meter. Cleanliness, system operating pressure, and materials of construction are all directly related to the characteristic elements that are managed to minimize ignition risks in an oxygen line. Challenges associated with the design included:

- To accelerate the schedule, the need to use a higher velocity flow meter made from stainless steel instead of a more burn resistant material like Hastelloy or Monel

- The need to minimize high velocity start-up transients identified in the design hazard review

- $\quad$ The need to identify an operating pressure that was high enough to satisfy process needs and low enough to minimize ignition mechanism risks

- Cleaning of the existing oxygen header required to remove particle contamination in the oxygen supply piping 
An oxygen design engineer was engaged to assist the NCCC design group. The consultant evaluated the probability and potential consequence of ignition, assisted with inspection of the oxygen system, and made recommendations on cleaning of the system. After the final report from the consultant was received, the new flow meter design was validated, and the equipment was installed. A scope was developed for cleaning the oxygen header, a contractor selected to perform the work, and the oxygen header was cleaned prior to R08. Design work was also completed to incorporate interlocks to address the high velocity start-up transients that had been identified as a risk factor.

Some additional design and field work continued during R08 to address start-up transients upon introduction of oxygen, primarily implementation of a method to pre-pressurize the oxygen line to reduce start-up velocity.

\subsection{Hot Gas Filtration}

PCD research efforts continued during the year focusing on the long-term evaluation of material performance of several types of filter elements and failsafe devices. The failsafes installed include Pall Dynalloy devices constructed of forward (supporting screen on the inner surface of the failsafe) and reverse structures (supporting screen on the outer surface), and PSDF-designed devices constructed of HR-160 material. The filter elements installed consist of sintered fiber elements — some elements manufactured by Porvair and HR-160 elements from Pall—and sintered powder filter elements - iron aluminide elements from Pall and elements with a highalloy material from Mott.

The PCD operated with a high collection efficiency and stable pressure drop during R08 and R09 with particulate outlet loading typically less than $0.1 \mathrm{ppmw}$. However, operations were interrupted during the R08 run due a weld failure in the PCD tubesheet discussed in Section 4.5.2. Due to the compressed timeframe of the required repair, the PCD plenums were fitted using spare filter elements from the on-site inventory. There was insufficient time available to clean off the filter cake and inspect the elements to ensure that they did not contain a leak source. The spare filter elements consisted of both new and used iron aluminide and HR160 elements from Pall and used sintered-fiber elements with an inert coating from Porvair.

After completion of the R09 test, the filter elements installed in the PCD prior to the tubesheet failure, which have the most hours of run time, were re-installed to continue long-term material evaluation. The elements with the greatest exposure time, which are iron aluminide elements, had accumulated over 16,200 hours of syngas and fine ash particulate exposure prior to the tubesheet failure during R08. Most of the failsafes were cleaned and re-installed during the repair including both Pall Dynalloy devices and PSDF-designed devices. A new set of failsafes will be installed following the planned repair and/or replacement of the PCD tubesheet and plenum components.

\subsection{Sensor Development}

The in-house development of advanced sensors continued with a sapphire thermowell for gasifier service, a coal flow measurement device, and coal feeder level probes. 


\subsubsection{Sapphire Thermowell}

An agreement was reached with Emerson to continue testing of the Rosemount thermocouple technology employing a sapphire thermowell in the riser section of the Transport Gasifier.

Previous testing of this technology conducted during R04 through R06 showed good responsiveness to gasifier temperature changes, but the temperature indication continued to drift relative to the reference thermocouple, housed in a HR-160 thermowell, as shown in Figure 58. The sapphire thermowell and assembly was in service for over 2,700 hours.

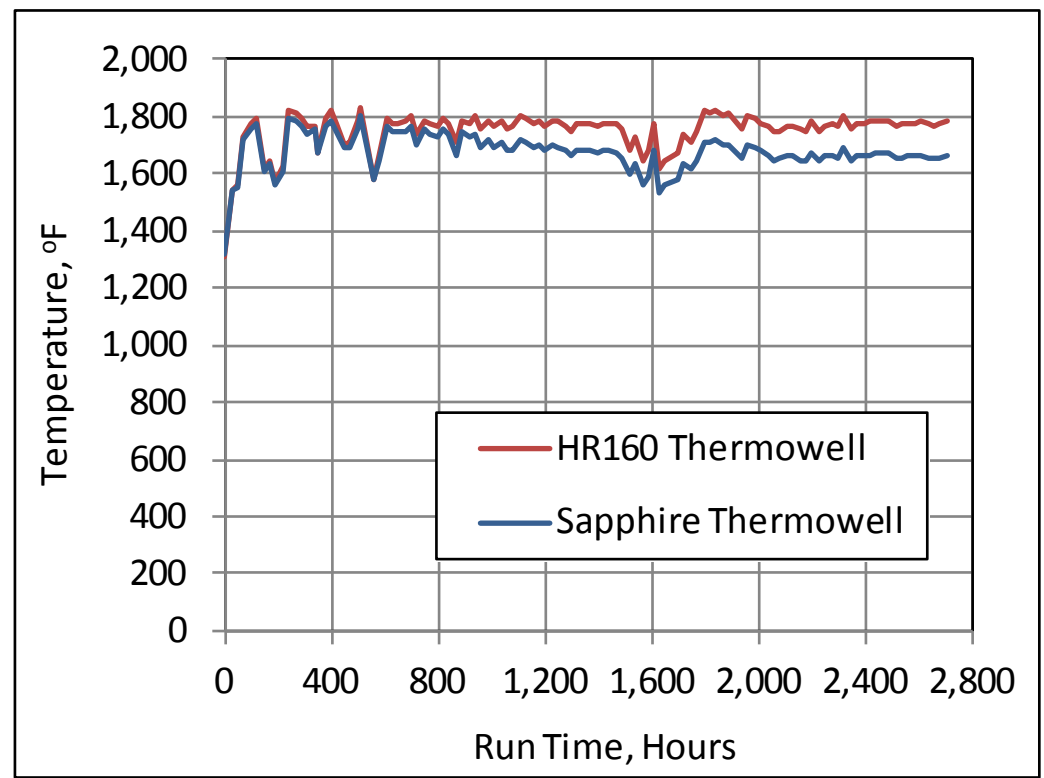

Figure 58. Temperature Readings for Sapphire and HR-160 Thermowells.

Inspection of the thermocouple following the R06 run showed corrosive attack and microcracking of the thermocouple, indicating that the thermocouple had been exposed to syngas. The thermowell likely had a crack or weak point prior to the beginning of gasifier operation, which led to the syngas exposure and slow decay in thermocouple reading.

As a result of these findings, Emerson personnel fabricated a new thermowell assembly to reinstall in the same location prior to run R08 and were on-site to assist during the initial inspection and installation of the assembly. The thermowell assembly was identical the assembly tested previously with the exception that a new smart Hart transmitter was added to provide early detection of a sensor failure. Unfortunately, the transmitter/thermocouple failed shortly after R08 began, and a post-run inspection showed that the assembly had broken.

Testing of the sapphire thermowell technology was suspended following the second assembly failure at the beginning of R08. NCCC staff has been collaborating with Rosemount to understand better the mode of the two failures and reach a decision regarding future testing. One potential path forward may include testing different sapphire thermowell assembly designs in other gasifier locations. More detailed test plans will be developed after technology collaboration agreements are finalized. 


\subsubsection{Densflow Coal Flow Meter}

Testing of the DensFlow coal flow meter from SWR Engineering continued during R08 and R09. The device is a non-intrusive technique of measuring solids flow using a patented alternating electromagnetic field. The solids flowing through the device absorb this field energy, and a measurement of density of the material is inferred. Conveying velocity is simultaneously calculated by the same sensors. The combination of the two measurements with the cross sectional area of the device yields a mass flow rate of material through the feeder discharge line.

While the measurement provided by the meter has shown good response to instantaneous changes in coal feed rate when compared to existing conveying line differential pressure readings, the absolute reading has not matched up well with the loss in weight calculation provided by the PDAC feeder surge bin weigh cell device. Although the original design intent was to measure dense flow solid streams at pressure, SWR Engineering has maintained that the device is capable of measuring the more dilute phase flow regime of the PDAC feeder discharge to the gasifier.

Following operation during R07, the decision was made to recalibrate the instrument following the manufacturer's guidelines and to perform off-line feeder testing at higher coal feed rates than had previously been achieved during on-line operation prior to R08. The rationale for the offline testing was that at higher coal feed rates, the solids flow in the feeder discharge line should be less dilute and more closely approach dense-phase flow conditions. However, the data collected during the off-line test period revealed that the discrepancy in coal feed rates between the weigh cell calculation and flow meter still existed at the higher rates. This result was further substantiated with flow rate data collected during R08 and R09 as illustrated in Figure 59.

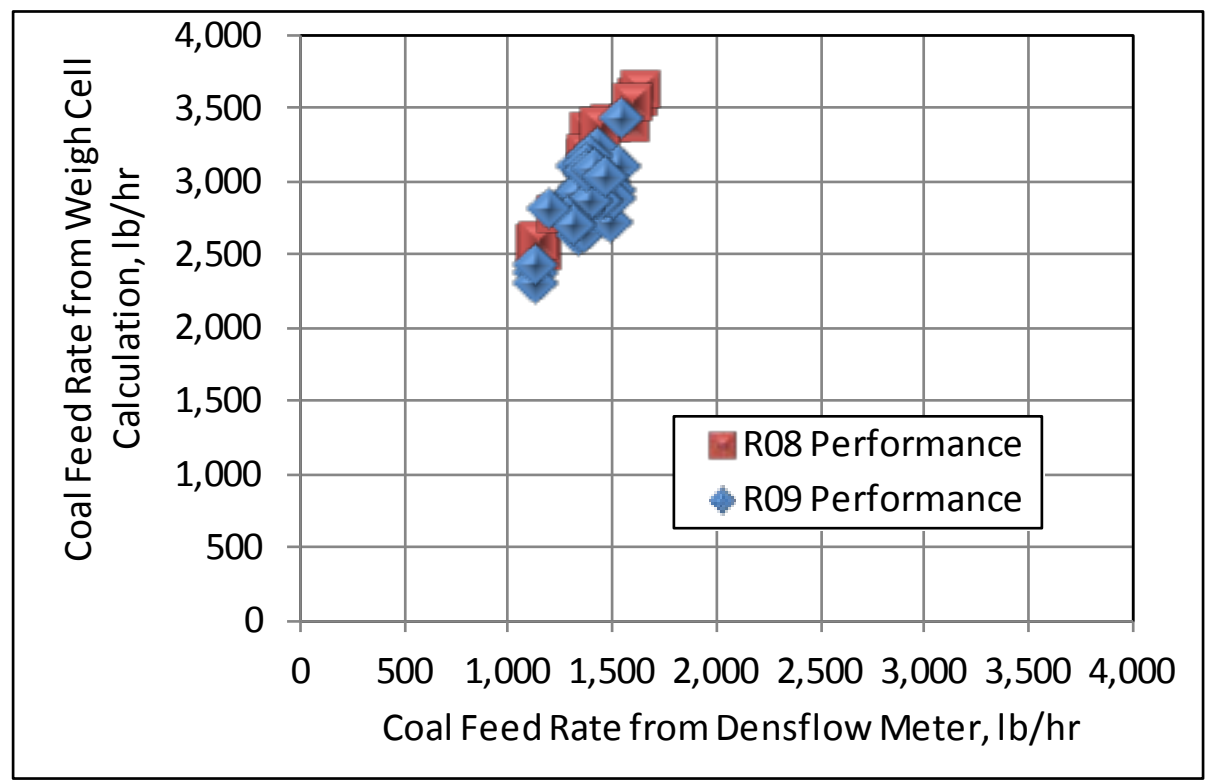

Figure 59. Comparison of Coal Feed Rates Indicated by Weigh Cells and Densflow Meter. 
Collaboration with SWR Engineering personnel regarding the outcome of the data generated will be needed to determine what changes are necessary to address the difference for future testing.

\subsubsection{Coal Feeder Level Probes}

Long-term evaluation of two coal feeder solids level probes continued during both R08 and R09. The Dynatrol vibration level probes installed in the PCAD feeder dispense vessel and lock vessel prior to the R02 run have continued to provide very reliable indication of solids level in both vessels for lignite and sub-bituminous coals. Further optimization of the lock vessel fill cycle has been made possible by the performance of these devices. The level probes have operated for almost 6,000 hours.

Evaluation of the Drexelbrook point sensitive level probe also continued during both test runs. The probe was vertically installed in the top of the PDAC feeder dispense vessel prior to the R04 test run to permit higher level control of the coal inventory in the vessel. Since installation, the probe has continually provided steady solids level control, mitigating the impact of solids level variation on coal feed rate. Over 4,700 hours of operation have been achieved to date.

\subsection{Gasification Process Modifications}

Several modifications were made to the gasification process during the year to address equipment related issues. These changes included replacement of the gasifier standpipe and repairs to the PCD tubesheet and primary gas cooler. Additionally, work began on design of a new pressure letdown device for the Continuous Fine Ash Depressurization (CFAD) system to decrease construction costs of the system.

\subsubsection{Gasifier Standpipe Replacement}

A 2012 project deliverable for DOE was the replacement of the gasifier standpipe. During routine inspections of the gasifier in 2009, refractory damage was identified in the standpipe arising from the loss of hot-face refractory. Two places of concern were the intersection of the solids separation unit and standpipe, and the intersection of the J-leg and standpipe. The refractory in the standpipe and J-leg was the refractory originally installed in the gasifier, and had been in service for 15 years and almost 22,000 hours of operation, experiencing more thermal cycles than would a commercial unit. Figure 60 shows boroscope inspection photographs of the standpipe refractory. As seen in the figure, the refractory was in excellent condition following initial operation in runs R08 and R09. 


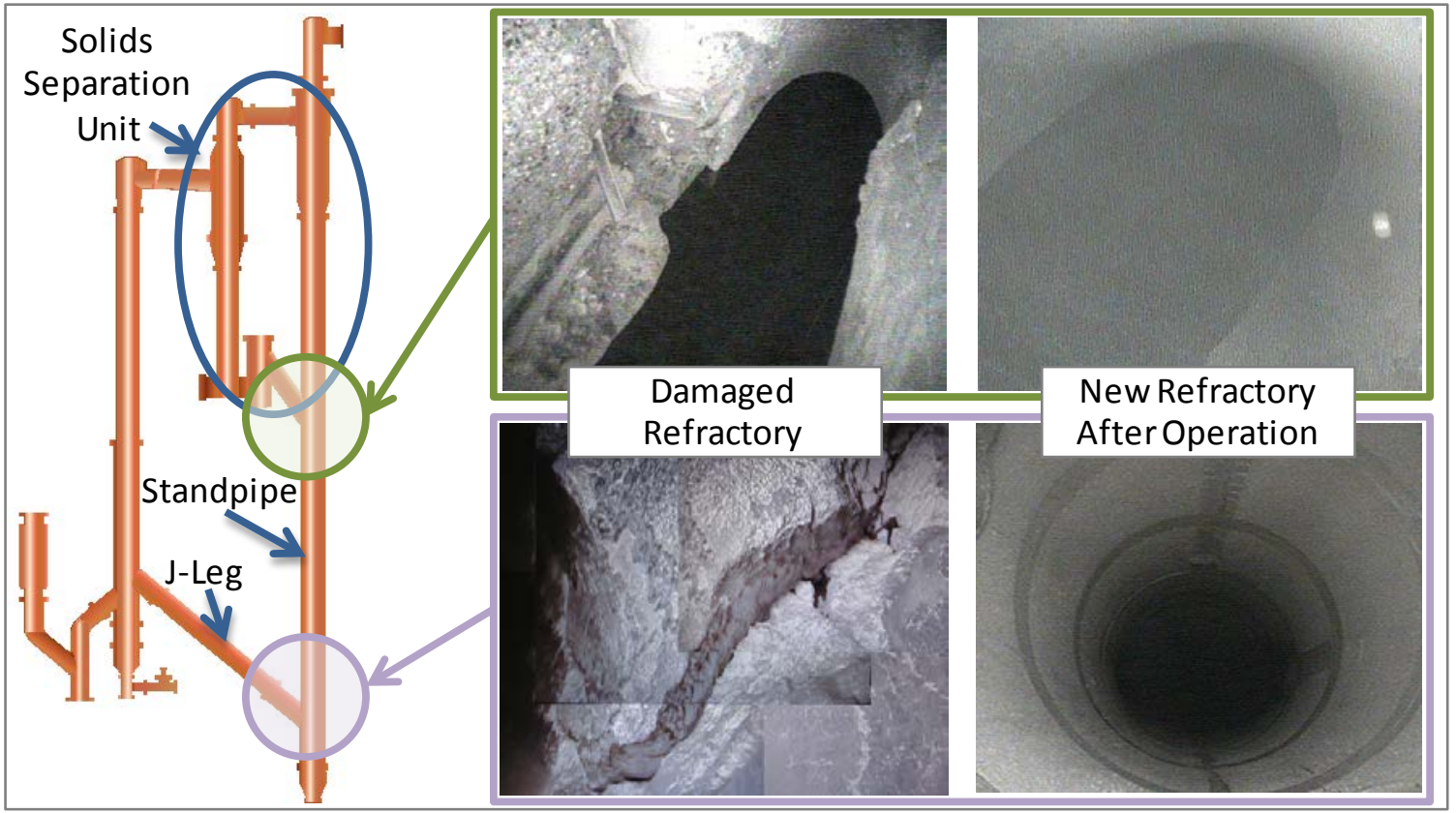

Figure 60. Gasifier Standpipe Refractory before and after Standpipe Replacement.

The work scope of the project included the following items in addition to the physical replacement of the standpipe itself:

- Removal and re-installation of 10 tons of structural steel and grating, 50 small bore piping runs, and nearly 100 tubing runs

- Disconnection and re-termination of over 190 instrumentation loops and 170 powerrelated loops

- Installation of 49 new area gas detectors (to upgrade to current models supported by the supplier which is necessary to maintain the emergency response infrastructure) and checkout of over 140 associated instrumentation loops

- Separation and re-surfacing of the riser/mixing zone body flange to address a leak found during R07

Demolition of small bore piping and dismantling of related instrumentation and the original standpipe was completed during the first quarter of 2012 (see Figure 61). Installation of the first two of the four new standpipe sections was also completed in the first quarter. However, a fit-up problem was identified with the first piece of refractory-lined pipe. NCCC design and construction groups, KBR engineering, and a contracted laser alignment company developed an appropriate field modification, but the installation of the first standpipe piece took longer than initially projected. 


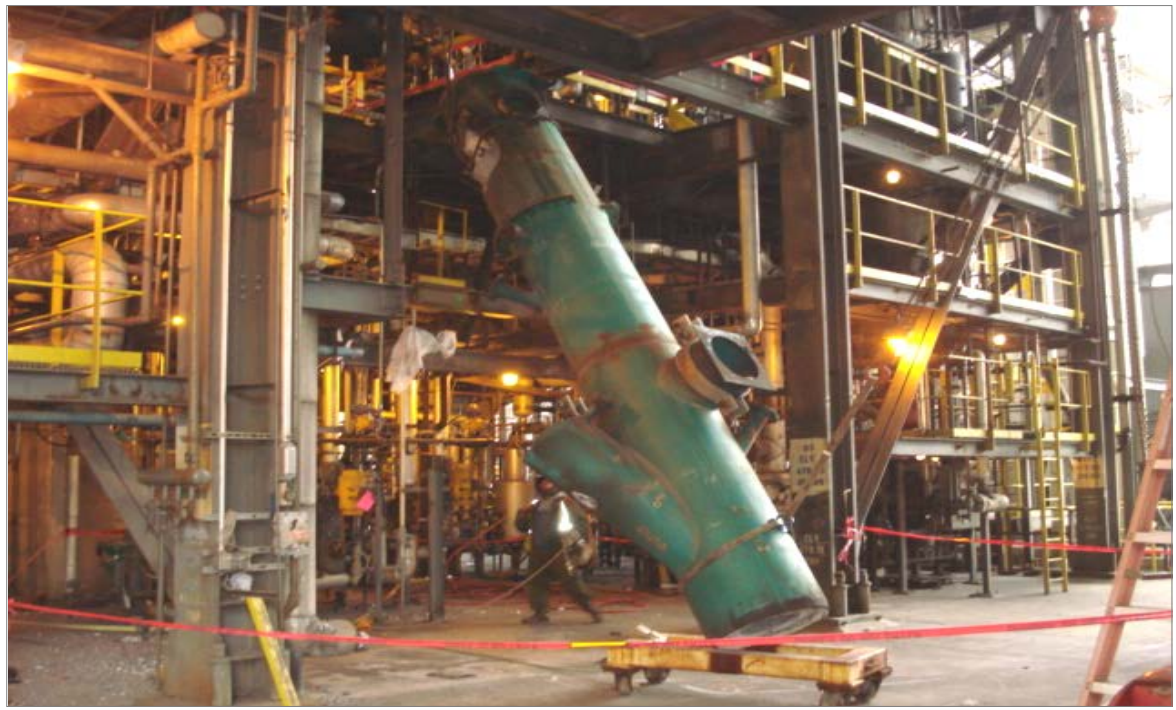

Figure 61. Standpipe Demolition in Progress.

The standpipe replacement was completed in May with installation of the remaining two sections of the new standpipe and small-bore piping, instrumentation, and tubing. Checkout and calibration of all instrumentation and wiring started in May and was completed in early June. Functional testing of all associated system control logic was completed prior to R08 start-up.

\subsubsection{PCD Tubesheet Repair}

Inspections of the PCD tubesheet were performed in August during the second R08 outage following the detection of high solids loading in the outlet syngas, and a significant crack was found in the tubesheet outer-ring to outer-cone weld, as shown in Figure 62. This is a structural weld that supports the weight of the tubesheet and plenum assemblies. Working with the original designer (Siemens Westinghouse), it was determined that the weld could be repaired. NCCC construction and maintenance personnel made the repairs and reinstalled the PCD tubesheet at the end of August.

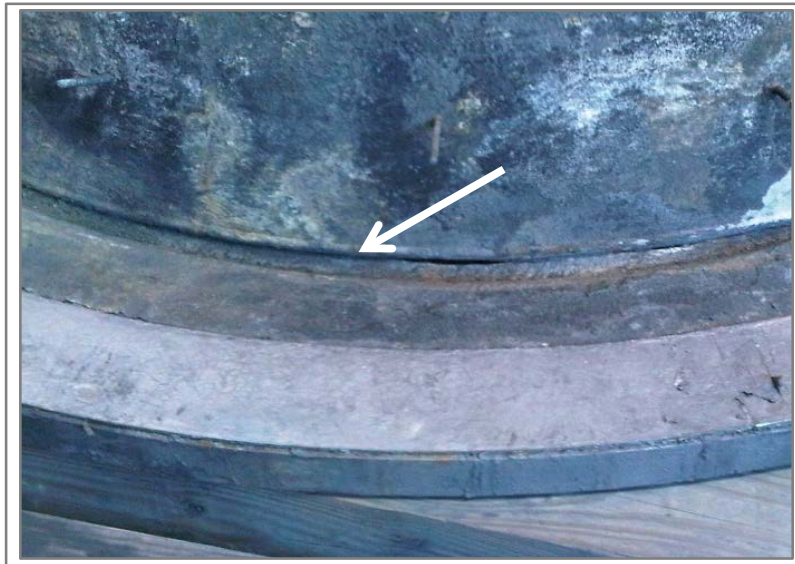

Fractured Tubesheet

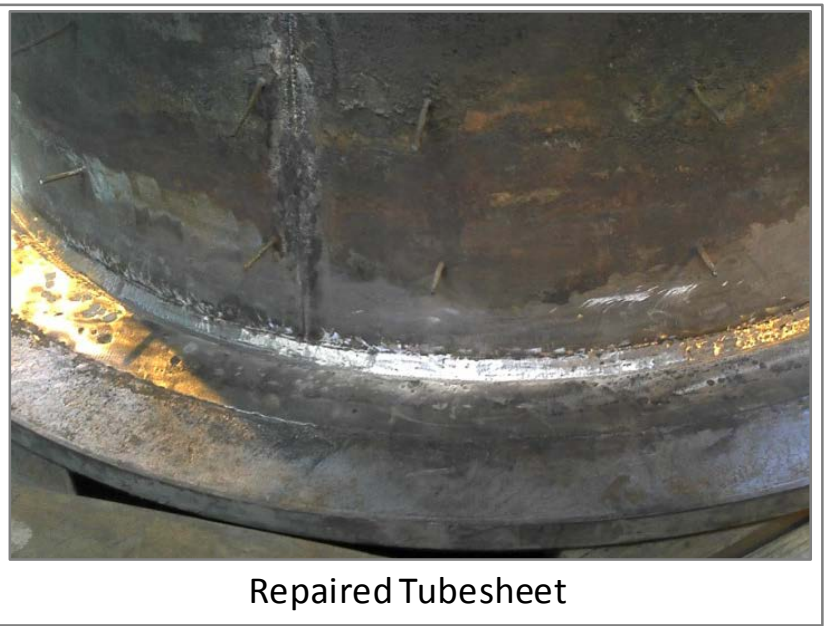

Figure 62. PCD Tubesheet Fracture and Repair. 
Options are being considered for major repairs and/or replacements of the PCD tubesheet and plenum components due to the tubesheet outer-ring to outer-cone weld damage that was identified and repaired during R08. NCCC engineers are evaluating options and will submit proposals to management for review in early 2013.

\subsubsection{Primary Gas Cooler}

During the R09 start-up, a leak was identified in the primary gas cooler, which is located between the gasifier and the PCD. Hydrostatic pressure testing identified one leaking tube, the ends of which were plugged to prevent further leaking. While the primary gas cooler operated satisfactorily during R09, it will be replaced due to the likelihood of future tube leaks. Plans call for the replacement cooler to be delivered and installed in 2013.

\subsubsection{Pressure Letdown Device Design Modifications}

The current CFAD system pressure letdown device (PLD) design has been utilized at NCCC for a number of years. A project was initiated to investigate and test proposed modifications to the PLD, which should significantly decrease fabrication cost and time without affecting performance. Mechanical design drawings were completed in December. Fabrication and installation will commence in early 2013 with plans to test the new concept in R10. Following the R10 run, the same proposed PLD design will be installed on the PDAC feeder and tested offline prior to R11.

\subsection{Stanford University Tunable Diode Laser}

During R09, Stanford University’s Hanson research group tested tunable diode laser (TDL) sensor technology in the syngas downstream of the PCD. Preliminary findings validated the TDL technology's ability for real-time in-situ monitoring of $\mathrm{H}_{2} \mathrm{O}, \mathrm{CO}_{2}$, and gas temperature in a gasification process.

Prior to the campaign, Stanford collaborated with NCCC to design an apparatus capable of supporting the measurement device on the particulate free syngas stream exiting the PCD. In conjunction, both teams developed a robust plan to assess the durability and accuracy of the sensor across a wide range of operating conditions. Throughout the testing, readings from the unit were consistent, with no significant measurement drift observed.

In addition to the validation of the sensor's measurement methodologies, a technical assessment was performed by NCCC to ascertain the performance of the sapphire window assemblies employed to provide a pressure boundary between the process gas and the laser emitter/receiver. During the two-month campaign, a number of events occurred which required the use of the safety systems designed to respond to gasifier upsets. In each case, the system responded as expected, allowing rapid return to normal and safe operation with no observed window fouling or laser path obstruction. 


\subsubsection{Stanford's Development Work}

\section{Sensor History}

The Hanson research group at Stanford University has a long and successful history of research to develop laser absorption sensors for combustion and propulsion applications. Recently, one of the goals of this research has been to demonstrate the applicability of these measurement techniques for coal gasification systems. Laser absorption sensors have good potential to provide in-situ monitoring of syngas from coal gasification, providing control signals for the gasification process as well as real-time monitors for the energy content and composition of the product syngas.

There are three important challenges to the development of laser absorption sensors for gasifier applications:

- Modern gasification processes utilize high pressures, and absorption sensing at such conditions is complicated by collisional broadening and the resulting blending of absorption transitions.

- Absorption measurements rely on the transmission of a laser beam, and gasifier product streams can be heavily laden with particulate, which can scatter light and strongly attenuate the transmitted laser intensity.

- Optical absorption sensing requires optical access for line-of-sight laser transmission measurements in the explosive and toxic syngas; thus, the optical access must provide security for safe operation if a window fails or if the sensor requires maintenance during the long operation cycle of a commercial gasification plant.

Stanford's vision for laser-sensor control IGCC utilization of clean coal is illustrated in Figure 63. Here gas temperature is monitored in the gasifier (location 1 in the figure), the syngas concentration marker (e.g., $\mathrm{CO}$ or $\mathrm{H}_{2} \mathrm{O}$ ) is tracked at the gasifier exit (location 2), and syngas quality (e.g., Wobbe index) is monitored before (location 3) and after (location 4) the particulate cleanup of the syngas.

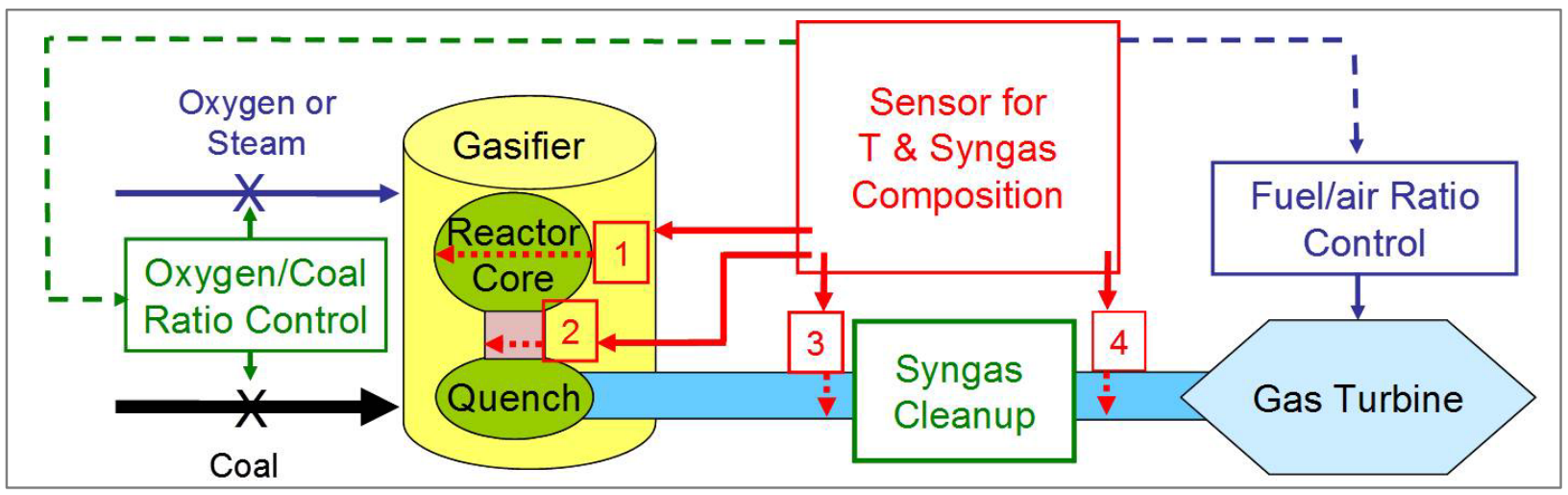

Figure 63. Conceptual Use of TDL Sensor for Control of an IGCC Plant. 
Sensor 1 provides a control signal to optimize the gasifier (e.g., temperature), sensor 2 monitors exit syngas for gasifier control (e.g., the fuel/oxidizer), sensors 3 and 4 monitor syngas quality (e.g., energy content) to control the gas turbine fuel/air ratio. The use of optical fibers enables simultaneous measurements at multiple locations and remote installation of the lasers, detectors, and control electronics.

Stanford's research to develop TDL absorption sensors for gasifier applications for temperature and $\mathrm{H}_{2} \mathrm{O}$ content has been sponsored by EPRI. Related research to extend these sensors to syngas composition measurements of $\mathrm{CO}, \mathrm{CO}_{2}, \mathrm{CH}_{4}$, and $\mathrm{NH}_{3}$ has been sponsored by NETL. This research has included optimization of sensor design for gasifier conditions, laboratory validation of sensor performance analyzing synthetic syngas, and field measurements in two pilot-scale facilities at the Institute for Clean and Secure Energy at the University of Utah. In 2009, the first proof-of-concept TDL absorption measurements were preformed in syngas flows above the fluidized bed of a pilot-scale black-liquor gasifier, and time-resolved temperature was measured successfully even with significant $\left(10^{4}\right)$ attenuation of the transmitted laser beam by particulate scattering. Between 2010 and 2012, the sensor was extended to monitor four species $\left(\mathrm{H}_{2} \mathrm{O}, \mathrm{CO}_{2}, \mathrm{CO}\right.$, and $\left.\mathrm{CH}_{4}\right)$ and temperature in a pilot-scale, down-fired, oxygen-blown coal gasifier. The results showed that in-situ TDL measurements provided real-time monitoring of wet syngas without the time delays of wall-imbedded thermocouples and GC measurements of sampled and dried syngas.

\section{Basis of Operation}

Although the Stanford TDL sensor was applied successfully in university research gasifiers, all previous tests were limited to relatively short run times ( $<12$ hours), and the sensors could be adjusted by operators during the run. Testing at NCCC offered the first opportunity for measurements in an engineering-scale system, with the safety and access limitations expected for industrial-scale gasifiers over a duration of several weeks. The demonstration of the Stanford TDL sensor at the NCCC during the R09 test run focused on five areas:

- Design, fabrication, and operation of the TDL sensor while meeting the requirements for safe operation on the syngas process piping

- Evaluating in-situ syngas TDL measurements with only remote access

- Correlation of in-situ syngas TDL measurements with NCCC diagnostic equipment

- Comparison of increased time resolution against current sampling-based GC and $\mathrm{H}_{2} \mathrm{O}$ measurements

- Reliability of the optical windows to provide safe, stable, long-term operation

The results, summarized here and presented in more detail below, from the TDL sensor during the R09 test campaign were positive for all of these areas of focus. With significant assistance from NCCC staff, optical access was engineered, constructed, and installed in the syngas product line 99 feet downstream of the PCD. A Stanford sensor for $\mathrm{H}_{2} \mathrm{O}$ and gas temperature was designed for optimal performance at the conditions expected for the measurement location (620

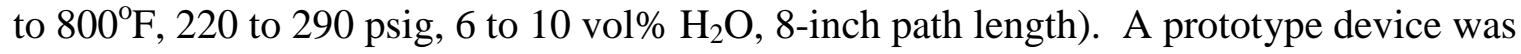
constructed and tested at Stanford and shipped to NCCC. 
Measurements were conducted during R09 from the beginning (hour 0) until end (hour 630) of the campaign. During the entire test period, the laser transmission was stable and the window performance and optical alignment did not degrade with time or ambient temperature or during gasifier warm-up. There were no leaks or failures in the TDL sensor package. Measurements of $\mathrm{H}_{2} \mathrm{O}$ and temperature were made with a time resolution of a few seconds. Sensor performance was evaluated with wide variety of laser scan and modulation parameters. From hours 62 through 97, temperature measurements were suspended and bonus proof-of-concept measurements of $\mathrm{CO}_{2}$ were conducted. Raw sensor data from the entire campaign was recorded for subsequent optimization of the data analysis procedures. Measurements of moisture content were in good agreement with sampling data although with significantly faster time resolution; temperature measurements also agreed with thermocouple data. Even though successful measurements of moisture and temperature were acquired over the entire campaign (no temperature readings for hours 62 through 97), lessons were learned about optical alignment, optical engineering, and optical transmission that suggest improvements for further refinement of sensor performance.

\subsubsection{Test Objectives and Sensor Installation}

Laser absorption is a line-of-sight measurement and requires optical access across the measurement volume. This was a challenge at NCCC where engineering design of optical access in the syngas process piping had not been previously performed. The experience and expertise of the NCCC team was crucial in selecting a measurement location and guiding the engineering and construction of safe installation of optical access for the TDL sensor. A location was selected 99 feet downstream from the exit of the PCD, with the sensor lasers and electronics remotely located in an existing instrumentation shelter, as illustrated in Figure 64.

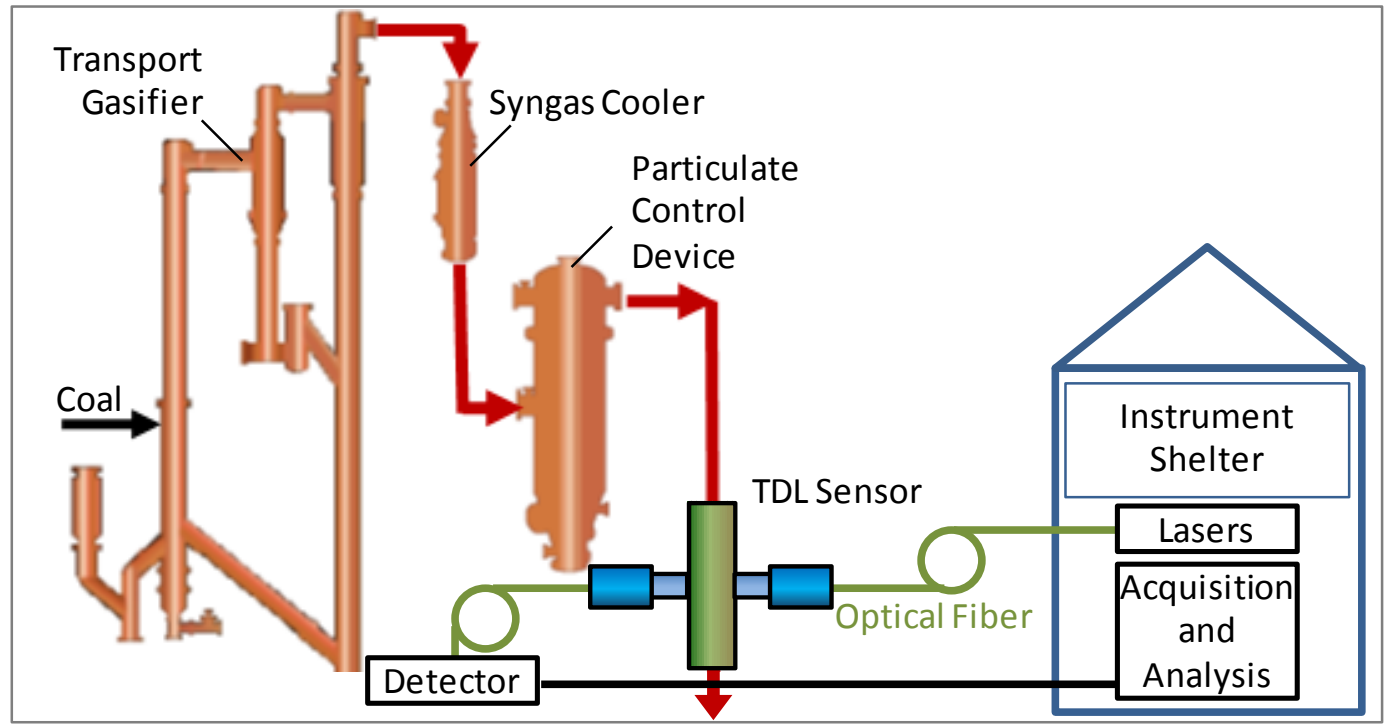

Figure 64. Location of TDL Sensor in NCCC Transport Gasification Process.

To enable safe maintenance of the TDL sensor, if needed during the gasifier run, shut-off valves were installed on either side of the process pipe as depicted in Figure 65. These redundant valves would allow the transmitter or receiver enclosures to be opened to examine the windows 
providing optical access. A pair of flange-mounted sapphire windows was installed on either side of the rig, and measurement of temperature and pressure between the windows provided a safety alarm to signal valve closure in the event of window failure.

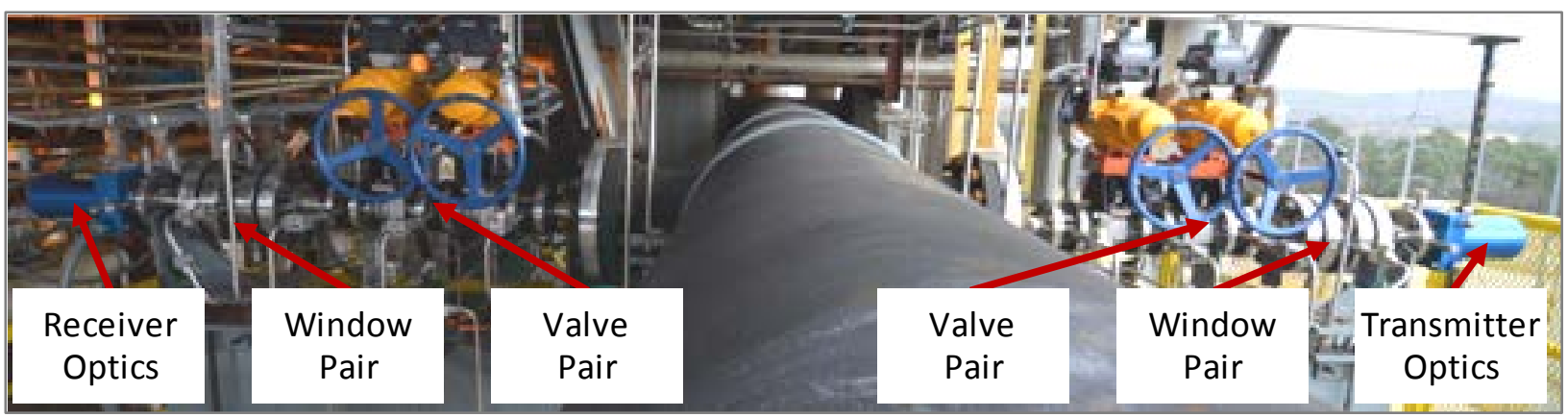

Figure 65. TDL Sensor Assembly Installed in Gasification Process.

The transmitter and receiver packages for the TDL lasers were enclosed in purged metal enclosures, and the optics were remotely adjusted to optimize sensor alignment using lowvoltage direct current (DC) motors. Laser light was produced in the instrumentation shelter and coupled to the transmitter via optical fiber, and the transmitted light was collected and delivered via optical fiber to a detector located nearby (about 6 feet away) in a purged enclosure. The light was detected on a low-voltage DC detector and the DC signal returned to the instrument shelter for processing. The entire sensor flange stack from transmitter to receiver was mounted on a rail suspended from the syngas process pipe to maintain clear line-of-sight for the laser sensor and to minimize deviations from temperature variations.

\subsubsection{TDL Sensor Design for $\mathrm{H}_{2} \mathrm{O}$ and Temperature Measurements}

A modulation strategy, wavelength-modulation spectroscopy (WMS), developed at Stanford for measurements of gas temperature and concentration in harsh environments was selected for the TDL sensor to provide sensitive and accurate detection of absorption over a wide dynamic range of optical transmission. The degree of non-absorption losses from phenomena such as beam steering were unknown for this application, and the installation of the optical access produced a long (15 feet) line-of-sight sensor path, producing a long moment arm for angular beam misalignment from transmitter/detector vibration or beam steering in the syngas. Stanford's WMS strategy has proven to be highly robust to such effects.

\subsubsection{TDL Sensor Testing and Results}

\section{Testing During Start-up}

The TDL-measured moisture level in the syngas, with a 2-second time resolution as shown in Figure 66 from hour 0 to hour 50. During the first few hours, the sensor successfully tracked ignition of the propane burner used for initial warm-up of the gasifier by the appearance of water vapor combustion product. The stability of the $\mathrm{H}_{2} \mathrm{O}$ signal during this period mirrored the stability of the propane burner. Hence, the TDL signal has good potential for rapid feedback to the operator on the stability of the heater. During hour 7, the warm-up period of the gasifier began with a stable propane flame. The moisture content of the syngas steadily increased at the 
sampling location downstream of the PCD during warm-up; this variation was expected as the fuel/air ratio of the propane burner was being increased as seen in Figure 66.

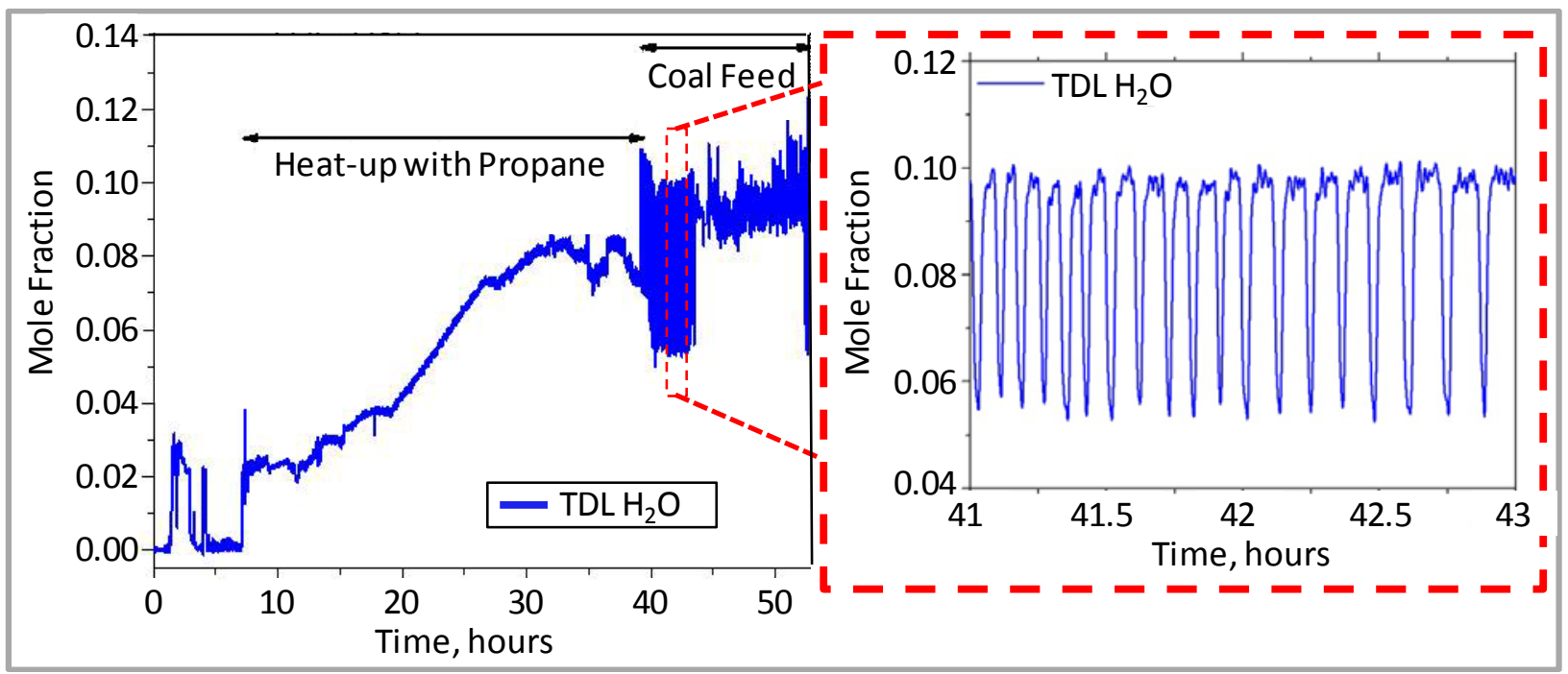

Figure 66. In-Situ Measurements of Flue Gas Moisture during Gasifier Start-Up.

The fuel was transitioned to coal (in combustion mode) at approximately hour 40, and the coal feed rate was pulsed to control the warm-up rate of the gasifier. This transient cycling of the coal fuel is captured in the right panel by the $\mathrm{H}_{2} \mathrm{O}$ content variation (with 2-second time resolution) in the flue gases (note that this is not yet syngas as the gasifier is in combustion mode). During this period, propane was terminated at hour 44, and the coal feeding transitioned into gasification mode. This process continued to hour 52 when coal feeding was terminated. This shutdown is also reflected in the TDL measurement of water vapor.

\section{Capturing Transients in Operation}

Figure 67 presents the syngas moisture level and temperature measurements from the TDL sensor from hours 105.5 to 112; these data are compared to thermocouple data at the PCD outlet and at a location 24 feet downstream of the PCD outlet. The differences between these readings are consistent with the temperature gradient with distance. All three temperatures were stable as a function of time. However, the TDL-measured $\mathrm{H}_{2} \mathrm{O}$ content fluctuated with an approximately 10 minute cycle, which correlated with the gasifier temperature also shown in Figure 67. The transients captured in the gasifier temperature were also reflected in the syngas moisture content. Two conclusions drawn from these observations are:

- The syngas $\mathrm{H}_{2} \mathrm{O}$ level indicates the transient behavior in the gasifier, demonstrating the feasibility of a gasifier control sensor for the located downstream of the PCD.

- The stable syngas temperature measured by the TDL sensor reflects the large thermal mass of the gasifier and all its piping between gasifier and TDL sensor locations; however, the moisture level measurement is unaffected by this thermal mass, and the high velocity of the syngas flow avoids diffusive mixing. 


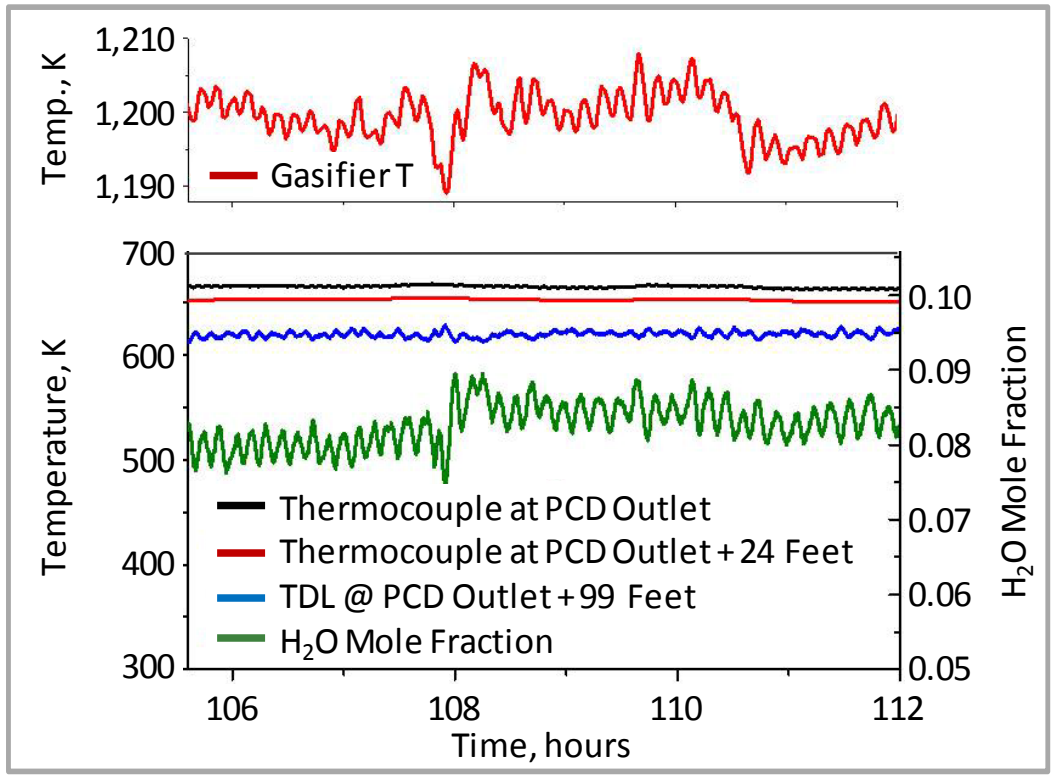

Figure 67. Thermocouple Measurements Compared with TDL Temperature and Syngas $\mathrm{H}_{2} \mathrm{O}$ Measurements

\section{Continuous Monitoring}

The TDL sensor collected continuous records of $\mathrm{H}_{2} \mathrm{O}$ from hour 140 until hour 575, except for three short periods when the sensor valves were closed as a precaution when gasifier upsets occurred. During the entire period, transmission of the TDL sensor was stable, the windows did not exhibit any indications of fouling, and there were no noticeable effects of variations in temperature. Figure 68 plots the syngas $\mathrm{H}_{2} \mathrm{O}$ measurements from the sensor and from condensate samples. These two $\mathrm{H}_{2} \mathrm{O}$ measurements methods have similar mean values over the 435-hour record with larger variations in the condensate sampling.

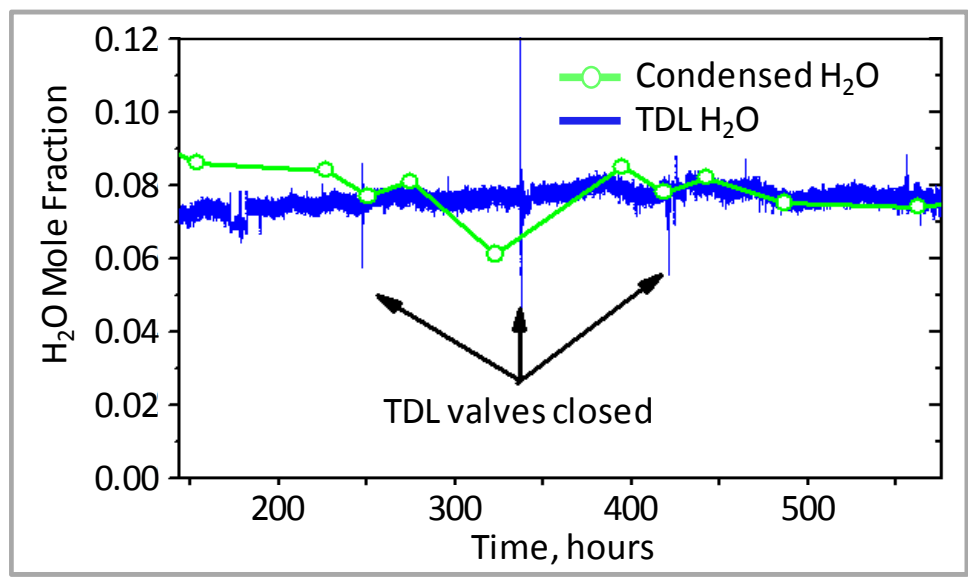

Figure 68. Continuous TDL $\mathrm{H}_{2} \mathrm{O}$ Measurements Compared with $\mathrm{H}_{2} \mathrm{O}$ Sampling Data.

The $\mathrm{H}_{2} \mathrm{O}$ mole fraction data of Figure 68 varies with time by approximately \pm 0.002 , which might suggest that the TDL sensor has a \pm 3 percent statistical uncertainty. However, when the $\mathrm{H}_{2} \mathrm{O}$ data are examined on a more expanded time scale, the measured $\mathrm{H}_{2} \mathrm{O}$ content has a distinct 
oscillation suggesting that the sensor is capturing a real variation of $\mathrm{H}_{2} \mathrm{O}$ mole fraction. These oscillations in $\mathrm{H}_{2} \mathrm{O}$ are strongly correlated with the gasifier temperature, as shown in Figure 69 . (Note that the gasifier temperature fluctuations are less than 0.5 percent of the gasifier temperature.) NCCC engineers were able to correlate the variations in the $\mathrm{H}_{2} \mathrm{O}$ mole fraction with other data sets: PDAC feeder dispense vessel and discharge line pressure, and PCD backpulse nitrogen receiver tank pressure. These correlations led NCCC staff to infer that the fluctuations in syngas moisture resulted from variations in coal feed rate.

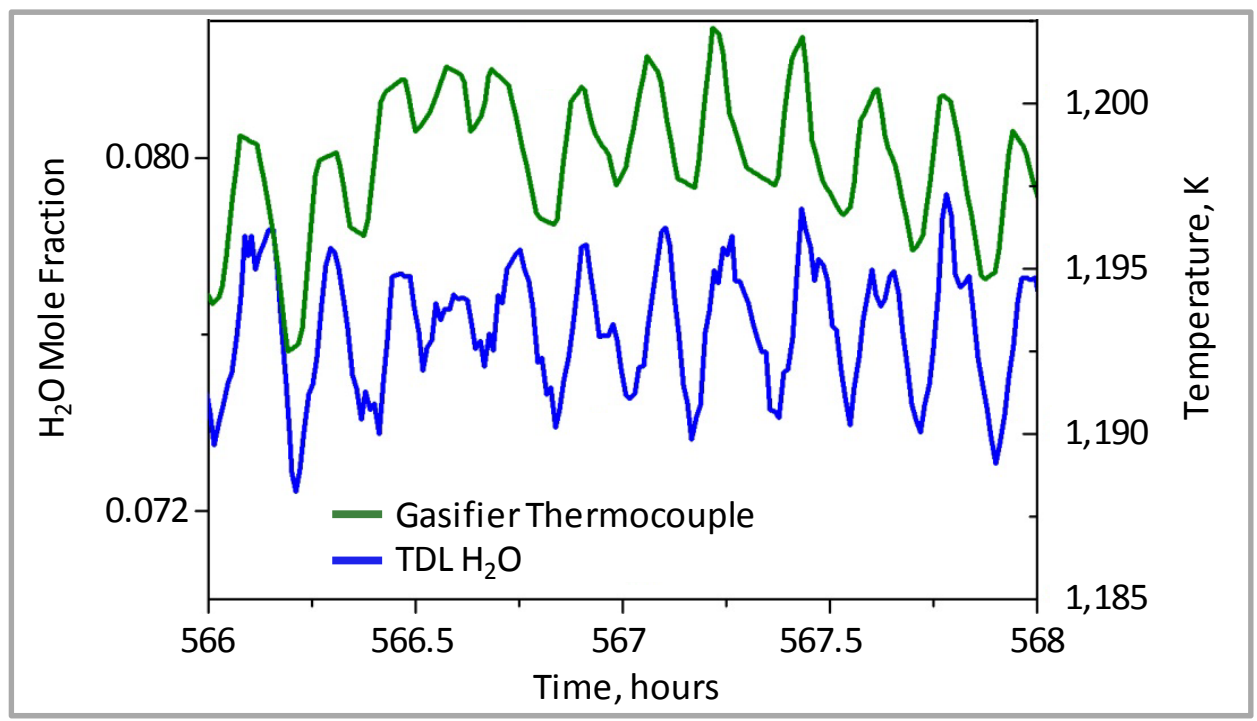

Figure 69. Fluctuations in TDL $\mathrm{H}_{2} \mathrm{O}$ Measurements and Gasifier Thermocouple Measurements.

Figure 70 demonstrates the nearly perfect correlation of the TDL-measured $\mathrm{H}_{2} \mathrm{O}$ mole fraction with the PDAC dispense vessel pressure. As this pressure increases, so does the coal feed rate assuming constant gasifier pressure.

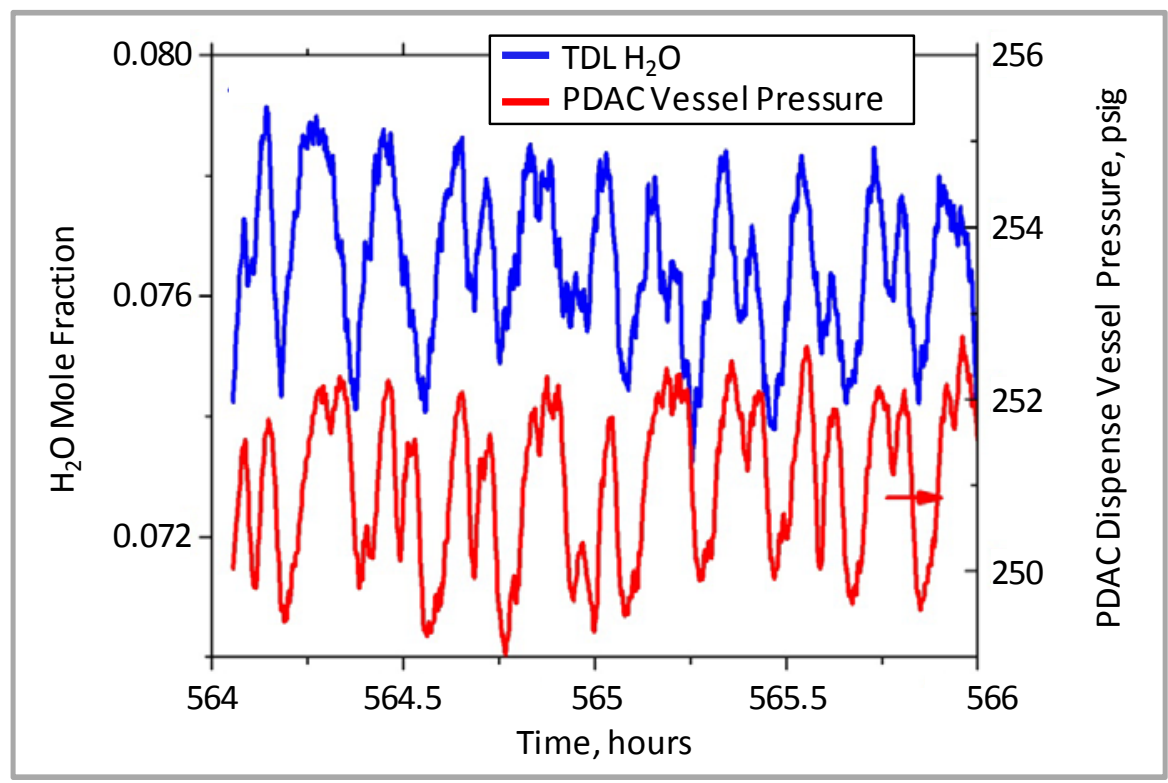

Figure 70. Fluctuations in TDL $\mathrm{H}_{2} \mathrm{O}$ Measurements and PDAC Feeder Pressure. 
Changes in the TDL-measured $\mathrm{H}_{2} \mathrm{O}$ mole fraction mirrored changes in the GC measured $\mathrm{CO}_{2}$, and an example is given in Figure 71 for an event that occurred at approximately hour 420 . Note the changes in $\mathrm{CO}_{2}$ are mirrored in the changes in syngas $\mathrm{H}_{2} \mathrm{O}$. However, the improved time resolution of the TDL sensor provides $\mathrm{H}_{2} \mathrm{O}$ mole fraction that captures the variation in the gasifier conditions, and the TDL sensor data is approximately 30 minutes ahead of the GC, illustrating the long time delays from gas sampling, drying, and GC measurement time.

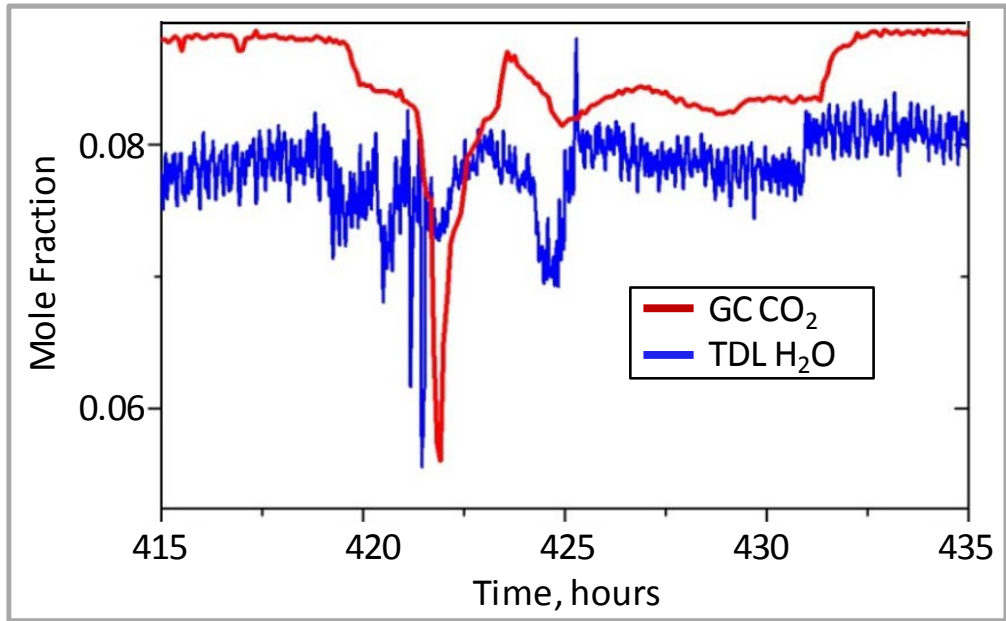

Figure 71. $\mathrm{TDL} \mathrm{H}_{2} \mathrm{O}$ Measurement and $\mathrm{GC} \mathrm{CO}_{2}$ Measurements during Upset Condition.

\subsubsection{Summary and Conclusions}

The first optical access in the NCCC fluidized-bed Transport Gasifier was designed, installed downstream of the PCD, and used for measurement in campaign R09 in November and December 2012. The optical system was stable over the entire campaign, with no obvious window fouling or loss of alignment due to gasifier or ambient temperature. This optical system was used for monitoring both water vapor content and temperature, the latter based on the ratio of absorption by two water vapor transitions.

One of the water vapor absorption transitions provided temperature-insensitive monitoring of water vapor mole fraction. The $\mathrm{H}_{2} \mathrm{O}$ mole fraction was recorded continuously from hour 0 to hour 630, with unattended operation from hour 140 to hour 575. The water mole fraction measurements were in good agreement with liquid water sampling data collected by NCCC. The precision of the $\mathrm{H}_{2} \mathrm{O}$ mole fraction measurements appeared to be on the order of one part in a thousand. Variations measured by the TDL sensor in the $\mathrm{H}_{2} \mathrm{O}$ mole fraction of the product syngas were on the order of \pm 2 parts in 80 , correlating well with temperature fluctuations in the gasifier of $\pm 2 \mathrm{~K}$ and with pressure variations in the coal feed system.

There were numerous lessons learned. For example, the fraction of transmitted light was less than expected, suggesting that improvements to the optical collection to suppress beam steering could improve sensor performance. Successful unattended operation of the TDL sensor suggests the utility of improving the sensor software for remote (e.g., internet) access to the sensor to assess sensor health and optical alignment. Stanford's first use of remote adjustment of optical alignment was successful, suggesting that remote alignment and sensor operation could be quite 
feasible for very long-term measurement campaign operation. Stanford's calibration-free, WMS strategy ensured accurate interpretation of absorption signals even at low light transmission ( $<0.01$ percent). This strategy also suppressed signal variation with changes in the optical transmission. The addition of automatic gain control in the signal processing has the potential for operation over even larger dynamic ranges. The rapid (seconds) time-resolution of the TDL sensor allowed it to capture changes in the syngas composition that were not evident in the GC monitor. The TDL sensor also responded to gasifier changes nearly 30 minutes before the GC instrument. The rapid time-resolution suggests that the TDL sensor has promise as a control sensor for the gasifier, even when the TDL sensor is located downstream of the PCD.

In addition to improving sensor performance with changes in the optical collection and software for long-term remote operations, extension of the sensor to add new species such as $\mathrm{CO}, \mathrm{CO}_{2}$, and $\mathrm{CH}_{4}$ could significantly extend the utility of laser-absorption sensing for this industry. The success of this TDL sensor campaign at the NCCC shows that laser absorption sensing is not only possible in engineering-scale gasifiers, but could be an important new diagnostic tool with the potential for new control strategies in future gasifier utilization and development.

\subsection{Engineering Studies}

Two draft NETL reports on air-blown Transport Gasification systems were reviewed, and comments and questions were sent to NETL. As a benchmark, the capital costs of an NETL oxygen-blown case were also compared with the published costs for the Duke Edwardsport IGCC plant. Feedback was provided to NETL on the relative accuracy of the estimates. 


\subsection{CONCLUSIONS AND LESSONS LEARNED}

\subsection{Pre-Combustion}

\section{SCU Upgrades}

Major upgrades to the SCU were incorporated to meet the expected requirements for future testing. A new control room and MCC building were installed. A new 1,000 lb/hr syngas cleaning system was installed and operated successfully for the first time during R09.

\section{Water-Gas Shift Catalyst}

A catalyst vendor has tested a WGS catalyst during the last three gasification runs, performing parametric tests and long-term evaluation. Test results showed that for one pass of syngas, over 80 percent $\mathrm{CO}$ conversion was achieved with a steam-to-CO ratio of 2 . For the intrinsic steamto-CO ratio of around 0.9 , CO conversion was almost 70 percent.

\section{WPI Hydrogen Membranes}

WPI continued to optimize the composition of its palladium-based membranes and demonstrated production of 99.9 percent pure hydrogen. WPI continues to investigate the cause of hydrogen flux decrease seen from test results, which appears to be related to carbon deposition on the membrane surface.

\section{MTR $\mathrm{CO}_{2}$ and Hydrogen Membranes}

MTR successfully demonstrated a 10:1 scale-up of its $\mathrm{CO}_{2}$ membrane with a $500 \mathrm{lb} / \mathrm{hr}$ integrated system featuring membrane, compressor, and refrigeration skids. The system operated as designed, and produced liquid $\mathrm{CO}_{2}$ with up to 92 percent purity. The initial testing showed the need for several modifications related to membrane design, $\mathrm{CO}_{2}$ liquid level control, and PLC logic. These modifications will be incorporated prior to further operation.

MTR also continued testing of its $50 \mathrm{lb} / \mathrm{hr} \mathrm{CO}_{2}$ membrane in two configurations - as a single membrane module and with two modules connected in series. R09 testing demonstrated $\mathrm{CO}_{2}$ enrichment from about $15 \mathrm{vol} \%$ in the feed to $50 \mathrm{vol} \%$ in the permeate stream. The hydrogen membrane stamp cell enriched the hydrogen from a feed concentration of 14 vol\% to nearly 80 vol\% in the permeate in R09. Both $\mathrm{CO}_{2}$ and hydrogen membranes performed stably during the operation, achieving separation performances equal to or slightly above what had been demonstrated previously.

\section{MPT Hydrogen Membrane}

Since recently scaling up its CMS membrane to a full-scale 86-tube bundle, MPT successfully incorporated a baffle design into its system to improve gas distribution through the bundle and increase hydrogen separation. The baffle design was developed in the MPT lab and further tested in off-line operation at the NCCC. Test results verified the efficacy of the baffle and demonstrated stable operation with hydrogen production of about 95 percent purity. 


\section{Eltron Hydrogen Membrane}

The first testing of Eltron's hydrogen transport membrane at the NCCC was achieved on an expedited schedule. The membrane demonstrated stable hydrogen flux and produced 99.87 percent pure hydrogen.

\section{Membrane Material Coupon Testing}

To evaluate their corrosion resistance, NETL has provided 25 sample coupons of selected hydrogen membrane materials (primarily palladium-based) to be installed in the head (dust-free side) of the hot gas filter. At this location, the syngas typically contains about $250 \mathrm{ppmv}_{2} \mathrm{~S}$ at around $750^{\circ} \mathrm{F}$. The NCCC results demonstrate that the palladium alloys with B2 crystalline structure tend to be more corrosion resistant than the alloys with face-centered cubic crystalline structures. Using coal-derived syngas provides a wider range of contaminants that the materials must prove resistant to, and so is extremely important in guiding future hydrogen separation membrane alloy development.

\section{University of Alabama $\mathrm{CO}_{2}$ Solvent}

UA's alkylimidazole solvent was tested in the SCU stirred batch reactor during R09 using bottled gases and syngas. Results indicated that the solvent performed as expected in regard to the solvent's capacity for $\mathrm{CO}_{2}$ and was within the range of solvents previously tested at the NCCC. Testing also showed that absorption of $\mathrm{H}_{2} \mathrm{~S}$ was essentially complete within an hour of operation.

Flash regeneration released all of the $\mathrm{CO}_{2}$ from the sample but was not effective at removing $\mathrm{H}_{2} \mathrm{~S}$ from the solvent (restoring less than 10 percent of the original capacity). Flash regeneration followed by thermally soaking the solvent at $212^{\circ} \mathrm{F}$ while purging with nitrogen did not appear to restore any additional $\mathrm{H}_{2} \mathrm{~S}$ capacity. This behavior seems to indicate that it acts as a physical solvent for $\mathrm{CO}_{2}$ but has some chemical solvent properties with $\mathrm{H}_{2} \mathrm{~S}$. This interaction will be studied more closely in future testing.

\section{Ohio State University Syngas Chemical Looping}

In this project, a $250 \mathrm{~kW}$ pilot scale SCL plant will be constructed adjacent to the NCCC gasification structure and will utilize up to $900 \mathrm{lb} / \mathrm{hr}$ of syngas. In 2012, demolition of unused equipment was completed to make room for the SCL unit. NCCC supported the OSU team by participating in an initial design hazard review and assisting with developmental engineering work. NCCC developed conceptual designs for connecting the SCL system to the Transport Gasifier process and balance of plant equipment. OSU and NCCC cooperatively developed plans for construction and operation of the system. Construction for the project is scheduled to begin in April 2013 with initial start-up planned for late 2013 and testing planned into the spring of 2014.

\subsection{Post-Combustion}

\section{PC4 Upgrades}

To meet the requirements of future testing at the PC4, work was in progress to increase the capacity of the flue gas supply, PSTU pre-scrubber $\mathrm{SO}_{2}$ removal, process cooling water, and 
electrical infrastructure. The NCCC purchased and began installation of the SSTU for increased flexibility in solvent testing.

\section{MEA Baseline Test Campaign}

A 400-hour MEA Baseline Test Campaign was conducted as a follow-up to the 1,140-hour campaign conducted in 2011. The 2012 campaign was performed to further investigate solvent carryover, degradation products, and metal concentrations in the solvent.

Evaluation of solvent carryover indicated that the carryover increased with $\mathrm{SO}_{3}$ level, decreased with increasing solvent temperature, with the upper absorber bed inactive, and with wash water MEA content. Almost all the MEA carryover from the capture plant occurred downstream of the wash tower. NCCC staff is currently working to incorporate a design by Sulzer to reduce carryover.

Regarding degradation products, the test campaign showed that over 97 percent of the ammonia emitted from the process is carried over from the wash tower. As ammonia is a degradation byproduct, it is likely that the other degradation products are also promoted by oxidation. The majority of the formaldehyde and acetaldehyde is carried over from the regenerator. Only two nitrosamines were detected: nitrosodimethylamine, which was below $1 \mathrm{ppb}$, and nitrosodiethanolamine, at about $1 \mathrm{ppb}$. Neither compound was detected in the liquid samples. Based on sampling using an impinger with acid, passing the $\mathrm{CO}_{2}$-depleted stream through an acid-wash stage would not be effective in removing degradation products. Adding an oxidation inhibitor will reduce solvent degradation and so lower ammonia release. Activated carbon filters are in place to remove degradation products, and their efficacy will be assessed in subsequent runs.

Solvent analysis showed that chromium was measured at 45,090 ppbw, well in excess of the 5,000 ppbw RCRA limit. The majority of the chromium originates from corrosion of the 316L stainless steel vessel material. The chromium would be significantly reduced by fabricating the plant from carbon steel, which is standard industrial practice. Selenium was measured at 1,950 ppbw, almost twice the 1,000 ppbw limit. The selenium originates mainly from the flue gas. The other RCRA metals present above the lower detection limits are arsenic (219 ppbw) and barium (265 ppbw), both originating mainly from the flue gas.

Methods investigated for metals removal from the solvent included waste water chemical treatment procedures, silica sorbents, and a ZVI method at Texas A\&M University. Of these, the ZVI method at Texas A\&M was the most effective. Other means of solvent removal being investigated include ion exchange and electrodialysis. In addition, the SSTU will be utilized to screen proposed measures to reduce solvent carryover and to maintain solvent metals content at low levels before confirming their long-term effectiveness in the PSTU.

Measurements from the PSTU outlet $\mathrm{CO}_{2}$-rich stream showed that the oxygen content of the stream is comfortably below the 100 ppmv limit required for pipeline transport.

\section{Hitachi Solvent}

Testing of Hitachi's H3-1 solvent in the PSTU comprised over 1,300 hours. On average, $\mathrm{CO}_{2}$ capture efficiency of over 90 percent was achieved over the test period. 
The variation of $\mathrm{CO}_{2}$ capture efficiency with solvent flow rate for a constant reboiler steam flow showed that capture efficiency reached a maximum at a particular solvent flow rate. Likewise, the variation of regeneration energy with solvent flow rate for a constant reboiler steam flow showed that regeneration energy reached a minimum at the same solvent flow rate producing the maximum $\mathrm{CO}_{2}$ capture.

The variation of $\mathrm{CO}_{2}$ capture efficiency with reboiler steam flow and flue gas $\mathrm{CO}_{2}$ content indicated that efficiency fell for steam flow rates below the optimum value. At the lower steam flows, the lean solvent returning to the absorber is richer in $\mathrm{CO}_{2}$, and this limits the amount of $\mathrm{CO}_{2}$ that can be captured. This testing also demonstrated decreased efficiency with increasing flue gas $\mathrm{CO}_{2}$ content.

Compared to 30 wt\% MEA, Hitachi's H3-1 operated with a 37 percent lower L/G ratio, achieving a 33 percent lower heat of regeneration. Operation with the H3-1 solvent required lower regeneration energy because of the smaller amount of liquid needing heating in the reboiler in combination with a lower heat of reaction with $\mathrm{CO}_{2}$. With three beds in service, using the intercoolers was shown to raise the $\mathrm{CO}_{2}$ capture efficiency from 89 to 94 percent. By lowering average solvent temperature in the absorber enabling operation in the optimal range of 100 to $140^{\circ} \mathrm{F}$, the intercoolers enhance $\mathrm{CO}_{2}$ capture efficiency. The $\mathrm{CO}_{2}$ capture efficiency increased with the number of absorber beds in service, as the beds provide surface area for gasliquid contacting and increase the gas residence time in the reaction zone.

\section{Cansolv Technologies Solvent}

Testing of the Cansolv DC-201 solvent was completed after 1,725 hours of operation in the PSTU. Data showed that the Cansolv solvent required 40 percent less energy than MEA to achieve the same capture rate using three packing sections in the absorber. The solvent also required 50 percent less circulation (L/G of $2 \mathrm{~kg} / \mathrm{Nm}^{3}$ for DC-201 and $4 \mathrm{~kg} / \mathrm{Nm}^{3}$ for MEA).

The operating conditions (liquid-to-gas ratio and steam usage per ton of $\mathrm{CO}_{2}$ captured) were not significantly affected while switching from three to two packing sections. The L/G did not vary, and the stripping factor increased from $2.2 \mathrm{GJ} /$ ton $\mathrm{CO}_{2}$ to $2.3 \mathrm{GJ} /$ ton $\mathrm{CO}_{2}$. When switching from two to one packing section in the absorber, the solvent flow rate requirement increased (L/G going from 2.0 to $2.5 \mathrm{~kg} / \mathrm{Nm}^{3}$ ), as did that for reboiler steam flow rate. (Stripping factor increased from $2.3 \mathrm{GJ} /$ ton $\mathrm{CO}_{2}$ to $2.8 \mathrm{GJ} /$ ton $\mathrm{CO}_{2}$.)

Testing demonstrated operational flexibility from 40 to $60 \mathrm{wt} \%$ solvent concentration and optimum operation with respect to energy consumption from 45 to $55 \mathrm{wt} \%$ solvent concentration. Results of solvent degradation sampling indicated very low degradation rate of the DC-201 solvent. Solvent sampling for metals showed that the solvent was contaminated with metals, although the metals concentrations did not impact solvent capture. The build-up of sulfates originating from $\mathrm{SO}_{2}$ and nitrates from $\mathrm{NO}_{2}$ also did not affect solvent performance.

Solvent degradations products, including formaldehyde, ammonia, and dimethylamine were found to be low, in the ppmv to the sub-ppmv range. Nitrosamines were also detected, but at the ppbv level. Further analyses related to solvent emissions are ongoing. 


\section{Chiyoda Solvent}

The NCCC completed design modification to the PSTU that Chiyoda requested for better representing their expected commercial operation. Chiyoda began testing its T-3 solvent in the PSTU in December 2012 and plans to continue operation into mid-2013 to complete parametric testing and achieve long-term operation.

\section{MTR 1-ton/day Flue Gas Membrane}

After initial operation in late 2011, the MTR 1 ton/day membrane operated intermittently during 2012. Due to corrosion and buildup of deposits in the compressor outlet, the screw compressor was replaced with a liquid-ring compressor. In the liquid ring compressor, cooling water comes into direct contact with the flue gas, which will prevent dry surfaces being created onto which the deposit can form. Moreover, any deposit that does form will rapidly dissolve in the water.

During an outage in August, two CFM modules (one from each vessel) were removed for inspection by MTR. These had been in operation since the beginning of testing in December 2011 and had been exposed to flue gas for almost 1,500 hours with some additional hours on air when flue gas was not available. No particulate was found on either end of the membranes or within the membrane envelopes. Membrane performance did not degrade with time or with pressure drops increase, suggesting that the pretreatment system worked effectively and prevented fouling of the membranes by flue gas contaminants.

During 100 hours of operation in December, the $\mathrm{CO}_{2}$ content of the flue gas feed was reduced from about 12 percent to around 1 percent in the residual stream leaving the skid, corresponding to $\mathrm{CO}_{2}$ capture greater than 90 percent. This is an improvement over the previous capture efficiency of 87 percent and indicates the continuing improvements being made in membrane performance.

\section{MTR 20-ton/day Membrane System}

Lessons learned from the operation of 1-ton/day unit provided valuable inputs to the 20-ton/day system design changes. Some of the critical skid modifications included equipment rearrangement to fit the skid to the footprint available at PC4, addition of a Venturi scrubber upstream of the compressor, replacement of a screw compressor with a liquid ring compressor, and provision of additional instrumentation for better monitoring and control.

\section{Codexis Enzymes}

Codexis performed testing at the PC4 on carbonic anhydrase enzymes to accelerate the rate of $\mathrm{CO}_{2}$ capture for solvents with low heats of reaction such as MDEA. The tests at the PC4 were the first using coal-derived flue gas to determine the stability of the enzyme under industrial operating conditions in the presence of trace contaminants. The two-week commissioning and testing period demonstrated $\mathrm{CO}_{2}$ capture averaging around 65 percent at a rate of capture over 25 times greater than for MDEA alone with $0.2 \mathrm{~g} / \mathrm{L}$ of enzyme loading. No apparent effect of trace metals or elevated process temperatures on enzyme performance was seen. 


\section{Akermin Enzymes}

In December 2012, Akermin completed checkout and commissioning of its pilot plant for evaluation of a carbonic anhydrase enzyme to accelerate the capture of $\mathrm{CO}_{2}$ by potassium carbonate. For this design, the enzyme is contained on the surfaces of the absorber packing. Testing is planned to proceed to mid-2013.

\section{Engineering Studies}

The NCCC's Engineering and Economic Evaluations group began work on a post-combustion $\mathrm{CO}_{2}$ capture (PCC) baseline study in collaboration with the NETL and EPRI.

\subsection{Gasification}

\section{Gasification Operation}

The gasification process operated over two test runs, R08 and R09, for a total of more than 1,250 hours. Progress continued on the development of the pressure decoupled advanced coal (PDAC) feeder, gasifier control automation, sensors, and instrumentation. Steady-state carbon conversions were comparable to previous test runs. At the conclusion of R09, the gasification process had operated for over 18,000 total hours with over 2,000 hours in oxygen blown operation.

Gasifier temperature control enhancements utilizing upper and lower mixing zone air flow adjustments were ongoing during R08 and R09. Gasifier temperature variation has been decreased from $5^{\circ} \mathrm{F}$ achieved during initial control implementation to less than $2^{\circ} \mathrm{F}$ during R08 and R09.

Testing of previous PDAC feeder control logic improvements also continued. The gasifier pressure feedback controller permitted automatic adjustments to feeder pressure and nitrogen flow as gasifier pressure was reduced for oxygen-blown operation. The adjustments made by the controller permitted the pressure differential between the feeder and the gasifier to be maintained at a constant level, helping keep the coal feed rate steady.

\section{Oxygen-Blown Biomass Co-Feeding}

During the final portion of the R08 run, 219 hours of oxygen-blown gasification testing were conducted with biomass co-feed on behalf of CCAT. The testing included co-feeding of two forms of biomass, raw pellets and torrified pellets, with PRB sub-bituminous coal during oxygen-blown gasifier operation. The actual co-feed percentages for the torrified biomass were 17,20 , and $29 \mathrm{wt} \%$. The actual co-feed percentages for the raw biomass were 12, 20, and $28 \mathrm{wt} \%$.

Gasifier operating conditions remained stable during all tests and yielded high carbon conversions during both coal-only and biomass co-feed operation. Syngas heating values remained stable during the biomass co-feed periods, and there was no appreciable tar generation during the testing. 


\section{PCD Operation}

PCD research efforts continued during the year focusing on the long-term evaluation of material performance of several types of filter elements and failsafe devices. The elements with the greatest exposure time, which are iron aluminide elements, have accumulated over 16,200 hours of syngas operation.

\section{Sensor Development}

Testing of an Emerson sapphire thermowell for gasifier service continued. Following removal of a previously tested thermowell that showed corrosion, a new thermowell assembly was reinstalled in the same location prior to run R08 with an added transmitter for detection of sensor failure. Unfortunately, the transmitter/thermocouple failed shortly after R08 began, and a postrun inspection showed that the assembly had broken. NCCC staff continues to collaborate with Emerson for future test plans.

Testing of the DensFlow coal flow meter from SWR Engineering during R08 and R09 continued to show discrepancy between the flow meter and the weigh-cell calculated coal flow rates.

NCCC staff are pursuing ways to improve the flow meter accuracy. The Dynatrol vibration level probes and a point sensitive level probe from Drexelbrook installed in the PCAD feeder vessels continued to provide reliable measurements.

\section{Gasification Process Modifications}

A major process modification was the replacement of the gasifier standpipe made because of refractory damage. Two places of concern were the intersection of the solids separation unit and standpipe, and the intersection of the J-leg and standpipe. The refractory in the standpipe and Jleg was the refractory originally installed in the gasifier, and had been in service for 15 years. The refractory was in excellent condition following initial operation in runs R08 and R09.

The PCD tubesheet required repair of a significant fracture, and plans began in evaluating options for further repairs or replacement of PCD vessel components. The primary gas cooler also required repairs due to a leaking tube, and the cooler is planned to be replaced in 2013. Modifications to the fine ash removal system were underway to incorporate an improved pressure letdown device.

\section{TDL Sensor}

Stanford University's Hanson research group tested the TDL sensor throughout R09, for more than 600 hours of operation. Testing at NCCC offered the first opportunity for measurements in an engineering-scale system, with the safety and access limitations expected for industrial-scale gasifiers. The sensor provided continuous, time-resolved measurements of moisture concentration and temperature. In addition, Stanford personnel also tested a proof-of-concept $\mathrm{CO}_{2}$ measurement during start-up.

Initial testing focused on testing the sensor during system heat-up and transition to steady state gasification conditions. The TDL was then setup for long-term monitoring and provided continuous unattended monitoring of $\mathrm{H}_{2} \mathrm{O}$ and temperature for over 400 hours. TDL measurements of moisture content were in good agreement with gas analyzer readings and 
temperature indications near the location of the sensor although with significantly faster time resolution

During the test period, the laser transmission was stable and window performance and optical alignment did not degrade with time, ambient temperature, or gasifier warm-up. There were no leaks or failures in the TDL sensor package.

Some of the lessons learned from this successful demonstration of the TDL follow.

- The fraction of transmitted light was less than expected, indicating that improvements to the optical collection to suppress beam steering could improve sensor performance.

- Successful unattended operation of the TDL sensor suggests the utility of enhancing the sensor software for remote access to the sensor to assess sensor health and optical alignment.

- Stanford's first use of remote adjustment of optical alignment was successful, suggesting that remote alignment and sensor operation is feasible for long-term measurement campaign operation.

- Stanford's calibration-free WMS strategy ensured accurate interpretation of absorption signals even at low light transmission (less than 0.01 percent). This strategy also suppressed signal variation with changes in the optical transmission. The addition of automatic gain control in the signal processing has the potential for operation over even larger dynamic ranges.

- The rapid time-resolution of the TDL sensor allowed it to capture changes in the syngas composition that were not evident in the GC monitor. The TDL sensor also responded to gasifier changes nearly 30 minutes before the GC data. The rapid time-resolution suggests that the TDL sensor has promise for gasifier control, even when located downstream of the PCD.

In addition to improving sensor performance with changes in the optical collection and software for long-term remote operations, extension of the sensor to add new species such as $\mathrm{CO}, \mathrm{CO}_{2}$, and $\mathrm{CH}_{4}$ could significantly extend the utility of laser-absorption sensing. The success of this TDL sensor campaign at the NCCC shows that it could be an important diagnostic tool with the potential for integration with control strategies for gasifiers.

\section{Engineering Studies}

In the area of gasification, NCCC staff reviewed and provided feedback on NETL reports on airblown Transport Gasification systems as well as an oxygen-blown case comparison to published costs for the Duke Edwardsport IGCC plant. 